$A l 1] 07245588$

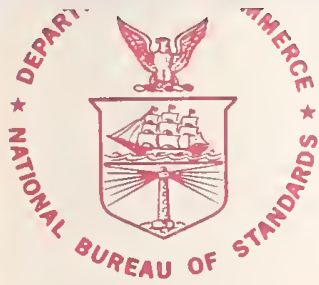

NBS

PUBLICATIONS

NBS SPECIAL PUblication 609

U.S. DEPARTMENT OF COMMERCE / National Bureau of Standards

\title{
Proceedings of a Meeting on Traceability for lonizing Radiation Measurements
}

$-Q C$

100

.457

iNo. 609

1932

C. 2 


\section{NATIONAL BUREAU OF STANDARDS}

The National Bureau of Standards' was established by an act of Congress on March 3, 1901. The Bureau's overall goal is to strengthen and advance the Nation's science and technology and facilitate their effective application for public benefit. To this end, the Bureau conducts research and provides: (1) a basis for the Nation's physical measurement system, (2) scientific and technological services for industry and government, (3) a technical basis for equity in trade, and (4) technical services to promote public safety. The Bureau's technical work is performed by the National Measurement Laboratory, the National Engineering Laboratory, and the Institute for Computer Sciences and Technology.

THE NATIONAL MEASUREMENT LABORATORY provides the national system of physical and chemical and materials measurement; coordinates the system with measurement systems of other nations and furnishes essential services leading to accurate and uniform physical and chemical measurement throughout the Nation's scientitic community, industry, and commerce; conducts materials research leading to improved methods of measurement, standards, and data on the properties of materials needed by industry, commerce, educational institutions, and Government; provides advisory and research services to other Government agencies; develops, produces, and distributes Standard Reterence Materials; and provides calibration services. The Laboratory consists of the following centers:

Absolute Physical Quantities ${ }^{2}$ - Radiation Research - Thermodynamics and Molecular Science - Analytical Chemistry - Materials Science.

THE NATIONAL ENGINEERING LABORATORY provides technology and technical services to the public and private sectors to address national needs and to solve national problems; conducts research in engineering and applied science in support of these efforts; builds and maintains competence in the necessary disciplines required to carry out this research and technical service; develops engineering data and measurement capabilities; provides engineering measurement traceability services; develops test methods and proposes engineering standards and code changes; develops and proposes new engineering practices; and develops and improves mechanisms to transfer results of its research to the ultimate user. The Laboratory consists of the following centers:

Applied Mathematics - Electronics and Electrical Engineering ${ }^{2}$ - Mechanical Engineering and Process Technology $y^{2}$ - Building Technology - Fire Research Consumer Product Technology — Field Methods.

THE INSTITUTE FOR COMPUTER SCIENCES AND TECHNOLOGY conducts research and provides scientific and technical services to aid Federal agencies in the selection, acquisition, application, and use of computer technology to improve effectiveness and economy in Government operations in accordance with Public Law 89-306 (40 U.S.C. 759), relevant Executive Orders, and other directives; carries out this mission by managing the Federal Information Processing Standards Program, developing Federal ADP standards guidelines, and managing Federal participation in A.DP voluntary standardization activities; provides scientific and technological advisory services and assistance to Federal agencies; and provides the technical foundation for computer-related policies of the Federal Government. The Institute consists of the following centers:

Programming Science and Technology-_Computer Systems Engineering.

'Headquarters and Laboratories at Gaithersburg, MD, unless otherwise noted;

mailing address Washington, DC 20234.

${ }^{2}$ Some divisions within the center are located at Boulder, CO 80303. 


\section{Proceedings of a Meeting on Traceability for lonizing Radiation Measurements}

NGE

Proceedings of a meeting held at the National Bureau of Standards, Gaithersburg, MD, on May 8-9, 1980

Edited by:

H. Thompson Heaton, II

Center for Radiation Research

National Measurement Laboratory

National Bureau of Standards

Gaithersburg, MD 20234
National Bureau of Standuds

Llbrary, Eol Aamin. Blab.

\section{MAR 11982}

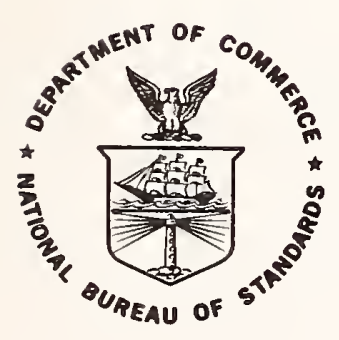

U.S. DEPARTMENT OF COMMERCE, Malcolm Baldrige, Secretary NATIONAL BUREAU OF STANDARDS, Ernest Ambler, Director

Issued February 1982 


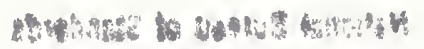

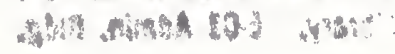

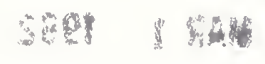

Library of Congress Catalog Card Number: 81-600197

National Bureau of Standards Special Publication 609

Nat. Bur. Stand. (U.S.), Spec. Publ. 609, 175 pages (Feb. 1982)

CODEN: XNBSAV 
The phrases "traceable to NBS" or "traceable to the national standards" are increasingly being used in Federal and State regulations, voluntary standards, technical articles, and advertisements, often without any indications of what is meant by the phrase or how it is achieved. To provide some guidance on how traceability can be achieved in the area of ionizing radiation measurements, a two-day seminar was organized and held at the National Bureau of Standards, Gaithersburg, Maryland, on May 8-9, 1980. These proceedings include the 21 papers presented at that seminar on Traceability for Ionizing Radiation Measurements.

The first six speakers in this meeting covered the basic concepts of traceability from different perspectives and described the national standards for radiation dosimetry, radioactivity measurements, and neutron measurements. The remainder of the speakers dealt with specific programs for achieving traceability for applications in governmental laboratories, and for medical, occupational, and environmental radiation measurements. An important point made by many of the speakers is that the development and use of secondary (intermediate level) standards laboratories offers an effective mechanism for responding to the rapidly increasing number of requests for instrument calibrations, radioactive sources, measurements, etc. which are traceable to national standards.

In order to achieve broad and even coverage of the field, papers were presented by invitation only, although the meeting was open to anyone. Eight of the speakers were from NBS and 13 from other organizations. A total of 79 people representing 45 different organizations registered for the meeting.
The papers are printed in the proceedings as they were received from the authors and in the order they were presented in the sessions. However, two of the sessions, Traceability in Governmental Laboratories and Traceability in Medical Applications, were actually presented in the reverse order. For convenience, the seminar notation for the sessions has been preserved. To speed publication of the proceedings, all papers were submitted by the authors in camera-ready form. The editor is greatly indebted to the authors and all those who assisted in the preparation of the manuscript. Their efforts have made it possible to get the proceedings in print much more rapidly than would otherwise have been the case.

When commercial equipment, instruments, and materials are mentioned or identified in these proceedings it is intended only to adequately specify experimental procedure. In no case does such identification imply recommendation or endorsement by the National Bureau of Standards, nor does it imply that the material or equipment identified is necessarily the best available for the purpose.

The editor gratefully acknowledges the assistance of the National Bureau of Standards Technical Information and Publications Division in the preparation of these proceedings; of Mrs. Kathy Stang of the National Measurement Laboratory and Miss Jo Ann Lorden of the Public Information Division for help in the arrangements for the seminar, and of Mrs. E. Kramer for the excellent secretarial assistance.

H. Thompson Heaton, II

Center for Radiation Research 
These proceedings are the compilation of 21 papers presented at a seminar on Traceability for Ionizing Radiation Measurements held at the National Bureau of Standards, Gaithersburg, MD, on May 8-9, 1980. General concepts for traceability were presented from several perspectives. The national standards for radiation dosimetry, radioactivity measurements, and neutron measurements were described. Specific programs for achieving traceability to the national standards for radiation measurements in medical, occupational, and environmental applications were summarized.

Key words: Calibrations, ionizing radiation, measurements, national standards, quality assurance, secondary standard laboratory, traceability. 


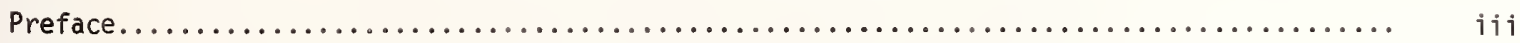

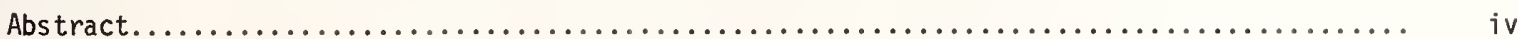

\section{INTRODUCTORY SESSION}

Chairperson: R.S. Caswe]1

Welcoming Remarks

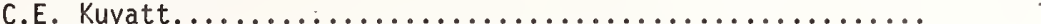

Traceability - A View From the NBS Center for Radiation Research

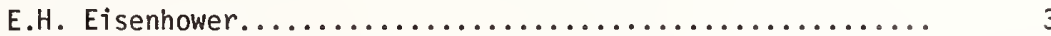

Traceability of Radiation Measurements: Musings of a User

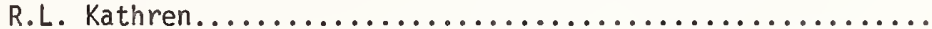

Radiation Measurement Traceability in the United Kingdom

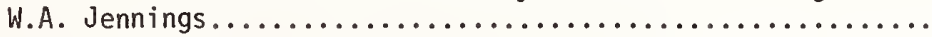

National Standards for Radiaton Dosimetry

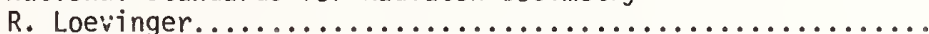

National Standards for Radioactivity Measurements

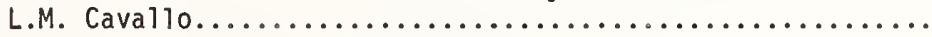

National Standards for Neutron Measurements

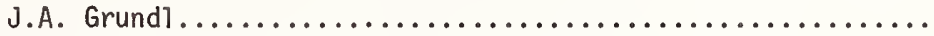

NBS Services for Ionizing Radiation Measurements

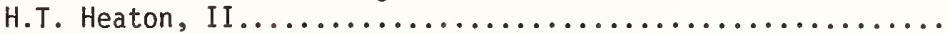

TRACEABILITY IN GOVERNMENTAL LABORATORIES

Chairperson: E.H. Eisenhower

The Calibration Program of the Bureau of Radiological Health

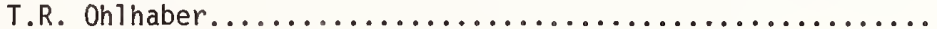

The EPA National Quality Assurance Program

A.N. Jarvis......................................

The LLL Calibration and Standards Facility

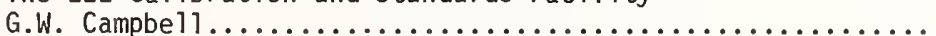

State of Illinois Regional Calibration Laboratory

M. Neuweg.

TRACEABILITY IN MEDICAL APPLICATIONS

Chairperson: R. Loevinger

The American Association of Physicists in Medicine's Regional Calibration Laboratory System

R.J. Shalek, L.J. Humphries, and W.F. Hanson.............

NBS Traceability Programs for Radiation Therapy

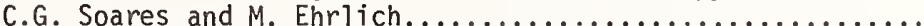

Traceability Programs for Nuclear Medicine

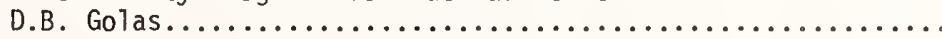


TRACEABILITY IN ENVIRONMENTAL APPLICATIONS

Chairperson: J.M.R. Hutchinson

The Role of Calibration Standards in Environmental

Thermoluminescence Dosimetry

T.F. Gesel1, M.F. Jones and G. de Planque................

The National Bureau of Standards Low-Level Radioactivity-

Measurements Program

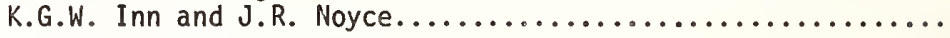

Nuclear Regulatory Commission Traceability Concerns in

Inspection and Enforcement Program

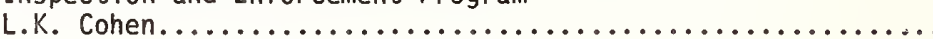

Radon and Radon Daughter Field Measurements

A.C. George.....................................

TRACEABILITY IN OCCUPATIONAL AND INDUSTRIAL APPLICATIONS

Chairperson: M. Ehrlich

Performance Testing of Personnel Dosimetry Services

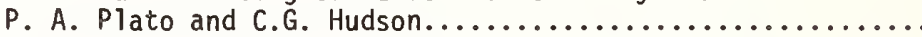

Occupational Exposure Measurements in NRC Regulatory Guides

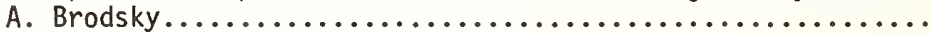

Dosimetry for Industrial Radiation Processing

W.L. McLaughl in, J.C. Humpreys and A. Miller.............. 171

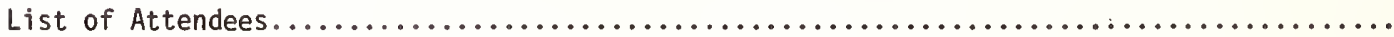


Chris E. Kuyatt, Director Center for Radiation Research National Bureau of Standards Washington, DC 20234

I am happy to have this opportunity to welcome you to NBS to attend the seminar on "Traceability for Ionizing Radiation Measurements". This meeting is sponsored by the Center for Radiation Research and is part of the 1980 series of "NBS Measurement Seminars". For those of you familiar with previous seminars the Center has organized as part of the NBS series, there are several new features of the present meeting. The biggest difference is that for the first time we have invited outside speakers. This will allow a broader view to be presented. Previous meetings have covered several major topics with detailed talks on how NBS performed its measurements. Since the specific laboratory techniques that NBS uses are not necessarily appropriate for others, this seminar will concentrate on a single broad topic, namely traceability. Speakers have been requested to submit written versions of their presentations and these will be published as an NBS Special Publication. You will be receiving a copy of this publication.

The term "traceability to NBS" or "traceability to the national standards" is being used more frequently. Several examples include: Federal and state regulations, voluntary standards such as those published by the American National Standards Institute, contracts (particularly military contracts including MIL specs), international sales of technical products, advertising (especially involving radioactive sources) internal quality control, and litigation. If the measurement process itself becomes challenged in court cases, this will probably have the greatest impetus in encouraging stronger ties to the national standards. Currently, the major pressure for traceability comes from regulatory action.

One of the major problems with the use of the word traceability is that it usually is not defined in the document in which it is used. In fact, traceability can be defined in several ways. If one uses a simple definition such as an unbroken path, one can almost always find some path, no matter how tenuous, which will lead back to the national standards. I am reminded of an incident a few years ago in which our storeroom was selling meter sticks which not only had a significant bow to them but the printing of the scale was very inaccurate. Since it came from the NBS storeroom, it would fulfill some definition of traceability to NBS yet it was valueless in its intended function of measuring distance. Clearly, we must first consider what we want to achieve through traceability, and then define traceability so that it will achieve the desired objective.

If one goes to the other extreme and gives a very technical definition for a commonly used word there can still be problems in that many people may not realize that the word is being used in a restricted manner. An example of assigning a technical meaning to a common word is "the quantity for measuring the amount of radiation resulting from the exposure of an individual to $x$ rays is exposure". In this case the word exposure is used in two quite different contexts. Even though the technical definition of exposure has existed since 1928, one can look at both the popular press and many scientific articles and observe that the technical application of the word is being misused. One possibility to avoid similar probiems with the word traceability is to always use the word with an adjective. Hopefully this will flag the reader that the word is not being used in its common sense.

These examples point to the need for everyone to understand what is meant in a particular situation when using the word "traceability". One fact which should be kept clearly in mind is that NBS does not have the legal authority to define what is meant by "traceability to NBS", and can only comment as to whether or not mechanisms exist which would allow the traceability required by someone else to be demonstrated. It is necessary that whoever uses the phrase "traceable to NBS" defines it in such a way that the objective of requiring it in the first place can be met.

One problem with having NBS define the meaning of "traceability to NBS" is that like all organizations NBS is a collection of individuals, each with his own concept of the meaning of traceability. These concepts are modified by the needs in each individual's specific measurement area. If one tries to give a general definition it may be so vague or complicated that it is not of much use in specific cases. The problem is somewhat easier if one goes to a specific measurement area such as ionizing radiation measurements; but, even in the past, various members of CRR have used different definitions of traceability, not all of which were completely compatible. One of the main objectives of this meeting is to examine how the various definitions could be made compatible when the objective of requiring traceability is to ensure that accurate measurements are being made. Several on-going programs will be described as examples of how traceability is achieved for particular types of radiation measurements. This seminar is intended to stimulate discussion, and hence, the meeting is designed to be somewhat flexible in its schedule to encourage an active interaction between the speakers and the audience. I hope all of you will take advantage of this opportunity and engage in a lively two days of discussion. 

Traceability - A View From the NBS Center for Radiation Research

\author{
Elmer H. Eisenhower \\ Office of Radiation Measurement \\ Center for Radiation Research \\ National Bureau of Standards \\ Washington, DC 20234
}

This paper presents general information about the traceability of ionizing radiation measurements to the appropriate national physical measurement standards. It describes fundamental concepts that should serve as the basis of more specific considerations of traceability, some common problems encountered in making statements about traceability, and the means and methods used to achieve traceability. Distinctions between the two principal types of traceability (instrument and measurement) are identified and the differences in the ways they are achieved are summarized. Some of the ambiguities that may occur in statements about traceability are recognized, and preferred ways of making unambiguous statements are given. The importance of means and methods for achieving traceability is emphasized, since statements about traceability have limited usefulness unless the specific means and methods can be identified for a particular measurement under consideration. The technical and institutional elements that provide these means and methods constitute the national measurement support system. Present weaknesses in this system are identified, and two measurement quality assurance programs are described as examples of how the system can be improved.

(Calibrations; instruments; ionizing radiation; measurements; measurement support system; quality assurance; standards; traceability)

\section{Introduction}

In recent years, it has become apparent that traceability is desirable but not particularly understandable. The desire arises from a growing national awareness of the value of quality assurance in products and procedures. The limited understanding results partly from the mistaken belief that the meaning of traceability is selfevident and therefore needs no discussion. This lack of discussion has resulted in a multitude of misinterpretations, ambiguous statements, and considerable confusion. Understanding is further limited by the fact that traceability is an evolving concept and lacks a universally accepted definition [1].

This paper will present some general information that should be useful in more specific considerations of traceability. It will describe the fundamental concepts that should be the foundation for such considerations, some problems encountered in making statements about traceability, and the means and methods used to achieve traceability. To avoid details that may only apply to a limited situation, the subject will be treated in a simplified manner and fundamentals will be emphasized. The views expressed in this paper are solely those of the author, and do not necessarily represent a consensus of the NBS staff or management. The subject matter will be limited to measurement of ionizing radiation.

Although any discussion of traceability could reasonably start at the international level and proceed from there, this paper will consider only the national structure. Thus the national physical measurement standards will be regarded as the common point to which measurements should be referred.

\section{Fundamental Concepts}

The desirability of measurements that are nationally consistent (in agreement) was expressed in 1778 by the Articles of Confederation. A more recent expression of this desire is contained in a 1950 statement of the primary function of the National Bureau of Standards, which is:

"The custody, maintenance, and development of the national standards of measurement, and the provision of means and methods for making measurement consistent with those standards..." [2]

Although this statement clearly assigns to NBS the responsibility for providing "means and methods" that enable measurement to be consistent wi th national standards, the Bureau has not been given any authority to require such consistency. Other organizations and agencies have, however, instituted requirements of this type. Any such requirements for consistency should be developed in consultation with NBS because the existing "means and methods" may not be adequate, and the requirements may therefore be impractical.

Consistency of measurements with the national standards may be either demonstrated or implied. Those who require that measurements be consistent with standards must decide whether implied consistency is adequate, or whether it must be demonstrated. In either case, some action or actions 
must be taken if consistency is to be achieved. These actions are the "means and methods" employed in the process of achieving consistency. If it can be shown that such actions have been taken and that they were appropriate, the measurement is considered to be consistent with the standard. Regardless of what actions are taken to achieve this consistency, it is essential that they be documented. Such documentation is the only evidence that the process occurred and was appropriate. Thus, in a general sense, traceability can be defined as the ability to show that appropriate documented actions have been taken to demonstrate or imply that a measurement is consistent with a standard.

\section{Instrument (Artifact) Traceability}

If implied consistency of a measurement with a standard is sufficient, it can be achieved through a calibration process. In this case, the instrument used to make the measurement is calibrated by comparison with the appropriate national standard, either directly or indirectly through intermediate calibrations. This is the traditional type of traceability and, in some cases, the only type that presently can be achieved.

Although a radiation source is not an instrument, it is frequently utilized in the instrument calibration process, and should therefore also be calibrated in a manner that provides traceability to the appropriate national standard. The term "instrument traceability" may therefore be used generically to include both instruments and sources. (The term "artifact traceability" may also be used to include instruments and sources generically.) It may be defined as the ability to show that a particular instrument or radiation source either has been calibrated against the appropriate national standard or against another standard in a chain or echelon of calibrations ultimately leading to a calibration against the national standard.

A major disadvantage of instrument traceability is the inability to demonstrate that the measurement made with a traceable instrument is indeed consistent with the national standard. since the traceability chain ends with the instrument, as shown in Figure 1, the consistency of the measurement must be implied. If the instrument is used properly, and if the conditions under which the measurement is made are favorable, this implication may be valid. However, since the quality of the measurement itself has not been demonstrated, there remains some degree of uncertainty about the validity of the result.

Since no calibration of an instrument or source is valid indefinitely, it should be repeated at suitable time intervals. The acceptable time between subsequent calibrations is dependent upon the circumstances of the particular situation.

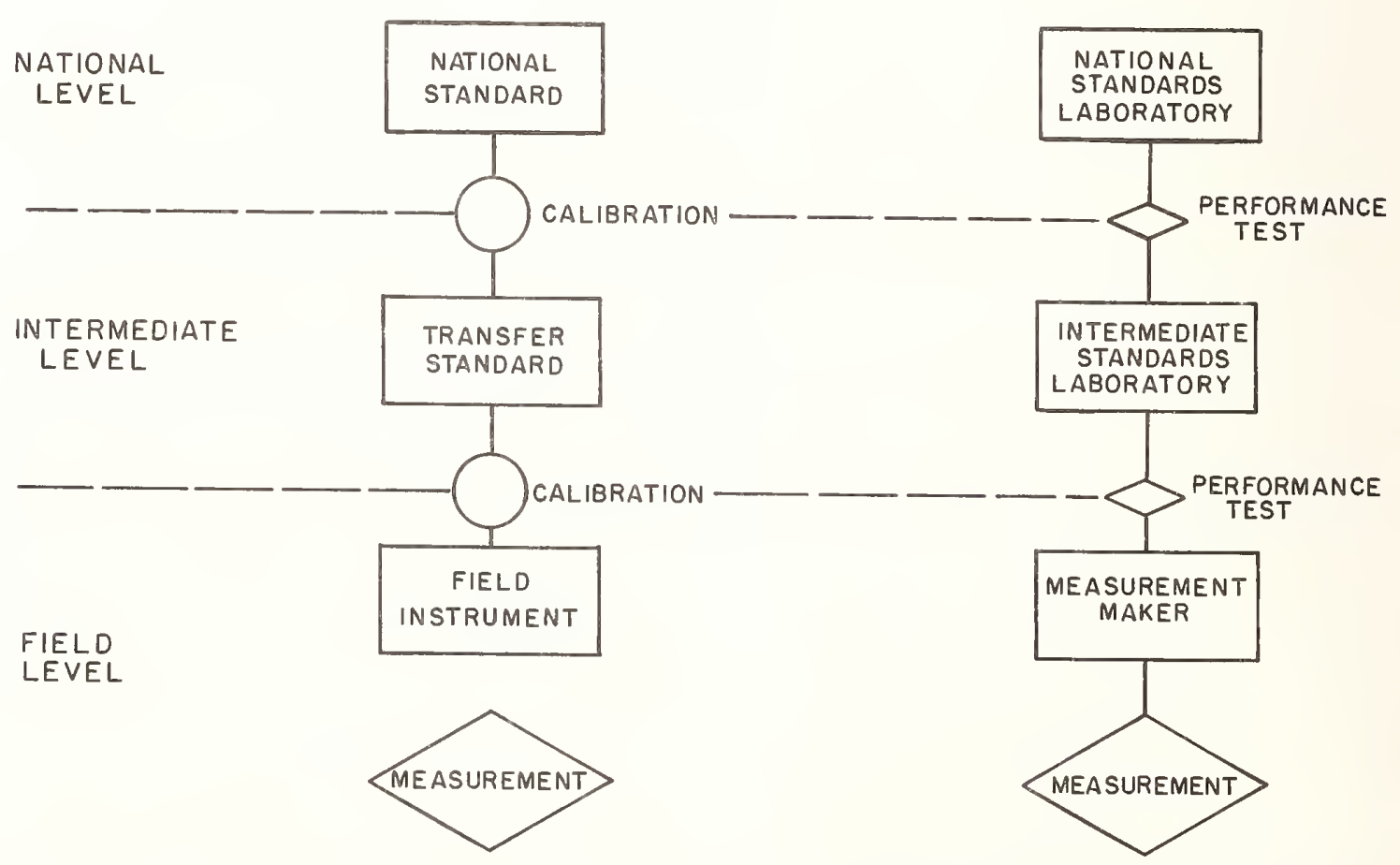

Figure 1. Schematic indication of the difference between the traceability chains for instrument traceability and measurement traceability. 
If demonstrated consistency of a measurement with a standard is desired or required, the traceability chain must be extended beyond the instrument to the measurement, as indicated in Figure 1. In this case, traceability is a characteristic of the measurement itself, and there is documented evidence that the measurement is consistent with the appropriate standard. Thus measurement traceability may be defined as the ability to show that a measurement process produces results for which the total measurement uncertainty relative to a national or other designated standard is quantified. This is the most desirable type of traceability, since it is based on a demonstration that the complete measurement process is under control, including the instrument, its user, and the procedures.

Measurement traceability is usually achieved through utilization of a transport standard*, which may be in the form of a radiation source or a dosimetry device that originates from NBS or an intermediate standards laboratory directly traceable to NBS for the particular measurement under consideration. When a radiation source is used, its output is measured by the participant who receives it, and the result is reported to the originating laboratory. If the reported value compares favorably with the value determined by the originating laboratory, a statement of satisfactory performance is provided to the participant.

When the transport standard takes the form of a dosimetry device, it is sent to the participant who administers a nominal measured dose (or exposure). The device is then returned to the originating laboratory, where the administered dose (or exposure) is evaluated. If the participant's nominal measured value is within the acceptable range of uncertainty, a statement of satisfactory performance is provided.

An obvious advantage of measurement traceability is that it can be achieved without utilization of a transfer standard (instrument or source) that has been calibrated by NBS. Measurement traceability is possible without instrument traceability, and the iatter can be optional for anyone who demonstrates measurement traceability. Thus periodic demonstration of adequate measurement performance through the use of a transport standard may eliminate, or substantially reduce, the need for (and cost of) periodic instrument or source calibrations.

Since a demonstration of satisfactory performance can not reasonably guarantee similar

\footnotetext{
*A transport standard is intended for use in the determination of measurement traceability through a performance test. In distinction, a transfer standard has been compared directly or indirectly with the national standard and is intended to serve as a reference for calibrations.
}

performance for an indefinite period of time, the demonstration process should be repeated periodically.

In summary, the relationship between the desired type of consistency of the measurement and standard, the process by which that consistency is achieved, and the resultant type of traceability is shown in the following table:

\begin{tabular}{ccc}
$\begin{array}{c}\text { Type of } \\
\text { consistency } \\
\text { desired }\end{array}$ & $\begin{array}{c}\text { Process by } \\
\text { which it is } \\
\text { achieved }\end{array}$ & $\begin{array}{c}\text { Type of trace- } \\
\text { ability which } \\
\text { results }\end{array}$ \\
\cline { 1 - 2 } Calibration & $\begin{array}{c}\text { Instrument } \\
\text { (Artifact) }\end{array}$ \\
Demonstrated & $\begin{array}{c}\text { Performance } \\
\text { Test }\end{array}$ & Measurement
\end{tabular}

Measurement Uncertainty

The objective of a measurement is to determine how many units of a particular radiation quantity are present, within an acceptable range of uncertainty. The uncertainty of the measurement ismeant to be a credible estimate of the likely limits to its actual error (i.e., the difference between the measured value and the "true" value), and is usually expressed as a percentage of the measured value. This uncertainty consists of both random and systematic components, and may be estimated in terms of the difference between the measured value and the value that would be obtained if the national standards themselves were used to make the measurement. In effect, the "true" value is defined by the national standards (at least in the legal sense). The uncertainty of the measurement is therefore an indicator of how consistent it is with the national standard. In practice, an upper limit of uncertainty (e.g., $5 \%, 10 \%$, etc.) is usually established as that which is deemed to be acceptable for the particular measurement of interest.

For implied consistency of a measurement with the national standard, the uncertainty of the measurement is also implied. In this case, the traceability chain ends with the instrument used to make the measurement, and the only definitive statement of uncertainty that can be made is that which applies to calibration of the instrument. It is somewhat presumptuous to assume that the measurement uncertainty is the same as the calibration uncertainty, unless the conditions encountered during the measurement are identical to those that existed at the time of calibration. Since this rarely (if ever) happens in practice, the measurement uncertainty is nearly always greater than the calibration uncertainty.

For demonstrated consistency of a measurement with a standard, the traceability chain ends with the measurement itself, and the uncertainty is determined without impication. 


\section{Statements About Traceability}

The National Bureau of Standards encourages and supports the concept of traceability, and its application by other organizations and agencies, because it leads to more accurate and uniform measurements on a national basis. However, since NBS must provide "means and methods" for achievement of traceability, it is an interested (and sometimes concerned) party when others make statements about traceability. Such statements are increasingly made in Federal regulations and regulatory guides, state regulations, contracts, voluntary standards, and in advertising.

Sometimes the statements about traceability are good, but many times they are vague, ambiguous, and lead to confusion. As a result, NBS is getting increasing numbers of requests for definition of traceability, for clarification of traceability statements made by others, and for recommended procedures to be used to achieve satisfactory traceability. In an attempt to study this general problem, and to possibly identify better ways to make statements about traceability, a cooperative effort was initiated with the Nuclear Regulatory Commission. The objective is to jointly develop more workable, understandable, and meaningful statements. This effort has resulted in significant improvements of traceability statements in several regulatory guides, with additional specific projects currently underway.

An early conclusion resulting from this cooperative effort was that general definitions of traceability, such as the one given earlier in this paper, are relatively easy to state, but are also of little value. To be more useful, a definition must be specific to the particular measurement and radiation quantity of interest. In effect, traceability must be defined for each type of measurement included in the variety of possible types of radiation measurements. A meaningful definition of traceability for a particular type of measurement must include an indication of the "means and methods" used to achieve consistency with the appropriate standard. These means and methods will be quite different, for example, for the measurement of low-energy $x$ rays as compared with the measurement of radon concentration.

\section{Statements About "Traceable To"}

Some ambiguous statements that appeared in various documents over the past few years name the following entities as the objectives to which traceability is desired:

NBS radiation measurement system

NBS radioactivity measurement system nationa 1 measurement system

national radioactivity measurement system NBS standard reference materials

national system of measurements and standards nationally accepted measurement system

$A$ basic problem arises from the fact that nearly all of these objectives are undefined and therefore are subject to a variety of interpretations. The readers must decide for themselves what is meant by ambiguous terms such as "system", "measurement system", "national system", "national measurement system", or "nationaliy accepted measurement system", and their interpretations will differ significantly.

When such statements are attempted, it is essential to keep in mind the relevant fundamental concept, i.e., the ability to show that actions have been taken to make a measurement consistent with a standard. If this basic concept is adhered to, an unambiguous statement is possible, namely "traceable to the national standard". Since national standards and NBS are synonymous, an alternative statement could be "traceable to NBS". If an appropriate national standard is not maintained by NBS for the quantity of interest and an alternative standard serves as the point of reference, it should be identified specifically in any statement about traceability to it.

\section{Statements About "Traceability Of"}

Most statements about traceability take the general form of " $X$ is traceable to $Y$ " (or should be). This is equivalent to saying that $X$ has the characteristic of traceability, and one can therefore recognize the traceability of $X$. In recent statements, the characteristic of traceability has been assigned to a range of things, including
a measurement
an instrument
a radiation source
a standard
a laboratory
a calibration
a measurement system
a technique

In descending order, statements about "traceability of" these items range from highly desirable to highly ambiguous. As indicated earlier in this paper, traceability of a measurement is the best indicator of consistency with a standard because it is based on demonstrated performance. Traceability of an instrument or source resuits in only implied consistency. If "a standard" is actually an instrument or a source, it can have the characteristic of (generic) instrument traceability.

When considering "traceability of a laboratory" the possibility of ambiguity increases substantially. This statement has little meaning unless additional information is provided for clarification, such as the particular type of measurement for which traceability is claimed. Since calibration is a process that provides to an instrument or radiation source the characteristic of traceability, that characteristic is a property of the instrument or source, and not of the process. The term "traceability of a measurement system" is subject to a variety of interpretations and can lead to confusion unless the "system" is carefully defined. Finally, the 
concept of traceability of a technique is invalid because there is no national standard technique to which one could be traceable. As mentioned earlier, traceability is a characteristic of either a measurement, instrument, or source, and a technique is none of these.

To avoid unnecessary confusion and misunderstandings, statements should be limited to traceability of either a measurement, an instrument, or a radiation source. It is reasonable to make statements about traceability of a standard as long as that standard consists of an instrument or source. This set of items which can have the characteristic of traceability (measurement, instrument, source, and standard) should be sufficient for the purpose of making unambiguous statements.

\section{Direct and Indirect Traceability}

To the extent possible, terms used in statements about traceability should be in agreement with common interpretation and usage. If unusual, uncommon meanings are assigned to common words, the potential for misinterpretation increases substantially. Thus the definition of direct traceability that would be most consistent with common expectation is "that traceability which results from direct comparison with a standard". If the standard under consideration is maintained by NBS, the result is direct traceability to the national standard. (One step removed from the national standard).

In contrast to direct traceability, indirect traceability results from indirect comparison with a standard, through one or more intermediates. (More than one step removed from the national standard).

\section{Means and Methods}

It is relatively easy to make the general observations that measurements should be consistent with standards, that measurement traceability is more desirable than instrument traceability, and that statements about traceability should be unambiguous. The achievement of these objectives is, however, more difficult. Even correct statements about traceability have little or no value unless they are supported by technical programs that provide the means and methods needed to enable measurements to be consistent with standards. An evaluation of existing national programs leads to the realization that there is a key problem, which is that the means and methods for achieving measurement consistency with the national standards (i.e., the traceability mechanisms) are unspecified and inadequate in many cases. As a result, many statements about traceability will have limited meaning and value until the means and methods become adequate.

\section{National Measurement Support System}

It is impractical and unnecessary for the thousands of radiation measurements made each day to be directly traceable to the national standards.7
For the majority of field measurements, it is sufficient to achieve traceability to NBS through an intermediate level of laboratories which provide calibrations and measurement - related services. Ideally, the laboratories at this level will have measurement traceability to NBS. At a minimum, they should have instruments or radiation sources which are either directly or indirectly traceable to the national standards.

Utilization of an intermediate level (or levels) results in the type of measurement support system (MSS) illustrated in Figure 2. In concept, this MSS can be an effective mechanism for providing consistency of measurements with the national standards. The problem is that the links between the various levels are presently undefined and undeveloped for many types of radiation measurements. These links consist of two basic types of interactions between levels -- technical and institutional.

The technical elements of the measurement support system are:

'measurement standards, including the national standards and the transfer standards used at the intermediate level

${ }^{\circ}$ calibrations of transfer standards by NBS, and of field instruments by intermediate laboratories

'measurement quality assurance programs, including performance testing services provided by NBS or by an intermediate laboratory

ufield instruments used to make measurements at the field (user) level

oprocedures used for measurements, calibrations, and measurement quality assurance (MQA)

${ }^{\circ}$ training of personnel who perform measurements, calibrations, and MQA

${ }^{\circ}$ records that document specific actions that have been taken

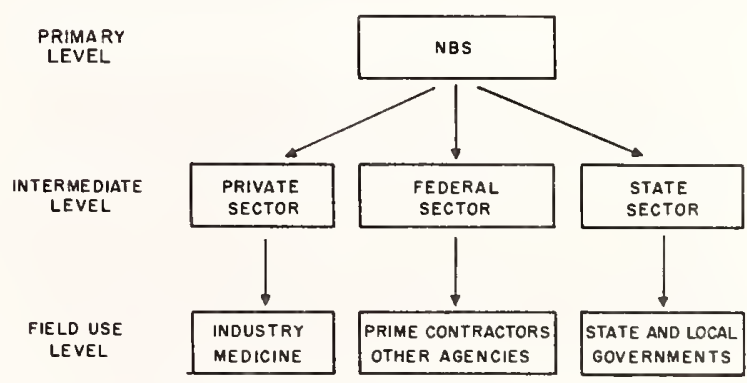

Figure 2. Schematic showing the national measurement support system three-level concept. 
The institutional elements of the measurement support system are the:

'national standards laboratory that maintains the national reference standards and provides related services

- intermediate standards laboratories that use transfer standards as the bas is of calibrations and other services provided by them

- field level entities, such as laboratories, companies, or individuals that measure radiation as a user or a concerned party

- voluntary standards-writing organizations and professional societies that define, develop, and document various traceability interactions.

Each element, whether of the technical or institutional type, is essential for an effective measurement support system. To the extent necessary, the actions of the various institutional elements should be coordinated and planned.

\section{Measurement Quality Assurance (MQA)}

The purpose of a measurement quality assurance program is to provide a satisfactory degree of assurance that the measurer's process is under control at all times. Such a program includes a variety of periodic actions, depending upon the specific nature of the measurement. In a general sense, an MQA program consists of procedures that enable a measurer to assure on a continuing basis that the total measurement uncertainty relative to the national standard is quantified and sufficiently small to meet requirements.

A performance test can be an important part of an overall MQA program. As mentioned earlier in this paper, such a test provides an effective method for achieving measurement traceability (demonstrated consistency with national standards). Each test is specific to a particular type of measurement, and usualiy employs a transport standard. If it is administered by NBS, it results in direct measurement traceability. When an MQA performance test is administered by some other laboratory that has traceability to the national standard for the measurement under consideration, it results in indirect measurement traceability.

Since MQA performance tests demonstrate proficiency only at the time a test is taken, it is desirable to take additional actions that assure adequate performance between tests. These can include internal consistency checks, such as the frequent use of stable radiation sources to check instrument response, and control charts that would warn of unusual response or instability in the measurement process.

It is important to recognize the desirability of measurement quality assurance, and the value of MQA performance tests, at all levels of the measurement support sytem -.. national, intermediate, and field.

\section{An Ideal Measurement Support System}

For many reasons which will not be treated in this paper, the support system illustrated in Figure 2 is felt to be highly desirable [3]. It represents the best conceivable long-term system for both technical and political reasons and, fortunately, comes very close to the present situation. The three primary sectors are Federal, state, and private, and each has a direct interaction with NBS. This arrangement avoids potential conflicts of interest, and is consistent with the present policies of most regulatory agencies.

In the interest of accuracy and uniformity for all measurements made in the United States, the technical nature of interactions between any two levels of the MSS should depend only on the radiation quantity of interest, and not on whether the Federal, state, or private sector is involved. For example, the interactions with NBS should be identical for intermediate laboratories in all sectors for a particular type of radiation measurement.

Intermediate standards laboratories can provide a number of services for the field level. Using transfer standards that were calibrated by NBS, they can calibrate instruments or sources for field use. They can also provide MQA performance tests and advice on MQA procedures for use at the field level. Intermediate standards laboratories can be convenient sources of education and training for fieldlevel measurers, for example by providing short courses or observation of calibration procedures. These laboratories can also test new instruments to determine whether stated performance speci. fications are actually achieved.

A number of intermediate laboratories already exist in the Federal sector, and their interactions with NBS are being improved. A recent survey conducted by the Conference of Radiation Control Program Directors identified laboratories presently existing in the private sector that can serve as intermediate standards laboratories [4]. At this time, NBS is cooperating with several states to develop pilot intermediate laboratories in their sector. Thus the ideal measurement support system appears to be feasible, at least in terms of a sufficient number of suitable intermediate standards laboratories.

As it presently exists, the national measurement support system has both strengths and weaknesses. To more nearly approach the ideal system, the following weaknesses should be corrected [3]:

-Additional national standards should be developed, specifically for high-energy photons, electrons, and neutrons.

-Transfer standards are needed for some radiation quantities. 
- More intermediate standards laboratories are needed in the state sector.

-Many documented procedures (criteria) should be developed for operation of intermediate laboratories, and for their interactions with NBS and the field level.

-Suitable measurement quality assurance programs should be designed and implemented, including MQA performance tests, for intermediate laboratories and the field level.

- Training is needed for operators of intermediate laboratories and for those who make field-level measurements.

Coordination of the MSS is needed to achieve national uniformity and consistency of measurement results.

It is encouraging to note that the present measurement support system is gradually being improved in response to various incentives. This progress is, however, quite slow and results primarily from the occasional need to solve specific, limited problems.

\section{Examples of Specific Traceability Programs}

As indicated earlier in this paper, general definitions of traceability have limited value. The most valuable statements about traceability are those that identify the specific means and methods by which it is achieved for a particular type of measurement. If the means and methods are we11-documented, and consistency with national standards is demonstrated, unambiguous traceability statements can be made and defended. Two examples of national programs that enable such statements follow.

The American Association of Physicists in Medicine (AAPM) has an ongoing program for accreditation of laboratories that calibrate radiation-measuring instruments used primarily in radiation therapy. Three laboratories have been accredited so far: M.D. Anderson Hospital (Houston, Texas), Sloan-Kettering Memorial Hospital (New York, N.Y.), and Victoreen Instrument Company (Cleveland, Ohio). Accreditation by the AAPM is based on documented criteria that must be satisfied by candidate laboratories. Interactions between NBS and the accredited laboratories are specified, including calibration of transfer standards by NBS and periodic MQA performance tests. All the technical requirements for unambiguous traceability are satisfied in this program: standards, calibrations, MQA, procedures and records. The institutional requirements are also satisfied, including three good examples of intermediate standards laboratories.

The second example consists of a national program that is still under development. Since 1973 NBS has cooperated with the states, various Federal agencies, and the Health Physics Society in an attempt to establish a performance testing program for the organizations that provide personnel monitoring services. Criteria have been developed that will form the basis of a future routine performance testing program [5]. As the future national program is envisioned, there will be a testing laboratory at the intermediate level which will periodically test the performance of personnel monitoring services. The NBS role will be to ensure that the testing laboratory uses procedures that maintain consistency with national measurement standards. In this quality assurance role, NBS will periodically calibrate the radiation sources and instruments used by the testing laboratory, and will monitor overall technical performance.

In these two examples, specific, documented criteria and intermediate standards laboratories serve as the principal ingredients of programs that result in unambiguous, easily-recognized traceability.

\section{Conclusion}

This paper was addressed to general considerations of traceability for measurements of ionizing radiation. Some of the fundamental concepts which are relevant to traceability for all types of measurements were identified, and the problem of ambiguity in statements about traceability was treated. The "means and methods" by which radiation measurements can be made consistent with national standards were recognized, and two examples were given of programs that employ appropriate means and methods to achieve unambiguous traceability.

The most effective national measurement support system would provide those technical and institutional elements required to ensure the continuing adequacy of radiation measurements for whatever purpose those measurements are made. Some of the required elements are in place and functioning for some types of measurements, but many have not yet been developed. These weaknesses must be corrected with additional technical programs and institutional improvements (particularly intermediate standards laboratories) before some present ambiguities about traceability can be eliminated.

\section{References}

[1] Belanger, Brian C., "Traceability: An Evolving Concept", ASTM Standardization News, $p$. 22 , January 1980.

[2] Act of 22 July 1950, 64 Stat. 371 (Public Law 619,81 Congress), to amend a 1901 Act to provide basic authority for the performance of certain functions and activities of the Department of Commerce.

[3] "Requirements for an Effective National Ionizing Radiation Measurements Program", a report to the Congress by the National Bureau of Standards. NBS Special Publication 603, March 1981.

[4] "Directory of Commercial Calibration Services for Ionizing Radiation Survey Instruments", prepared by the Conference of 
Radiation Control Program Directors, NBS GCR 80-296, Apri1 1981.

[5] Draft American National Standard N13.11, "Criteria for Testing Personnel Dosimetry Performance", prepared by the Health Physics Society Standards Committee, Working Group 1.4, April 1981. 


\author{
Ronald L. Kathren \\ Battelle, Pac if ic Northwest Laboratories \\ Richland, Washington 99352
}

\begin{abstract}
Although users of radiation desire measurement traceability for a number of reasons, including legal, regulatory, contractual, and quality assurance requirements, there exists no real definition of the term in the technical literature. Definitions are proposed for both traceability and traceability to the National Bureau of Standards. The hierarchy of radiation standards is discussed and allowable uncertainties are given for each level. Areas of need with respect to radiation standards are identified, and a system of secondary radiation calibration laboratories is proposed as a means of providing quality calibrations and traceability on a routine basis.
\end{abstract}

(calibration, definitions, hierarchy of standards, National Bureau of Standards, radiation, standards, traceability)

By Way of Introduction: Traceability and the User

Traceability--specifically traceability to the National Bureau of Standards-- is a much desired and sought after commodity among users of sources of ionizing radiations. Indeed, a 1976 study by the National Bureau of Standards revealed that the provision of transfer standards to "...establish and maintain traceability to NBS primary standards" was considered to be the most important possible NBS service by the Conference of Radiation Control Program Directors. [1]

While perhaps not all user groups would rank traceability of prime import within the possible range of NBS services, most users do consider NBS traceability important for a variety of reasons, including:

1. Legal and regulatory requirements, including license conditions imposed by regulatory agencies.

2. Contractual requirements.

3. Quality assurance/quality control.

4. Compliance with voluntary standards, both national and international.

5. Health and safety considerations, including protection against lawsuits stemming from improperly measured personnel exposures to radiation.

6. Legal protection.

7. Achieving a competitive edge.

8. Peace of mind and security in the knowledge that the "best" practicable measurements have been made.

\section{Scientific satisfaction.}

Some of the above overlap and the relative value given to each may vary among users, but in the main, the above reasons are explicit and do not require explanation or amplification.
There has, in recent years, been increasing effort within the broad area of ionizing radiation measurement traceability. Cavallo, Ehrlich, and Hutchinson recently described traceability programs and their results[2]; virtually all of the programs currently underway are for radioactivity or are applicable to medical (usually therapeutic) uses of radiation. [1,2] Most notable among the latter is the American Association of Physicists in the Medicine Regional Calibration Laboratory program, which provides radiological calibrations primarily for reference class instruments used in radiation therapy.

It might be a useful digression at this point to briefly touch on radioactivity, as opposed to radiological, standardization. Radioactivity standardization refers to measurement of the absolute or "true" disintegration of emission rate of a radioactive source; radiological standardization refers to dose or exposure rates associated with a particular source. Radioactivity measurements are usually made on fairly small (i.e. low activity) sources by direct measurement--i.e. counting--of the emitted particle or radiation; radiological measurements or standardizations are usually accomplished by measuring secondary effects of the emitted radiation(s), e.g. energy deposition in the form of heat produced in a spec if ic medium or current flow or capacitance changes produced by ionization in a gaseous medium. Hence, radioactivity standardization is usually achieved by direct means (i.e. counting of emitted particles) and reported in units of activity (becquerels, curies). Radiological standardization is usually accomp 1 ished by indirect means, and may be reported in units of exposure $(\mathrm{C} / \mathrm{kg}$ or $\mathrm{R})$, doses, fluence rate, or yield (e.g. particles per second) instead of activity. The distinction is important, because while traceability is important for both (particularly in health physics), there appear to be greater needs, probably because of the greater difficulties of measurement, conversion, and source characterization in the radiological area, and especially the greater uncertainty generally associated with radiological measurements. 
While on the subject of terminology, it might also be instructive to examine just what is meant by traceability. The dictionary, as expected, is of little use for a technical term, merely defining traceability as 'capable of being traced.' However, review of the dictionary also points to some interesting if unexpected relationships-similarities, that is, between traceability and a certain type of nonscientific endeavor.

On the Similarities Between Traceability and Pornography

Interestingly and perhaps surprisingly, pornography and traceability have certain similarities. Pornography, for example, has no true definition. According to the dictionary, pornography is simply "obscene literature or art"[3]; and since there exists no uniform legal definition of what is obscene, * by logical extension pornography is also not defined. However, the same jurists and legal scholars who fail at exact definition can readily recognize and identify pornography as such. Thus, they rest their case.

A similar situation exists with regard to traceability. We all know what it is, and can readily recognize and identify it, even though no definition apparently exists. While preparing this presentation, more than 150 works dealing with measurement of radiation were checked, including such standard texts as Johns [4]; 1$]$ four volumes of Attix, Roesch, and Tochilin [5]; such classics as Hine and Brownel1[6]; and some older but still excellent works, such as Glasser's Medical Physjcs[7]; Glasser, Quimby, Taylor and Weatherwax 8 ; that vade mecum of the health physicist, the Radiological Health Handbook [9], with its excellent and extensive glossary; numerous reports of the National Council on Radiation Protection and Measurements and International Commission on Radiological Units; various handbooks, encyclopedias, and dictionaries of physics and chemistry; ANSI and other standards; and, of course, various reports of the National Bureau of Standards. Nowhere was there a definition of traceability--not even in the ANSI glossaries of quality assurance of nuclear science and technology terms, $[10,11]$ although the paper by Caval1o, Ehrlich and Hutchinson, previously mentioned, did describe traceability as referring to the agreement between the measurement of a physical quantity with results of NBS within an acceptable limit of uncertainty. [2] This would seem to be more of a description of intercomparison, for among users, traceability, as used in the vernacular, goes somewhat beyond this description.

There is, however, a most interesting and germane discussion of traceability in a recent publication of the National Bureau of Standards which bears repetition here:

\# The definition of obscenity depends on the prevailing community standards, which, of course, means that what is obscene in one place may be quite proper elsewhere.
"Traceability is a term which a number of contracting and regulatory agencies have invoked to specify the standards used in the calibration of instruments.

Perhaps the first and most far-reaching traceability requirement has been that of the Dept. of Defense (MIL-C-45662A), "Calibration Systems Requirements," which states (sec. 3.2 .5 .1 ):

'Measuring and test equipment shall be calibrated by the contractor or a commercial facility utilizing reference standards (or interim standards) whose calibration is certified as being traceable to the National Bureau of Standards, has been derived from accepted values of natural physical constants, or has been derived by the ratio type of selfcalibration techniques.'

This specification does not define the term 'traceable' (nor do those of any other government agency)."[12]

The first and last sentences of the above quotation, taken from NBS Special Publication 250, tell the whole story, viz. a requirement for traceability without a definition of the term. Indeed, NBS points out further along in Publication 250 that it gives no special meaning to traceability and indeed legally cannot do so, at least in the context of procurement contracts or related activities.

Despite the fact that there is apparently no definition for traceability or traceable to the National Bureau of Standards, these terms äre coming into greater and more widespread use in science, engineering, industry, and commerce. The increased emphasis on quality assurance has led to the imposition of traceability requirements throughout the nuclear power industry and elsewhere, but the recipient of such requirements has little to go on other than word of mouth or vague guidelines.

An exception is the Institute of Electrical and Electronic Engineers standard on calibration, which provides the following statement regarding traceability:

M\&TE (measurement and test equipment) shall be calibrated utilizing reference standards whose calibration has a known valid relationship to nationally recognized standards or accepted values of natural physical constants. If no national standard exists, the basis for calibration shall be documented.

Reference standards used in the calibration program shall be identified on calibration data records and supported by certificates, reports, or data sheets attesting to the calibration date, calibration facility, environmental conditions, and data which shows conformance to accuracy requirements. [13]

This statement provides reasonable guidance as to how traceability might be achieved, but it falls short of being a definition. 
The concept of traceability has been discussed in a recent paper by Brian Belanger of NBS. [14] In his presentation before the ASTM, Belanger traced the historical development of traceability, noting its purposes and uses, as well as the legal and contractual requirements that may be imposed on the user. In threading his way through the legal and contractual requirements maze he clearly underscores, at least by implication, the need for a consistent and meaningful definition and application of traceability among them. Although his discussion is articulate, where definitions are concerned and with regard to how traceability might be achieved, he neither offers nor suggests the adoption of a specific 'universal' definition.

The legal vulnerability and intense frustration of attempting to fulfill traceability requirements is intensified by the lack of a practical and simple accepted definition. The apparent purpose of traceability is simply to assure that measurements are reasonably correct; as for a definition for traceability in the sense in which the word is commonly used (among those concerned with radiological measurements at least) the following is proposed:

traceability--the means or series of steps and associated documentation by which a measurement or measuring instrument is relatable to a recognized standard.

Similaḱly, by extension, traceability to NBS can be defined as

...the means or series of steps and associated documentation by which a measurement or measuring instrument is relatable to one or more standards or measurements of the U.S. National Bureau of Standards.

It would seem that acceptance or at least agreement with the above definitions would provide some modicum of relief from the present state of affairs, and at the same time remove an interesting parallel between radiological science and pornography.

\section{Of Standarus and Their Hierarchy}

Nearly a quarter century ago, A. G. McNish of the National Bureau of Standards put forth a classification scheme for standards of ionizing radiation that expanded the previously accepted two-tier level of primary and secondary standards. $[15,16]$ This classification scheme, recognized by the National Committee (now Council) on Radiation Protection and Measurements (NCRP) and described in simplified form in NBS Handbook $80,[17]$ showed the relationships among five categories (prototype, derived, calibration, instruments, and materials) and several orders or levels of standards. The levels or orders were, in effect, a hierarchy of standards.
At the top of the hierarchy, McNish proposed an international standard of a single (or group of) preparation(s) or radioactivity to be selected by an international committee. National standards, such as those held by NBS or its equivalent in other countries, would be a select group calibrated against the international one(s). To protect the national standards from wear and tear and to provide backup capability, another set of standards, national reference standards would be created, these of course being cross-calibrated against the national standards. Ordinary calibration work would be carried out with national working standards, cross-calibrated with the reference level. Also cross-calibrated with the national reference standards would be laboratory reference standards, maintained by an individual organization for its own purposes. Day-to-day work would involve the use of laboratory reference standards, these being analogous to the national working standards.

Implicit in the McNish scheme is a direct line of traceability to the NBS, with NBS providing laboratories with their basic calibrations or standardization. Recommended in somewhat modified form at least for radioactivity by the NCRP in 1978, [18] the McNish scheme has regretably never been fully adopted. Although it called for direct traceability to the NBS, it also hinted, albeit vaguely, at the possibilities of laboratories calibrating standards for other laboratories, but made no provision for a situation where direct traceability to NBS was not possible, as might be the case if a user desired a different energy, intensity, or geometry than could be conveniently supplied by the Bureau.

A few years later, a simple hierarchial standards scheme was proposed for radiological measurements by Kathren and Larson, [19] and by Kathren. [20] This scheme, applicable to radioactivity as well, is reproduced in Figure 1 . It features a six-level hierarchy of standards and makes allowance for the situation in which direct line traceability to NBS is impossible or other wise not feasible. In this scheme, international standards lie at the top of the hierarchy and are those fundamental physical standards which serve as the basis for our system of units and measurements. These are ordinarily established by treaty or agreement of international scientific bodies.

National standards are the exclusive province of the National Bureau of Standards and represent the highest achievable state-of-the-art. Thus, these would have the minimum of uncertainty and would represent the fruits of the most sophisticated instrumentation and measurement techniques. These would, wherever possible, be related to international standards. However, this need not be the case, for a specific national standard might be developed for a need more or less unique to one country although this situation would be considered exceptional.

Secondary or derived standards would be sources and instruments directly calibrated by 

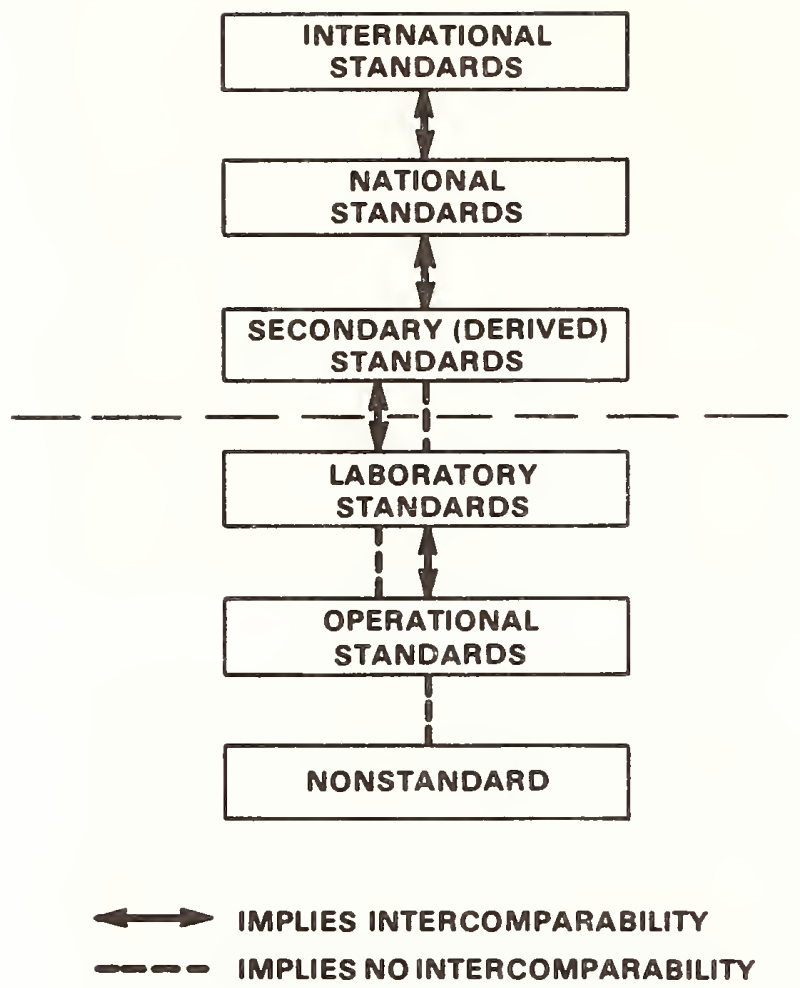

FIGURE 1. A Hierarchy of Standards [20]

the National Bureau of Standards or intercompared with NBS sources or instruments with no intervening steps. As such, these would have somewhat greater uncertainty than national standards but would serve satisfactorily as the basic standards of industrial and other users.

Instruments and sources calibrated against secondary standards, or well recognized instruments such as extrapolation chambers utilized for standardization would have larger allowable error and would qualify as laboratory standards. Included in this group are instruments and sources which are not routinely calibrated by NBS but which are utilized for standardization. For all practical purposes, use of these instruments and sources would be restricted to a well-controlled laboratory with known, if not controlled geometry, scattering and other conditions. Free air chambers, extrapolation chambers, and long counters can serve as laboratory standards, as can practically any detector if its response characteristics are known and the measurement conditions rigidly controlled.

Operational standards assume even greater but still acceptable and known error limits, and presume an instrument or source used under relatively uncontrolled conditions. As an example, the measurement of ionizing electromagnetic radiation levels inside a reactor containment might be accomplished with uncontrolled and unknown scattering conditions, a wide mixture of energies, and perhaps even a mixed radiation field. A wide variety of instruments might be used for operational purposes. Generally, these would have wide response characteristics, be simple and easy to use, and permit accumulation of several measurements, economically.

Table I sets down what appears to be the achievable uncertainty for various types of measurements at each level in the standards hierarchy, based on the present state-of-the-art.

TABLE I. Uncertainty of Measurements with the Radiation Standards Hierarchy

\begin{tabular}{|c|c|c|c|c|}
\hline Level & Radiation & Quantity & $\begin{array}{c}\text { Allowable } \\
\text { Uncertainty }\end{array}$ & Comments \\
\hline National & A11 & Any & State of & NBS Dnly \\
\hline Secondary & $\begin{array}{l}\text { Alpha, } \\
\text { Beta } \\
\text { IER } \\
\text { Neutron } \\
\text { Beta }\end{array}$ & $\begin{array}{l}\text { Activity } \\
\text { Exposure or } \\
\text { Dose } \\
\text { Fluence Rate } \\
\text { or Yield } \\
\text { Dose }\end{array}$ & $\begin{array}{l} \pm 1 \% \\
\pm 2 \% \\
\pm 5 \% \\
\pm 5 \%\end{array}$ & $\begin{array}{l}\text { Must specify } \\
\text { nuclide } \\
\text { All directly } \\
\text { traceable to } \\
\text { NBS; may be } \\
\text { only certain } \\
\text { specific } \\
\text { energies or } \\
\text { sources }\end{array}$ \\
\hline Laboratory & $\begin{array}{l}\text { Alpha, } \\
\text { Beta } \\
\text { IER } \\
\text { IER } \\
\text { Neutron } \\
\text { Neutron } \\
\text { Beta } \\
\text { Beta }\end{array}$ & $\begin{array}{l}\text { Activity } \\
\text { Exposure or } \\
\text { Dose } \\
\text { Dose } \\
\text { Fluence Rate } \\
\text { or Yield } \\
\text { Dose or Dose } \\
\text { Equivalent } \\
\text { Dose } \\
\text { Fluence rate }\end{array}$ & $\begin{array}{l} \pm 2 \% \\
\pm 5 \% \\
\pm 10 \% \\
\pm 10 \% \\
\pm 20 \% \\
\pm 10 \% \\
\pm 10 \%\end{array}$ & $\begin{array}{l}\text { All measure- } \\
\text { ments under } \\
\text { controlled, } \\
\text { specific } \\
\text { laboratory } \\
\text { conditions; wider } \\
\text { range of energies } \\
\text { and sources than } \\
\text { available above }\end{array}$ \\
\hline Operational & $\begin{array}{l}\text { Alpha, } \\
\text { Beta } \\
\text { IER } \\
\text { Neutron } \\
\text { Beta }\end{array}$ & $\begin{array}{l}\text { Activity } \\
\text { Exposure or } \\
\text { Dose } \\
\text { Dose or Dose } \\
\text { Equivalent } \\
\text { Dose }\end{array}$ & $\begin{array}{l} \pm 5 \% \\
\pm 20 \% \\
\pm 50 \% \\
\pm 35 \%\end{array}$ & $\begin{array}{l}\text { Allowable error } \\
\text { considered to } \\
\text { be currently } \\
\text { attainable by } \\
\text { measurement in } \\
\text { the field under } \\
\text { semi-controlled } \\
\text { conditions }\end{array}$ \\
\hline
\end{tabular}

*IER = ionizing electromagnetic radiation.

For dose measurements, medium must be specified.

Some Areas of Need

A1though NBS has, in general, done a fine jub of providing radiological calibrations, the magnitude of the task is growing at an enormous rate. The expansion of the nuclear industry, especially nuclear power, has created a breadth and quantity of calibrations that could not have been foreseen a generation ago. Moreover, new and increased quality assurance requirements and personnel dosimetry demands have put the user in an awkward situation, for what the user needs and demands, NBS may be unable to supply. Supply may be outside the scope of the NBS mission, or may be nighly specialized and out of limited application, or may be restricted by budgetary or manpower or equipment considerations, or may be simply not reasonable with the given state-of-theart. 
Moreover, the NBS emphasis has been primarily research, and in the case of calibration services, oriented to the medical profession. Those in industry, and in particular the nuclear industry, have urgent need for certain types of calibration and standardization services which NBS does not now offer. For example, there is a need for high level [on the order of $10^{6}$ rads (air) per hour] photon calibrations for emergency radiological monitoring instrumentation and for area monitoring instrumentation as may be installed in power reactor containments. In the wake of the accident at the Three Mile Island Nuclear Generating Station, this need may assume critical (pun not intended) dimensions, and capabilities in this area urgently need to be developed.

Another important area of need relates to the standardization and development of dose measurements. Radiological traceability, if it is to be truly meaningfu1, must provide the wherewithal of dose measurement traceability for not only photons--i.e. ionizing electromagnetic radiation (IER)--but also for betas, neutrons, and mixed fields. Dose traceability might also be necessary for high energy IER--i.e. photons with energies above a few MeV.

One area, ripe for development, relates to provision of different energies of IER. For many years, the NBS has provided a standard series of filtered $x$-ray beams, but these are now inadequate to the needs of greatly expanded user body. Specifical,ty, K-fluorescence $x$-rays, essentially monoenergetic, are highly useful and perhaps mandatory for energy dependence and dosimetry studies, radiological evaluation of monitoring instruments, calibrating dosimeters, and for a whole host of activities related to health and radiological physics. Regretably, this capability, so easily developed, does not exist within NBS, although it has been adopted elsewhere. [21] Hence, there can be no real traceability to NBS in this area, however great the need.

On the other hand, NBS has done an outstanding job developing monoenergetic or nearly monoenergetic neutron sources. [22] This valuable work should be extended, and the service advertised, so to speak, so that it can be taken advantage of by a larger segment of the industrial and research community. Greater neutron capability needs development; additional sources, with a wider range of neutron exposure rates would be welcomed by the users in the field. Indeed, calibration in units of dose as well as fluence rate would serve the users well.

Certainly there are many other areas in which traceability does not truly exist because of lack of capability within NBS; some of these include characterization of beta energy spectra along with the establishment of standard beta spectra and sources, standardized pulsed radiation fields, and the establishment of standards and traceability for instrumentation used for sampling environmental media for radioactivity. The task, taken in toto is clearly a herculean one, and not necessarily in keeping with the charter or existing capabilities of NBS. Certainly the NBS charter and funding level can be expanded, but there is perhaps another solution which may be more practicable.

\section{Towards a Meaningful and Pragmatic Solution}

Many of the above needs could be met by the establishment of secondary calibration and standards laboratories with appropriate capability. Such laboratories would be chartered by NBS and thus periodically be required to demonstrate their capabilities and quality in the manner prescribed by, and to the satisfaction of the Bureau. The secondary laboratories would be selffunding, and would not be operated by NBS. Rather they would be operated by appropriate organizations--national laboratories or universities, for example, with already existing specialized capabilities and with no commercial ax to grind. Secondary laboratories might be selected on the bas is of location (i.e. regional) as well as on the basis of specialized calibrations or measurements (e.g. pulsed radiations) they could perform.

Alternatively, NBS could develop a number of regional secondary laboratories for the performance of routine calibrations and certain specialized radiation measurements. However, the cost of such a program (not to mention the time necessary for their development) would work against them. Also, some may question whether or not this is an appropriate course for NBS. In any event, the system of secondary laboratories has precedent, namely the Regional Calibration Laboratories of the American Association of Physicists in Medicine and the Regional Radiologic Physics Centers of the National Cancer Institute. $[23,24]$ In either case, the Bureau itself would be freed from the need to provide more or less routine calibration services and could better fullfill its role as the national ionizing radiation standards laboratory, providing pioneering, fundamental research in radiological standardization, as well as specific reference sources and measurements.

One might use the word 'esoteric' to describe the NBS role, with the more applied and routine calibrations performed by a satellite or secondary laboratory. Although traceability would be sought wherever possible, in some cases the sources and/or instruments or techniques used by this laboratory might not be directly traceable to national standards held by NBS. One reason for this lack of traceability might be that no direct pathway exists. However, to serve the existing needs of the industry and research community, a secondary reference laboratory, providing standardized and precise radiological field and pragmatic, often ad hoc calibrations, could serve. As noted, this secondary laboratory may or may not be run by the Bureau, but in any case it must have close ties to the Bureau.

While users in general and in particular the nuclear power industry need a service facility of secondary standards level, they must be made to realize that Bureau "traceability" is not a mandatory or always available goal. Indeed, the quest to achieve such traceability is of ten 
counterproductive. For example, in nuclear power plants, a common quality assurance requirement is "traceability to the National Bureau of Standards." What may well be acceptable is traceability through a large number--perhaps as many as a dozen or even more--intervening steps, some of which may not even be continuous or relevant to each other. Similarly, "traceability to the National Bureau of Standards" for gamma spectroscopy may involve only a single source giving a single energy point, far removed from the energies the system is actually used for. These examples, in my view, are a distortion of the meaning of the phrase "traceable to the National Bureau of Standards", and may introduce sufficient uncertainty as to render the ultimate measurement meaningless. In general, the fewer number of steps the better, and a system of service oriented secondary laboratories attuned to the needs of its users could go a long way towards ensuring that radiation measurements in the field are within reasonable bounds of uncertainty, and that traceability remains a meaningful and useful concept and activity.

\section{References}

1 Eisenhower, E. H., "Report of the National Bureau of Standards' Survey of State Measurement Needs" in Proc. Ninth Annual National Conference on Radiation Control, Meeting Today's Challenges, June 19-23, 1977, HEW Publication (FDA) 78-8054 (Apri1 1978).

2 Cavallo, L., M. Ehrlich, and 3. M. Hutchinson, "Traceability in Ionizing Measurements Systems" in National and International Standardization of Radiation Dosimetry, Proc. Symp., Atlanta, 5-7 December 1977, Vol. 1, International Atomic Energy Agency, Vienna (1978), pp。65-88.

3 Barnhar , C. L., Ed., American College Dictionary, Random House, New York (1960), p. 944.

4 Johns, H. E., and J. R. Cunningham, The Physics of Radiology, Charles C. Thomas, Springfield, Illinois, Third Edition (1974).

5 Attix, F. H., W. C. Roesch, and E. Tochilin, Radiation Dosimetry, Academic Press, New York (Vol. 1, 1968; Vol. 2, 1966; Vol. 3, 1969). Also, Topics in Radiation Dosimetry, Academic Press, New York (1972).

6 Hine, G. J., and G. F. Brownel1, Radiation Dosimetry, Academic Press, New York (1956).

7 Glasser, 0., Ed., Medical Physics, YearBook Publishers, Chicago, 3 vols (1944, 1950, 1960).

8 Glasser, 0., E. H. Quimby, L. S. Taylor, and J. L. Weatherwax, Physical Foundations of Radiology, Paul B. Hoeber, New York, 2nd Edition (1952).
9 Radiological Health Handbook, U.S. Department of Health, Education and Welfare, Revised Edition (January 1970).

10 American National Standard "Glossary of Terms in Nuclear Science and Technology", ANS-9/ANSI N1.1 - 1976, American National Standards Institute, New York.

11 American National Standard "Quality Assurance Terms and Definitions", ANSI

N45.2.10-1973, American Society of Mechanical Engineers, New York.

12 National Bureau of Standards, "Calibration and Related Measurement Services", NBS Special Publication 250 (1978), pp. 7-8.

13 Institute of Electrical and Electronic Engineers, "Control of Measuring and Test Equipment", IEEE Standard 498-1975, New York (1975), p. 9 .

14 Belanger, B.C., "Traceability - An Evolving Concept", Standardization News 8:22 (1980).

$15 \mathrm{McNish}$, A. G. "Classification and Nomenclature for Standards of Measurement", IRE Trans. Instr. I-7:371 (1958).

16 McNish, A. G., "Nomenclature for Standards of Radioactivity", Int. J. Appl. Radiation Radioisot. 8:145 (1960).

17 National Comittee on Radiation Protection and Measurements, "A Manual of Radioactivity Procedures", U.S. National Bureau of Standards Handbook 80, Washington, D.C. (November 20, 1961).

18 National Council on Radiation Protection and Measurements, "A Handbook of Radioactivity Measurements Procedures", NCRP Report No. 58, Washington, D.C. (November 1, 1978).

19 Kathren, R. L. and H. V. Larson, "Radiological Calibration and Standardization for Health Physics", Health Prys. 16:177 (1969).

20 Kathren, R. L., "Standard Sources for Health Physics Instrument Calibration", Health Phys. 29:143 (1975).

21 Thompson, I. M. G., "International Standard Reference Radiations and their Application to the Type Testing of Dosimetric Apparatus", in National and International Standardization of Radiation Dosimetry, Proc. Symp., Atlanta, 5-9 December 1977 , Vol. 1, Internationa 1 Atomic Energy Agency, Vienna (1978), pp. 343-365.

22 Schwartz, R. B., and J. A. Grund1, "NBS Standard Reference Neutron Fields for Personnel Dosimetry Calibration", op. cit., pp. 367-376. 
23 "AAPM Radiological Physics Center: A Status Report", Medical Phys. 1:41 (1974).

24 "Regional Radiological Physics Center Coordinating Committee: Cancer Control Program", Medical Phys. 1:287 (1974).
Acknowledgement. The helpful discussions with Dale Fleming and Craig Yoder, Battelle, Pacific Northwest Laboratories, and Daniel Garland, Westinghouse Hanford Corporation, are appreciated and hereby acknowledged. 


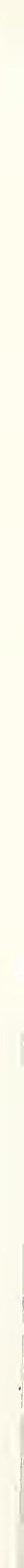




\title{
RADIATION NEASUREMENT TRACEABILITY IN THE UNITED KINGDOM
}

\author{
W. A. Jennings \\ National Physical Laboratory \\ Teddington, Middlesex, TW11 OLW, UK
}

\begin{abstract}
The concept of traceability in the UK, along with the role of the National Physical Laboratory, is presented. In respect of the measurement of ionizing radiations, the legal position in the UK is summarised and a three-tier system of Regulations, Codes of Practice and Guidance Notes is described, with particular reference to the field of radiological protection. The impact of the relevant European Directive in this field, and the preparation of the consequential Ionizing Radiation Regulations in the UK, are discussed, including the need for type-testing, etc. The role of the British Calibration Service, including the operation of personal dosimetry services is introduced. Radiotherapy calibrations, radioactivity measurements, and industrial radiation processing are then considered, and finally, the role of the various international links is mentioned.
\end{abstract}

(Calibrations, codes of practice, ionizing radiation, regulations, standards, traceability, type testing.)

\section{Introduction}

I was delighted to receive, last November, an invitation to participate in this seminar on traceability in radiation measurement. At that time, there was reason to believe that some uncertain features in the UK traceability chain would be clarified by the Spring, but in the event, the uncertainties in question have yet to be resolved: Adding to these the uncertainties in the parallel intermational scene, I can only present the position as I understand it at this moment in time, partly operational, partly propositional and partly aspirational, - to coin a word or two!

\section{Traceability}

What is meant by 'traceability' in this context? Looking at the programme, I note that this talk will have been preceded by two major contributions providing two views on 'traceability', one from the Centre for Radiation Research, and the other from the standpoint of the user. Moreover, I am aware of several discussions on this topic in the US literature, such as those by Belanger (1), Daneman (2), Landvater (3), and others. Indeed Belanger discusses the merits of some four possible definitions of traceability. Since I am here to report on the UK scene, I propose to confine myself to presenting the definitions currently put forward by two of the interested organisations in my country, the British Standards Institution, BSI, and the British Calibration Service, BCS. (a) From the British Standards Institution, we find (4):

Traceability, "the concept of establishing a valid calibration of a measuring instrument or measurement standard, by a step-by-step comparison with better standards up to an accepted or specified standard. In general, the concept of traceability implies eventual reference to an appropriate national or international standard".

In a recent BSI document entitled -Specification for Measurement and Calibration Systems' (5), under 'traceability', further provisos are made; for example, it states that all measurement standards in use in the calibration system shall be supported by certificates, reports, or data sheets attesting to the data, accuracy and conditions under which the results were obtained and are valid. All documents must be signed by a responsible person".

(b) My second definition is taken from the British Calibration Service, (6):

"Traceability to national standards means:-

That each standard used for calibration purposes has itself been calibrated against a standard of higher quality up to the level at which the higher quality instrument is the accepted national standard". 
(ii)

"That the frequency of such calibration, which is dependent on the type, quality, stability, use and environment of the lower quality standard, is such as to establish reasonable confidence that its value will not move outside the limits of its specification between successive calibrations".

(iii) "That the calibration of any instrument against a standard is valid in exact terms only at the time of calibration, and its performance thereafter must be inferred from a knowledge of the factors mentioned in (ii) above".

The BCS operates through 'Approved Laboratories', and approval entails much more than the validity of the calibration standards in use. In addition to the equipment, approval relates to the quality of the staff, organisation and procedures employed. Supervision subsequent to approval includes the operation of an audit measurement scheme. Such features are considered necessary to ensure that the concept of traceability has any real meaning. On the other hand, traceability does not necessarily imply high accuracy as such, as sometimes assumed. Clearly the number of steps, or echelons, in the calibration chain must be limited, and the prom cedure adopted at each step must be consistent with whatever accuracy is deemed appropriate, and the accuracy claimed must be specified. It is perfectly reasonable, for example in radiation protection measurements in the field, to insist on traceable readings, even at a low accuracy.

\section{The National Physical Laboratory}

In the UK, the National Physical Laboratory, NPL, develops the techniques for the realisation of the units of measurement of the principal physical quantities, and is the custodian of the resulting national primary standards. It is responsible both for the comparison of these with those of other countries, and for providing essential calibration services based upon them, with a view to disseminating measurement units throughout the UK. Generally, the NPL endeavours to develop and promote good measurement practice; and provides advisory services to government, industry and others. The standards which are in service, or under development, include the principal ones for the quantities of interest in the measurement of ionizing radiations, - namely the quantity exposure for $X$ and $\gamma$-rays; absorbed dose for $X$, $\gamma$ and $\beta$-rays, and electrons; fluence for neutrons; and activity for radiomaclides.

In addition, in order to disseminate the units for these quantities, secondary standards have been developed at NPI as transfer devices where this was considered necessary. Such transfer devices may take various forms, such as an instrument with an appropriate probe, as in the case of $\mathrm{X}$-ray measurements, or calibrated radioactive sources used in a jig to produce standardised fields, as in the case of $\beta$-ray measurements. These different approaches were described in a talk which I gave at a Symposium on -National and International Standardisation in Radiation Dosimetry held in Atlanta in 1977 (Jennings (7)).

Before summarising dissemination procedures, we must first examine the legal requirements, as these differ in the different fields of application. Thus, the position in the medical field, in radiation processing, and in respect of radiation hazards, will require separate consideration.

\section{Legal requirements}

Although the national measurements standards are located at NPL, and the NPL comes under the Department of Industry, the NPL is not responsible for legal metrology as such, - apart from the provision of the relevant primary standards. Responsibility for the Weights and Measures Act (1963), which lays down legal requirements for regular comparisons of secondary and local standards, and thus effectively provides for a traceability chain, is now vested in the Department of Trade. However, this does not relate to radiation measurement. Indeed, the evolution of radiation control in the UK from Common Law to Legislation and Codes of Practice, over the years since 1946, would call for a talk on that topic alone. I can only summarise the salient points.

\section{'Statute Law', embodying Acts of} Parliament, differs from 'Common Law', which is built up from precedents resulting from previous judgments. Common Law included, for example, the doctrine of 'strict liability', which imposed a duty on mamufacturers, and other persons who are in possession of goods which they know to be umusually dangerous, to exercise reasonable care to make the goods as safe as possible, and to explain their hidden dangers before parting with them. More recently, the Health and Safety at Work etc Act, 1974, introduced wider statutory duties where the goods are for the use of persons at work.

\section{Radiological Protection}

Let us consider the position in respect of radiological protection. The Radioactive Substances Act, 1948, gave powers which later resulted in regulations regarding the carriage of radioactive materials. The Factories Act, 1961, resulted in regulations concerning the use of ionizing radiations for both unsealed (1968) and sealed (1969) radioactive sources. In addition, a series of non-statutory codes of Practice have been issued by a number of government departments, official bodies and associations, having a bearing on the radiological protection of persons. For example, the Radioactive Substances Advisory 
Committee, set up under the Radioactive Substances Act, 1948, sponsored, and the Department of Health published, a 'Code of Practice for the Protection of Persons against Ionizing Radiations arising from Medical and Dental Use' (revised version, 1972). A similar Code in respect of teaching establishments was published by the Depertment of Employment, in preference to Regulations (revised version, 1968).

This approach may be difficult at first to appreciate, but it is demonstrably more flexible than legislation alone. Indeed, a three-tier structure is now proposed:Regulations, Codes of Practice, and Guidance Notes:

Regulations set down requirements and duties, and procedures where no choice or alternative is acceptable. They specify basic permissible levels of exposure, make provision for record keeping, create a system of recognition of qualified experts, and deal in a general way with the provision of suitable plant, facilities and specialised protection and medical services.

Approved Codes of Practice provide practical guidance as to the general requirements to meet the Regulations. This avoids making the Regulations too lengthy, or too specific where alternatives are possible. Such Codes occupy a special position in the enforcement of legal requirements. If a prosecution is taken under the Health and Safety at Work etc Act, during which a person is alleged to have failed to comply with the terms of the Code, then such failure will be prima facie evidence that he has not complied with the Regulations. However, it will be open to him to show that he has met the legislative requirement in some other way which is equally effective. Thus a more flexible approach results, which can take account of new developments.

(iii) Guidance Notes may be provided to give detailed advice in considerable depth, where appropriate. Such Notes can relate to precautions in particular fields, such as industry, teaching, medicine, dentistry or veterinary work. Guidance Notes do not have a special legal status, but will nevertheless reflect legal requirements.

At this point I need to make reference to the impact in this area of the UK joining the European Community, an impact which will result in new ionizing radiation regulations in the UK.

\section{The European Directive and the HSC Consultative Document}

On joining the European Community, the UK became subject to the provisions of the Treaty establishing the European Atomic Energy Community, or Euratom. This treaty requires that basic standards should be laid down in the Commity for the health protection of workers and the general public against the dangers arising from ionizing radiations, and the instrument chosen has been a 'Directive', the contents of which must be given effect in member states. The Directive adopted on 1 June 1976, (8), reflected the thinking of ICRP Publication 9, (9). More recently, the ICRP have revised and updated their philosophy, and in 1977 presented this in ICRP Publication 26, (10). In consequence, the Directive is also being revised, and proposals to amend the Directive have been circulated. In the meantime, another Directive issued in 1979, (11), extends the time for implementation of the original 1976 Directive.

These Directives are having direct consequences on the UK scene. Fortunately, the Health and Safety at Work etc Act, already provides comprehensive powers to give effect to many of the requirements of the Directive. Several government departments are taking the necessary steps, and in particular, the Health and Safety Executive, HSE, is drafting new Ionizing Radiation Regulations, along with Approved Codes of Practice and Guidance Notes for publication by the Health and Safety Commission, HSC. A Consultative Document' was issued by HSC in 1978 , (12), and following comments received, and the updating of the Directive, a further Consultative Document is expected later this year (1980).

Such a Consultative Document, making reference to all facets of the problem, enables all interested parties to react to the proposals made, in time for account to be taken prior to the final version. To give just one example, there is need to designate some individuals as 'Radiation Protection Advisors' (RPAs), 'Radiation Protection Supervisors', and 'Qualified Experts', - with specified responsibilities. Indeed, interested bodies like the Society for Radiological Protection, SRP, and the Hospital Physicists ${ }^{\circ}$ Association, HPA, have been busy devising schemes to provide for the certification of members who may qualify as RPA's, etc.

According to the current draft proposals, such Advisors and Experts will have a part to play in respect of traceability, as will the British Calibration Service, BCS, at different stages in the calibration chain. However, while consultations continue, I can only refer to some proposals currently under discussion. Thus, to ensure adequate performance and traceability in respect of instrumentation, three levels of 
testing are envisaged, type testing, acceptance testing, and routine testing:

(i) Type testing relates to specimens of new instruments, and comprises wide-ranging tests of compliance with, or 'conformance to' agreed specifications or criteria.

(ii) Acceptance testing relates to more restricted tests on individual instruments, prior to being put into service, and

(iii) Routine testing relates to simple periodic in-service checks on performance.

We must now consider who should carry out these respective tests, and how the scheme can be monitored. Calibration may be regarded as a part of testing, in so far as it constitutes one aspect, - though a vital aspect, of performance under restricted, but specified conditions.

Let us return to the possible role of the $\mathrm{BCS}$, to which reference in regard to Laboratory Approval, has already been made.

\section{The British Calibration Service}

The British Calibration Service, BCS, was established by the govermment to provide British Industry with a comprehensive service for the calibration of instruments against recognised standards, the calibration work being carried out in existing laboratories which have been specifically approved for the purpose. The Service headquarters is now an integral part of NPL. An Advisory Council on Calibration and Measurement advises on the operation of the service, and a series of expert panels assist in each field of activity, including the drawing up of criteria for the approval of laboratories. At present, some 80 laboratories are approved for measurements in electrical, mechanical, fluid, thermal and optical fields, and they are currently issuing certificates at a rate of about 30,000 per year, overall.

It had become clear, even before the forthcoming Ionizing Radiation Regulations were drafted, that a national dissemination scheme was needed to calibrate the 20,000 or so monitors in use for protection measurements in the field in the UK. To this end, 'Radiological Measurements' was added to the BCS list of activities, another Advisory Panel set $u p$, and a series of criteria prepared in respect of laboratory approval to act as secondary standardising centres. These criteria, listed in Table 1, relate to both protection and therapy-level instruments, and to their use for $X, \gamma, \beta$-rays and neutrons. Some details regarding the approval procedure were summarised by $\operatorname{Dr} M J$ Rossiter, of NPL, in a paper also delivered at the Symposium held in Atlanta in 1977, (13).
TABLE 1

BCS RADIOLOGICAL CRITERIA, INSTRUMENT CALIBRATION

\begin{tabular}{|c|c|}
\hline $\begin{array}{l}\text { Document } \\
\text { Number }\end{array}$ & Title \\
\hline 0802 & $\begin{array}{l}\text { General Criteria for Laboratory Ap- } \\
\text { proval. Calibration of Radiological } \\
\text { Instruments. }\end{array}$ \\
\hline 0811 & $\begin{array}{l}\text { Supplementary Criteria for Laboratory } \\
\text { Approval. Calibration of Radiological } \\
\text { Protection-Level Instruments: X-, } \\
\text { Gamma- and Beta-Rays. }\end{array}$ \\
\hline 0812 & $\begin{array}{l}\text { Supplementary Criteria for Laboratory } \\
\text { Approval. Calibration of Radiological } \\
\text { Therapy-Level Instruments: X- and } \\
\text { Gamma-Rays. }\end{array}$ \\
\hline 0813 & $\begin{array}{l}\text { Supplementary Criteria for Laboratory } \\
\text { Approval. Calibration of Radiological } \\
\text { Protection-Level Instruments: Neutrons }\end{array}$ \\
\hline 6601 & $\begin{array}{l}\text { Calibration of Radiological Instruments } \\
\text { at Protection and Therapy Levels (Guid- } \\
\text { ance Publication). }\end{array}$ \\
\hline
\end{tabular}

However, no such approvals have yet been finalised, pending the outcome of the discussions initiated by the HSC Consultative Document previously mentioned. Thus, it may now be necessary for such secondary standardising laboratories to be formally approved by $\mathrm{HSE}$, having met $\mathrm{BCS}$ criteria. Moreover, there is now the additional matter of type testing, and laboratories carrying out this work may also require HSE approval, such approval being based on the assessment of the laboratory by BCS in the light of appropriate criteria for this purpose. Such criteria have yet to be written, and it has been proposed that this should be done by the relevant BCS panel. based no doubt on existing specifications such as the IEC standards now nearing completion.

Similar proposals are under discussion in respect of acceptance and routine tests, the latter being carried out by means of standards, either instmuments or radioactive sources, and in either case, they will need to be certified in order to confirm traceability to national standards. In regard to routine tests, the Radiological Protection Advisors, and others, will clearly have a recognised part to play.

It is difficult to be sure how comprehensive the final scheme will be, bearing in mind the costs of implementation, in the present economic climate in the UK, as well as the need for safety. As far as BCS is concerned, the above proposals extend its role beyond that of 'calibration'. However, consideration is presently also being given to setting up a broader-based 'National Testing Laboratory Accreditation Scheme ${ }^{\prime}$, NATLAS, also to be based at NPL, which would involve the 
TABLE 2

BCS RADIOLOGICAL CRITERIA, PERSONAL DOSTMETRY SERVICES

\begin{tabular}{c|l}
\hline $\begin{array}{c}\text { Document } \\
\text { Number }\end{array}$ & \multicolumn{1}{|c}{ Title } \\
\hline 0803 & $\begin{array}{l}\text { General Criteria for Laboratory } \\
\text { Approval. Provision of Personal } \\
\text { Dosimetry Services. }\end{array}$ \\
0821 & $\begin{array}{l}\text { Supplementary Criteria for } \\
\text { Laboratory Approval. Provision of } \\
\text { Personal Dosimetry Services using } \\
\text { Film Dosemeters for Beta, Gamma, } \\
\text { X- and Thermal Neutron Radiations. }\end{array}$ \\
\hline \multirow{5}{*}{0823} & $\begin{array}{l}\text { Supplementary Criteria for } \\
\text { Laboratory Approval. Provision of } \\
\text { Personal Dosimetry using Nuclear } \\
\text { Emulsion Film Dosemeters for } \\
\text { Neutron Radiations. } \\
\text { Supplementary Criteria for } \\
\text { Laboratory Approval. Provision of } \\
\text { Personal Dosimetry Services using } \\
\text { Thermoluminescent Dosemeters for } \\
\text { Beta, Gamma, X- and Neutron } \\
\text { Radiations, }\end{array}$ \\
\hline
\end{tabular}

assessment of all kinds of testing laboratories to establish whether they are competent to carry out a wide variety of tests.

\section{Personal Dosimetry}

Before leaving the topic of radiation hazards, mention must be made of one other area, namely, personal dosimetry services, using either TLD or film badges, for $X, \gamma, \beta$-rays and neutron radiations. At present, some 50 laboratories in the UK supply such services, and these laboratories are now subject to HSE approval, based on criteria prepared by the BCS Technical Panel, as listed in Table 2. Traceability is ensured through intercomparisons, and proposals for an NPL-based audit scheme are under discussion.

\section{Radiotherapy Calibrations}

Turning now to radiotherapy-levels, it will be appreciated that this field is subject to Codes of Practice, rather than regulations, which have been elaborated over the years. Indeed, a nation-wide scheme for the calibration of X-ray treatment machines was established well before the BCS was set up. The scheme is comprehensive in extent, in that it reaches 100 percent of the treatment machines in use in the UK, with the possible exception of a few units in private dermatological practice. On the other hand, the scheme depends on the expertise of the hospital physicists involved with very limited central verification.
The scheme was started in 1950, soon after the UK National Health Service, NHS, was launched, when the demand for calibrations grew to a level in excess of the NPL capability to accept all the dosemeters submitted. Following joint consultations between the Department of Health and Social Security, DHSS, the Hospital Physicists' Association, HPA, and the NPL, a series of Centres were designated as 'secondary standardizing centres' and a dosemeter from each one was selected as the transfer instrument for calibration at NPL. There are at present some 30 such centres within the UK. Each centre became responsible for the calibration of all the dosemeters in use in its region. Over the years, this scheme has been elaborated by the introduction of an NPL-designed secondary standard instrument, along with a Code of Practice, agreed between DHSS, HPA and NPL, on its use in the calibration of tertiary standards or field instruments. The secondary standard was developed specifically as the link in the NHS dissemination chain, and is produced commercially. Some 30 instruments were centrally purchased by DHSS, and allocated to the 30 designated centres. This approach, made possible by the operation of the NHS, helped NPL to streamline its own procedures, and also provided for a certain measure of control in the system. Thus, these instruments are specifically restricted for use as transfer devices only, and they must be returned, complete with the log-book recording radioactive check-source readings taken between calibrations, to NPL for recalibration every three years. The Code of Practice recommends in-phantom comparisons, and the necessary phantoms were also made available to all the centres.

It must be stressed that the designated centres are all within competent, long-established hospital physics departments, but generally do not possess any X-ray equipment dedicated to standards work. Indeed, the secondary standard instrument may be mobile in the region. There are no laboratory criteria or approval procedures at present. Indeed, in the past there has been some resistance to any form of inspection or audit. However, there have been occasional field trials in which a number of centres irradiated TLD and/or Fricke capsules, supplied by NPL, under specified conditions with encouraging results. For example, in 1975, six radiotherapy centres in the UK, all of which were actually sub-centres of the secondary standardizing centres, irradiated such capsules in a phantom each using a single beam of cobalt 60 gamma rays. The results, taken from a paper by $\mathrm{Dr}$ Rossiter (14) are shown in Table 3.

Recently, seven radiotherapy centres, this time all possessing a secondary standard instrument, were interested in checking the dose delivered as the basis of a clinical field trial, this time employing multiple field techniques. This trial is not yet complete, but the available results of measurements in a phantom, employing various techniques, are given in Table 4 .

We would be happy to see more such field trials in the UK, along the lines of the excellent trials conducted both by NBS, and 
FIELD TRIAL, 1975 (Rossiter, 1975)

\begin{tabular}{|c|c|c|c|}
\hline \multirow{2}{*}{$\begin{array}{l}\text { UK } \\
\text { Centre }\end{array}$} & \multicolumn{2}{|c|}{$\frac{\text { Nominal dose }}{\text { Measured dose }}{ }^{*}$} & \multirow{2}{*}{ Comment } \\
\hline & $\begin{array}{l}\text { (mean) } \\
\text { THD }\end{array}$ & $\begin{array}{l}\text { (mean) } \\
\text { Fricke }\end{array}$ & \\
\hline 1 & 0.944 & 0.954 & $\begin{array}{l}5 \% \text { error in ion } \\
\text { chamber reading }\end{array}$ \\
\hline 2 & 0.963 & 1.001 & $\begin{array}{l}\text { TLD discrepancy } \\
\text { unresolved }\end{array}$ \\
\hline 3 & 0.991 & 1.002 & - \\
\hline 4 & 1.008 & 1.018 & - \\
\hline 5 & 1.004 & 1.003 & - \\
\hline 6 & 1.000 & 0.991 & - \\
\hline
\end{tabular}

* based on ionization chamber measurements.

TABLE 4

FIELD TRIAL, 1979-80 (not yet completed)

\begin{tabular}{|c|c|c|c|}
\hline $\begin{array}{c}\text { UK } \\
\text { Centre }\end{array}$ & Machine & $\frac{\text { NPL }}{\text { stated }}$ dose & $\begin{array}{l}\text { Revised } \\
\text { dose - Reason }\end{array}$ \\
\hline A & Co 60 & 0.964 & $\begin{array}{l}0.980 \text { - Water/ } \\
\text { Perspex correc- } \\
\text { tion, and } \\
\text { cobalt } 60 \text { decay }\end{array}$ \\
\hline B & $"$ & 1.020 & $\begin{array}{l}\text { ? - Some evid- } \\
\text { ence for being } \\
1-2 \% \text { high }\end{array}$ \\
\hline C & $"$ & 1.004 & - \\
\hline D & $"$ & 1.016 & $\begin{array}{l}1.006 \text { - Soft } \\
\text { tissue/water } \\
\text { correction }\end{array}$ \\
\hline$E$ & $"$ & 1.012 & - \\
\hline$F$ & $"$ & 1.041 & ? - Under study \\
\hline G & $4 \mathrm{MV}$ & 1.020 & - \\
\hline
\end{tabular}

through the AAPM Regional Laboratory scheme, - to be described later in this seminar.

\section{Radioactivity Measurements}

Next, a few words about the dissemination of standards of activity in the UK. For many years, NPL has provided absolute standards of activity for many radiomuclides, along with the determination of decay schemes. Such standards are made available to the user, either by the despatch of the standards themselves, or through the use of the commercially available ionization chamber, type 1383A, developed at NPL, and for which the Laboratory publishes calibration factors. This latter approach is particularly appropriate for short-lived maclides, and indeed, an improved NPL calibrator will soon be available.

The Radiochemical Centre, TRC, also provides standards, and traceability to national standards has been maintained through periodic two-way exchanges of standards between NPL and IRC for measurement for a large number of muclides. Recently, it has been proposed that BCS should be directly concerned in regard to the certification of sources (cobalt 60, caesium 137 and radium 226) which may be used for the routine testing of the large mumer of protection monitors in the field, as previously mentioned. Such sources are calibrated in terms of exposure rate, and it is of interest to note that the small discrepancy found between exposure rate measurements and the activity of the NFL standard radium source, is within the measurement uncertainties (Read, Burns and Liquorish, 1978, (15)).

From the legal standpoint, the main provisions of the legislation in respect of activity relate to safety. The Euratom Directive has called for some changes. For example the DHSS is setting up new procedures under the Medicines Act, 1968, for the authorisation of persons entitled to administer radiopharmaceuticals. However, the principal impact in regard to traceability concerns instrumentation for the measurement of surface and air contamination. The HSC Consultative Document lists levels of contaminam tion which must not be exceeded, and hence there is now a clear need for new reference standards for the calibration of appropriate monitors. NPL has now commenced a programme of work to this end, though there is still a debate in relation to the relative merits of surface 'activity' and 'emission rate' as the quantity of interest.

\section{Industrial Radiation Processing}

Facilities are available at NPL for the calibration of the type of dosemeter normally used in radiation sterilization processes, such as polymer, or polymer-dye combinations which undergo change in optical absorption on irradiam tion. Uniform fields are available in the form of anmular arrays of cobalt 60 rod sources, and these fields are calibrated in terms of absorbed dose to water by means of chemical dosemeterns, which themselves are cross-checked against the NPL exposure standards. Plant operators can submit a sample, from a batch of dosemeters in use, for irradiation to known dose levels prior to assessment in their reader, and thus achieve a calibration of their dosimetry system, ie, dosemeter material and readout. Two types of dosimetry material based on polymethylmethacrylate are made available by bulk purchase by AERE Harwell, and by the UK Panel for Gamma and Electron Irradiation', a body on which the DHSS, 
industry and NPL have representatives. This panel has also supported the requirement that sterile goods supplied to the National Health Service should receive a minimum dose of $2.5 \mathrm{Mrad}$, or $25 \mathrm{kGy}$; although micro-biological counts prior to sterilization must also be kept down to agreed limits, the DHSS does not accept a safety index system dependent on biological tests alone.

In addition to the calibration of the dosemeter material and readout, the establishment of traceability for the dose to the irradiated product depends also on the relation between the test dose and the product dose, and routine dosimetry must be carried out on each batch of products put through the plant. The adequacy of the dosimetric system employed, and the competence of the staff, is assessed during the commissioning of the plant, and test measurements are carried out periodically thereafter, though no formal audit procedure is in use. If the plant is to supply sterile goods to the NHS, DHSS will need to approve the plant prior to recommending the firm concerned as a recognised source of supply. This approval is usually exercised under contractual arrangements and is only statutory when the plant is used for those few devices which have been deemed medicinal products under the Medicines Act - and where pharmaceutical products e.g. eye drops may be irradiated. Incidentally, UK legislation (The Food (Control of Irradiation) Regulation, 1967) prohibits the application of ionizing radiation to food intended for sale for human consumption, except in those cases receiving prior approval, and in the case of sterile diets for patients prescribed such diets.

\section{International Links}

I cannot close this talk without a brief reference to certain international links, entailing NPL involvement, which have a bearing on traceability, with particular reference to the possibility of international recognition of certification. (See Table 5).

I will assume that everyone present is familiar with (i) the role of CIPM, through CCEMRI and BIPM, in the comparison of national standards, Sections I, II and III of CCEMRI covering the areas of dosimetry, activity and neutron measurements respectively. (ii) the role of IEC and ISO in regard to specification standards:- thus IEC Committees and Working Parties have much to contribute to good measurement practice through improved instrumentation at both therapy - and protection - level, for photons, beta rays, and neutron measurements. ISO Collmitiees are recommending optimum reference radiations, and so on.

The EEC involvement in such activities may be less familiar to this audience. In addition to the Euratom Directive, the EEC has set up various programmes, such as the Biology and Health Protection Programme', and more recently, the 'Applied Metrology Programme'. NPL, and PTB amongst others, participate as contractors on such community projects as the comparison of personal dosemeters for $X, \beta$ rays and neutrons.

\begin{tabular}{|c|c|}
\hline CIPM & $\begin{array}{l}\text { - Intermational Committee on Weights } \\
\text { and Measures }\end{array}$ \\
\hline CCEMRI & $\begin{array}{l}\text { - Consultative Committee on Standards } \\
\text { for the Measurement of Ionizing } \\
\text { Radiations }\end{array}$ \\
\hline BIPM & $\begin{array}{l}\text { - International Bureau on Weights and } \\
\text { Measures }\end{array}$ \\
\hline IEC & $\begin{array}{l}\text { - International Electrotechnical } \\
\text { Commission }\end{array}$ \\
\hline ISO & - Intermational Standards Organisation \\
\hline $\mathrm{EEC}$ & - European Economic Community \\
\hline PTB & - Physikalisch-Technische Bundesanstalt \\
\hline ICRU & $\begin{array}{l}\text { - International Commission on Radiation } \\
\text { Units and Measurements }\end{array}$ \\
\hline ICRP & $\begin{array}{l}\text { - International Commission on Radio- } \\
\text { logical Protection }\end{array}$ \\
\hline IAEA & - International Atomic Energy Agency \\
\hline OTML & $\begin{array}{l}\text { - International Organisation for Legal } \\
\text { Metrology }\end{array}$ \\
\hline WEMMC & - Western European Metrology Club \\
\hline
\end{tabular}

TABLE 6

FRACTION OF MAXIMUM PERMISSIBLE FLUENCE

EXPOSURE

AIR KERMA

ABSORBED DOSE TO AIR, free in air

ABSORBED DOSE TO TISSUE, free in air

ABSORBED DOSE INDEX

DOSE EQUIVALENT INDEX

SHALLOW DOSE EQUTVALENT INDEX

DEEP DOSE EQUTVATENT INDEX

SKIN DOSE EQUTVALENT

DEPTH DOSE EQUTVALENT

DOSE EQUIVALENT CEILING

AVERAGE DOSE EQUTVALENT

EFFECTIVE DOSE EQUTVALENT 
Another group is discussing protection instrumentation, though they are currently still debating the merits of various alternative field quantities, as listed in Table 6 , in respect of their appropriateness for use with both personal and environmental monitoring. This work overlaps the interests of other bodies, and I trust that ICRU and ICRP will take the lead in resolving these problems.

However, from the standpoint of traceability, the position can be dealt with. All the 'dose equivalent" quantities can now be expressed in sieverts, and units for such quantities can in principle be derived by the application of appropriate conversion factors to the units of the more basic physical quantities exposure, fluence or absorbed dose, which are realised by the Standards laboratories. A similar position has arisen in radiotherapy calibrations, where improved factors to convert from either exposure, or from absorbed dose in graphite, to "absorbed dose in water under specified conditions", will need to be established and agreed. The procedures for both therapy-level and protection-level calibrations may thus run along parallel lines.

The IAEA has a programme for the comparison of high-dose measurement systems, and the OIML has an interest in both radiation instrumentation and calibration. Unlike IAFA or BIPM, OINL has no central laboratory, so presumably their interest relates primarily to specifications and the contents of calibration certificates, from the legal standpoint.

There is one informal body which has taken a lead in regard to the international acceptance of calibration certificates, and that is the West European Metrology Club, WEMC. This 'club", which is broader-based than EMC, comprises some 14 countries represented by the Directors of national standards laboratories, or equivalent establishments, in 'Western' Europe. Amongst its activities, it has set up a Calibration Group, and this provides a framework for the coordination of BCS-type activities, which are now being established in other countries, such as in the Federal Republic of Germany and in the Netherlands.

It would clearly be advantageous if calibration certificates issued through such activities; were mutually acceptable between countries. Initially, this would depend on the comparison of the respective national standards of the countries concerned, either through BIPM, or bi-laterally. For example, as regards the UK and the USA, tables listing comparisons relating NPL and NBS measurements in respect of activity, neutron fluence and X-ray dosimetry have been prepared, and all show excellent agreement.

Thus, there are many threads in the tapestry of traceability, - legal, technical, scientific, political ... I believe that it is indeed a tapestry, and not a tangled web!
1 Traceability - An Evolving Concept, Brian C. Belanger, National Bureau of Standards, Washington, USA, 1979.

Some Aspects of Traceability, H. L. Daneman, Metrology Consultant, 390 Meadowbrook Road, N. Wales, PA 19454, USA. Paper presented to the Japan Industrial Technology Association, Tokyo, 1975.

Assuring Accurate Measurement and Traceable Standards, J.Landvater, Consultant, Industrial Research Development, Part 1, p 97, July 1979; Part 2, p 35, August 1979; Part 3, p 129, September 1979.

4 Glossary of terms used in Metrology, BS 5233, item 4.4, British Standards Institution, 2 Park Street, London W1A 2BS, United Kingdom.

Specification for Measurement and Calibration Systems, BS 5781, item 4.13, British Standards Institution, 2 Park Street, London W1A 2BS, United Kingdom.

The British Calibration Service, Document 0021, BCS, National Physical Laboratory, Teddington, Middlesex TW11 OLW, United Kingdom.

7 Standardization in Radiation Dosimetry in the United Kingdom, W.A.Jennings, p 119, Proceedings of a Symposium on 'National and International Standardization of Radiation Dosimetry, Atlanta, USA, 1977, Vol 1, International Atomic Energy Agency, Vienna, 1978.

Council Directive, 76/579/Euratom, laying down the basic safety standards for the health protection of the general public and workers against the dangers of ionizing radiation, Official Journal of the European Communities, L187/p19 (1976).

9 Recommendations of the Intemational Commission on Radiological Protection, ICRP Publication 9, Pergammon Press, Oxford, 1966.

Recommendations of the International Commission on Radiological Protection, ICRP Publication 26, Annals of the ICRP, Vol 1, No 3, Pergammon Press, Oxford, 1977.

11 Council Directive, 79/343/Euratom, amending Council Directive 76/579/Euratom (see (8) above), Official Journal of the European Communities, L83/p18 (1979). 
Ionizing Radiations, Proposals for Provisions on Radiological Protection, A Consultative Document, Health and Sefety Commission, HMSO, 1978 (See (16) below).

13

Activities of the British Calibration Service in the Radiological Field, M.J.Rossiter, p 133, Proceedings of a Symposium or National and International Standardization of Radiation Dosimetry, Atlanta, USA, 1977, Vol 1, International Atomic Energy Agency, Vienna, 1978.

14 The Use of Precision Thermoluminescence Dosimetry for Intercomparison of Absorbed Dose, M.J. Rossiter, Physics in Medicine and Biology, p 735, Vol 20, 1975.

15

Exposure-Rate Calibration of Small Radioactive Sources of $60 \mathrm{Co}, 226_{\mathrm{Ra}}$ and $137_{\mathrm{Cs}}$ L. R. Read, J.E. Burns, and R.A.C. Liquorish, Int. Journal of Applied Radiation and Isotopes, p 21, Vol 29, 1978.

The Acts, Regulations, Codes of Practice and Guidance Notes referred to in the text can be obtained from Her Majesty's Stationery Office (HMSO); US Agents:- Pendragon House of Connecticut Inc., P.O. Box 255, Old Mystic, Connecticut 06372, USA. These Acts, etc serve as examples only; there are many others relevant to this field.

Acts and Regulations:

The Radioactive Substances Act, 1948 The Ionizing Radiations (Sealed Sources), Regulations, 1969

The Ionizing Radiations (Unsealed Radioactive Sources) Regulations, 1968.

The Factories Act, 1961.

The Health and Safety at Work, etc. Act, 1974.

The Medicines Act, 1968.

The Food and Drug Act, 1955

The Food (Control of Irradiation) Regulations, 1967.

Non-Statutory Codes of Practice and Guidance Notes

Code of Practice for the Protection of Persons against Ionizing Radiations arising from Medical and Dental Use, 1972.

Guidance Notes for the Protection of Persons exposed to Ionizing Radiations in Research and Teaching, 1968. 



\title{
NATIONAL STANDARDS FOR RADIATION DOSIMETRY
}

\author{
Robert Loevinger \\ Center for Radiation Research \\ National Bureau of Standards \\ Washington, DC 20234
}

\begin{abstract}
NBS measurement standards for radiation dosimetry, the radiations with which they are used, and the corresponding calibration uncertainties, are described briefly.

(Calorimeter; cavity ionization chamber; extrapolation chamber; free-air chamber; ionizing radiation; measurement standards; radiation dosimetry; standards)
\end{abstract}

In radiation dosimetry we are concerned with the physical quantities exposure, absorbed dose, and (rarely) the mass of radium. The word "standard" is used here in the sense of measurement standard, i.e., the physical realization of a unit (of a physical quantity) in terms of its definition. Since the physical realization of a unit is independent of its magnitude, the question of special units versus SI units is irrelevant to the consideration of standards.

The quantity exposure is limited in its application to photon beams with energies below a few MeV. The standards of exposure at the National Bureau of Standards (NBS) are of two kinds. A free-air chamber measures the ionization current in a known wall-less volume of air, under approximately equilibrium conditions, hence the name. The mean range of the secondary electrons increases rapidly with energy, and increases more rapidly with energy than the mean free path of the photons. As a result, considerations of both size and accuracy limit the NBS free-air chambers to photon beams with energies below several hundred keV. For higher energy photons, the standard is a set of graphite cavity ionization chombers, each of which determines the ionization in a known volume of air in graphite. Using appropriate physical factors, that ionization is converted to absorbed dose to graphite, then to absorbed dose to air under equilibrium conditions, and then to exposure.

A graphite calorimeter is the standard of absorbed dose for photon beams, at present limited to coba 1t-60 gamma-ray beams, which have a photon energy of $1.25 \mathrm{MeV}$. Since it is absorbed dose to water, not to graphite, that is desired, procedures have been developed for obtaining absorbed dose to water traceable to a graphite calorimeter.
An extrapolation chomber is the standard of absorbed dose for beta-particle sources and beams. This instrument measures the ionization current in a small volume of air inside tissue-like materials, under circumstances where the results can be interpreted as absorbed dose rate to water, tissue, or similar material.

Gamma-ray brachytherapy sources are calibrated in terms of exposure rate at 1 meter, and the standards are those of exposure described above. An exception to this is radium-226, for which the NBS standards are Hönigschmid sources specified in terms of milligrams of radium. At present these play a relatively minor role in dosimetry standards activity at NBS.

The NBS dosimetry standards program has recently been described in detail [1]. The table that follows illustrates the radiation beams and sources that are used at NBS with the radiation dosimetry standards.

The uncertainties 1 isted in the table are the values associated with an instrument calibration factor or a source strength obtained by comparison with the relevant NBS primary standard. The stated uncertainty represents a combination of the uncertainty derived from statistical considerations with uncertainties obtained by other methods. The uncertainties are intended to represent overall values that have a high probability of bracketing the final errors, very roughly corresponding to $95 \%$ confidence limits. The method of obtaining these uncertainties has been described in part in [16]. The numbers given in the table are recent estimates and will not in a11 cases agree with values quoted in the references cited. The quoted uncertainties are subject to revision, in light of new experience or techniques. 


\begin{tabular}{|c|c|c|c|c|}
\hline National Standard & $\begin{array}{l}\text { Physical } \\
\text { Quantity }\end{array}$ & Radiation & $\begin{array}{l}\text { Calibration } \\
\text { Uncertainty } \\
(\%) \\
\end{array}$ & Reference \\
\hline Free-air chamber 1 & Exposure & $10-60 \mathrm{kV} x$-ray beam & 1 & 2,3 \\
\hline Free-air chamber 2 & $"$ & 20-100 kV x-ray beam & 1 & 4 \\
\hline Free-air chamber 3 & $"$ & $60-250 \mathrm{kV} x$-ray beam & 1 & $4,5,6,7$ \\
\hline $\begin{array}{l}\text { Graphite cavity } \\
\text { chambers }\end{array}$ & " & $\begin{array}{l}\text { Cobalt- } 60 \text { and cesium- } 137 \\
\gamma \text {-ray beam }\end{array}$ & 1 & 8 \\
\hline $\begin{array}{l}\text { Graphite cavity } \\
\text { chambers }\end{array}$ & " & $\begin{array}{l}\text { Cobalt- } 60 \text {, cesium- } 137 \text {, and } \\
\text { iridium- } 192 \text { brachytherapy sources }\end{array}$ & 2 & 9,10 \\
\hline Free-air chamber 2 & $"$ & Iodine-125 brachytherapy sources & ? & \\
\hline Graphite calorimeter & $\begin{array}{l}\text { Absorbed } \\
\text { dose }\end{array}$ & Cobalt-60 $\gamma$-ray beam & 1 & 11,12 \\
\hline Extrapolation chamber & $"$ & B-particle applicator and beams & $5-10$ & 13 \\
\hline Hönigschmid sources & $\begin{array}{l}\text { Mass of } \\
\text { radium }\end{array}$ & Radium brachtherapy sources & 1 & 14,15 \\
\hline
\end{tabular}

\section{References}

[1] Loevinger, R., Medical Dosimetry Standards Programme of the National Bureau of Standards, National and International Standardization of Radiation Dosimetry, IAEA-SM-222, International Atomic Energy Agency, Vienna (1978) 159.

[2] Lamperti, P.J., Wyckoff, H.O., J. Res. Nat. Bur. Stand. (U.S.) 69C 1 (1965) 39.

[3] Boutillon, M., Henry, W.H., Lamperti, P.J., Metrologia 51 (1969) 1.

[4] Ritz, V.H., Radio1. 736 (1959) 911; 3. Res. Nat. Bur. Stand. (U.S.) 64C (1960) 49.

[5] Wyckoff, H.O., Attix, F.H., Design of Freeair ionization Chambers, Bur. Stand. (U.S.) Handbook 64 (1957).

[6] Wyckoff, H.O., Aston, G.H., Smith, E.E., Brit. J. Radiol. 27 (1954) 325.

[7] Aitken, J.H., DeLaVergne, L., Henry, W.H., Loftus, T.P., Brit. J. Radiol. 35 (1962) 65.

[8] Loftus, T.P., Weaver, J.T., J. Res. Nat. Bur. Stand. (U.S.) 78A 4 (i974) 465.
[9] Loftus, T.P., J. Res. Nat. Bur. Stand. (U.S.) 74A 1 (1970) 1.

[10] Loftus, T.P., J. Res. Nat. Bur. Stand. (U.S.) 851 (1980) 19.

[11] Domen, S.R., Lamperti, P.J., J. Res. Nat. Bur. Stand. (U.S.) 78A 5 (1974) 595.

[12] Pruitt, J.S., Domen, S.R., Loevinger, R., J. Res. Nat. Bur. Stand. 865 (1981) 495 .

[13] Loevinger, R., Trott, N.G., Int. J. App. Rad. Isot. 172 (1966) 103.

[14] Hönigschmid, 0., Anz. Akad. Wiss. Wien 828 and 9 (1945) 30.

[15] Loftus, T.P., Mann, W.B., Paolella, L.F., Stockmann, L.L., Youden, W.J., J. Res. Nat. Bur. Stand. (U.S.) 584 (1957) 169.

[16] Loevinger, R., and Loftus, T.P., Uncertainty in the Delivery of Absorbed Dose, Ionizing Radiation Metrology, (Ed. E. Casnati) Editrice Campositori Bologna (1977) 459. 


\title{
NATIONAL STANDARDS FOR RADIOACTIVITY MEASUREMENTS
}

\author{
L. M. Caval10 \\ National Bureau of Standards \\ Washington, DC 20234
}

The National Bureau of Standards provides the foundation of the National Radioactivity Measurements System: radioactivity Standard Reference Materials, calibration services, measurements assurance programs, and traceability to the international radioactivity measurements system.

(Calibration; intercomparisons; measurements; radioactivity; standards; system)

\section{Introduction}

Radioactivity Standard Reference Materials (SRM's) are essential links in representing one facet of the national and international measurements systems. The critical part of the mission of NBS is to provide a basis for a complete and consistent system of radioactivity measlirements. The responsibilities, in addition to the development and production of SRM's, include participation in the extension and improvement of the international system, overall improvement in the state of the art of radioactivity measurements, and maintenance of the system to meet national needs. The systems approach is the only approach that provides the requisites and flexibility necessary to compensate for the lack of permanent standards of radioactivity.

The specific functions of the Radioactivity Group are the

1. development, production and distribution of well-characterized standards of radioactivity,

2. provision of calibration, referee, and special services,

3. provision of measurements-assurance programs,

4. participation in international comparisons and studies programs, and

5. dissemination of information.

Radioactivity Standard Reference Materials (SRM's)

The preparation of good radioactivity SRM's requires considerable time and continuing effort. Those people experienced in SRM production can prepare standards with overall uncertainties of from 0.1 to $2 \%$. In order to achieve the lesser uncertainty, extensive knowledge and experience are required because of

1. the chemical behavior of substances at low concentrations, such as

a. hydrolysis resulting in gradual precipitation, b. sorption of hydrolysis products,

c. polymerization,

d. oxidation of reducing agents by dissolved oxygen,

e. change in $\mathrm{pH}$ if carbon dioxide is or was present,

f. decomposition of some compounds when exposed to light,

g. absorption of activity by microorganisms, and

h. solubility of glass,

2. the possible presence of radionuclidic and radiochemical impurities,

3. complex decay schemes,

4. special requirements for source deposition, and

5. instrumentation problems.

There are many steps in the production and distribution of NBS radioactivity SRM's. To begin with, information on needs is collected from a wide spectrum of contacts. Because the needs always surpass the Group's resources, a priority assessment is imperative to select those SRM's which will be produced in a given year. If there is no need for development work, that is, if SRM's of a particular radionuclide in a specific physical form have already been developed and there is to be a reissue, then one proceeds by procuring, processing, measuring and certifying the material. If on the other hand it is to be a new SRM, development work on preparation and stability must be tested, and a direct or near direct method of measurement decided upon. Implicit in the decision is the knowledge of the nature of the nuclear decay of the radionuclide in question and the assumption that the attainable accuracy of the measurement method is acceptable. Some fundamental or direct methods of measurement of activity in radioactive decay are: beta-gamma coincidence counting; $4 \pi$ 
calorimetry; mass spectrometry; defined-solidangle-counting.

A radioactivity SRM must be meticulously calibrated and described in a certificate, for if it is to be used in an intelligent manner, the technical user must have a knowledge of the following [1]:

1. the principal radionuclide,

2. the chemical and physical form of the SRM (where applicable: mass, volume, density, pressure),

3. the stability of the solution or sample after opening,

4. the reference time and date,

5. the method of calibration,

6. the certified values (activity, radioactivity concentration, number of particles or photons of a particular energy emitted per unit time, where applicable),

7. the decay-scheme assumptions,

8. an assessment of radionuclidic and radiochemical purity, and

9. a detailed assessment of both random and systematic uncertainties.

When calibration and certification are completed, potential users of the SRM's are notified of their availability.

Since 1940, SRM's of 95 radionuclides have been developed, prepared and "maintained". Some have been prepared in several physical forms and in as many as 10 different activity levels to meet specific needs (radium-226). There are solution standards (e.g. cesium-137), electroplated standards (e.g. americium-241), autoabsorbed standards (e.g. polonium-210), gaseous standards (e.g. krypton-85), solid standards of the radioactive material implanted in a metal (e.g. krypton-85), standards of material quantitatively dispensed onto a source mount and dried (e.g. cesium-137). There are standards of alphaparticle-, beta-particle- and photon-emitting radionuclides. These radioactivity SRM'S are used primarily to calibrate radiation-detection instruments so that activities or emission rates can be computed from instrument readings. SRM's are used to check instrument calibrations, especially after changes or repairs, and or, to extend the detector-calibration to other radionuclides, energy ranges, or types of radiation. Even laboratories that specialize in relative measurements often need to determine radioactivity values if only to assess radiation hazards from the use or discharge of radionuclides. SRM's are used to produce scientific data which can then be referenced to a common base; in the exchange of data it is important that quantities be expressed so that they are understood. Nuclear properties such as fission yields and decay schemes are determined by measurements for which very precise standards of radioactivity are required. "Through the use of standards, a cross section obtained in Vinca can be compared with one measured in Chalk River without the necessity of moving equipment or people from one place to another." [2] Standards by themselves, do not guarantee meaningful measurements! They do not obviate the prerequisite for trained, experienced personnel:

As we cannot "freeze" time and keep it on hand for future reference, so too, radioactivity standards cannot be salted away in some repository for future reference because every radionuclide has a decay scheme peculiar to it, and most importantly, radioactivity is ephemeral. Standards of most radionuclides can be produced "but keeping a continuous supply available at all times, including standards of the shorterlived activities, is beyond the production" and financial "capacity of the national and commercial laboratories in most countries. Therefore, throughout the world, the need for radioactivity standards has been met by calibrated instruments of greater or lesser degrees of complexity, all of which are normalized to the national or international radioactivity measurements systems by calibrations using radioactivity standards over a wide spectrum of radionuclides with widely different modes of decay. Thus the national standard of iodine-131 in the U.S.A. is, for the periods between calibrations, a " $4 \pi^{1 "} \gamma$ ionization chamber and a sealed radium-226 reference source at NBS, and any laboratory that wishes to check the calibration of its own measuring equipment for iodine-131 can, at any time, send a wellcharacterized solution of that radionuclide to NBS for assay." [2]

\section{Calibration Services}

Throughout the U.S. there are private metrological laboratories which offer services to the general public. [3] For those who must make measurements consistent with national standards and who require higher accuracy calibrations, there is available a variety of scheduled NBS calibration services for alpha-particle-, betaparticle-, and photon-emitting radionuclides. Those for whom the scheduled services are insufficient may request special services, and if it can be demonstrated that a real need exists, and if the service is within the capacity of the Group, it will be performed. The charges will reflect the cost of the materials involved, the time used to perform the services and to write a calibration or traceability report. Many radionuclides in different sample configurations and at different activity levels can be measured, or prepared and measured, at reas onable costs, but some requests are tantamount to research projects and the costs may be prohibitative. Descriptions of scheduied calibration services can be found in NBS Special Publication 250. [4] For those who must show continually that their measurements are "in control", NBS offers several measurements-assurance programs. 


\section{Measurements-Assurance Programs}

Measurements-assurance programs are the last links in the National Radioactivity Measurements System and are essential to long-term reliability because they yield information that can be used to initiate searches for sources of error. NBS is conducting formal radioactivity measurements-assurance programs with the Atomic Industrial Forum, the Environmental Protection Agency's Environmental Monitoring and Support Laboratory in Las Vegas, the Food and Drug Administration, and the Nuclear Regulatory Commisson's Health Services Laboratory in Idaho Falls. Informal programs are conducted with the College of American Pathologists and both the public (including industry and universities) and government. All programs, except the latter (the informal programs for the public and government will be discussed in detail by my colleagues.

Both the formal and informal programs involve one or both of the following basic mechanisms:

1. A laboratory submits a radioactivity sample (selected randomly from a prepared series of samples) with complete documentation as to the activity or emission rate at a specified time and date, error analysis, method of measurement, assessment of radionuclidic purity, etc., to NBS, and receives a report of measurement which is expressed in percent as laboratory value - NBS value $\times 100$. NBS value

If there is significant difference between the laboratory's value and that of NBS, the NBS value can be used to calibrate the laboratory's measuring system, and we try to discover the source of error and to assist the laboratory in eradicating it.

2. NBS provides a radioactivity standard of undisclosed activity or emission rate to a laboratory where measurements are performed on the sample. On returning the results and details of the measurements to NBS the laboratory receives the relevant certificate and a report of measurement plus assistance if needed.

The first mechanism monitors the steps in the production of radioactivity samples and provides a measure of the quality of samples that are prepared; the second checks the ability of those in a laboratory to make measurements that are consistent with the national radioactivity measurements system. The following table illustrates the types of laboratories that have engaged in the informal measurements-assurance program, the radionuclides measured by those laboratories, and the deviations of the reported results from those of NBS.

Typical Results of Institutions Participating in Informal Measurement-Assurance Programs

\begin{tabular}{|c|c|c|c|}
\hline TYPE OF LABORATORY & YEAR & RADIONUCLIDE & $\begin{array}{c}\text { DIFFERENCE FROM } \\
\text { NBS VALUE }(\%)\end{array}$ \\
\hline Hospital & 1978 & $\begin{array}{l}\text { Cobalt-57 } \\
\text { Gold-198 } \\
\text { Lead-203 }\end{array}$ & $\begin{array}{l}0.80 \\
1.84 \\
5.16\end{array}$ \\
\hline Utilities Co. & 1979 & $\begin{array}{l}\text { Barium-133 } \\
\text { Xenon-133 }\end{array}$ & $\begin{array}{c}16.46 \\
6.4\end{array}$ \\
\hline $\begin{array}{r}\text { Commercial } \\
\text { Supplier }\end{array}$ & 1979 & Barium-133 & 8.53 \\
\hline Utilities Co. & 1979 & Barium-133 & 21.6 \\
\hline Hospital & 1979 & $\begin{array}{l}\text { Tha } 11 \text { ium-201 } \\
\text { Iodine-131 } \\
\text { Technetium-99m }\end{array}$ & $\begin{array}{l}6.60 \\
0.77 \\
3.7\end{array}$ \\
\hline $\begin{array}{r}\text { Commercial } \\
\text { Supplier }\end{array}$ & 1979 & Barium-133 & 3.70 \\
\hline State & 1979 & Iodine- 125 & 3.84 \\
\hline $\begin{array}{l}\text { Commercial } \\
\text { Supplier }\end{array}$ & 1979 & Barium-133 & 1.76 \\
\hline University & 1979 & Barium-133 & 0.95 \\
\hline Federal & 1979 & Iodine-131 & 0.72 \\
\hline
\end{tabular}




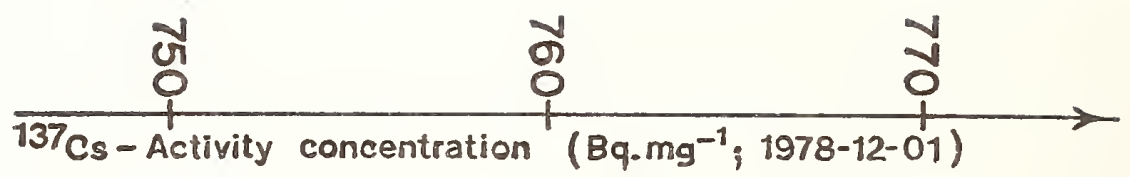

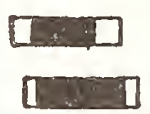

口x
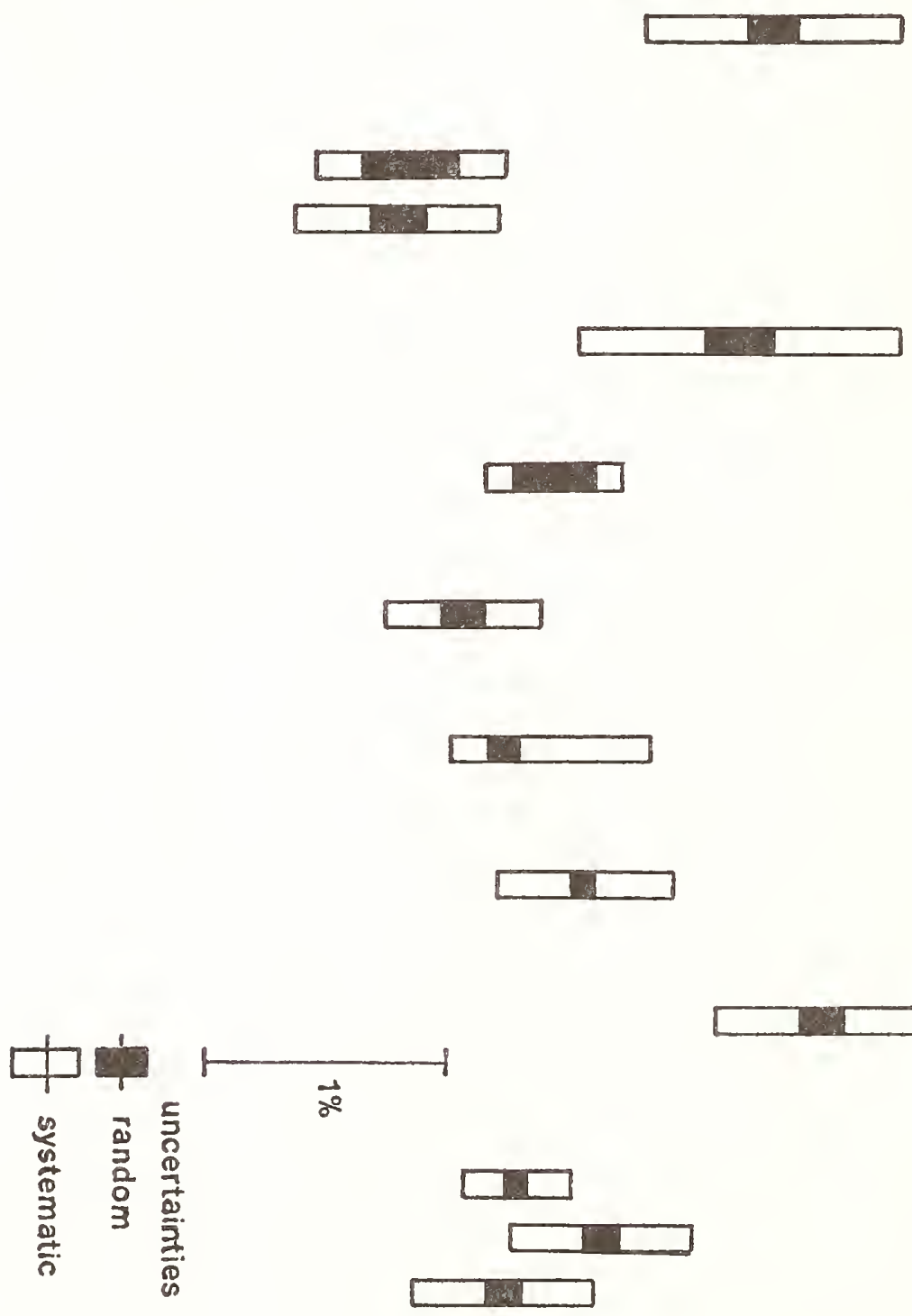

$4 \pi(P C)-\gamma \quad \sum_{0}^{5}$

$4 \pi(P P C)-\gamma A C \underset{G}{Z}$

$4 \pi(P C)-\gamma$
$4 \pi \gamma i C$
relativer
counting

$4 \pi(P C)-\gamma \quad \frac{2}{2}$

$\begin{array}{ll}4 \pi(P C)-\gamma & \infty \\ \text { relative } \gamma \\ \text { counting }\end{array}$

$4 \pi(P C)-\gamma \quad \frac{\mathscr{g}}{3}$

$4 \pi(P P C)-\gamma A C \sum_{0}^{\circ}$

$4 \pi(P C)-\gamma$

옾

Figure 1. Results of an International Intercomparison of ${ }^{137} \mathrm{Cs}$ 


\section{International Involvement}

Since NBS provides the foundation of the National Radioactivity Measurements System (NRMS), and in the absence of permanent standards of radioactivity, it is incumbent on this agency to maintain traceability to the international radioactivity measurements system (IRMS), and to periodically demonstrate professional competence. NBS seeks to fulfill these obligations through

1. participation in intercomparisons under the aegis of the Bureau International des Poids et Mesures (BIPM),

2. participation in both the International Reference System for Measuring Activity of Gamma-Ray-Emitting Nuclides (BIPM) and the International Service of Calibrated Radioactive Solutions (International Atomic Energy Agency, IAEA), and

3. membership on the International Committee for Radionuclide Metrology (ICRM) and participation through membership in its working groups.

\section{International Comparisons and Standards Registries}

Three-way intercomparative measurements of artificially prepared radionuclides were initiated in the late 1940's by Canada, the United Kingdom and the United States. Such intercomparisons were extended to world-wide participation by the International Commission on Radiological Units and Measurements (ICRU) from 1955 until the responsibilities for such measurements were assumed by the BIPM Consultative Committee for Measurement of Standards of Ionizing Radiations Section II (CCEMRI II). The goal of this Committee is the improvement of the overall accuracy and uniformity of measurements of activity, which includes techniques of measurement, the determination of constants necessary for disintegration-rate measurements and their application. "The spread of results of an international comparison of measurements carried out by competent laboratories is the traditional yardstick by which accuracy can be gauged. However, it must be emphasized that the results of such intercomparisons, even when the spread of results is consistent with the individual uncertainties, only provide an estimate of the accuracy of that particular measurement". [5] Since 1955, the following radionuclides have been studied:

sodium-22, sodium-24, phosphorus-32, sulfur-35, potassium-42, manganese-54, iron-55, cobalt-60, zinc-65, strontium-90, iodine-131, cesium-134, cesium-137, cerium-139, mercury-203, thallium-204, americium-241.

A graphical representation of the results obtained by the ten participants in a recent cesium-137 comparison [8], is shown in Figure 1:
It is stated in the BIPM Report [8] that "Mean values from international comparisons are often difficult to interpret and may be misleading. However, the request to "conserve" a representative result of the present comparison by means of the International Reference System for Activity Measurements of $\gamma$-ray emitters (SIR) made it neccessary to take an average value. Since the weighted and unweighted means nearly coincided, an intermediate value and its (external) standard deviation were chosen:

$$
A=(760.0 \pm 4.0) \mathrm{Bq} \mathrm{mg}^{-1} . "
$$

In the report are described the different solution and source preparations, counting methods, extrapolation procedures, and methods of calculating radioactivity concentration. It may be noted that the range of results is $1.7 \%$, and that the NBS value differs by $0.5 \%$ from the "chosen value".

When results of intercomparisons showed little or no improvement over those of earlier studies of the same radionuclide, CCEMRI II organized working groups to examine problems associated with radionuclide metrology such as

1. principles of the coincidence method,

2. problems in microweighing,

3. procedures for accurately diluting and dispensing radioactive solutions, and

4. study of reference techniques for the assay of radionuclides.

The object of these studies is the production of a series of monographs to be used as guides to good laboratory practice.

The organization of intercomparions, the collection and analysis of the data and the publication of the results require a great deal of work and time. W. B. Mann, the principal scientist in the Radioactivity Group, suggested that international traceability could be maintained by establishing stable ionization chambers at BIPM for the purpose of measuring national standards of photon-emitting radionuclides. [9] In this way consistency would be maintained between national laboratories and also within individual national laboratories over extended periods of time. Such chambers, "with calibrations derived from standards produced by many national laboratories, could provide other countries with more limited facilities with calibrations for radionuclides that, because of complicated decay schemes, might present serious problems in measurement". This scheme was adopted by the IAEA and first put into operation in 1973 followed by BIPM in 1975". [6]

The ionization current produced by the stancuard submitted to BIPM or IAEA is compared to that produced by a radium-226 reference source and the "equivalent activity" is calculated for the submitted solution standard. The equivalent activity $\left(A_{e}\right)$ is the stated activity of the radionuclide in the submitted standard that would have produced the same ionization current as the radium-226 reference source, at a specified time. Both BIPM 
and IAEA then issue registration tables for each radionuclide in which is recorded the equivalent activities for the samples submitted by the different laboratories. [7] "If in the course of the measurement and registration of any standards serious discrepancies between national labora- tories are revealed, then international measurements can be organized on split samples of the same solution of that radionuclide in the hope of elucidating the nature of the discrepancy". [6]. The following information is taken from the BIPM Registration Table for ${ }^{134} \mathrm{Cs}$ :

BIPM Registration Table for ${ }^{134} \mathrm{Cs}$

\begin{tabular}{|l|l|l||c|c|c|c|}
\hline \multicolumn{3}{|c||}{ REPORTING LABORATORY } & \multicolumn{5}{|c|}{ MEASUREMENTS MADE AT BIPM } \\
\hline \multirow{3}{*}{ NPL } & $\mathrm{R}(\%)$ & $\mathrm{S}(\%)$ & DATE & $U(\%)$ & $\mathrm{A}$ ( $(\mathrm{k} \mathrm{Bq})$ & T.U. (k Bq) \\
BIPM & 0.067 & 0.35 & $12 / 30 / 76$ & 0.06 & 10087 & 36 \\
AECL & 0.013 & 0.27 & $11 / 21 / 75$ & 0.29 & 10047 & 40 \\
NBS & 0.014 & 0.32 & $5 / 23 / 77$ & 0.07 & 10071 & 33 \\
IER & 0.009 & 1.10 & $10 / 18 / 77$ & 0.05 & 10117 & 117 \\
UVVVR & 0.08 & 0.63 & $2 / 24 / 78$ & 0.09 & 10023 & 64 \\
BIPM & 0.20 & 0.40 & $4 / 17 / 78$ & 0.07 & 10124 & 46 \\
OMH & 0.025 & 0.13 & $11 / 13 / 78$ & 0.05 & 10092 & 14 \\
AIEA & 0.05 & 0.30 & $1 / 26 / 79$ & 0.06 & 10124 & 31 \\
\hline
\end{tabular}

$R=$ random uncertainty, reporting laboratory (one standard error)

$S=$ systematic uncertainty, reporting laboratory

$\mathrm{U}=$ random and systematic uncertainty, BIPM

T.U. $=$ total uncertainty $=\left[R^{2}+S^{2}+U^{2}\right]^{\frac{1}{2}}$

International Committee for Radionuclide Met rology

In 1974, the International Committee for Radionuclide Metrology (ICRM) came into existence. It is an association of scientists representing national laboratories producing radioactivity standards and international organizations such as BIPM, IAEA and the EURATOM Central Bureau of Nuclear Measurements. The objectives formulated by the ICRM are:

1. to promote the advancement of applied radionuclide metrology,

2. to study metrological problems arising from worldwide development of applied radioactivity and nuclear energy,

3. to cooperate with other organizations concerned with radionuclide metrology,

4. to engage in such activites as are conducive to the applications of radionuclide metrology, and

5. to disseminate knowledge pertinent to such application.
The ICRM is operating through 5 working groups, concerned with

1. non-neutron nuclear data,

2. 1ow-level techniques,

3. alpha-, beta- and gamma-ray spectrometry,

4. radionuclide-metrology needs in relation to nuclear energy, and

5. radionuclide-metrology needs in the 1 ife sciences.

The working group on low-level techniques organized a symposium on environmental problems; the need for natural-matrix (NM) standards for measurements assurance in monitoring for radioactivity in the environment was accentuated and work was initiated on NM standards containing plutonium-239 in human lung, in human liver, in Rocky flats soil, etc. The proceedings have been published in the International Journal of the Environment, 1, No. 1/2 1978. An intercomparison of the measurement of photon-emission rates at energies between 120 and $1408 \mathrm{keV}$ with germanium-spectrometer systems was arranged by the 
spectrometry working group; a "best set "of gammaray-emission probabilities per decay for the ten strongest lines of europium-152 were derived and details of the measuring and evaluation methods" have been presented in a recent publication. [10] In 1980 the life sciences work ing group distributed, worldwide, a questionnaire which is designed to identify those radionuclides which will become important in nuclear medicine so that the metrologists can initiate programs of work to solve problems relating to decay schemes, standards and measuring equipment.

Other important functions of national laboratories are the accumulation and distribution of technical knowledge and skill and the dissemination of this knowledge and skill to other nations. Many countries have learned to augment their resources by participating in training and technical exchange programs with other national laboratories.

In the past three years, the Radioactivity Group has had guest workers from Korea, Japan, India and France, as well as individuals from U.S. laboratories who spent from one to three days with metrology personnel. Additionally, a revised version of NBS Handbook 80 , A Manual of Radioactivity Procedures, has been prepared with a considerable part written by members of the Radioactivity Group and entitled National Council on Radiation Protection and Measurements Report (NCRP-58) A Handbook of Radioactivity Measurements Procedures. The report includes nuclear data for about 200 "biologically important" radionuclides.

\section{References}

[1] Certification of Standardized Radioactive Sources, International Commission on Radiation Units and Measurements, ICRU Report 12

(1968).

[2] Needs for Radioactivity Standards and Measurements in Different Fields, L. M. Cavallo, B. M. Coursey, S. B. Garfinkel, J.M.R. Hutchinson, W. B. Mann, Nuc l. Instrum. Methods 112 (2973)5.
[3] A Directory of Standards Laboratories, National Conference of Standards Laboratories (1979).

[4] Calibration and Related Measurement Services of the National Bureau of Standards, ed. B. C. Belanger, National Bureau of Standards Special Publicaton 250 (1978).

[5] The Work of the BIPM Consultative Committee for Measurement Standards of Ionization Radiations Section II, P. J. Campion, Nucl. Instrum. Methods 112 (1973)41.

[6] The Radioactivity Standards Programme of the National Bureau of Standards, W. B. Mann, National and International Standardization of Radiation Dosimetry, IAEA I (1978)147.

[7] A Handbook of Radioactivity Measurements Procedures, National Council of Radiation Protection and Measurements, NCRP Report No. 58 (1978).

[8] Activity Measurements of a Solution of ${ }^{137} \mathrm{Cs}$ : An International Comparison on Efficiency Tracing by ${ }^{134}$ Cs, A. Rytz, Rapport BIPM-80/1 (March 1980).

[9] Radioactivity Calibration Standards, ed. W. B. Mann and S. B. Garfinkel, National Bureau of Standards Special Publication 331 (1970)7.

[10] International Intercomparison of Gamma-Ray Emission-Rate Measurements by Means of Germanium Spectrometers and ${ }^{152}$ Eu Sources, Klaus Debertin, Nucl. Instrum. Methods 158 (1979) 479 . 



\title{
NATIONAL STANDARDS FOR NEUTRON MEASUREMENTS
}

\author{
J. A. Grundl \\ National Bureau of Standards \\ Washington, DC 20234
}

Brief description of NBS capabilities for neutron measurement standardization is provided along with a characterization of these activities in the context of traceability and measurement assurance.

(Calibration; neutrons; standardization)

\section{Introduction}

Neutron measurement requirements for modern technology are diverse. The range of neutron intensities is large, the detection methods may be sophisticated or primitive, and the needs for accuracy vary from beyond state-of-the-art to semiquantitative calibrations undertaken to maintain reproducibility. The response of NBS to these diverse requirements over the past decade has been framed largely as a set of connections to National programs and priorities. Consequently, standardization in the context of traceability and measurement assurance is often a matter of individual efforts tailored to specific needs.

\section{Characteristics of Neutron Measurement Standardization}

Examples of these kinds of standards activities are listed in Table 1. They are organized according to the characteristics of traceability discussed by $E$. H. Eisenhower in this session:

\section{Traceability}

--direct versus indirect

--artifact versus measurement traceability or equivalently, implied versus demonstrated measurement consistency

Measurement Support System (MSS) Elements

--measurement standards: national or transfer

--calibrations

--measurement quality assurance program (MAP)

--field instruments

--procedures, training, and records

\section{Neutron Measurement Standardization Capabilities at NBS}

In spite of the concentration of specific needs, some generally available neutron measurement standardization capabilities have been developed. Two of them, which are most nearly complete for purposes of traceability and for which there is a maturity of measurement assurance experience, are radioisotope neutron source strength determination and isotopic fission rate measurements. A brief description of these capabilities is given in Table 2. Also, over the past few years, a broad range of neutron fields with established intensities and spectra have become available. Three classes of these fields, fission neutron sources, near-monoenergetic filtered reactor beams, and Maxwellian thermal neutron beams have seen substantial use for detector calibrations and measurement assurance programs. Characteristics of these fields, seven in all, are outlined in Table 3 . Other neutron fields associated with the Van de Graaff and with the reactor ISNF facility also represent a considerable neutron standards development effort but have been employed primarily for neutron cross section measurements. Along with a new moderated ${ }^{252} \mathrm{Cf}$ fission source, these fields are expected to contribute to the growing need for improvement and standardization of neutron personnel and therapy dosimetry. Characteristics of these fields which are in early use for neutron neasurement standardization are given in Table 4 . 
TABLE 1. EXAMPLES OF NEUTRON MEASUREMENT STANDARDIZATION ACTIVITIES AT NBS

(a) ACTIVITY

\section{(b) TRACEABILITY}

Direct or Artifact or Indirect Measurement (c) MSS ELEMENTS

(1) Radioactive neutron source calibrations at the Mn-Bath Facility.

$D$

0

I

$D$

$D$

I

I
A

msn, cal

A

msn, finst

A

mst, cal, map

A or $M$

msn, cal

M

mst, map, proc.

M map, proc.

A msn, finst., proc.

(7) Joint pilot program of testing personnel dosimetry services.

(a) See Tables 2, 3, and 4 for description of facilities.

(b) Direct traceability results from direct interaction with NBS; indirect traceability involves interaction with NBS through one or more intermediates. Artifact traceability refers to calibrations of instruments or radiation sources either directly or indirectly; measurement traceability is the ability to quantify a total measurement uncertainty relative to a national or other designated standard.

(c) Measurement Support System (MSS) elements are (1) msn: national measurement standards; (2) mst: transfer national standards; (3) cal: calibration; (4) map: measurement quality assurance program; (5) finst.: field instruments; (6) proc.: procedures, training or records. 


\section{NEUTRON EMISSION RATE OF RADIOISOTOPE SOURCES}

(1) National Standard Radium-Berylium Photoneutron Source (NBS-I)

- Primary artifact standard for all fast-neutron source strength determinations and related measurements of neutron fluence rates.

0 Emission rate of $1.25 \times 10^{6}$ neutrons per second is established to an accuracy of $\pm 1.0 \%$ (10). Decay rate is $0.04 \%$ per year. Consistency among source strengths of similar world standard neutron sources including NBS-I is $\pm 0.6 \%(1 \sigma)$.

(2) Managanous-Sulfate Water Bath for Neutron Source Intercomparison

- Neutron source immersion system for comparing neutron emission rates based on observation of neutron induced activity in manganese.

- Neutron sources with emission rates of up to $10^{10} \mathrm{n} / \mathrm{sec}$ can be compared with NBS-I to an accuracy of $\pm 0.4 \%$.

- Source strength determinations have been rendered as "Report of Test" since 1952.

\section{ISOTOPIC FISSION RATES}

(1) Reference and Working Fissionable Deposits

- Artifact isotopic mass standards designed for measuring absolute isotopic fission rates

- Reference deposits have been established for eight fissionable isotopes with one standard deviation mass assay errors as follows: U238 U238

$\underline{\text { U235 }} \quad \underline{\text { (depleted) }} \quad \underline{\text { (natural) }} \underline{\text { U233 }} \quad \underline{\text { Pu239 }} \quad \underline{\text { Pu240 }} \quad \underline{\text { Np237 }}$ Th232

$\begin{array}{lllllllll}\text { Mass (mg): } & 0.25 & 0.25 & 0.23 & 0.12 & 0.10 & 0.15 & 0.12 & 0.60 \\ \text { Error(Jan 1980): } & 1.0 \% & 1.5 \% & 1.5 \% & 1.5 \% & 1.0 \% & 1.5 \% & 1.7 \% & 2.0 \%\end{array}$

- Collection of working deposits of various thicknesses, mass intercompared with the reference deposits, are available for measuring fission rates in NBS supported measurement or for loan to outside users under cooperative agreement.

(2) Double Fission Ionization Chamber

- Back-to-back ionization chambers which record fission events in a fissionable deposit with an intrinsic efficiency of better than $99.6 \%$.

- Dynamic range: (1) fission rate: $10^{-1}$ to $10^{4} \mathrm{f} / \mathrm{sec}$; (2) fluence rate: $10^{4}$ to $10^{11}$ $\mathrm{n} / \mathrm{cm}^{2} \mathrm{sec}$. Negligible sensitivity to gamma-ray induced ionization at intensities up to $10^{\mathrm{S}} \mathrm{R} / \mathrm{hr}$. Designed to small volume and light weight for wide range application.

- Operated with NBS fissionable deposits the chamber is an absolute measuring device available for NBS programmatic measurements or for loan to outside users. Performance maintenance is kept as an NBS responsibility. 
TABLE 3. NEUTRON FIELDS IN SUBSTANTIAL USE FOR CALIBRATION AND MEASUREMENT ASSURANCE

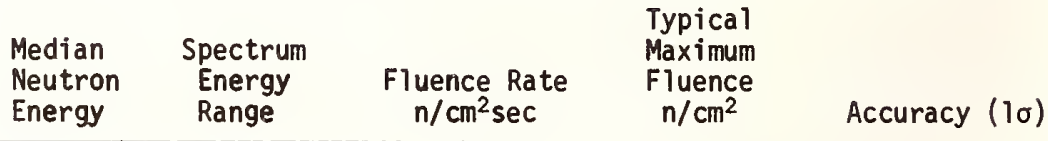

(1) FISSION NEUTRON SPECTRA ${ }^{252}$ Cf Irradiation Facility

$1.7 \mathrm{MeV}$

0.3-6 MeV

$4 \times 10^{8}$

Source strength, + $1.1 \%$ Cavity ${ }^{235} \mathrm{U}$ Fission Source:

$1.6 \mathrm{MeV}$

0.2-5 MeV

$2 \times 10^{10}$

(e $5 \mathrm{~cm})$

based on NBS-I; f fuence

at $5 \mathrm{~cm}$ distance, $\pm 1.4 \%$

Cavity 235 Fission source: $10^{15}$

Flux relative to ${ }^{252} \mathrm{Cf}$ Irradiation Facility, $\pm 5 \%$

(2) REACTOR FILTERED BEAMS

\begin{tabular}{lrccc} 
Scandium & $2 \mathrm{keV} \pm 0.3 \mathrm{keV}$ & $3.9 \times 10^{4}$ & $\pm 5 \%$ \\
Iron - Aluminum & $24.5 \mathrm{keV} \pm 1 \mathrm{keV}$ & $3.6 \times 10^{4}$ & $\pm 10 \%$ \\
Silicon & $144 \mathrm{keV} \pm 12 \mathrm{kev}$ & $1.4 \times 10^{5}$ & $\pm 10 \%$ \\
\hline
\end{tabular}

(3) THERMAL ENERGY FIELDS

*Therma1 Flux Density

Standard:

$0.005-0.4 \mathrm{eV}$

Reactor Thermal Column

External Beams:
4391

2 to $2000 \times 10^{4} 2 \times 10^{12}$ Fluence $+2 \%$ based on $235 \mathrm{U}$ fission chamber monitor
Flux density $+1.5 \%$;

internationalTy compared.

Incomplete thermalization

* Free-field fluence rate are rendered as "Report of Test." 
TABLE 4. NEUTRON FIELDS IN PREPARATION OR USE FOR NEUTRON DATA MEASUREMENT STANDARDIZATION

$\begin{array}{lccc}\text { Median } & \text { Spectrum } & & \begin{array}{c}\text { Typical } \\ \text { Neutron }\end{array} \\ \text { Energy } & \text { Energy } & \text { Fluence Rate } & \begin{array}{c}\text { Maximum } \\ \text { Rluence } \\ \mathrm{n} / \mathrm{cm}^{2} \mathrm{sec}\end{array} \\ \mathrm{n} / \mathrm{cm}^{2}\end{array}$
Accuracy $(1 \sigma)$

(1) MONOENERGETIC VAN DE GRAAFF SOURCES

${ }^{7} \mathrm{Li}(p, n)^{7}$ Be target reaction: 0

0.2 to $1 \mathrm{MeV}$

$\varkappa \pm 20 \mathrm{keV}$

$600-2100$

$0.3-1 \times 10^{9}$ $\pm 2 \%$

${ }^{3} \mathrm{H}\left({ }^{2} \mathrm{H}, n\right){ }^{4} \mathrm{He}$ target reaction: $14 \mathrm{MeV}$

$1 \times 10^{5}$

(0 $10 \mathrm{~cm})$

$1 \times 10^{9}$

(2) INTERMEDIATE-ENERGY STANDARD

NEUTRON FIELDS (ISNF)

$\begin{array}{lccccc}\text { Sub-MeV (ISNF-1): } & 0.6 \mathrm{MeV} & 0.003-3 \mathrm{MeV} & 10^{9} & 10^{14} & \begin{array}{c}\text { Total fluence } \\ < \pm 2.5 \% \\ \text { spectrum } \\ <\end{array} \\ \text { Near-1/E (ISNF-CV) } & 0.17 \mathrm{MeV} & 6 \mathrm{eV}-3 \mathrm{MeV} & 10^{9} & 10^{14}\end{array}$

(3) PARTIALLY MODERATED FISSION SPECTRUM

Heavy Water Sphere

Surrounding ${ }^{252} \mathrm{Cf}$ Source:

$8.2 \mathrm{keV} \quad 5 \mathrm{eV}-3 \mathrm{MeV} \quad 0.5 \times 10^{5}$

(a $50 \mathrm{~cm})$ 



\title{
NBS SERVICES FOR IONIZING RADIATION MEASUREMENTS
}

\author{
H.T. Heaton, II \\ Center for Radiation Research \\ National Bureau of Standards \\ Washington, D.C. 20234
}

\begin{abstract}
The NBS measurement support services relevant to establishing traceability to the national standards for ionizing radiation are described. These services can be grouped into four categories: calibrations, standard reference materials, measurement quality assurance services, and special services. Within each category, the services for photon and electron dosimetry, radioactivity measurements, and neutron measurements are summarized.
\end{abstract}

(calibration, ionizing radiation, national standards, measurement, quality assurance, standard reference material, traceabilityl

\section{Introduction}

The first three papers [1-3] in this publication describe various concepts of traceability to national standards for ionizing radiation and the kinds of mechanisms, including institutional, by which this traceability can be established.

The next three papers [4-6] describe the national standards for photon and electron dosimetry, radioactivity measurements, and neutron measurements to which measurements can be traceable.

To make maximum use of NBS resources there should be some kind of intermediate laboratory between NBS and the ultimate user. This means that measurements can still be traceable to NBS through the intermediate laboratory without a direct interaction with NBS. For those cases where a direct interaction with NBS is necessary, this paper will summarize those services which NBS offers which are useful in establishing traceability for ionizing radiation measurements. Additional information about these services may be found in other papers in this publication.

For ionizing radiation measurements, the NBS services can be grouped into four categories:

'Calibrations
- Standard Reference Materials (SRM)
oMasurement Assurance Program (MAP) or
Measurement Quality Assurance (MQA)
Services
ospecial Services

The first two categories are relevant for establishing what Eisenhower [1] called "artifact traceability". This is the traditional concept of traceability. The calibration services that NBS offers are described in NBS SP 250 [7]. Similarly, currently available SRMs are listed in NBS SP 260 [8]. Both of these publications are regularly updated with the latest editions being respectively 1980 and 1979-80. Both publications have appendices which contain the latest price information. In addition to NBS SP 250 and SP 260 , the Radioactivity Group also distributes two documents which list the currently available radioactivity SRMs [9a] and radioactivity calibration services [9b]. The former also includes a schedule of when standards containing shortlived radionuclides will be issued.

The third category is relevant to what Eisenhower [1] called "measurement traceability". The programs and services in this category can be used to test the participant's entire measurement system. In order to be listed as an "officially recognized" NBS Measurement Assurance Program service (i.e. to be listed as offering a MAP service in NBS SP 250) it historically has been necessary for the Statistical Engineering Division of NBS to have evaluated the participating company's quality control procedure to ensure that the process can be maintained in statistical control. Measurement Quality Assurance services, as used in this paper, are conceptually the same as a MAP service with the exception that a participating company's quality control program need not be evaluated by NBS. Only the term MQA service will be used throughout the remainder of this paper since, in the area of ionizing radiation, there is no NBS evaluation of the participant's quality control program. Participants should, however, still have a quality control program to make effective use of an MQA service.

The last is a broad category and the nonroutine services listed could, for example, include a short or long term interagency agreement, an internal project which will result in a new calibration service, or a standard calibration of an instrument using non-standard techniques.

\section{Calibration Services}

The various calibration services that NBS offers provide one way of achieving "artifact traceability". In all of these services, some artifact (radioactive source, dosimeter, etc.) is sent to NBS and the response of that artifact is determined under specified conditions. NBS will calibrate certain instruments used in photon and electron dosimetry and in neutron measurements, and will measure the radioactivity of samples 
which meet certain physical and chemical criteria. Before any of the artifacts are sent to NBS for calibration, arrangements should be made in advance.

\section{Dosimetry}

Loevinger [10] has previously discussed the calibration services offered by the Dosimetry Group. These are summarized in Table $1^{*}$ and are

Table 1

Summary of Dosimetry Services

\begin{tabular}{|c|c|c|c|c|}
\hline Service & Items Calibrated/Readout & $\begin{array}{l}\text { Energy } \\
\text { Range* } \\
\text { (MeV) }\end{array}$ & $\begin{array}{c}\text { Exposure or } \\
\text { Absorbed Dose } \\
\text { Range }\end{array}$ & Comments \\
\hline $\begin{array}{l}\text { Exposure (Rate) } \\
\text { calibrations }\end{array}$ & $\begin{array}{l}\text { 1) Reference class instruments } \\
\text { which serve as user's "in-house" } \\
\text { standards } \\
\text { 2) Instruments suitable for } \\
\text { calibrating therapy units } \\
\text { 3) TLD's (both personnel } \\
\text { and environmental) for cali- } \\
\text { brating user's readout unit }\end{array}$ & $\begin{array}{l}0.01-1.25 \\
0.01-1.25 \\
0.01-1.25\end{array}$ & $\begin{array}{l}10^{-6}-10^{0} \mathrm{R} / \mathrm{s} \\
10^{-6}-10^{0} \mathrm{R} / \mathrm{s} \\
10^{-6}-10^{0} \mathrm{R} / \mathrm{s}\end{array}$ & $\begin{array}{l}\text { Not all intensities } \\
\text { are available at all } \\
\text { energies } \\
\text { This service is in- } \\
\text { tended to provide } \\
\text { a known exposure which } \\
\text { can be used to char- } \\
\text { acterize the user's } \\
\text { readout systems and it } \\
\text { is not intended to be } \\
\text { a large scale commer- } \\
\text { cial TLD irradiation } \\
\text { service. }\end{array}$ \\
\hline $\begin{array}{l}\text { Absorbed dose } \\
\text { calibrations }\end{array}$ & $\begin{array}{l}\text { 1) Reference class instruments } \\
\text { which serve as user's "in-house" } \\
\text { standards } \\
\text { 2) Instruments suitable for } \\
\text { calibrating therapy units } \\
\text { 3) Radiochromic dye } \\
\text { dosimeters (film and liquid) } \\
\text { 4) Beta-particle sources }\end{array}$ & $\begin{array}{l}1.25 \\
1.25 \\
1.25\end{array}$ & $\begin{array}{cc}1-2 & \mathrm{rad} / \mathrm{s} \\
1-2 & \mathrm{rad} / \mathrm{s} \\
0.1-60 & \mathrm{Mrad} \\
.20-200 & \mathrm{rad} / \mathrm{s}\end{array}$ & $\begin{array}{l}\text { Calibrations in terms } \\
\text { of absorbed dose to } \\
\text { water } \\
\\
\text { Surface absorbed dose } \\
\text { rate to graphite, } \\
\text { plastic or water } \\
\text { Mainly for } 90 \text { o } 5{ }^{\circ} \text { Y } \\
\text { ophthalmic (beta-ray) } \\
\text { applicators }\end{array}$ \\
\hline $\begin{array}{l}\text { Exposure rate } \\
\text { at } 1 \text { meter } \\
\text { calibrations } \\
\text { Spectrophotometric } \\
\text { readout of customer } \\
\text { irradiated dosi- } \\
\text { meters }\end{array}$ & $\begin{array}{l}\text { Encapsulated sources of } \\
{ }^{137} \mathrm{Cs},{ }^{60} \mathrm{Co},{ }^{192} \mathrm{Ir} \\
\text { 1) Ferrous sulfate (Fricke) } \\
\text { solution } \\
\text { 2) Radiochromic dye } \\
\text { dosimeters }\end{array}$ & $5-50$ & $\begin{array}{ll}1-400 & \mathrm{mR} / \mathrm{h} \\
5-8 \quad \mathrm{krad} \\
0.1-60 \quad \mathrm{Mrad}\end{array}$ & $\begin{array}{l}\text { Radium is calibrated in } \\
\text { terms of equivalent } \\
\text { radium mass } \\
\text { This is part of an } \\
\text { MQA service to check } \\
\text { consistency of high } \\
\text { energy electron beams. } \\
\text { Can readout optical } \\
\text { density at several } \\
\text { wavelengths }\end{array}$ \\
\hline Other & $\begin{array}{l}\text { 1) Determine temperature de- } \\
\text { pendence of radiochromic dye } \\
\text { dosimeter in range }-78^{\circ} \mathrm{C} \text { to } 100^{\circ} \mathrm{C} \\
\text { 2) Cal ibration of penetrameter } \\
\text { (Ardran -Crookes-type cassette) }\end{array}$ & & & \\
\hline
\end{tabular}

*See Table 16 for conversion of special units to SI units. 
presented in more detail in Tables 2-5. Table 2 lists the exposure and exposure rate services for ionization chambers and passive dosimeters. Their response is compared with that of a free air ionization chamber for $x$ rays or determined in standardized beams for gamma rays [11]. Before an instrument is calibrated, the ionization chamber is tested for leakage, radiation induced leakage, stabilization time, short term stability, recombination loss, communication to the atmosphere, and guard electrode insulation (if applicable). The ionization chamber must have sufficient wall thickness to provide electron equilibrium for the highest energy photons selected for calibration. If the ionization chamber is submitted with an associated electrometer, a dimensionless correction factor is provided for

Table 2

Exposure (Rate) Calibration Services scales marked in terms of exposure or exposure rate. Otherwise, the ionization chamber is calibrated in terms of exposure per unit charge. The calibrations can be made with polarizing potentials of either polarity or with both polarities. Values of the ionization current at half and full polarizing potentials are available. In Table 2, the homogeneity coefficient is the ratio of the first half-value layer (HVL) of Al to the second HVL of Al. For monoenergetic beams this coefficient is unity, hence the smaller the coefficient, the poorer the approximation that the filtered $x$-ray beam can be represented by a monoenergetic photon beam. In many applications, it is useful to think in terms of an "equivalent energy"* of the filtered $x$-ray beam. Table 3

\begin{tabular}{|c|c|c|c|c|c|c|c|c|c|c|c|}
\hline Beam & $\begin{array}{c}\text { Constant } \\
\text { Potential } \\
(\mathrm{kV})\end{array}$ & $\mathrm{Pb}$ & \multicolumn{2}{|c|}{$\begin{array}{l}\text { Added Filter } \\
\text { (mm) }\end{array}$} & A1 & \multicolumn{2}{|c|}{$\begin{array}{l}\text { Half-Value } \\
\text { Layer }(\mathrm{mm})\end{array}$} & $\begin{array}{l}\text { Homogene ity } \\
\text { Coefficient }\end{array}$ & $\begin{array}{c}\text { Equivalent } \\
\text { Energy* } \\
\text { (keV) }\end{array}$ & \multicolumn{2}{|c|}{ 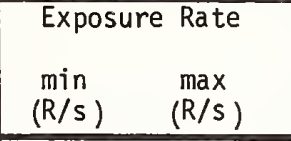 } \\
\hline \multicolumn{12}{|c|}{ Lightly Filtered $X$ Ray $(1)$} \\
\hline $\begin{array}{l}L-B \\
L-C \\
L-D \\
L-E \\
L-G \\
L-I \\
L-K \\
L-M\end{array}$ & $\begin{array}{r}10 \\
15 \\
20 \\
20 \\
30 \\
50 \\
75 \\
100\end{array}$ & & & & $\begin{array}{l}0 \\
0 \\
0 \\
0.5 \\
0.5 \\
1.0 \\
1.5 \\
2.0\end{array}$ & & $\begin{array}{l}0.029 \\
0.050 \\
0.071 \\
0.23 \\
0.36 \\
1.02 \\
1.86 \\
2.78\end{array}$ & $\begin{array}{l}0.79 \\
0.74 \\
0.76 \\
0.78 \\
0.64 \\
0.66 \\
0.63 \\
0.59\end{array}$ & $\begin{array}{r}7.2 \\
9.1 \\
9.8 \\
13.6 \\
16.8 \\
24.4 \\
31.9 \\
38.3\end{array}$ & $\begin{array}{l}10^{-6} \\
10^{-6} \\
10^{-6} \\
10^{-6} \\
10^{-6} \\
10^{-6} \\
10^{-6} \\
10^{-6}\end{array}$ & $\begin{array}{l}1.7 \\
4.2 \\
3.3 \\
0.13 \\
0.3 \\
0.4 \\
0.4 \\
0.4\end{array}$ \\
\hline \multicolumn{4}{|c|}{ Moderately Filtered X Rays $(2)$} & & & & & & & & \\
\hline $\begin{array}{l}\text { MFB } \\
\text { MFC } \\
\text { MFE } \\
\text { MFG } \\
\text { MFI } \\
\text { MFK } \\
\text { MFM } \\
\text { MFO }\end{array}$ & $\begin{array}{r}60 \\
60 \\
75 \\
100 \\
150 \\
200 \\
250 \\
250\end{array}$ & & & $\begin{array}{l}0 \\
0 \\
0 \\
0 \\
0.25 \\
0.50 \\
1.01 \\
3.20\end{array}$ & $\begin{array}{l}0 \\
2.50 \\
2.51 \\
3.50 \\
3.49 \\
3.49 \\
3.50 \\
3.47\end{array}$ & $\begin{array}{l}0.090 \\
0.116 \\
0.20 \\
0.66 \\
1.24 \\
2.23 \\
3.25\end{array}$ & $\begin{array}{r}1.62 \\
2.79 \\
3.39 \\
5.03 \\
10.25 \\
13.20 \\
15.80 \\
18.30\end{array}$ & $\begin{array}{l}0.68 \\
0.79 \\
0.74 \\
0.73 \\
0.89 \\
0.92 \\
0.92 \\
0.98\end{array}$ & $\begin{array}{l}28.5 \\
34.2 \\
38.7 \\
48.5 \\
76.9 \\
101 \\
131 \\
153\end{array}$ & $\begin{array}{r}7 \times 10^{-3} \\
7 \times 10^{-3} \\
7 \times 10^{-3} \\
1.5 \times 10^{-2} \\
1.5 \times 10^{-2} \\
3.0 \times 10^{-2} \\
4.0 \times 10^{-2} \\
2.0 \times 10^{-2}\end{array}$ & $\begin{array}{l}0.12 \\
0.04 \\
0.07 \\
0.10 \\
0.13 \\
0.22 \\
0.28 \\
0.15\end{array}$ \\
\hline \multicolumn{4}{|c|}{ Heavily Filtered $X$ Rays $\left(\frac{1}{2}\right)$} & & & & & & & & \\
\hline $\begin{array}{l}\text { HFC } \\
\text { HFE } \\
\text { HFG } \\
\text { HFI } \\
\text { HFK }\end{array}$ & $\begin{array}{r}50 \\
100 \\
150 \\
200 \\
250\end{array}$ & \begin{tabular}{|l}
0.10 \\
0.50 \\
0 \\
0.77 \\
2.72
\end{tabular} & $\begin{array}{l}0 \\
0 \\
1.51 \\
4.16 \\
1.04\end{array}$ & $\begin{array}{l}0 \\
0 \\
4.00 \\
0.60 \\
0.60\end{array}$ & $\begin{array}{l}2.50 \\
2.50 \\
2.50 \\
2.47 \\
2.50\end{array}$ & $\begin{array}{l}0.14 \\
0.74 \\
2.45 \\
4.09 \\
5.25\end{array}$ & $\begin{array}{r}4.19 \\
11.20 \\
16.96 \\
19.60 \\
21.55\end{array}$ & & $\begin{array}{r}38 \\
70 \\
117 \\
167 \\
210\end{array}$ & $\begin{array}{l}3 \times 10^{-4} \\
8 \times 10^{-4} \\
7 \times 10^{-4} \\
5 \times 10^{-4} \\
5 \times 10^{-4}\end{array}$ & $\begin{array}{l}1.5 \times 10^{-3} \\
4 \times 10^{-3} \\
4 \times 10^{-3} \\
4 \times 10^{-3} \\
4 \times 10^{-3}\end{array}$ \\
\hline \multicolumn{2}{|c|}{ Gamma Rays } & & & & & \multirow{2}{*}{\multicolumn{2}{|c|}{$\begin{array}{l}10.8^{(3)} \\
14.9^{(3)}\end{array}$}} & & & & \\
\hline $\begin{array}{l}\text { Cs }-137 \\
\text { Co-60 }\end{array}$ & & & & & & & & & $\begin{array}{r}662 \\
1250\end{array}$ & $1.5 \times 10^{-3}$ & $\begin{array}{l}0.1 \\
2.5\end{array}$ \\
\hline
\end{tabular}

(1) The inherent filtration is approximately $1.0 \mathrm{~mm} \mathrm{Be}$

$\left({ }^{2}\right)$ The inherent filtration is approximately $1.5 \mathrm{~mm} \mathrm{Al}$

$\left({ }^{3}\right)$ Calculated

*For lightly and moderately filtered x-ray beam, the "equivalent energy" is the mean energy for the exposure spectra as reported in Seelentag et al [12]. For heavily filtered $x-$ rays, the "equivalent energy" is the "effective energy" listed in the "Report of Calibration" for the IIBS Dosimetry Group and it is based on the initial slope of good geometry copper absorption data. For gamma-rays, the "equivalent energy" is the mean energy of the gamma-rays occuring in the radioactive decay. 
lists the absorbed dose calibrations available: calibration in a water phantom in a standardized ${ }^{60} \mathrm{C} 0$ beam [13], calibration of radiochromic dye dosimeters in a standardized ${ }^{60} \mathrm{Co}$ beam in an irradiation pool [14, 15] and calibration of beta-particle sources in terms of surface $a b-$ sorbed dose rate. Table 4 lists the sources which can be calibrated in terms of exposure rate at one meter: ${ }^{60} \mathrm{Co}_{0}{ }^{13}{ }^{7} \mathrm{C}_{5}$ [16] and ${ }^{192} \mathrm{Ir}$ [17]. Radjum sources are calibrated in terms of equiva- lent radium mass. Table 5 lists the dosimeters which can be irradiated by the user and sent to NBS for spectrophotometric readout to determine the dose delivered to the dosimeter. Services are available for reading ferrous sulfate (Fricke) solution dosimeters [18-20] irradiated according to a prescribed protocol [21], and for spectrophotometrically reading irradiated radiochromic dye dosimeters at specified wavelengths. [14, 15].

Table 3

Absorbed Dose Calibrations

\begin{tabular}{|c|c|c|c|c|}
\hline Radiation & $\begin{array}{l}\text { Calibration } \\
\text { Method }\end{array}$ & $\begin{array}{l}\text { I tems } \\
\text { Calibrated }\end{array}$ & $\begin{array}{l}\text { Absorbed Dose } \\
\text { Range }\end{array}$ & Comments \\
\hline${ }^{60} \mathrm{Co}$ & $\begin{array}{l}\text { Standardized } \\
\text { beam and water } \\
\text { phantom }\end{array}$ & $\begin{array}{l}\text { 1) Ionization } \\
\text { chambers } \\
\text { 2) Passive } \\
\text { dosimeters }\end{array}$ & $1-2 \mathrm{rad} / \mathrm{s}$ & $\begin{array}{l}\text { Calibration is done in a water } \\
\text { phantom at a depth of } 5 \mathrm{~g} / \mathrm{cm}^{2} \\
\text { in a } 10 \mathrm{~cm} \times 10 \mathrm{~cm} \text { field }\end{array}$ \\
\hline${ }^{60} \mathrm{Co}$ & $\begin{array}{l}\text { Standardized } \\
\text { beam in an } \\
\text { irradiator } \\
\text { pool }\end{array}$ & $\begin{array}{l}\text { Radiochromic } \\
\text { dye dosimeters }\end{array}$ & $0.1-60 \mathrm{Mrad}$ & $\begin{array}{l}\text { Dosimeters are placed known } \\
\text { distances from a }{ }^{60} \mathrm{Co} \text { source } \\
\text { at the bottom of an irradia- } \\
\text { tion pool. }\end{array}$ \\
\hline $\begin{array}{l}\text { Beta } \\
\text { particles }\end{array}$ & $\begin{array}{l}\text { Extrapolation } \\
\text { chamber }\end{array}$ & $\beta$-particle sources & $20-200 \mathrm{rad} / \mathrm{s}$ & $\begin{array}{l}\text { Source calibrated for surface } \\
\text { absorbed dose rates. }\end{array}$ \\
\hline
\end{tabular}

Table 4

Exposure Rate at one Meter

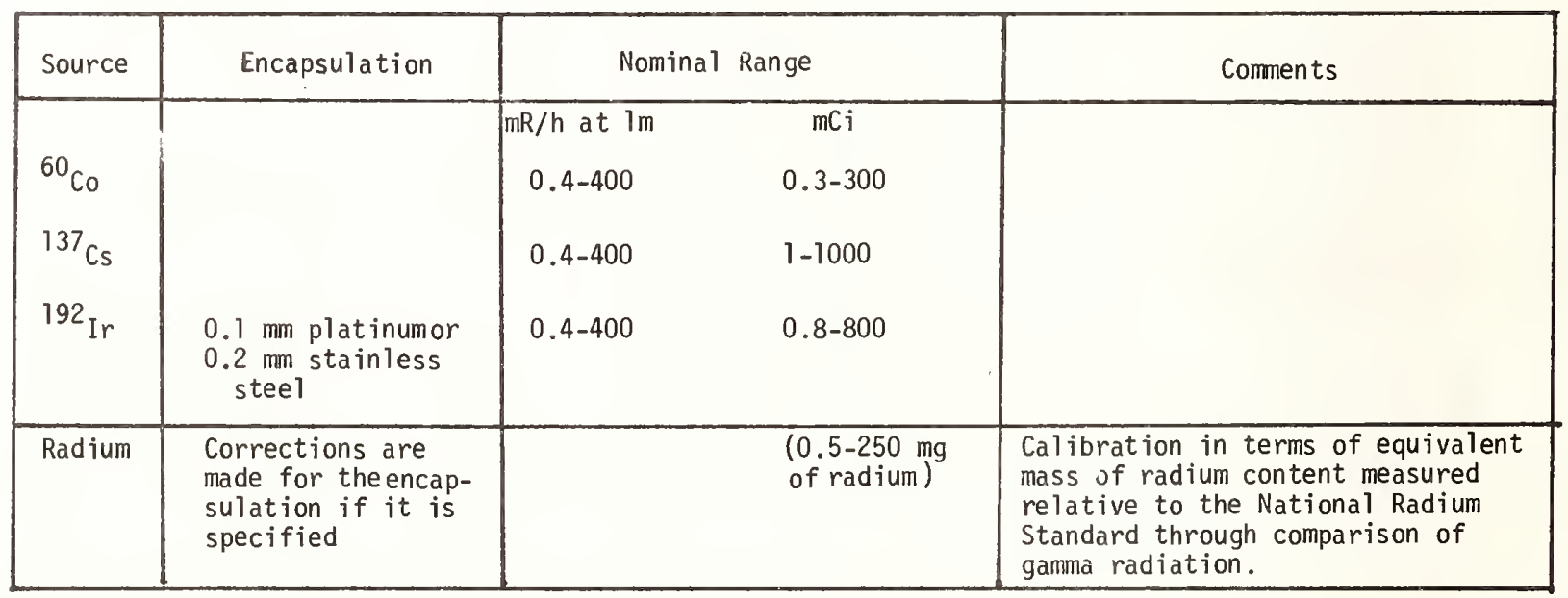

\section{Radioactivity}

In addition to providing SRMs with known .. activities, NBS will also measure the radioactivity of $\gamma$-ray, $\beta$-particle and $\alpha$-particle emitting samples subject to certain conditions. Contact the Radioactivity Group beture sending any samples to NBSS to ensure that all physical and chemical requirements of the sample are met, that resources will be available to calibrate the sample when it arrives, and that all possession and shipping regulations are being followed. Tables 6-9 are 
Table 5

Spectrophotometric Readout of Customer Irradiated Dosimeter

\begin{tabular}{|c|c|c|c|c|c|}
\hline Dosimeter & Application & $\begin{array}{c}\text { Absorbed } \\
\text { Dose } \\
\text { Range }\end{array}$ & $\begin{array}{l}\text { Wavelength(s) of } \\
\text { Readout }\end{array}$ & $\begin{array}{l}\text { Containers for } \\
\text { Dosimeters }\end{array}$ & Comments \\
\hline $\begin{array}{l}\text { Ferrous sulfate } \\
\text { (Fricke) solution }\end{array}$ & $\begin{array}{l}\text { high energy } \\
\text { electron beams }\end{array}$ & $5-8 \mathrm{krad}$ & $304 \mathrm{~nm}$ & $\begin{array}{l}\text { Radiation resistant } \\
\text { silica-glass } \\
\text { spectrophotometric } \\
\text { cell, polystyrene } \\
\text { malling containers } \\
\text { to be irradiated in } \\
\text { polystyrene phantom }\end{array}$ & $\begin{array}{l}\text { Normally three } \\
\text { cells are shipped, } \\
\text { one as a control } \\
\text { and two for ir- } \\
\text { radiation, The } \\
\text { irradiation should } \\
\text { be performed ac- } \\
\text { cording to a } \\
\text { prescribed pro- } \\
\text { tocol (Reference } \\
\text { 21) }\end{array}$ \\
\hline Radiochromic dye & $\begin{array}{l}\text { commercial } \\
\text { irradiators }\end{array}$ & $\begin{array}{l}0.1-60 \\
\text { Mrad }\end{array}$ & $\begin{array}{l}\text { ultraviolet and } \\
\text { visible, depends on } \\
\text { particular type of } \\
\text { dosimeter and } \\
\text { amount of absorbed } \\
\text { dose }\end{array}$ & & $\begin{array}{l}\text { These dosimeters } \\
\text { are used to mea- } \\
\text { sure radiation in } \\
\text { processes such as } \\
\text { sterilizing medical } \\
\text { products, curing } \\
\text { plastics, etc. }\end{array}$ \\
\hline
\end{tabular}

Table 6

Calibration of Radioactive Samples

\begin{tabular}{|c|c|c|c|c|c|}
\hline \multirow[b]{2}{*}{$\begin{array}{l}\text { Calibration } \\
\text { Instrument }\end{array}$} & \multirow{2}{*}{$\begin{array}{l}\gamma \text {-ray } \\
\text { "4ח" } y \text { ionization } \\
\text { chamber }\end{array}$} & \multicolumn{2}{|c|}{$\alpha$-particle } & \multicolumn{2}{|c|}{ B-particle } \\
\hline & & $\begin{array}{l}2 \pi \alpha \text { proportiona } 1 \\
\text { counter }\end{array}$ & $\begin{array}{l}0.8 \pi \alpha \text { defined- } \\
\text { solid-angle }\end{array}$ & $\begin{array}{l}\text { Liquid Scint- } \\
\text { illator }\end{array}$ & $\begin{array}{l}4 \Pi \beta \text { proportional } \\
\text { counter }\end{array}$ \\
\hline $\begin{array}{l}\text { Activity } \\
\text { Range }\end{array}$ & $10-1500 \mu \mathrm{Ci}$ & $0.04-300 \mathrm{nCi}$ & $5-300 \mathrm{nCi}$ & $0.5-50 \mathrm{mC} \mathrm{i} / \mathrm{L}$ & $0.5-50 \mathrm{mCi} / \mathrm{L}$ \\
\hline $\begin{array}{l}\text { Nominal } \\
\text { Uncertainty }\end{array}$ & $0.8-3.4 \%$ & $1.5 \%$ & $1.0 \%$ & $1.5-2 \%$ & $2-3 \%$ \\
\hline $\begin{array}{l}\text { Physical } \\
\text { Form }\end{array}$ & solution & solid & solid & solution & solution \\
\hline $\begin{array}{l}\text { Sample } \\
\text { Container }\end{array}$ & $\begin{array}{l}\text { Flame sealed } \\
\text { glass ampoule (1) }\end{array}$ & $\begin{array}{l}\text { Such that neither } \\
\text { the container nor } \\
\text { packaging material } \\
\text { contacts the } \\
\text { active surface }\end{array}$ & same & $\begin{array}{l}\text { flame sealed } \\
\left.\text { glass ampoule( }{ }^{2}\right)\end{array}$ & $\begin{array}{l}\text { flame sealed } \\
\text { glass ampoule }(1)\end{array}$ \\
\hline $\begin{array}{l}\text { Sample } \\
\text { Dimens ions }\end{array}$ & 5 or $50 \mathrm{~mL}$ & $\begin{array}{l}\text { diameter: } 10 \mathrm{~cm} \text { max } \\
\text { thickness; such } \\
\text { that } 99.5 \% \text { of the } \\
\text { a-particles are } \\
\text { emitted wi th energy } \\
\text { greater than } 400 \\
\text { kev. }\end{array}$ & $\begin{array}{l}\text { diameter: } 1.6 \mathrm{~cm} \\
\text { thickness: same }\end{array}$ & $5 \mathrm{~mL}$ & $5 \mathrm{~mL}$ \\
\hline $\begin{array}{l}\text { Radiation } \\
\text { Quantity }\end{array}$ & activityd $\left.{ }^{2}\right)$ & $\begin{array}{l}\text { Alpha-particle } \\
\text { emission rate into } \\
2 \pi \text { steradians }\end{array}$ & activity & activity & activity \\
\hline
\end{tabular}

( ${ }^{1}$ ) appropriate borosilicate-glass ampoules are available from NBS

( ${ }^{2}$ ) calibrations for ${ }^{65} \mathrm{Zn}$ and ${ }^{209} \mathrm{Cd}-{ }^{209} \mathrm{~m} \mathrm{Ag}$ are in terms of emission rate rather than activity. 
based on information found in Radioactivity Caljbration Services of the National Bureau of Standards [9b]. This reference contains additional information on suggested chemical forms for the carrier and solution of the radionuclides and information on the borosilicate glass ampoules used for radioactivity calibrations. For samples emitting $\gamma$-rays, $\alpha$-particles or $\beta$ particles, Table 6 summarizes the type of instrument used for calibrating the sample, the nominal activity range, nominal uncertainty, physical form of the sample, sample container, limitations on sample sizes and what radiation quantity is determined. The actual uncertainty depends on the activity level, source geometry and chemical form. It is the linear sum of the random uncertainty at the $99 \%$ confidence level plus the estimated maximum limits for all conceivable sources of systematic uncertainty. Table 7

Table 7

Gamma-Ray Emitting Solution Samples

\begin{tabular}{|c|c|}
\hline Radionuclide & Nominal Uncertainty $(\%)$ \\
\hline $\begin{array}{l}{ }^{22} \mathrm{Na} \\
{ }^{4} \mathrm{Na} \\
{ }^{42} \mathrm{~K} \\
{ }^{46} \mathrm{Sc} \\
{ }^{51} \mathrm{Cr} \\
{ }^{54} \mathrm{Mn} \\
{ }^{57} \mathrm{Co} \\
{ }^{59} \mathrm{Fe} \\
{ }^{60} \mathrm{Co} \\
{ }^{65} \mathrm{Zn}(1) \\
{ }^{67} \mathrm{Ga} \\
{ }^{75} \mathrm{Se} \\
{ }^{85} \mathrm{Sr} \\
{ }^{88} \mathrm{Y} \\
{ }^{9} \mathrm{Mo}-{ }^{9}{ }^{9} \mathrm{mTC} \\
99 \mathrm{mTC} \\
10{ }^{9} \mathrm{Cd}-109 \mathrm{mAg}(1) \\
110 \mathrm{mAg}-110 \mathrm{Ag} \\
111 \mathrm{In} \\
113 \mathrm{Sn}-11{ }^{3} \mathrm{mIn} \\
123 \mathrm{I} \\
13^{1} \mathrm{I} \\
133 \mathrm{Ba} \\
13{ }^{4} \mathrm{Cs} \\
137 \mathrm{Cs}-137 \mathrm{mBa} \\
139 \mathrm{Ce} \\
140 \mathrm{Ba}-140 \mathrm{La} \\
141 \mathrm{Ce} \\
152 \mathrm{Eu} \\
154 \mathrm{Eu} \\
155 \mathrm{Eu} \\
169^{9} \mathrm{Yb} \\
195 \mathrm{Au} \\
197 \mathrm{Hg} \\
198 \mathrm{Au} \\
201 \mathrm{Tl} \\
20{ }^{3} \mathrm{Hg} \\
20{ }^{3} \mathrm{~Pb} \\
226 \mathrm{Ra}\end{array}$ & $\begin{array}{l}1.6 \\
0.8 \\
2.0 \\
0.8 \\
1.0 \\
1.2 \\
0.8 \\
1.4 \\
0.8 \\
1.7 \\
1.4 \\
2.4 \\
2.0 \\
0.7 \\
1.6 \\
1.5 \\
1.7 \\
0.9 \\
1.3 \\
2.7 \\
1.5 \\
1.3 \\
1.5 \\
1.0 \\
1.5 \\
1.0 \\
3.4 \\
2.0 \\
1.6 \\
0.8 \\
1.5 \\
2.5 \\
2.3 \\
2.4 \\
1.3 \\
1.9 \\
1.4 \\
1.7 \\
1.1\end{array}$ \\
\hline
\end{tabular}

lists $39 \gamma$-ray-emitting radionuclides with the nominal calibration uncertainty. Table 8 provides similar information for the 8 -particleemitting radionuclides together with which instrument is used for calibrating that radionuclide. Table 9 lists the 9 a-particleemitting radionuclides calibrated at NBS. In addition to the calibration services listed in Tables 6-9, some gaseous radionuclides can be calibrated by internal gas-counting measurements and gamma-ray point sources and solution sources may be assayed with calibrated $\mathrm{Ge}(\mathrm{Li})$ spectrometers.
Table 8

Beta-Particle Emission Solution Samples

\begin{tabular}{|c|c|c|}
\hline Radionuclide & Counting System(1) & $\begin{array}{c}\text { Nominal } \\
\text { Uncertainty }(\%)\end{array}$ \\
\hline $\begin{array}{l}{ }^{3} \mathrm{H} \\
{ }^{14} \mathrm{C} \\
{ }^{32} \mathrm{P} \\
{ }^{36} \mathrm{Cl} \\
{ }^{89} \mathrm{Sr} \\
{ }^{90} \mathrm{Sr}-{ }^{90} \mathrm{Y} \\
1{ }^{4} 7 \mathrm{Pm} \\
2^{204} \mathrm{Tl}\end{array}$ & $\begin{array}{l}\text { L.S. } \\
\text { L.S. } \\
4 \Pi \beta \text { (PC) } \\
\text { L.S. } \\
4 \pi \beta \text { (PC) } \\
\text { L.S. } \\
4 \pi B \text { (PC) } \\
\text { L.S. }\end{array}$ & $\begin{array}{l}1.5 \\
2.5 \\
2.0 \\
2.0 \\
3.0 \\
2.5 \\
3.0 \\
2.0\end{array}$ \\
\hline
\end{tabular}

$\left.{ }^{1}\right)$ L.S. is Liquid Scintillation counter. $4 \Pi B$ (PC) is $4 \Pi \beta$ proportional counter.

Table 9

Alpha-Particle Emitting Solid Source Samples

\begin{tabular}{|c|c|c|}
\hline \multirow{2}{*}{ Radionuclide } & \multicolumn{2}{|c|}{ liominal Uncertainty (\%) } \\
\cline { 2 - 3 } & $\begin{array}{c}2 \Pi \alpha \text { proportional } \\
\text { counter }\end{array}$ & $\begin{array}{r}0.8 \Pi \alpha \text { defined- } \\
\text { solid-angle }\end{array}$ \\
\hline $14^{8} \mathrm{Gd}$ & 1.5 & 1.0 \\
$210 \mathrm{Po}$ & 1.5 & 1.0 \\
$23{ }^{0} \mathrm{Th}$ & 1.5 & 1.0 \\
$238 \mathrm{Pu}$ & 1.5 & 1.0 \\
$239 \mathrm{Pu}$ & 1.5 & 1.0 \\
$2{ }^{41} \mathrm{Am}$ & 1.5 & 1.0 \\
$2{ }^{2} \mathrm{Pu}$ & 1.5 & 1.0 \\
$2{ }^{3} \mathrm{Am}$ & 1.5 & 1.0 \\
$\mathrm{U}$ & 1.5 & 1.0 \\
\hline
\end{tabular}

(1) in terms of gamma-pay-emission rate rather than activity 
Neutrons

Traditionally, the services INBS offered for neutron measurements included neutron source strength determinations [22-23] and foil irradiations in a thermal neutron flux density [24-25]. These services are described in Table 10. Within the past several years, NBS has developed a set of standardized neutron fields $[26,27]$ which can be used to calibrate instruments and dosimeters or can be used to evaluate their performance. These fields are summarized in Table 11 . The energy, fluence rate, and uncertainty in the fluence rate (at the $67 \%$ confidence level) are 1 isted. The uncertainty does not include any components due to gamma rays which may be present in the neutron beam. The gamma-ray component has been measured for the filtered beams [27] and the gamma-ray spectrum per unit mass of ${ }^{252} \mathrm{Cf}$ is listed in ICRU 26 [28]. In addition to the fields 1 isted in Table 11 , a $14 \mathrm{MeV}$ facility using a $d, T$ reaction at the Van de Graaff will soon be available for calibration purposes.

Table 10

Neutron Calibrations

\begin{tabular}{|l|l|l|l|}
\hline \multicolumn{1}{|c|}{ Service } & Method & Range & \multicolumn{1}{c|}{ Comments } \\
\hline $\begin{array}{l}\text { Neutron source } \\
\text { emission rate } \\
\text { (into 4I) }\end{array}$ & $\begin{array}{l}\text { manganous } \\
\text { sulfate } \\
\text { bath }\end{array}$ & $10^{5}-10^{10} \mathrm{n} \cdot \mathrm{s}^{-1}$ & $\begin{array}{l}\text { Measure the saturated }{ }^{56} \mathrm{Mn} \\
\text { activity produced by neutron } \\
\text { capture in the bath. Source } \\
\text { composition and encapsulation } \\
\text { should be specified. Source } \\
\text { length must be less than } \\
1.2 \text { cm. }\end{array}$ \\
$\begin{array}{l}\text { Thermal neutron } \\
\text { irrimeter } \\
\text { irradiation }\end{array}$ & $\begin{array}{l}\text { neutron standard } \\
\text { thermal neutron } \\
\text { fluence }\end{array}$ & $4000 \mathrm{n} \cdot \mathrm{cm}^{-2} \cdot \mathrm{s}^{-1}$ & $\begin{array}{l}\text { Dosimeters (gold foils) may } \\
\text { be irradiated both with and } \\
\text { without cadmium covers. } \\
\text { Response to gamma rays in } \\
\text { the thermal beam is not } \\
\text { provided. }\end{array}$ \\
\hline
\end{tabular}

Table 11

Standard Neutron Fields

\begin{tabular}{|c|c|c|c|}
\hline Field & $\begin{array}{l}\text { Energy } \\
(\mathrm{MeV})\end{array}$ & $\begin{array}{l}\text { Fluence rate } \\
\left(\mathrm{n} \cdot \mathrm{cm}^{-2} \cdot \mathrm{s}^{-1}\right)\end{array}$ & Uncertainty $(\%)(?)$ \\
\hline $\begin{array}{l}{ }^{252} \text { Cf } \\
\text { Van de Graaff } \\
\text { Cavity (Reactor) } \\
235 U \\
\text { ISNF }{ }^{(3)} \\
\text { Thermal } \\
\text { Filtered Beams } \\
\text { Silicon } \\
\text { Iron } \\
\text { Scandium } \\
\text { External Thermal } \\
\text { Thermal flux densitystd. }\end{array}$ & $\begin{array}{c}2.1 \\
0.1-1.5 \\
1.6 \\
0.6 \\
2.5 \times 10^{-8} \\
0.144 \\
0.026 \\
0.002 \\
2.5 \times 10^{-8} \\
2.5 \times 10^{-8}\end{array}$ & $\begin{array}{l}2 \times 10^{7} \\
10^{3} \\
2 \times 10^{10} \\
10^{9} \\
10^{11} \\
10^{5} \\
4 \times 10^{4} \quad(4) \\
4 \times 10^{4} \\
2 \times 10^{7} \\
4 \times 10^{3}\end{array}$ & $\begin{array}{c}5 \\
3 \\
2.5 \\
10 \\
10 \\
5 \\
5 \\
1.5\end{array}$ \\
\hline
\end{tabular}

$\left.{ }^{(}{ }^{1}\right)$ Uncertainty at the $67 \%$ confidence level. It does not include the uncertainty components due to any $\gamma^{\prime}$ 's present in the beam

( $\left.{ }^{2}\right) 5 \mathrm{~cm}$ from the source

$\left({ }^{3}\right)$ ISNF is Intermediate-energy Standard Neutron Field

$\left({ }^{4}\right) 225 \mathrm{~cm}$ from the reactor 
Table 12

Standard Reference Materials (SRMs) are materials which have been certified by NBS for specific chemical composition, chemical property or physical property. Currently, the only SRMS developed at the Center for Radiation Research are produced by the Radioactivity Group. In this case the activity or emission rate is certified. Many of the SRMs have a short half-life and, hence, are not always available. One can be put on a mailing list, maintained by the Radioactivity Group, to be notified when a particular SRM will be (re)issued. Information on ordering these SRMs is given in INBS SP 260 [8] or may be obtained from the Radioactivity Group [9a].

Table 12 summarizes the radionuclides and the classification in which they have been issued as SRMs. A numerical entry in the Table gives the nominal value (or range) of the activity or activity concentration of the SRM. In a few cases a symbol appears in the parentheses after the value. This indicates that the certification is for the emission rate of that particle in the same units as the heading, i.e. for ${ }_{23}{ }^{\mathrm{Pu}}, 6$ alpha particles $\mathrm{s}^{-1} \mathrm{~g}^{-1}$. For the $K$ $x$ rays, the emission rate is per steradian. An "*" in a column means that the SRM was originally issued in that form but is temporarily out of stock. The overall uncertainty (see section on Calibration Services) for most of the SRMS is 1 to $2 \%$.

In addition to the SRMs 1 isted in Table 12 the following SRMs are available in the special form indicated:

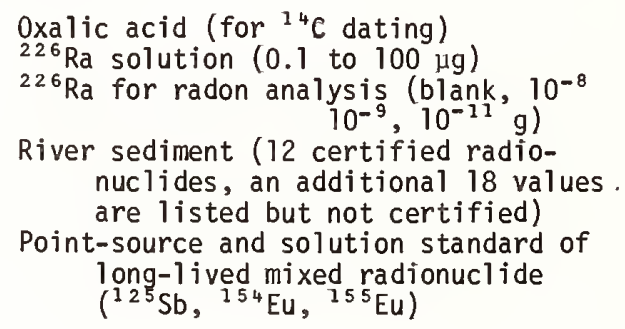

SRM Nominal Activity at Time of Calibration

\begin{tabular}{|c|c|c|c|c|}
\hline \multirow{2}{*}{ Radionuclide } & \multicolumn{4}{|c|}{ Classification of Standard } \\
\hline & Solution & Point & $\begin{array}{l}\text { Gas- } \\
\text { eous }\end{array}$ & $\begin{array}{l}\text { Radiopharm- } \\
\text { aceutical }\end{array}$ \\
\hline 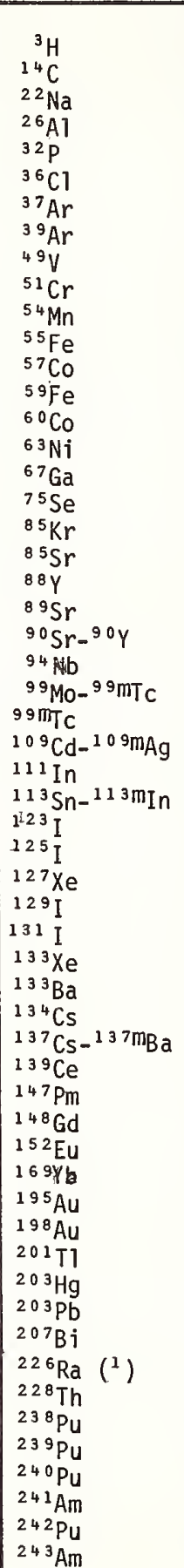 & $\begin{array}{c}\left(s^{-1} \mathrm{~g}^{-1}\right) \\
1,10^{3}, 10^{5} \\
10^{4}, 10^{5} \\
39 \\
10^{4}\end{array}$ & $\begin{array}{c}10^{4}(\mathrm{Kx}) \\
10^{4}{ }^{10^{5}}(\mathrm{Kx}) \\
10^{5} \\
10^{5}-10^{7} \\
10^{5} \\
10^{3} \\
10^{3}(\gamma)\end{array}$ & $\begin{array}{l}10^{6} \\
3 ; 0^{6}, 10^{8}\end{array}$ & $\begin{array}{l}10^{6} \\
10^{9} \\
10^{6} \\
10^{5} \\
10^{7} \\
10^{5} \\
\\
10^{6} \\
10^{8}\end{array}$ \\
\hline
\end{tabular}




\section{Measurement Quality Assurance Services}

Currently there are measurement quali-ty assurance services in the areas of photon and e]ectron dosimetry and radioactivity measurements. The advantage of an MQA service is that it tests the participant's entire measurement system so that variation due to different personnel, "in house" standards, systematic procedures, etc., can become apparent. In principle, the MQA services should be a true blind test of the participant's measurement capability but in practice the transport standard is often of significantly different form so that special non-routine measurement procedures must be used. Hence, one might argue that this does not properly tes $t$ the measurement system. It does, however, demonstrate how well the user's sytem is performing under a specific set of conditions at the time the MQA service is carried out. To make effective use of this type of program, the participant must be making a conscious effort to maintain his own quality control program.using "in-house" standards so that trends and abrupt changes in the measurement process can be detected. If the participant's measurement system properly characterizes the transport standard, then there is demonstrable evidence that the participant is able to maintain calibration of his sytem and can use it to make correct measurements. This assurance is further built up with each successful participation in the MQA service, particularly if the transport standard can be designed so that it will test the user's system under different conditions. The long-term use of an MQA service, together with the user's own quality control program, significantly reduces the chance that the correct values of the transport standard was obtained as the result of a "lucky" measurement.

The MQA services for ionizing radiation operate in the following modes:

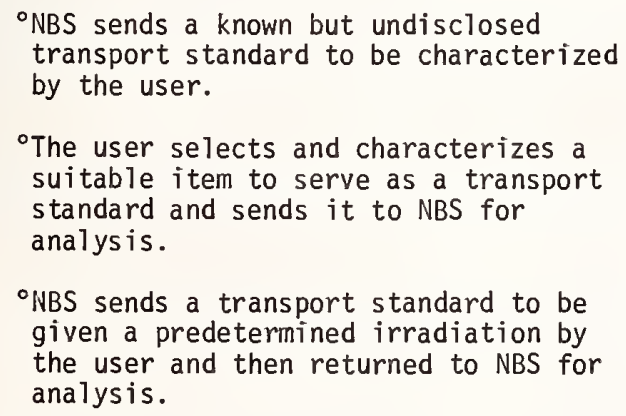
transport standard to be characterized by the user.

${ }^{\circ}$ The user selects and characterizes a suitable item to serve as a transport standard and sends it to NBS for analys is.

-NBS sends a transport standard to be given a predetermined irradiation by the user and then returned to NBS for analysis.

Conceptually these programs are very similar to the types of programs in which NBS participates with the National Standards Laboratories of other countries to ensure that there is a common basis for measurements on the international level.

Tables 13 and 14 respectively summarize the Dosimetry and Radioactivity MQA services. The first columns in these tables identify the program and the participants in the NBS MQA services. The second half of these tables gives the details of the various programs including information on the transport standards and results. The results are expressed in slightly different form through- out the tables although all are in terms of $\Delta$ where

$$
\Delta=100\left|\frac{\text { Participant value }}{\text { NBS value }}\right|
$$

Since there were so few participants and so few results in the first two programs of Table 13, the actual values of $\Delta$ are specified. Many more results have been obtained for the last program listed in Table 13 and for all the programs listed in Table 14. For these cases, the percentage of participants' results for various ranges of $\Delta$ are specified. (e.g. for the electron beam dosimetry uniformity study in the years $1967-1975,59 \%$ of the participants' values were within $\pm 5 \%$ of the NBS value, $\Delta \leq 5$ ). 
Table 13

Dosimetry MQA Services

\begin{tabular}{|c|c|c|}
\hline $\begin{array}{c}\text { Program } \\
\text { Designation }\end{array}$ & $\begin{array}{c}\text { Participants } \\
\text { wi th NBS }\end{array}$ & Comments \\
\hline AAPM RCL $[29,30]$ & $\begin{array}{l}\text { The three RCL's } \\
\text { accredited by } \\
\text { the AAPM }\end{array}$ & $\begin{array}{l}\text { The RCL laboratories calibrate } \\
\text { instruments used for standardizing } \\
\text { therapy beams. }\end{array}$ \\
\hline $\begin{array}{l}\text { Federal Agency } \\
(\mathrm{BRH})[31]\end{array}$ & $\begin{array}{l}\text { Bureau of Radio- } \\
\text { logical Health Cali- } \\
\text { bration Laboratory }\end{array}$ & $\begin{array}{l}\text { This laboratory calibrates instruments } \\
\text { for FDA compliance inspections of } x \text { ray } \\
\text { units and for state agencies for their } \\
\text { compliance and contract inspections. }\end{array}$ \\
\hline State RCL[32] & $\begin{array}{l}\text { An RCL is being es- } \\
\text { tablished in thestate } \\
\text { of Illinois }\end{array}$ & $\begin{array}{l}\text { This laboratory will calibrate instru- } \\
\text { ments used in their radiological health } \\
\text { programs and similar instruments for } \\
\text { other state agencies. }\end{array}$ \\
\hline $\begin{array}{l}\text { Electron Beam } \\
\text { Dos imetry } \\
\text { Uniformity } \\
\text { study }[18-20]\end{array}$ & $\begin{array}{l}\text { Actual users of } \\
\text { high energy } \\
\text { electron beam } \\
\text { therapy units }\end{array}$ & \\
\hline
\end{tabular}

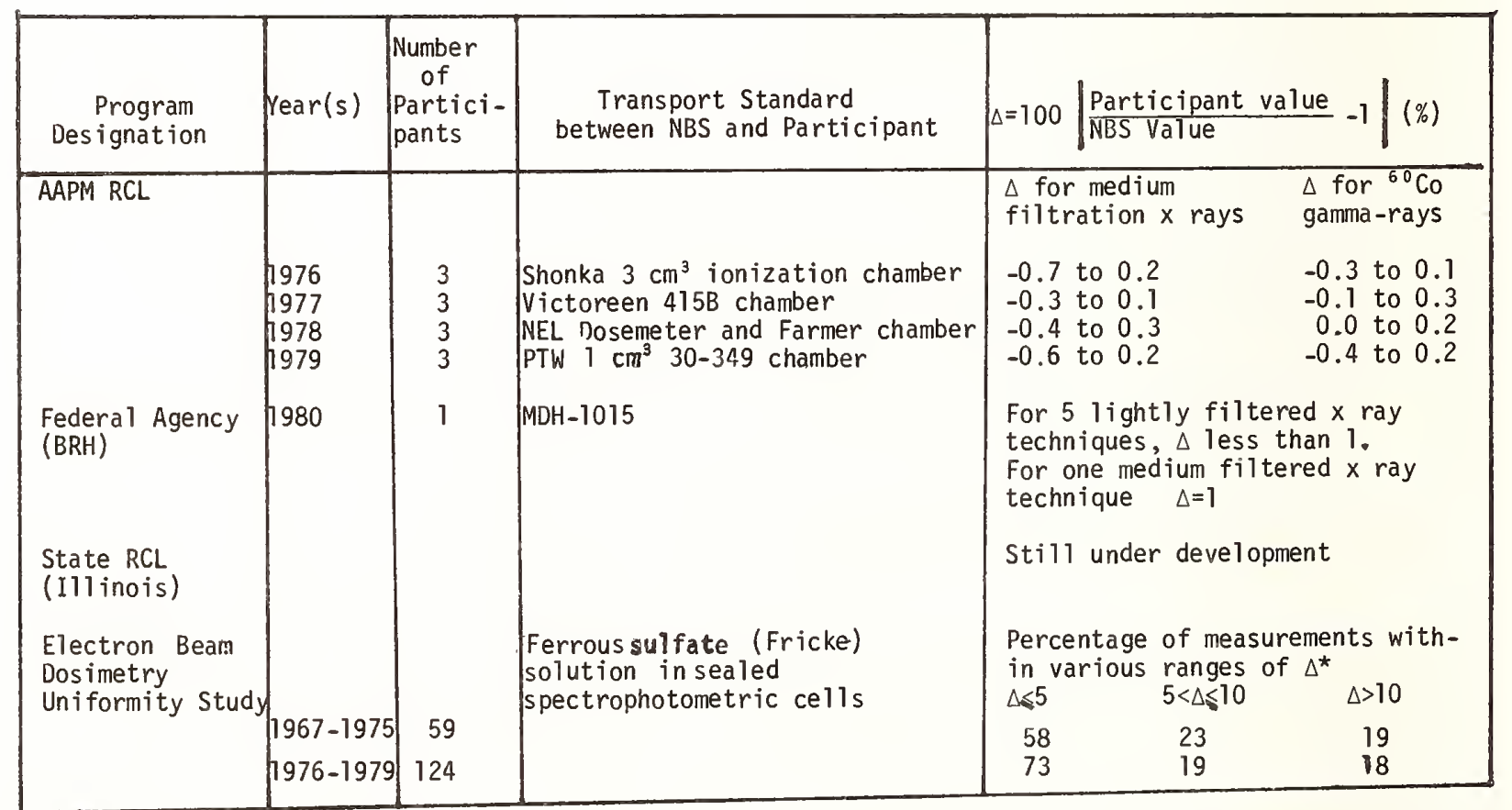

*These values of $\Delta$ are averaged over the time interval. The numerical values are the percentage of participants in the specified range of $\Delta$. 
Table 14

Radioactivity MQA Services

\begin{tabular}{|c|c|c|}
\hline $\begin{array}{c}\text { Program } \\
\text { Designation }\end{array}$ & $\begin{array}{l}\text { Participants } \\
\text { with NBS }\end{array}$ & Comments \\
\hline $\begin{array}{l}\text { EPA National } \\
\text { Quality Assurance } \\
\text { Program [33] }\end{array}$ & $\begin{array}{l}\text { EPA Las Vegas } \\
\text { Laboratory }\end{array}$ & $\begin{array}{l}\text { This laboratory provides both } \\
\text { standard samples and samples } \\
\text { to be used in QA programs. }\end{array}$ \\
\hline $\begin{array}{l}\text { NRC Confirmatory } \\
\text { Measurement [34] }\end{array}$ & $\begin{array}{l}\text { DOE Laboratory at } \\
\text { Idaho Falls }\end{array}$ & $\begin{array}{l}\text { The DOE lab 1) provides radioactive } \\
\text { standards to the NRC for its use and } \\
\text { 2) at NRC direction sends test samples } \\
\text { to NRC licensees. }\end{array}$ \\
\hline AIF [35-37] & $\begin{array}{l}\text { Radiochemical and } \\
\text { radiopharmaceutical } \\
\text { manufacturers }\end{array}$ & $\begin{array}{l}\text { Typicaliy } 7 \text { companies plus FDA } \\
\text { participate in monthly distribution } \\
\text { of high and low level SRMs }\end{array}$ \\
\hline $\begin{array}{l}\text { CAP "Q" Program } \\
{[35-37]}\end{array}$ & $\begin{array}{l}\text { Hospital and } \\
\text { nuclear pharmacies }\end{array}$ & $\begin{array}{l}\text { Typically } 30 \text { to } 50 \text { laboratories report } \\
\text { back results. Up to } 1977 \text { participants } \\
\text { were asked to identify and quantify } \\
\text { the SRMs but after } 1977 \text { only to quantify. }\end{array}$ \\
\hline
\end{tabular}

\begin{tabular}{|c|c|c|c|c|c|c|}
\hline \multirow{2}{*}{$\begin{array}{l}\begin{array}{l}\text { Program } \\
\text { Designation }\end{array} \\
\\
\text { EPA National } \\
\text { Quality Assurance } \\
\text { Program }\end{array}$} & \multirow{2}{*}{\begin{tabular}{|c|} 
Year(s) \\
p76-Present \\
976
\end{tabular}} & \multirow[t]{2}{*}{ 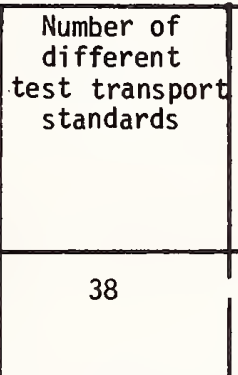 } & \multirow{2}{*}{$\begin{array}{l}\text { Transport Standard } \\
\text { between NBS } \\
\text { and participant } \\
\text { iRrts and specially' } \\
\text { rated sources. }\end{array}$} & \multicolumn{3}{|c|}{$\begin{array}{c}\text { Percentage of sample } \\
\text { measurements for various } \\
\text { ranges of } \Delta \text { where } \\
\Delta=100\left|\frac{\text { reported value }}{\text { NBS value }}-1\right| \\
(\%)\end{array}$} \\
\hline & & & & $\begin{array}{r}\Delta \leqslant 2 \\
55\end{array}$ & $\begin{array}{c}2<\Delta \leqslant 5 \\
37\end{array}$ & $\begin{array}{r}\Delta>5 \\
8\end{array}$ \\
\hline $\begin{array}{l}\text { NRC Confirmatory } \\
\text { Measurement Program }\end{array}$ & 1974-Present & 87 & $\begin{array}{l}\text { NBS SRMs and specially } \\
\text { calibrated sources. }\end{array}$ & $\begin{array}{r}\Delta \leqslant 2 \\
54\end{array}$ & $\begin{array}{l}2<\Delta \leqslant 5 \\
38\end{array}$ & $\begin{array}{c}\Delta>5 \\
8\end{array}$ \\
\hline AIF & 1975-1980 & 44 & $\begin{array}{l}5 \mathrm{~mL} \text { solutions in standard NBS } \\
\text { borosilicate glassampoules } \\
\text { Hignlevel range: } 1-300 \mathrm{mCi} \\
\text { Low level range: } 0.050-5 \mathrm{mCi} \\
24 \text { different radionuclides. } \\
\text { Each participant can submit } \\
\text { one calibrated sample per year } \\
\text { for measurement by NBS }\end{array}$ & $\Delta \leqslant 5$ & $\begin{array}{l}5<\Delta \leqslant 10 \\
16.1\end{array}$ & $\begin{array}{l}\Delta>10 \\
6.5\end{array}$ \\
\hline CAP "Q" Program & $1972-1979$ & 16 & $\begin{array}{l}5 \mathrm{~mL} \text { solutions in standard NBS } \\
\text { borosilicate glass ampoules } \\
\text { Typically in range: } 0.05-5 \mathrm{mCi}\end{array}$ & $\begin{array}{c}\Delta \leqslant 10 \\
55\end{array}$ & & $\begin{array}{l}>>10 \\
45\end{array}$ \\
\hline & 1972* & 1 & $\begin{array}{l}50 \mathrm{mCi} \text { of }{ }^{51} \mathrm{Cr} \text { with serum } \\
\text { bottle }\end{array}$ & $\begin{array}{c}\Delta<20 \\
81\end{array}$ & & $\begin{array}{l}>20 \\
19\end{array}$ \\
\hline
\end{tabular}

${ }^{\star}$ This was a one time test in which the participants were asked to inject a known amount of ${ }^{51} \mathrm{Cr}$ into a serum bottle, return it, the syringe and needle to NBS. 


\section{Special Services}

NBS will perform many measurements or calibrations which are not part of the regularly offered services. Often these services are requests for calibrations beyond the range NBS normally offers (e.g. calibrate neutron sources with greater source strengths, determine the radioactivity in samples in non-standard configurations, etc.). Other examples of special services result when some agency wants to develop a joint program to test the measurement capability of a particular measurement community. Four examples of this type of special seryice are summarized in Table 15. Who requested the service,

Table 15

Examples of Special Services the services requested, the NBS measurements inyolved, and results obtained are listed. The type of traceability resulting from cooperative studies which use some NBS facilities or measurement systems (e.g. characterizing instruments with the filtered beams of the rectorl is somewhere between "artifact" and "measurement" in that several facets of the user's measurement system are involved but not necessarily his whole system in its normal environment.

\begin{tabular}{|c|c|c|c|}
\hline $\begin{array}{l}\text { Source of } \\
\text { support }\end{array}$ & Project & $\begin{array}{c}\text { NBS } \\
\text { Measurements }\end{array}$ & $\begin{array}{l}\text { Percentage of measurement within } \\
\text { various ranges of } \Delta \text { where } \\
\Delta=100\left|\frac{\text { mea sured value }}{\text { delivered value }}-1\right|(\%)\end{array}$ \\
\hline BRH $[38,39]$ & $\begin{array}{l}\text { Voluntary survey of } \\
{ }^{60} \mathrm{Co} \text { teletherapy } \\
\text { units. }\end{array}$ & $\begin{array}{l}\text { Evaluate dose delivered to } \\
\mathrm{CaF}_{2}: \text { Mn TLD shipped in } \\
\text { a polystyrene block }\end{array}$ & $\begin{array}{ccc}\Delta \leqslant 5 & 5<\Delta \leqslant 10 & \Delta>10 \\
83 & 13 & 4\end{array}$ \\
\hline NCI $[10,40]$ & $\begin{array}{l}\text { Calibration of beams } \\
\text { used for therapy in a } \\
\text { hospital setting. }\end{array}$ & $\begin{array}{l}\text { Measurement of photon } \\
\text { beams using the NBS } \\
\text { portable graphite } \\
\text { calorimeter and an NBS } \\
\text { calibrated ionization } \\
\text { chamber. }\end{array}$ & \\
\hline $\operatorname{NRC}[41-44]$ & $\begin{array}{l}\text { Test of a draft ANSI } \\
\text { standard containing } \\
\text { a protocol for } \\
\text { establishing a test- } \\
\text { ing laboratory to } \\
\text { deliver known doses } \\
\text { to personnel } \\
\text { monitors which } \\
\text { would then be re- } \\
\text { turned to companies } \\
\text { providing this } \\
\text { dosimeter service. }\end{array}$ & $\begin{array}{l}\text { Supply calibrated sources } \\
\text { and correction factors } \\
\text { to the pilot test } \\
\text { laboratory. }\end{array}$ & $\begin{array}{l}\text { Percentage of personnel dosimeter } \\
\text { readings within } 50 \% \text { of the dose } \\
\text { delivered by the pilot test lab- } \\
\text { oratory } \\
\qquad \begin{array}{l}\Delta<50 \% \\
80\end{array}\end{array}$ \\
\hline LLL $[2], 45]$ & $\begin{array}{l}\text { Remmeter and albedo } \\
\text { dosimeter response } \\
\text { to low energy mono- } \\
\text { energetic neutrons. }\end{array}$ & $\begin{array}{l}\text { Joint NBS-LLL measurement } \\
\text { using the } 2,24 \text {, and } 144 \mathrm{keV} \\
\text { filter beams at the NBS } \\
\text { reactor. }\end{array}$ & $\begin{array}{l}\text { Information at } 2 \mathrm{keV} \text { is new. } \\
\text { Good agreement in region where } \\
\text { previous measurements exist. }\end{array}$ \\
\hline
\end{tabular}

Units

This paper is intended to provide the reader with information on the wide range of radiation measurement services offered by NBS. It was felt that this could best be accomplished by using special units for the radiation quantities rather than SI units. Table 16 provides the conversion factors between SI units and the special units used in this paper.
Table 16

Conversion Factor for Special to SI units

\begin{tabular}{|ll|}
\hline $1 \mathrm{R} / \mathrm{s}$ & $25.8 \mathrm{~mA} / \mathrm{kg}$ \\
$1 \mathrm{mR} / \mathrm{h}$ & $71.7 \mathrm{pA} / \mathrm{kg}$ \\
$1 \mathrm{rad} / \mathrm{s}$ & $0.01 \mathrm{~Gy} / \mathrm{s}$ \\
$1 \mathrm{Ci}$ & $37 \mathrm{GBq}$ \\
$1 \mathrm{mCi} / \mathrm{L}$ & $37 \mathrm{GBq} / \mathrm{m}^{3}$ \\
$1 \mathrm{n} \cdot \mathrm{cm}^{-2} \cdot \mathrm{s}^{-1}$ & $10^{-4} \mathrm{n} \cdot \mathrm{m}^{-2} \cdot \mathrm{s}^{-1}$ \\
\hline
\end{tabular}




\section{References}

[1] Eisenhower, E.H., This publication

[2] Kathren, R.L., This publication

[ 3] Jennings, W.A., This publication

[ 4] Loevinger, R., This publication

[5] Cavallo, L.M., This publication

[ 6] Grundl, J.A., This publication

[7] Calibration and Related Measurement Service of the National Bureau of Standards, 1980 Edition (Ed. B.C. Belanger) NBS SP 250

[ 8] NBS Standard Reference Material Catalog 19791980 Edition, NBS SP 260

[ 9] References 9a and 9b are available from:

National Bureau of Standards

Radioactivity Group, B7dg. 245

Washington, D.C. 20234

[9a] NBS Radioactivity Standards for Science, Industry, Environment and Health.

[9b] Radioactivity Calibration Services of the Nationa $i$ Bureau of Standards

[10] Loevinger, R. Medical Dosimetry Standards Programme of the National Bureau of Standards, National and International Standards for Radiation Dosimetry, IAEA-SM222 International Atomic Energy Agency, Vienna, (1978) Vol I, 159

[11] Loftus, T.P., and Weaver, J.T. Standardization of the ${ }^{60} \mathrm{Co}$ and ${ }^{13}{ }^{7} \mathrm{Cs}$ Gamma-Ray Beams in Terms of Exposure, Journal of Research of the National Bureau of Standards, Part A 78A (1974) 465

[12] Seelentag, W.W., Panzer, W., Drexler, G., Platz, L., and Santner, F., A Catalogue of Spectra for the Calibration of Dosimeters, GSF Bericht 560 , Gesell schaft fur Strahlenund Utmwel tforschung mbH, Munchen (1979)

[13] Loevinger, R., National Measurement Standards for Radiation Dosimetry, Lecture prepared for the AAPM 1976 Summer School at Trinity College, Burlington, Vermont, July 1976

[14] McLaughlin, W.L., This publication

[15] McLaughlin, W.L., Radiation Sterilization of Plastic Medical Devices, Radiat. Phys. Chem. 15 (1980) 9

[16] Loftus, T.P., Standardization of Cesium-137 Gamma-Ray Sources in Terms of Exposure Units (Roentgens), Journal of Research of the National Bureau of Standards, Part A, 74A (1970) 1

[17] Loftus, T.P., Standardization of Iridium-192 Gamma-Ray Sources in Terms of Exposure. Journal of Research of the National Bureau of
Standards, $85(1980) \quad 19$

[18] Soares, C.G., and Ehrlich, M., This publication

[19] Ehrlich, Margarete and Lamperti, P.J., Uniformity of High-Energy Electron-Beam Calibrations, Phys. Med. Biol 14 (1969) 305

[20] Ehrlich, M. and Lamperti, P.J., Electron Therapy Dosimetry, Measurements for the Safe Use of Radiation, (Ed. S.P. Fivozinsky) NBS Special Publication 454 (1976) 365

[21] Protocol for Dosimetry of High-Energy Electrons Physics in Medicine and Biology, II (1966) 505

[22] Spiegel, V. Neutron Source Calibrations at NBS for Calibration Checks of Neutron Radiation Instruments, Measurements for the Safe Use of Radiation, (Ed. S.P. Fivozinsky) NBS Special Publication 456 (1976) 87

[23] Noyce, R.H., Mosburg, E.R. Jr., Garfinkel, S.B., and Caswell, R.S., Absolute Calibration of the National Bureau of Standards Photoneutrons Source: III. Absorption in a Heavy Mater Solution of Manganous Sulfate. J. Nucl. Eng. 17 (1963) 313

[24] De Juren, J.A. and Rosenwasser, H. Absolute Cal ibration of the NBS Standard Thermal Neutron Density. J. Res. Nat. Bur. Stand. (DS) $52 \quad$ (1954) 93

[25] Mosburg, E.R. Jr., and Murphy, W.M., A Recalibration of the NBS Standard Thermal Neutron Flux, Reactor Science and Technology (J.N.E. Parts A/B) 14 (1961) 25

[26] Wasson, O.A. NBS Facilities for Standardization of Neutron Dosimetry from 0.001 to $14 \mathrm{Mel}$. Neutron Standards and Applications CEds. C.D. Bowman, A.D. Carlson, H.O. Liskien, and L, Stewart L, NBS Special Pubjication 493 (1977) 111

[27] Schwartz, R.B,, and Grundl, J.A., NBS Standard Reference Neutron Fields for Personnel Dosimetry Calibration, National and International Standards for Radiation Dosimetry, Proceeding of a Symposium, Atlanta 5-9 December 1977, IAEA-SM-222, International Atomic Energy Agency, Vienna Yol. I (1978)

[28] Neutron Dosimetry for Biology and Medicine, ICRO Report 26, International Commission on Radiation Units and Measurements, Washington, DC (1977)

[29] Shalek, R.J., Humphries, L.J., and Hanson W.F., This publication 
[30] Shalek, R.J., Kennedy, P., Stovall, M., Andiff, J.H., Gagnon, W.F., Frant, W.III, Hanson, W.F., Quality Assurance for Measurements in Therapy, Measurements for the Safe Use of Radiation, (Ed S.P. Fivozinsky) NBS Special Publication 456 (1976) 111

[31] Ohlhaber, T:R. This publication.

[32] Neuweg, M., This publication

[33] Inn, K. G.W., This publication

[34] Cohen, L.K., This publication

[35] Collé R., AIF-NBS Radioactivity Measurements Assurance Program for the Radiopharmaceutical Industry, Measurements for the Safe Use of Radiation, (Ed S.P. Fivozinsky) NBS Special Publication 456 (1976) 71

[36] Golas, D.B., This publication

[37] Cavallo, L, Ehrlich, M, Hutchinson, J.M.R., Traceability in Ionizing Radiation Measurement Systems, National and International Standards for Radiation Dosimetry, Proceedings of a Symposium, Atlanta, 5-9 December 1979, IAEA-SM-222, International Atomic Energy Agency, Vienna Vol 1, (1978) 65

[38] Soares, C.G., and Ehrlich, M., National Survey of Cobalt-60 Teletherapy Dosimetry, NBS Technical Note 978 (1978)

[39] Thompson, D.L., Kearly, F.E., Wyckoff, H.O., Gitlin, J.N., Reffit, E.B., and Shangold, E.J., National Survey of Cobalt-60 Teletherapy, Final Report, HHS Publication (FDA) 80-8130(1980)

[40] Loevinger, R., private communication (1980)

[41] Plato, This publication

[42] Plato, P. and Hudson, G., Performance Testing of Personnel Dosimetry Services, Final Report of a Two-Year Pilot Study October 1977-September 1979, NUREG/CR-1064, U.S. Nuclear Regulatory Commission (1980)

[43] Plato, P., and Hudson, G., Performance Testing of Personnel Dosimetry Services, Supplementary Report of a Two-Year Pilot Study, October 1977-September 1979, NUREG/CR1304, U.S. Nuclear Regulatory Commission (1980)

[44] Plato, Phillip and Hudson, Glenn, Performance Testing of Personnel Dosimetry Services: Procedures Manual, NUREG/CR-1063, U.S. Nuclear Regulatory Commission (1980).
[45] Hankins, D.E., Energy Dependence Measurements of Remmeters, and Albedo Dosimeters at Neutron Energies of Thermal, and Between 2 $\mathrm{keV}$ and $5.67 \mathrm{MeV}$, Proceeding International Radiation Protection Association, IV th International Congress, Paris (1977) p. 533 (also preprint-UCRL-78307) (1977) 
THE CALIBRATION PROGRAM OF THE BUREAU OF RADIOLOGICAL HEALTH

\author{
T. R. Ohlhaber \\ DHHS, PHS, FDA \\ Bureau of Radiological Health \\ Rockville, Maryland 20857
}

\begin{abstract}
The x-ray calibration program of the Bureau of Radiological Health is described including users, workload and relationship to Bureau programs. Traceability of field measurements to national standards through this laboratory are discussed.
\end{abstract}

(Calibration; instruments; measurements; standards; traceability; $x$-ray)

Introduction

In 1966, the Bureau of Radiological Health (BRH) performed its first documented calibrations. It was evident at that time that high quality measurements were important if any conclusions were to be drawn from the work in the laboratory and applied to radiation reduction programs for the country.

The Bureau has operated under the Public Health Service Act and its 1968 amendment, Public Law 90-602 "The Radiation Control for Health and Safety Act." The intent of this legislation is "to provide for the protection of the public health from radiation emissions from electronic products." [1] In 1976 the mission of the Bureau was expanded with the "Medical Device Amendments" to the "Food, Drug, and Cosmetic Act." [2] Under an agreement with the Bureau of Medical Devices, BRH performs the lead role within the Food and Drug Administration (FDA) for all medical devices which emit radiation.

In order to comply with the above legislation, BRH must monitor possible radiation hazards from electronic products and medical devices. This entails measurement of emissions from various products and devices in the labora tory, factories, distributorships, and wherever used. It is obvious that the quality of these measurements must be assured if rational decisions are to result from the data.

Under Public Law 90-602, various performance standards have been promulgated as regulations of the FDA. Specific electronic products are monitored and tested under these regulations and compliance is man- datory. In the ionizing radiation area, standards exist for television receivers, cold cathode demonstration tubes, diagnostic x-ray systems, and cabinet x-ray systems. [3] In order to determine compliance with these standards, a nationwide measurement program has been established. The basis of this program rests with the FDA field force and State Radiological Health Agencies.

In addition to compliance programs, the Bureau conducts various voluntary programs (BENT, DENT, and NEXT) [4-6], in cooperation with State Agencies to reduce radiation exposure to the public and improve the quality of radiographs used for medical diagnosis. Both the compliance and voluntary programs use large numbers of survey instruments and passive dosimeters.

\section{Calibration Program}

\section{Services}

The BRH ionizing radiation facility is directly tailored to support the role of the Bureau in the medical and electronic products area. Therefore, the services offered correspond to the typical energies and intensities found in diagnostic $x$-ray machines and consumer products such as color television. Table 1 lists the current calibration beams and additional techniques under development. Since 1966, the calibration program has steadily increased. In 1979, approximately 1200 calibrations were performed. For 1980, 1400 are anticipated. The Bureau calibrates for Federal and State Agencies as shown in Table 2. Various Bureau programs are supported by the calibration program. Table 3 shows a breakdown by program.

Table 1. BRH CALIBRATION TECHNIQUES

\begin{tabular}{cccccc}
$\begin{array}{c}\text { ASSOCIATED } \\
\text { NBS CODE }\end{array}$ & $\begin{array}{c}\text { CONSTANT } \\
\text { POTENTIAL } \\
\mathrm{kV}\end{array}$ & $\begin{array}{c}\text { HVL } \\
\text { Al } \\
\mathrm{mm}\end{array}$ & $\begin{array}{c}\text { HOMOGENEITY } \\
\text { COEFFICIENT }\end{array}$ & $\begin{array}{c}\text { EXPOSURE RATE } \\
\begin{array}{c}\text { MIN. } \\
\mathrm{mR} / \mathrm{SEC}\end{array}\end{array}$ & $\begin{array}{c}\text { MAX. } \\
\mathrm{mR} / \mathrm{SeC}\end{array}$ \\
\hline L-E & 20 & 0.2 & 0.63 & 2 & 100 \\
L-G & 30 & 0.4 & 0.68 & 2 & 100 \\
L-I & 50 & 1.0 & 0.70 & 2 & 100 \\
L-K & 75 & 1.8 & 0.63 & 2 & 200 \\
L-M & 100 & 2.9 & 0.58 & 2 & 200 \\
MFG & 100 & 5.0 & 0.72 & 2 & 100 \\
HFC* & 50 & 4.2 & - & $0.5 \mathrm{mR} / \mathrm{hr}$ & 100
\end{tabular}

*TECHNIQUE IS UNDER DEVELOPMENT 
Table 2. CALIBRATIONS LISTED BY AGENCIES

\begin{tabular}{lrr} 
AGENCY & NUMBER & PERCENT \\
\hline BRH & 457 & 37 \\
FDA Field & 466 & 37 \\
Army & 35 & 3 \\
Air Force & 13 & 1 \\
Navy & 14 & 1 \\
States & $1 \frac{263}{248}$ & $\frac{27}{100}$
\end{tabular}

Table 3. CALIBRATIONS LISTED BY PROGRAM

\begin{tabular}{lcc} 
AGENCY & NUMBER & PERCENT \\
\hline Compliance & 437 & 35 \\
BENT & 245 & 20 \\
NEXT & 325 & 26 \\
DENT & 29 & 2 \\
BRH Lab & 212 & 17 \\
& $\frac{1248}{1248}$ &
\end{tabular}

Instruments Calibrated

Any reasonable quality instrument which is consistent with the calibration techniques listed above is accepted for calibration. Examples of these are electrometer and ion chamber sets such as MDH Model 1015, Victoreen Model 666, Keithley Model 35020 etc.; Condensor-R sets and pocket dosimeters such as Victoreen Model 570, DCA Model 002, Capintec Model SEQ6 etc.; passive dosimeters such as TLD and film; and other instruments such as G-M and scintillation detectors.

All active instruments are checked for proper operation upon receipt. These checks depend on the. ability to separate functions such as electrical response and radiation response. Usually, manufacturers suggested checks and adjustments are performed.

For instruments with separable ionization chambers and electrometers, electrical calibration of the electrometer may be performed. This is routine on all $\mathrm{MDH}$ Model 1015 and Victoreen Model 666 instruments. This calibration determines proper electrical operation on all modes and scales of measurement and adjusts all electrometers for equal response to charge and current.

The equipment used for electrical calibration is a Keithley Model 261 Picoampere Source and a BRH constructed charge source. The Picoampere Source is used to provide precise currents simulating the current from an ionization chamber being used for an exposure rate measurement. The charge source provides a known amount of charge to test the integrated exposure function.

For instruments which are prone to chamber or high impedance cable leakage, a charge leakage test is performed by exposing the instrument to radiation and then monitoring the leakage of charge in the integrate mode. The leakage rate is compared to the manufacturer specification to determine whether the chamber, cable or integrate capacitor is faulty.

If an instrument exhibits erratic readings or does not function and minor repairs are indicated, these will be performed in-house. For major repairs, the symptoms are noted and the instrument is returned.
Radiation Calibration

Upon successful completion of the above tests, the instrument is set up on the x-ray calibration facility. The technique used for calibration consists of a comparison between the response of the laboratory standard and the instrument under test in a known radiation field.

The radiation field is produced by an industrial x-ray tube powered by a specially designed high voltage generator. The output of this system is gated by a pneumatic shutter. Filters are inserted into the x-ray beam appropriate for each technique. Multiple collimators are used to control beam size and reduce scatter (Figure 1).

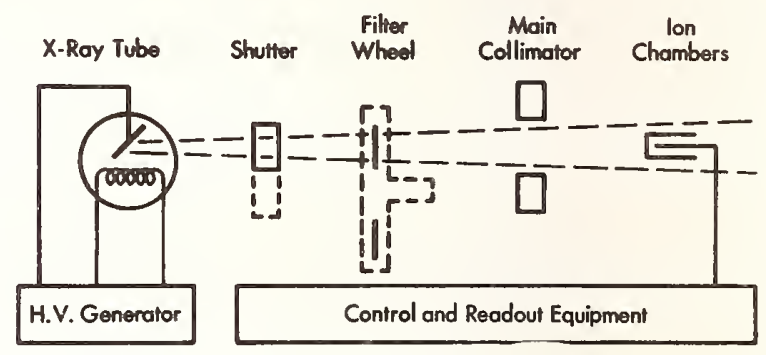

Figure 1. Radiation Calibration Range

The standard is composed of a high quality ionization chamber and a readout system. Most commonly used is a low energy secondary standard such as a Victoreen Model 415-A. The laboratory also maintains Models 415-B, 415D and Exradin Models A5 and A6 chambers. These chambers provide complete coverage of energies employed in diagnostic $x$-ray machines.

The readout system is composed of a Keithley Model 616 electrometer with a General Radio Model 1403 Standard Air Capacitor inserted in the feedback loop. This configuration provides an integrating electrometer with a low leakage and precise capacitance (Figure 2).

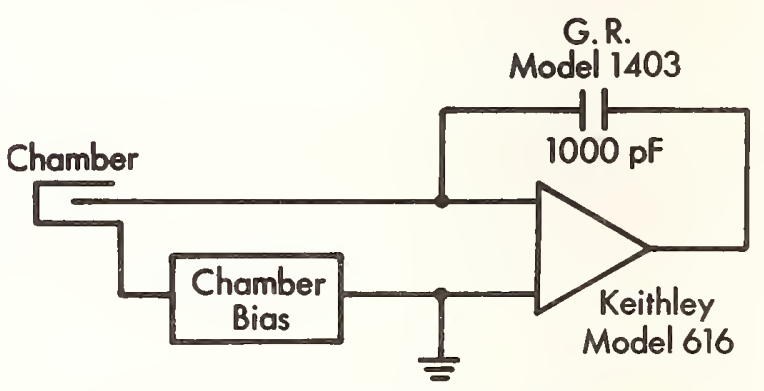

Figure 2. Charge Collection System

Because the measurement is a comparison of the response of two devices, a positioner is used at the calibration site which allows precise positioning of the standard and device under test, with standard mounts to hold the most commonly calibrated instruments (Figure 3). Temperature and pressure are recorded 
because a correction for air density must be performed for all the standards and most instruments containing vented ionization chambers.

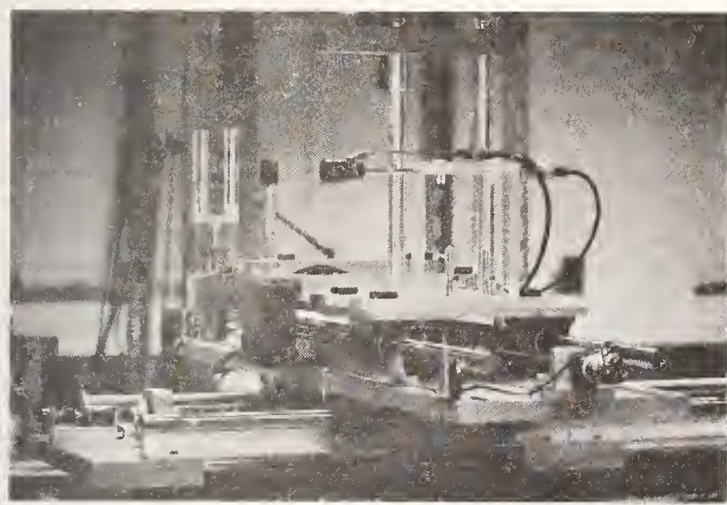

Figure 3. Positioner With Two Chambers and TLD Holder Mounted

\section{Associated Calculations}

All phases of calibration involve the production or measurement of a physical or electrical property and, therefore, errors are inherent in each phase of calibration. The calculations used in radiation calibration are straightforward.

$$
C F=\frac{x_{S}}{x_{I}}
$$

Where: $C F$ is the correction factor for the instrument under test;

$\mathrm{X}_{\mathrm{S}}$ is the response of the radiation standard in Roentgens per second;

$X_{I}$ is the response of the instrument in Roentgens per second.

$\mathrm{X}_{\mathrm{S}}$ is calculated at STP by:

$$
X_{S}=(R C C F) \frac{Q C_{S T P}}{t}
$$

Where: $Q$ is the integrated charge in Coulomb

RCCF is the NBS conversion factor for the standard chamber in $\mathrm{R} /$ coulomb

CSTP is the correction factor for air density at standard temperature and pressure and;

$t$ is the exposure time in seconds.

For the equipment used in this laboratory, $Q$ is measured as the product of voltage (V) and capacitance (C).

$$
Q=C V
$$

CSTP is calculated from $T$ (ambient temperature in ${ }^{\circ} \mathrm{C}$ ) and $\mathrm{P}$ (ambient pressure in $\mathrm{mm}$ of mercury) as follows:

$$
C_{\text {STP }}=\left(\frac{273.15+T}{273.15}\right)\left(\frac{760}{P}\right)
$$

Combining equation (2), (3), and (4) and applying to the standard chamber $(\mathrm{S})$ :

$$
X_{S}=(R C C F) \frac{C V}{t_{S}}\left(\frac{273.15+T_{S}}{273.15}\right)\left(\frac{760}{P_{S}}\right)(5)
$$

For a typical instrument which measures directly in Roentgens the term $\mathrm{CV}$ ( $\mathrm{RCCF}$ ) reduces to the instrument reading in Roentgens $\left(r_{\Gamma}\right)$. Thus:

$$
X_{I}=\frac{r_{I}}{t_{I}}\left(\frac{273.15+T_{I}}{273.15}\right)\left(\frac{760}{P_{I}}\right)
$$

If the instrument has a sealed chamber, the terms containing $\mathrm{T}$ and $\mathrm{P}$ are dropped indicating no correction for air density.

There are basic assumptions in the above equations. The most important assumption is that both the standard and the instrument under calibration are exposed to identical radiation, both in energy spectrum and intensity. Also, it is assumed that effects from other variables such as charge leakage, relative humidity, air composition (pollutants) and electromagnetic fields are negligible.

The parameters in equations (5) and (6) must be measured with reasonable accuracy to maintain an overall accuracy sufficient for the calibration of field instruments and dosimeters. Table 4 lists the equipment used to measure the parameters. Table 5 provides the specifications of the radiation source.

The instruments are typically used indoors at room temperature. Therefore, all correction factors are recalculated for $22^{\circ} \mathrm{C}$.

$$
\mathrm{CF}_{22^{\circ}}{ }^{\circ}=\mathrm{CF}\left(\frac{273.15+22}{273.15}\right)
$$

Table 4. RADIATION CALIBRATION MEASUREMENT EQUIPMENT

\begin{tabular}{cc} 
PARAMETER MEASURED & EQUIPMENT \\
\hline V (Voltage) & $\begin{array}{c}\text { Keithley Model } 616 \\
\text { Electrometer }\end{array}$ \\
C (Capacitance) & $\begin{array}{c}\text { General Radio Model } \\
1403 \text { Capacitor }\end{array}$ \\
t (Time) & ERC Model 2612-33 \\
& Timer, Operating with \\
& BRH Constructed \\
& Shutter Controller \\
P (Pressure) & Sensotec Model Z \\
& Transducer and ERC \\
& Model 3501 Readout \\
T (Temperature) & ERC Model 9300-C \\
& Thermometer
\end{tabular}


On the intermediate level, various approaches can be

\begin{tabular}{|c|c|c|}
\hline Generator Model & : & BRE-150-20-DHEW1 \\
\hline Manufacturer & : & Universal Voltronics \\
\hline Output D.C. & ： & $10-150 \mathrm{kV}$ \\
\hline Regulation & : & $0.1 \%$ \\
\hline Stability & : & $0.1 \mathrm{kV} / \mathrm{hr}$ \\
\hline Metering & & $+0.5 \%$ \\
\hline Emission Current & : & $0.01-30 \mathrm{~mA}$ \\
\hline Emission Control & t & Active Feedback Loop \\
\hline Regulation & & $\begin{array}{lll}+5 \% & 0.01 & -0.299 \mathrm{~mA} \\
+1 \% & 0.30-30.0 \mathrm{~mA}\end{array}$ \\
\hline Stability & & $\mp 7 \%$ \\
\hline Metering & & $\begin{array}{l}\mp 2 \% \text { or }+0.01 \mathrm{~mA} \\
\text { (Whichever is Less) }\end{array}$ \\
\hline Tube Model & & $M G-150$ \\
\hline Manufacturer & 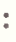 & Phillips \\
\hline $\begin{array}{l}\text { Continuous Rating } \\
\text { Inherent }\end{array}$ & : & 3000 Watts \\
\hline tion & & $3 \mathrm{~mm} \mathrm{Be}$ \\
\hline
\end{tabular}
used. Traceability can be achieved for each individual component of the measurement system. This usually results in a long and torturous chain to the national standard. An example of this can be shown for the measurement of charge in this laboratory. This measurement is a product of capacitance and voltage. The air capacitor is calibrated directly by NBS. The voltage measured by the Keithley Model 616 electrometer is traceable through a Fluke Model 335D voltage calibrator and Fluke Calibration Center standards. This is also verified at BRH by directly measuring a set of saturated standard cells (Eppley Model 121) which are calibrated by NBS. The combination of the capacitor and electrometer is also checked by a Keithley Model 261 picoampere source and a BRH constructed charge source. The Keithley picoampere source is traceable through Keithley to NBS. Figure 4 outlines the relationship of measurement of charge at BRH to NBS. It is obvious that errors or equipment failure could occur at any point in this complicated system. Although redundancy is present, a systematic error could be present and undetected.

Traceability

National Standard

The above measurements with associated internal quality control provide a consistent measure of "exposure." If BRH were the only facility performing these measurements, this would be sufficient. However, "exposure" is measured at a multitude of facilities and calibrations must relate to a single standard if meaningful measurements are to be performed. In this country, the National Bureau of Standards is the only facility empowered to maintain the national standard of "exposure." All measurements and calibrations must be traceable to this standard with in the necessary accuracy of the measurement.

Reasons for Traceability

$\mathrm{BRH}$ is responsible for enforcing performance standards which involve radiation measurements. In order to determine compliance with these standards numerous field and laboratory measurements are performed across the nation. These measurements must provide data which can be defended. In other words, the data must relate to the national standard and provide evidence "beyond reasonable doubt" that the product does not comply with the performance standard. These measurements have to be made with the thought that they may have to be legally defensible.

In addition to measurements made to determine compliance with Federal performance standards, the States use these instruments to determine compliance with State laws protecting the public health and safety. Again, the measurements must relate to the national standard and might have to be legally defensible.

\section{Traceability Mechanisms}

Various approaches can be used to achieve agreement between field measurements and the national standard. The most direct would be to compare each instrument to the standard. This is obviously impossible since thousands or tens of thousands of instruments are involved. This indicates the need for intermediate laboratories to provide reliable calibration services.

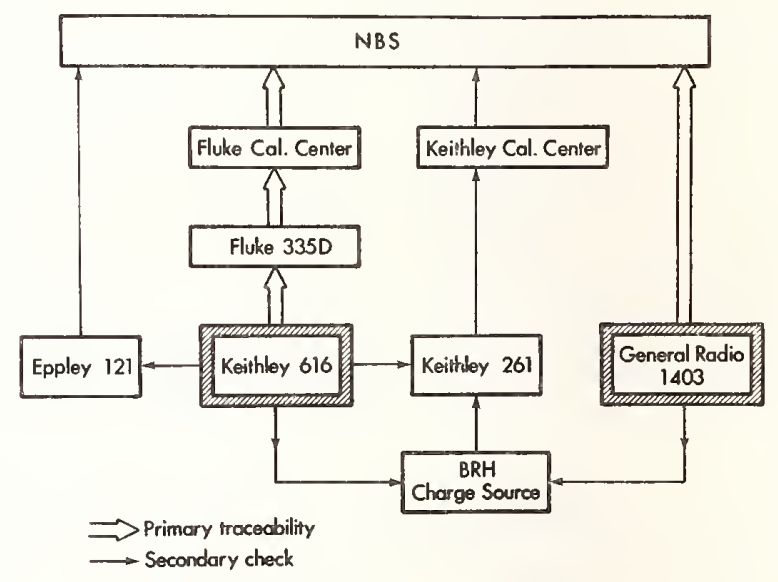

Figure 4. Traceability of Measurement of Charge

The final output of this process yields a measurement system for charge which documents that the instruments used in this system are traceable to a national standard. It does not ensure that the use of these instruments will yield an accurate measurement of charge.

Extensive quality control systems can be implemented for each instrument involved in the measurement. However, it is still possible for the final product to deviate from the national standard.

A far better program to determine agreement with the national standard is to test the total operation of the calibration laboratory. Not only are the calibration instrument errors detected but also human, calculational and systematic errors. All of these contribute to the total disagreement from the national standard.

Since the final output of this laboratory is the calibration of survey meters and passive dosimeters at diagnostic $x$-ray energies, the test for determination of agreement with the national standard should involve the calibration of an instrument at both BRH (using the 
normal laboratory protocol) and at NBS. Disagreement between these calibrations will indicate the typical performance of the laboratory as related to the national standard. This should be an on-going program continually documenting the performance.

In addition, cross calibrations between intermediate laboratories serve a useful purpose. Measurements showing agreement between two or more laboratories would indicate that the national measurement system is operating properly at the intermediate level. If the cross calibrations disagree, a need for improvement is indicated.

\section{BRH View of Traceability}

The instruments calibrated by this facility are used to enforce Federal and State laws for the protection of the public and, therefore, the measurements made with these instruments must be accurate and defensible. It is the intention of BRH to provide calibrations of sufficient accuracy so that the field instruments can be used to their full potential with confidence in the measurements. At present this can be interpreted as meaning the calibrations must exhibit less than $5 \%$ error. This number is based on the accuracy of present field instruments and on the reported needs of the States. [7]

The goal of the laboratory is to maintain an overall error of $3 \%$ or less. This provides a comfortable margin of safety for unexpected errors. In order to maintain such a limit, an active quality assurance program must exist. To be most effective, NBS should be an integral part of this program. The program should include testing of the BRH facility by checking instruments calibrated in the normal manner at.BRH against the national standard and providing a report documenting the degree of agreement. This should be performed on a regular basis, preferably twice a year. As of this date, such a comparison has been performed.

An MDH Model 1015 instrument was calibrated at BRH following the normal laboratory protocol. The instrument and associated $\mathrm{BRH}$ calibration report were sent to NBS for comparison to the National Standard. The results of this test are present in Table 6. Excellent agreement was obtained, verifying a reasonable transfer of the National Standard to the intermediate level.

This program does not replace any in-house quality assurance program nor does it alleviate the need for calibration of the individual components of the calibration system. The program is an independent measure of the total system.

Table 6. BLIND COMPARISON OF MDH MODEL 1015 INSTRUMENT CALIBRATED AT BRH TO NATIONAL STANDARD

PERCENT TECHNIQUE BRH VALUE NBS VALUE DISAGREEMENT

$\begin{array}{llll}\text { L-E } & 1.11 & 1.11 & * \\ \text { L-G } & 1.05 & 1.05 & \text { * } \\ \text { L-I } & 0.99 & 0.99 & * \\ \text { L-K } & 0.98 & 0.98 & \text { * } \\ \text { L-M } & 0.99 & 0.99 & \text { * } \\ \text { MFG } & 1.01 & 1.00 & 1 \%\end{array}$

*NO APPARANT DISAGREEMENT WITHIN ACCURACY OF TEST INSTRUMENT

\section{Tests of Agreement}

Since 1976 a specific Condensor-R electrometer and chamber have been used to monitor the output of the BRH facility. This instrument has been calibrated at both NBS and BRH. Figure 5 contains both sets of data for the instrument. Variations in the BRH data result from several sources:

1. Standards in the laboratory are interchanged and returned for recalibration on 7 - to 8-month schedules. The disagreement between the standards amounts to $2 \%$ or less.

2. Various operators have performed these calibrations. Since the display for this instrument is an analog system, variability has occurred in their readings. This can amount to differences as much as $2 \%$.

3. The basic errors in the set-up, measurement and generation of the beams can amount to approximately $1 \%$.

In spite of these errors most BRH points fall within $3 \%$ of the NBS points.

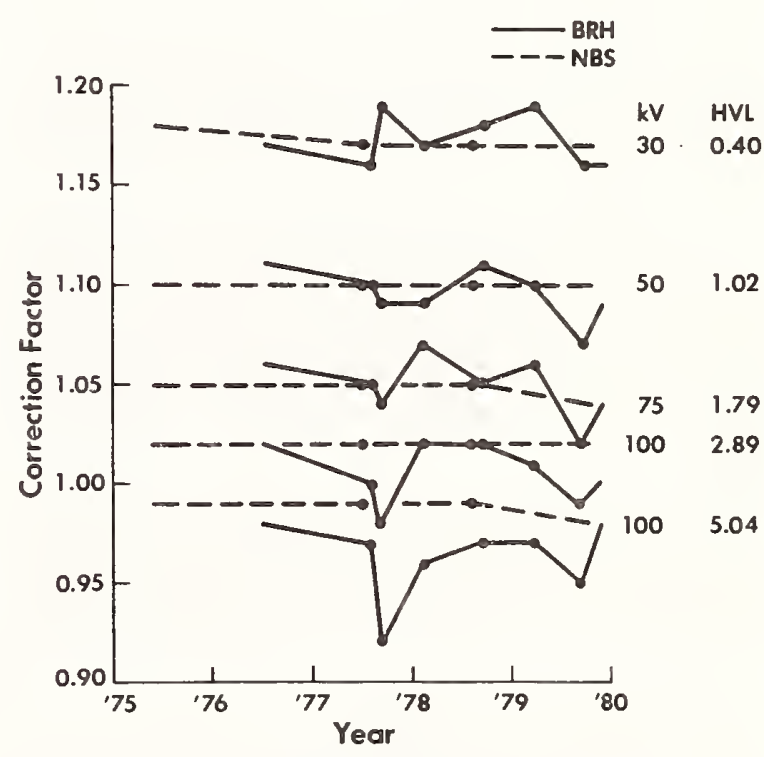

Figure 5. Calibration of Victoreen Condensor-R Chamber Model 70-5

To eliminate some of the inherent errors in the above test, an independent Keithley electrometer system and standard chamber were compared to the laboratory system. The results of these tests verify the sources of errors in routine calibration.

The two systems were compared at five different techniques. Then the chambers were interchanged and the comparisons were rerun. Two general assumptions were made, namely that the radiation delivered to each system was identical and that the spectrum of energies was a reasonable approximation to the NBS techniques. Both of these assumptions have been shown to be reasonable from other tests. 
Calculations were then performed to determine the deviation in readout systems and the deviation in chamber response from the NBS calibration of each chamber. Table 7 summarizes the results of these comparisons.

Table 7. PERCENT DISAGREEMENT OF TWO MEASURING SYSTEMS LISTED BY CALIBRATION TECHNIQUE

\begin{tabular}{ccc} 
TECHNIQUE & $\begin{array}{c}\text { CHARGE } \\
\text { COLLECTION }\end{array}$ & $\begin{array}{c}\text { CHAMBER } \\
\text { RESPONSE }\end{array}$ \\
\hline L-E & $0.28 \%$ & $2.21 \%$ \\
L-G & $0.29 \%$ & $1.13 \%$ \\
L-I & $0.33 \%$ & $1.20 \%$ \\
L-K & $0.23 \%$ & $1.20 \%$ \\
L-M & $0.32 \%$ & $2.07 \%$
\end{tabular}

As can be seen, the difference between the two charge collection systems amounts to approximately 0.3\%. The amount of difference between the two chambers seems excessive. The worst point was repeated with both chambers used on the same charge collection system. Again, the difference in response, using the NBS calibration factors was $2.2 \%$.

It appears that the greatest error in the BRH calibration facility can be traced to the transfer chambers. It is believed that this error may be attributed to changes in the volume of the chambers because of small movements of the thin window.

This effect has been noted by changes in the NBS reports for these chambers. It appears that the disagreement shown in this analysis represents the maximum chamber error. Of the chambers used by BRH, the two chosen for this test represent the two extremes of change in NBS reports. Any other combination of chambers chosen for this test should result in a smaller disagreement.

Because of realization of this effect, more extensive tests will be performed to determine if these changes occur while the chamber is in use or only while it is being transported and exposed to varying environmental conditions.

\section{Field Measurement Traceability}

The traceability of intermediate laboratories is only one step in the establishment of field measurements which are traceable to the national standard. After calibration by an intermediate lab, the instrument must be transported properly, set up properly and used properly. BRH has attempted to solve these problems by supplying simple to use instruments coupled with training and written test procedures. All programs the Bureau initiates or cooperates in have a manual which documents the needed measurements and equipment.

The step from the intermediate laboratory to the final field measurement is the most difficult portion of the traceability. Usually, direct control is lost and even though procedures exist, these may be ignored at the time of the measurement.
Instruments purchased from or repaired at the manufacturer may be assumed to be calibrated when, in fact, they may not be traceable to a reliable standard. Such calibrations should be verified and repeated if necessary.

\section{Conclusion}

In order to achieve traceability for field measurements, all facilities in the chain of calibration must be traceable to the national standard. There must be an active measurement assurance program to document continued agreement to the national standard. Also, a mechanism should be developed to extend measurement assurance to the field level. This may be accomplished by a more general revision or compilation of existing procedures.

$B R H$ is an active participant in diagnostic $x$-ray measurements for the public health and safety. Since 1966, BRH has served as an intermediate laboratory for diagnostic x-ray energies resulting in over 5000 documented calibrations. It is anticipated that this program will continue with increasing demand for services and with more emphasis on total traceability of field measurements.

\section{References}

[1] Radiation Control for Health and Safety Act of 1968, Public Law 90-602, 42 U.S.C., (1968)

[2] Medical Device Amendments of 1976, Public Law94295, 21 U.S.C., (1976)

[3] Regulations for the Administration and Enforcement of the Radiation Control for Health and Safety Act of 1968, HEW Publication (FDA 79-8035), (1978)

[4] Reduced Dose Mammography - Results of a Nationwide Study, R.G. Jans and T.R. Ohlhaber; Proceedings of the Second Reduced - Dose Mammography Meeting, Roswell Park Institute, Buffalo, New York, (1978)

[5] Dental Exposure Normalization Technique (DENT) Instruction Manual, HEW Publication (FDA 768042), (1976)

[6] Nationwide Evaluation of X-Ray Trends: Organ Dose Index System, HEW Publication (FDA 778006), (1977)

[7] Ionizing Radiation Measurement Criteria for Regulatory Purposes, Conference of Radiation Control Program Directors, Inc., NBS Publication (GCR 79-174), (1979)

The mention of commercial products, their sources, or their use in connection with material reported herein is not to be construed as either an actual or implied endorsement of such products by the Department of Health and Human Services (HHS). 
The EPA National Quality Assurance Program

A. N. Jarvis

Office of Quality Assurance-Radiation

National Environmental Research Center

U.S. Environmental Protection Agency

Las Vegas, NV 89114

The speaker submitted neither an abstract nor written version of his talk for inclusion in the proceedings of this seminar.

For further information, contact the speaker directly. 



\author{
George W. Campbe 11 \\ Jack H. Elliott \\ Hazards Control Department \\ Lawrence Livermore Laboratory \\ University of California \\ P.0. Box 5505 Livermore, California 94550
}

\begin{abstract}
The capabilities of Lawrence Livermore Laboratory's Calibration and Standards Facility are delineated. We describe the facility's ability to provide radiation fields and measurements for a variety of radiation safety applications and the available radiation measurement equipment. The need for national laboratory calibration labs to maintain traceability to a national standard are discussed as well as the areas where improved standards and standardization techniques are needed.
\end{abstract}

(Standards; calibrations; traceability; calibration instruments; calibration techniques.)

\section{Introduction}

The Lawrence Livermore Laboratory Caijbration and Standards Laboratory is operated by the Dosimetry Group of the Hazards Control Department's Radiation Safety Division. The purpose of the facility is to maintain radiation standards for LLL and to offer radioactive sources that provide $x$ - and gamma rays, neutrons and beta particles so that all instruments at LLL may be standardized [1].

The functions of this facility include:

- Providing accurate measurements and calibration of radioactive gamma ( $>1 \mathrm{mCi})$ and neutron sources, and providing in situ measurements of photon fields produced by $x-r$ ay machines.

- Providing accurate irradiations using fields of gamma rays, x-rays, beta and neutrons over a wide range of energy and intensity.

- Performing routine calibrations for the Personnel Dosimetry program.

- Performing high-leve 1 ( $\left.>10^{4} \mathrm{rad}\right)$

irradiations for radiation damage and dosimetry development programs.

- Maintaining radiation instrumentation standards and neutron source standards for accurate comparisons with other radiation instruments and neutrons sources within the Laboratory.

- Evaluating new and old radiation detection instruments.

- Maintaining portable radiation survey instruments.

\section{Facility Description}

The facility is composed of a low scatter cell (Cell A), an x-ray cell (Cell B), a source storage cell (Cell C), a control room, a dosimetry laboratory, and a portable instrument calibration laboratory as shown in Fig. 1. An elevation of cells $A, B$ and $C$ is shown in Fig. 2 .

Neutron and gamma sources are pneumatically fired from Cell C to Cell A. Table 1 lists the sources available in the pneumatic transfer system. Cell $A$ has an aluminum grating floor that is $3 \mathrm{~m}$ above the solid concrete floor and $5 \mathrm{~m}$ below the concrete ceiling. The locations of the neutron and gamma irradiation heads in Cell $\mathrm{A}$ are shown in Figs. 3 and 4 . The heads are positioned $1 \mathrm{~m}$ above the aluminum-grating which is as $f$ ar from the ceiling and walls as possible to reduce the effects of scattering. Boggs [2] has shown that the aluminumgrating contributes little to neutron scattering and that the major contribution to scattering is from the ceiling and walls. To keep the scattering to $1 \%$ or less the source should be less than 140 $\mathrm{cm}$ from the detector, greater than $50 \mathrm{~cm}$ from the false floor, and greater than $200 \mathrm{~cm}$ from the walls.

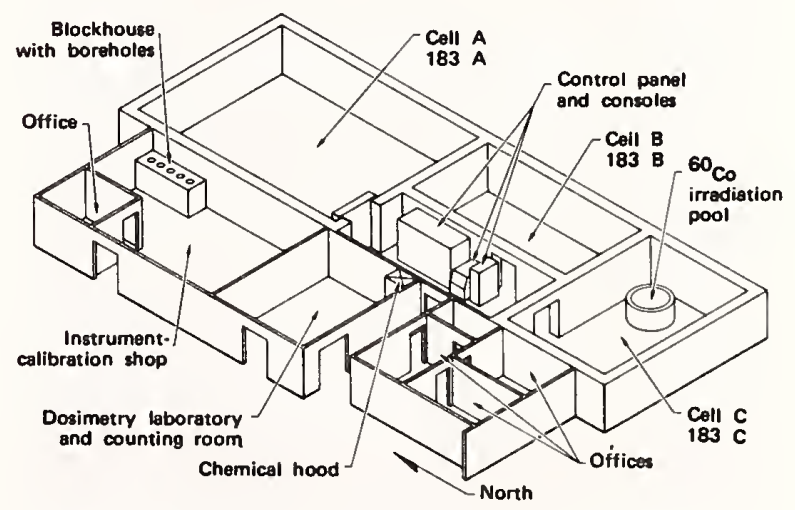

FIG. 1. Sketch of Hazards Control standards and Calibration Laboratory in bldg. 255 (not to scale).

\footnotetext{
${ }^{\star}$ This work was performed under the auspices of the U.S. Department of Energy

by the Lawrence Livermore Laboratory under contract number W-7405-ENG-48.
} 


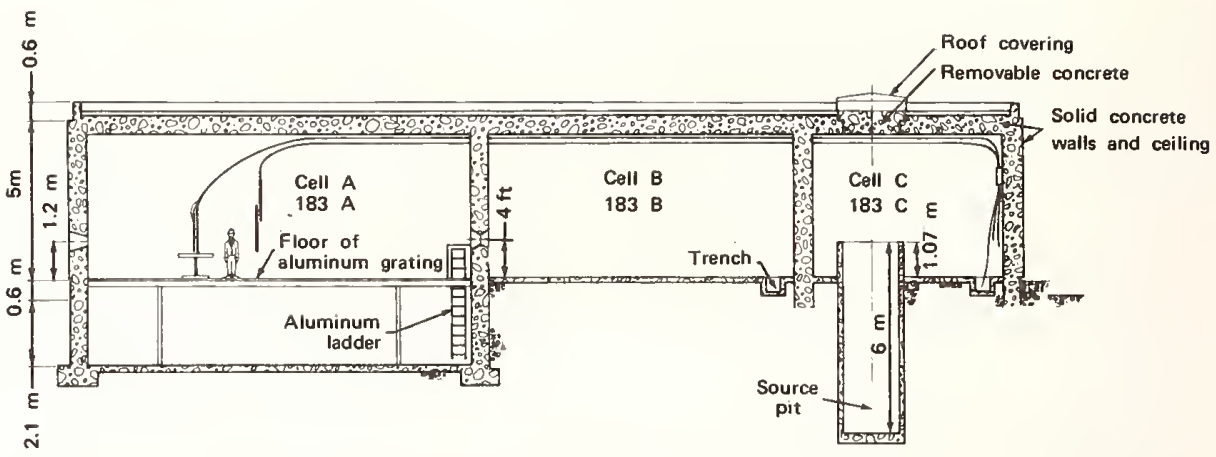

FIG. 2. Cross section of cells $A, B$, and $C$.

TABLE 1. Available source choices in the gamma and neutron pneumatic source-transfer systems.

\begin{tabular}{|c|c|c|c|c|c|}
\hline \multicolumn{3}{|c|}{ Gamma system } & \multicolumn{3}{|c|}{ Neutron system } \\
\hline Source ${ }^{a}$ & $\begin{array}{l}\text { Dose rate at } \\
1 \mathrm{~m}(\mathrm{mR} / \mathrm{min})^{\mathrm{b}}\end{array}$ & $\begin{array}{l}\text { Half Tife } \\
(y r)\end{array}$ & Source & $\begin{array}{c}\text { Dose rate at } \\
1 \mathrm{~m}(\mathrm{n} / \mathrm{s})\end{array}$ & $\begin{array}{c}\text { Half life } \\
(y r)\end{array}$ \\
\hline${ }^{60} \mathrm{Co}$ & 136 & 5.263 & ${ }^{252} \mathrm{Cf}$ & $1.316 \times 10^{9^{b}}$ & 2.646 \\
\hline${ }^{60} \mathrm{Co}$ & 29.2 & 5.263 & 238puBe & $7.8 \times 10^{7 c}$ & 86.4 \\
\hline${ }^{137} \mathrm{Cs}$ & 406 & 30 & 238puBe & $1.6 \times 10^{8}$ & 86.4 \\
\hline${ }^{137} \mathrm{Cs}$ & 12.9 & 30 & $\begin{array}{l}\text { Photoneu } \\
\text { source s }\end{array}$ & & Short \\
\hline
\end{tabular}

aIsotopes.

bose rate as of 1 June 1978 .

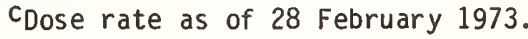
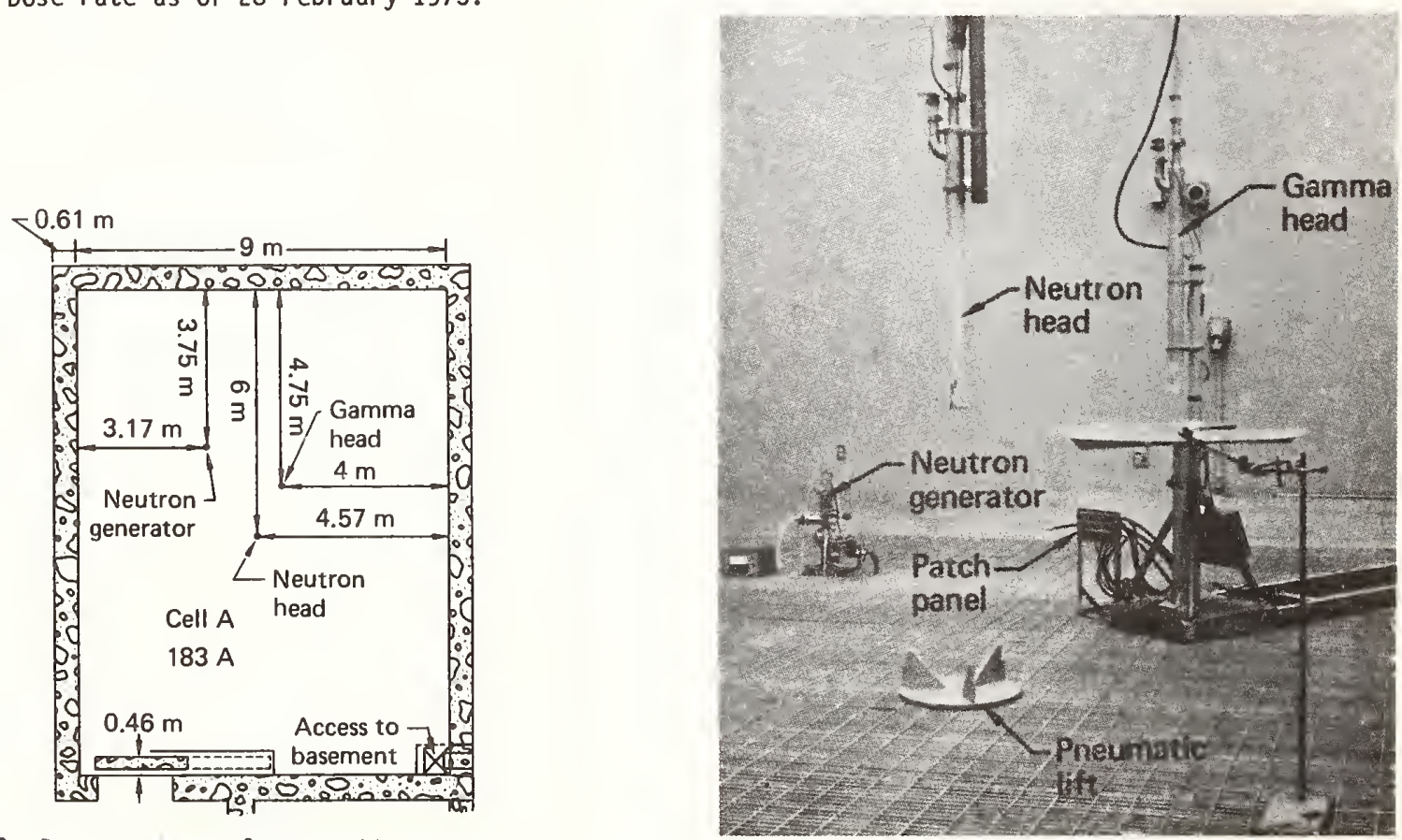

FIG. 3. Locations of pneumatic sourcetransfer heads and neutron generator in Cell A. See the heads, generator, and aluminum-grating floor in Fig. 4 .

FIG. 4. Pneumatic source-transfer heads and neutron generator shown in place in Cell A. 
Note that Cell A also contains a neutron generator suspended below the aluminum-grating floor as shown in Fig. 5. This neutron generator can produce $14.6 \mathrm{MeV}$ neutrons through the $\mathrm{T}(d, n)^{4} \mathrm{He}$ reaction and $2.8 \mathrm{MeV}$ neutrons through the $D(d, n)^{3} \mathrm{He}$ reaction. More detailed information $c$ an be found in the operation manual developed by Elliott. [3]. The exposure rate from the gamma sources is measured with Shonka-type ionization chambers calibrated by the NBS, [4]. The pneumatic ${ }^{252} \mathrm{Cf}$ source was calibrated by NBS and the ANISN code has been used to characterize the neutron fields in Cell A. The neutron flux in Cell A can also be measured using a dePangher modified precision long counter. The long counter (Fig. 6) has been calibrated from $2 \mathrm{keV}$ to $19 \mathrm{MeV}$ by Slaughter. [5]

Cell A also contains a television camera and remote screwdriver to calibrate high range survey instruments as shown in Fig. 7 .

Cell B contains three $x$-ray systems, a manganese sulfate bath for neutron source calibrations, and a beta exposure range.

One $x$-ray system is a $150 \mathrm{kV}, 10-\mathrm{mA} x$-ray unit used to produce filtered $x$-ray spectra. The other two systems are transmission anode $x-r a y$ tubes (TRAX) [6]. These TRAX tubes produce $x$ rays characteristic of the anode material giving a fairly discrete or narrow band of energy depending on the anode materials. We presently have tubes with copper, silver, neodymium, tungsten and uranium targets with principal energies of 8,22 , 38, 60 and $107 \mathrm{keV}$, respectively.

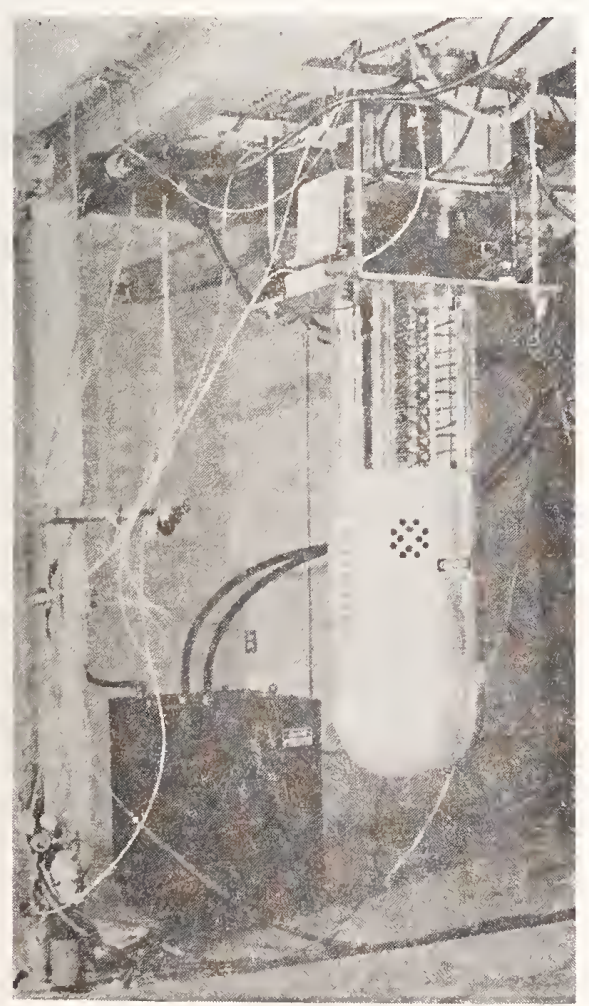

FIG. 5. Neutron-generator accelerator suspended below aluminum-grating floor of Cell A.

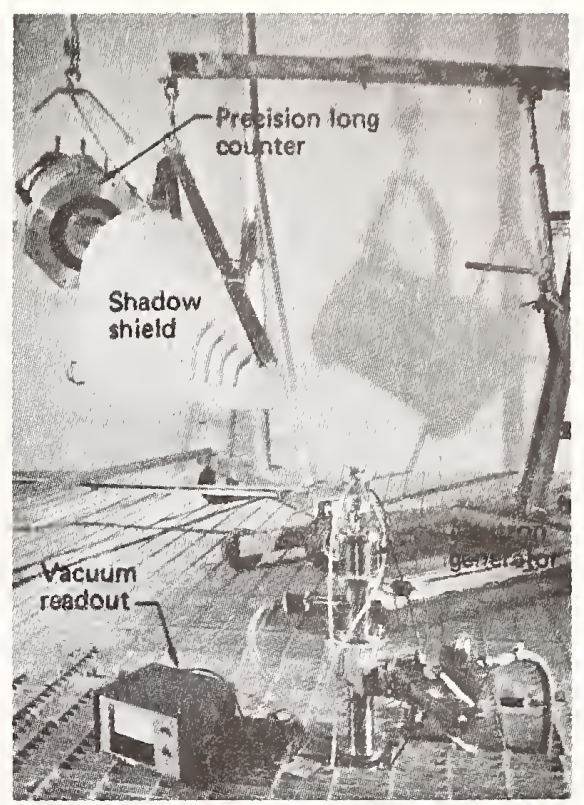

FIG. 6. Top target portion of neutron generator shown with de Pangher precision long counter and shadow shield.

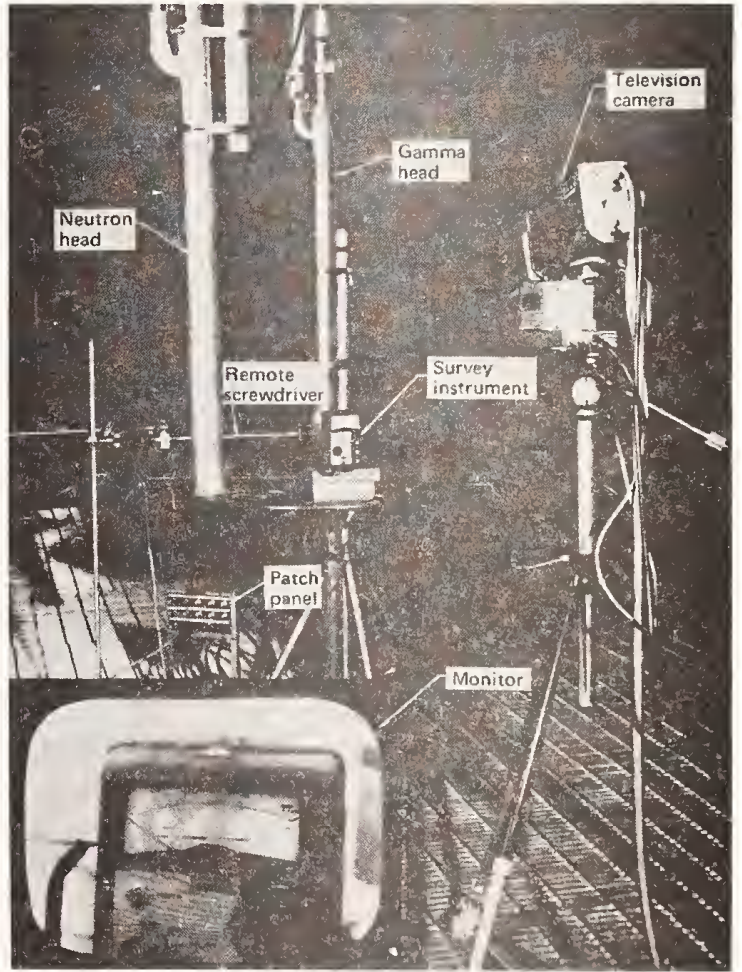

FIG. 7. The kiloroentgen/hour scales on portable survey instruments are calibrated with pneumatically transferred sources, a remote screwdriver, and a television monitor (inset). 
The manganese sulfate bath is used to calibrate neutron sources using a NBS calibrated neutron source as a reference (see Table 2) [7]. Table 3 lists the beta sources that are available. These beta sources are used to calibrate portable survey instruments and TLD's. We need some type of NBS calibration for these sources.

Cell $C$ is used to store the sources listed in Tables 1 and 5; however, the most intense source is located at the bottom of the ${ }^{60} \mathrm{Co}$ pool. The irradiation pool (Fig. 8 ) is about $2 \mathrm{~m}$ in diameter and $6 \mathrm{~m}$ deep. The source consists of 72 pencilshaped, encapsulated ${ }^{60} \mathrm{Co}$ rods arranged vertically in a wire basket so they form a circle approximately $25 \mathrm{~cm}$ in diameter. Table 4 lists the dose rate at different positions in the pool. The pool water is kept pure by continuous recirculation of the water through a resin deionizer and filters. These filters are continuously monitored for radioactivity as a leak test mechanism.

FIG. 8. A pneumatic sample capsule transfers samples to the source at the bottom of the 6-m-deep ${ }^{60} \mathrm{Co}$ irradiation pool in Cell C. The blue glow is produced by high-intensity gamma rays causing Cerenkov radiation.

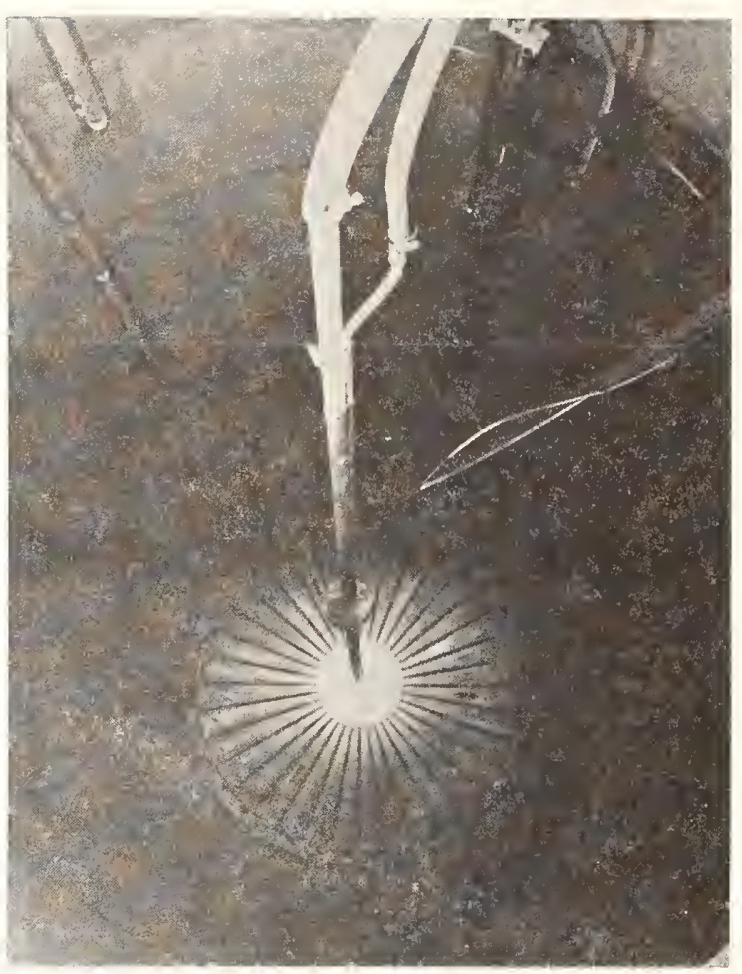

TABLE 2. Calibration of neutron sources.

\begin{tabular}{|c|c|c|c|}
\hline Uses & Method & Reference Standard & Standard Calibration \\
\hline $\begin{array}{l}\text { All low level neutron } \\
\text { sources used for } \\
\text { - dosimeter exposure } \\
\text { - detector \& spectro- } \\
\text { meter development }\end{array}$ & $\begin{array}{l}\text { Intensity }(\mathrm{n} / \mathrm{s}) \text { by } \\
\text { activation comparison } \\
\text { Mn } \mathrm{SO}_{4} \text { Bath } \\
\text { Estimated error-counting } \\
\text { statistics }+1 \% \text { max. } \\
\text { combined with source } \\
\text { error }+2 \%\end{array}$ & $\begin{array}{l}238 \mathrm{pu}-\mathrm{Be}(\alpha, n) \\
\# 300094\end{array}$ & $\begin{array}{l}\text { NBS } \\
\text { Emission rate, } n / s \\
1.7 \% \text { standard error }\end{array}$ \\
\hline
\end{tabular}

TABLE 3. Beta-source choices in the standards and calibrations laboratory beta-source range.

\begin{tabular}{|c|c|c|c|c|c|c|c|c|}
\hline Isot ope & $\begin{array}{c}\bar{E} \\
(k e V)\end{array}$ & $\max _{(\mathrm{keV})}$ & $\begin{array}{l}\mathrm{T} \\
1 / 2 \\
(\mathrm{yr})\end{array}$ & $\begin{array}{l}\text { Calibration } \\
(\mathrm{mC} i)\end{array}$ & Date & Window & $\gamma$ & $\begin{array}{l}\text { Dose rate } \\
(R / h)^{a}\end{array}$ \\
\hline $85 \mathrm{Kr}$ & 249 & 672 & 10.76 & $\sim 13$ & $9 / 75$ & $\begin{array}{l}0.002-i n .- \text { thick } \\
\text { stainless steel }\end{array}$ & $\begin{array}{l}\text { None, } \\
\text { samarium } x \text { rays }\end{array}$ & 2.2 \\
\hline${ }^{90} \mathrm{Sr} / 90 \gamma$ & $200 / 931$ & $546 / 2270$ & 28 & $21 \pm 10 \%$ & $10 / 75$ & $\begin{array}{l}0.002-i n .-t h i c k \\
\text { titanium }\end{array}$ & $\begin{array}{l}\text { Significant } \\
\text { bremsstrahlung }\end{array}$ & 18.2 \\
\hline
\end{tabular}

aDose rate of 25 February 1977, using JUNO at $\sim 25 \mathrm{~cm}$ with all shields open. 
The portable survey instrument calibration laboratory maintains the radioactive-source blockhouse [8] shown in Fig. 9. The two main sources used are ${ }^{137} \mathrm{Cs}$ and $252 \mathrm{Cf}$. This source range is calibrated using IAEA transfer standard techniques and the Cell $A$ sources (see Table 5) [9].

\section{Typical Calibration Fields and Uses}

The accuracy required in most of our uses is $+5 \%$. In some cases we can do better than this value, but we strive not to exceed it.

Table 6 lists some uses and calibration techniques for the ${ }^{252} \mathrm{Cf}$ and PuBe neutron sources. We can moderate these sources with Al, polyethe1ene, $D_{2} 0$ and water to provide a variety of spectral distributions (Fig. 10). Our 252 Cf source was calibrated by NBS. Our largest PuBe source is calibrated by the activation comparison method and is traceable to NBS.

Table 7 lists albedo dosimeters, neutron remmeters, spectrometers and neutron activation detectors as typical uses for the neutron generator. The neutron generator was calibrated using the dePangher long counter.

Table 8 lists possible uses for the betasource fields including dosimeter exposures and instrument response checks. Note that we need to be able to calibrate these sources and we hope NBS will provide this much needed service in the near future.

Table 9 lists some typical uses for gamna fields. The calibration instruments are Shonka chambers with air equivalent walls that have been calibrated by NBS.

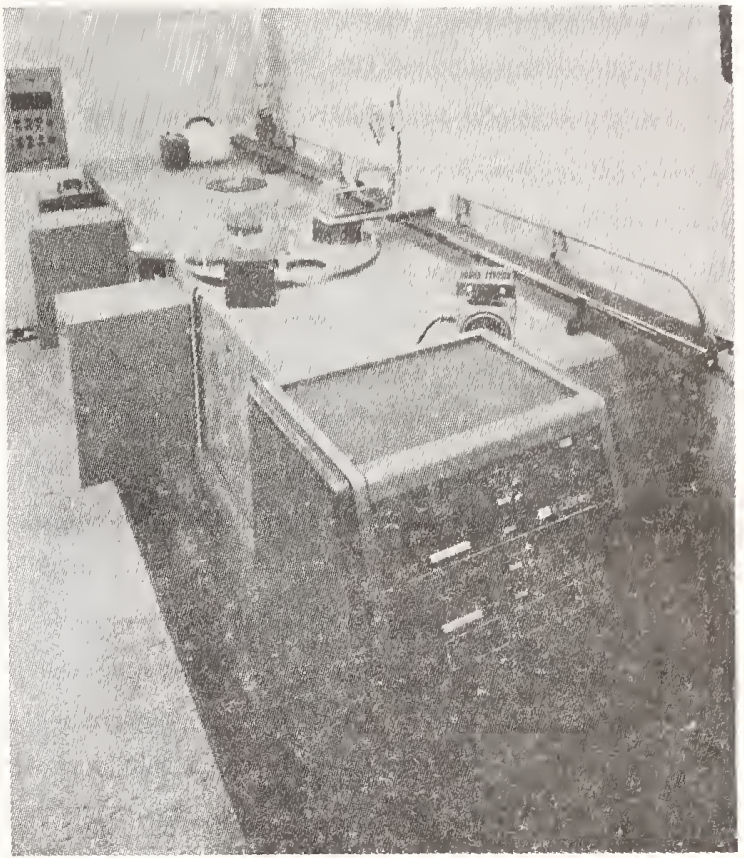

FIG. 9. Radioactive-source blockhouse for calibrating portable survey instruments. Sources are stored at the bottom of vertical holes $4 \mathrm{~m}$ below the top surface.

Table 10 lists the type of x-ray fields we can produce. The exposure rate can be measured using Victoreen Radocon probes, free-air ionization chambers, or Shonka chambers.

TABLE 4. Sample dose rates at three ${ }^{60} \mathrm{Co}$ source positions as of May 1980.

\begin{tabular}{lc}
\hline Position & Dose Rate (rads/s) \\
\hline & $1710 \pm 171$ \\
A Center & $1664 \pm 166$ \\
B Pneumatic & $278 \pm 39$ \\
C Outer ring &
\end{tabular}

TABLE 5. Portable survey instruments calibration range.

\begin{tabular}{llll}
\hline Uses & Method & Calibration & Fields Calibrated \\
\hline All portable survey & IAEA transfer- & Placement of transfer & Gamma source fields \\
instruments gamma & standard method & standard in known & determined by NBS \\
and neutron & radiation fields & calibrated Shonka \\
& (gamma or neutron) & Chamber \\
& & \\
& & \\
& & \\
& Estimated errors 2.5\% & \\
& &
\end{tabular}




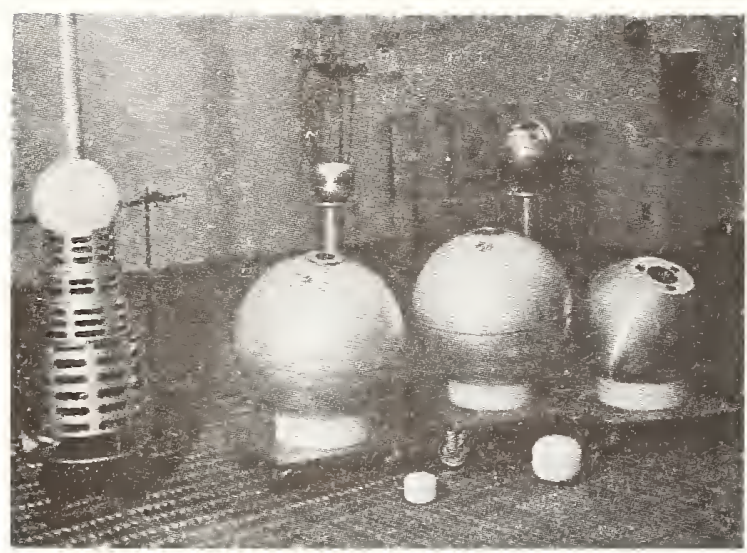

FIG. 10. A variety of neutron source moderators are available to simulate the variety of spectra workers might be exposed to. Moderator materials available are polyethylene, water, $\mathrm{D}_{2} \mathrm{O}$, and solid aluminum. A hydraulic jack positions the spheres about the source head.

TABLE 6. Neutron fields.

\begin{tabular}{|c|c|c|c|}
\hline Uses & Source & Dose Rate & Calibration \\
\hline $\begin{array}{l}\text { Albedo TLD Badge } \\
\text { Calibration \& } \\
\text { Development }\end{array}$ & $C f-252$ & $\begin{array}{l}\text { Based on Decay Program } \\
\text { by Fabricator ORNL for } \\
\text { emission rate }\end{array}$ & $\begin{array}{l}\text { NBS } \\
\text { Emission Rate } \mathrm{n} / \mathrm{s} \\
1.6 \% \text { standard error }\end{array}$ \\
\hline & & and & \\
\hline $\begin{array}{l}\text { Remneter Calibration } \\
\text { (\& Transfer Std. for } \\
\text { Cal. Range) }\end{array}$ & & $\begin{array}{l}\text { ANISN code or similar } \\
\text { code for lowscatter-ce } 11 \\
\text { to give rem/neutron, }\end{array}$ & \\
\hline As Above & PuBe \#300084 & $\begin{array}{l}\text { Emission rate \& ANISN } \\
\text { (or similar) Code }\end{array}$ & $\begin{array}{l}\text { Activation comparison } \\
\text { method traceabie to NBS }\end{array}$ \\
\hline Moderators Available & & Uses Code & \\
\hline
\end{tabular}

TABLE 7. Neutron generator fields.

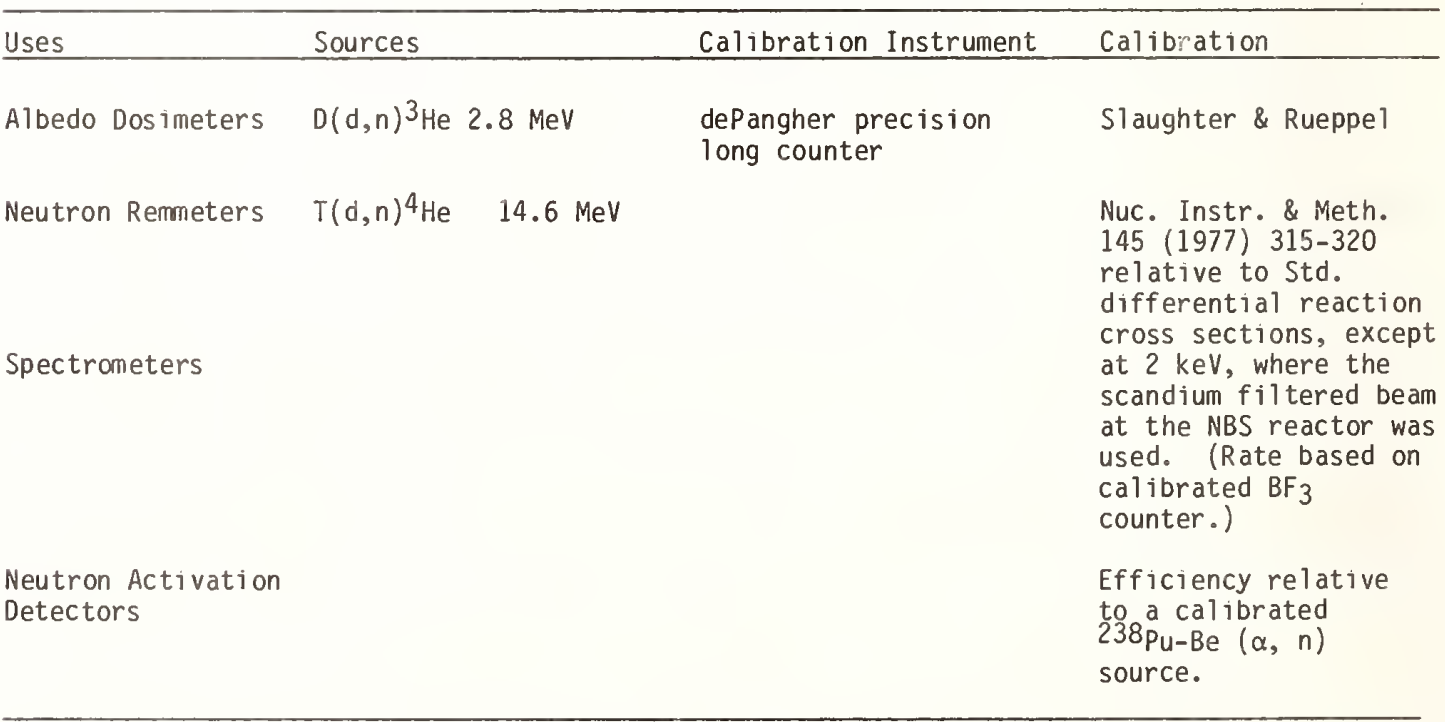


TABLE 8. Beta-source fields.

\begin{tabular}{llll}
\hline Uses & Fields From & Instrument & Calibration \\
\hline Dosimeter & $147 \mathrm{Pm}$ & $\begin{array}{l}\text { Beta Extrapolation } \\
\text { Chamber }\end{array}$ & Not Available \\
Exposures & $85 \mathrm{Kr}$ & & \\
$\begin{array}{l}\text { Instrument } \\
\text { Response checks }\end{array}$ & $90 \mathrm{Sr} / 90 \mathrm{Y}$ & & \\
\hline
\end{tabular}

TABLE 9. $\gamma$ fields.

\begin{tabular}{|c|c|c|c|}
\hline Uses & Location & Calibration Instrument & Calibration \\
\hline $\begin{array}{l}\text { Calibrated doses to } \\
\text { TLD's } \\
\text { High Range Calibration } \\
\text { of Portable Survey } \\
\text { Instrument } \\
\text { Calibrate Transfer } \\
\text { Standards for Survey } \\
\text { Instrument Calibration } \\
\text { Range }\end{array}$ & $\begin{array}{l}\text { Low Scatter Cell } \\
\text { fields from } \\
137 \text { Cs, } 60 \text { Co sources }\end{array}$ & $\begin{array}{l}\text { Shonka Chambers ionization } \\
\text { chambers with air equivalent } \\
\text { plastic wall } \\
\text { Error Estimates } \\
\text { Electrometer readings } \pm 1 \% \\
\text { Distance measurements } \pm 0.5 \% \\
\text { NBS cal ibration } \pm 2 \% \\
\text { Combined, } \pm 2.3 \%\end{array}$ & $\begin{array}{l}\text { NBS } \\
{ }^{137} \mathrm{Cs},{ }^{60} \mathrm{Co} \\
\text { accuracy within } 2 \%\end{array}$ \\
\hline
\end{tabular}

TABLE 10. X-Ray fields.

\begin{tabular}{|c|c|c|c|c|}
\hline & & & Instrument & Calibration \\
\hline \multirow[t]{4}{*}{ Low Energy } & $\begin{array}{l}\text { Fields produced by } \\
\text { Transmission Anode } \\
\text { X-ray Tubes } 8,22 \\
\& 38 \mathrm{keV}\end{array}$ & $\begin{array}{l}\text { Radocon 10LA keV } \\
\pm 3.8 \%\end{array}$ & $\begin{array}{l}\text { Victoreen Corp } \\
\text { fields }\end{array}$ & $\begin{array}{l}\text { Traceability to } \\
\text { NBS }\end{array}$ \\
\hline & \multicolumn{4}{|c|}{ or } \\
\hline & Above & Free-air ionization & Victoreen claims & no traceability \\
\hline & $5-40 \mathrm{keV}$ range & $\begin{array}{l}\text { we estimate } \pm 1.4 \% \\
\text { optimum }\end{array}$ & NBSS HB 64 & \\
\hline \multirow[t]{3}{*}{ High Energy } & $\begin{array}{l}\text { Fields over } \\
40 \mathrm{keV}\end{array}$ & $\begin{array}{l}\text { Shonka Chamber } \\
\text { est. } \pm 2.3 \% \text { combined }\end{array}$ & $\begin{array}{l}\text { NBS } \\
\text { a } 37 \mathrm{keV} \& 115 \mathrm{keV} \\
\text { effective } \\
\text { accuracy within } 2 \%\end{array}$ & \\
\hline & \multicolumn{4}{|c|}{ or } \\
\hline & $\begin{array}{l}\text { Above } \\
40-250 \text { keV range }\end{array}$ & $\begin{array}{l}\text { Free-air ionization } \\
\text { chamber } \\
\text { Est. }+1.4 \%\end{array}$ & $\begin{array}{l}\text { Victoreen claims } \\
+0.54 \% \text {. } \\
\text { Cross check with } \\
\text { Shonka chamber. }\end{array}$ & no traceability \\
\hline
\end{tabular}


TABLE 11. ${ }^{60}$ Co irradiation pool.

\begin{tabular}{lll}
\hline Uses & Calibration Methods & NBS \\
\hline $\begin{array}{l}\text { High dose rate } \\
\text { dosimeter studies }\end{array}$ & $\begin{array}{l}\text { TLD's } \\
\text { Chemical dosimetry } \\
\text { Nylon film }\end{array}$ & $\begin{array}{l}\text { Offers calibration } \\
\text { service for Nylon film }\end{array}$ \\
Radiation Damage & Current value \\
- Light pipes & TLD's $\pm 10 \%$ est. \\
- epoxy plates & \\
- batteries & & \\
- granite & & \\
\hline
\end{tabular}

Table 11 lists some uses and calibration methods for the ${ }^{60} \mathrm{Co}$ pool. The uses are usually high dose rate dosimeter studies or radiation damage studies. The pool has been calibrated using TLD's, chemical dosimeters and Nylon film. Nylon film can be calibrated by NBS, and we plan to use their service.

\section{Traceability}

As we have shown in Tables 6-11 many of our source calibrations are directly traceable to NBS. That is, either the emission rate from the source or the calibration instrument must have been calibrated by NBS. Experience has shown us that this level of traceability is necessary, because we have found that instruments calibrated by someone other than NBS may be calibrated incorrectly. In such a case, a well equipped facility such as ours will usually discover an incorrectly calibrated instrument and return it to the manufacturer for recalibration. However, many small laboratories cannot afford the number of overlapping instruments that we maintain. It is, therefore, imperative that NBS provide an instrument and source calibration service for all types of radiation, or at a minimum certify several 1 aboratories to provide secondary calibrations.

Do national labs need to be traceable to national standards? Since national labs are required to meet essentially the same standards as other users of radioactive sources, we feel it is a necessity for all national labs standards to be related to NBS standards. For example, the new ANSI standard for personnel dosimetry performance testing is being implemented by the NRC, and DOE intends to use the same testing $1 \mathrm{ab}$ and standards. In order to pass this standard each national $1 \mathrm{ab}$ will need sources and instruments calibrated by NBS to properly calibrate their personnel dosimeters and to relate to the NBS calibrated sources that the testing lab will use.

\section{NBS Calibration Services}

We feel that the NBS needs to increase or improve their services in two areas. One is the area of $x$-ray calibration. For filtered $x$-rays NBS should provide standard filter packs that are equivalent to those used at NBS. They should also provide a source of monoenergetic $x$-rays for calibration of instruments at specific energies. For example, the filtered x-ray calibration offered by NBS is not useful for instruments used to calibrate our TRAX systems. That is, we need a correction factor for a specific energy, not a range of energies.

The other area where we reel a calibration service is needed is for beta sources. This service could be either calibrating the users' source or providing NBS calibrated sources. At a minimum we need calibrated beta sources for personnel dosimetry and portable survey instrument exposure and energy response tests. In short, this troublesome area needs immediate help.

\section{Summary}

We have described the LLL Standards and Calibration facility. It is composed of a low scatter cel1, an $x$-ray cel1, a source storage cel1, and a portable survey instrument calibration facility. Several typical uses for the facility were described as well as the typical calibration instrumentation and techniques that are used. We discussed the traceability of our radioactive sources. Finally we stated that national labs do need to maintain a traceability to the NBS and that national standards are needed for $x-r a y$ and beta sources.

\section{References}

[1] Elliott, Jack H., "Tour of the Standards \& Calibrations Laboratory," LLL, UCRL -52537 (1978).

[2] Boggs, J. V., "Neutron Scattering in the Hazards Control Low Scatter Ce11," Hazards Control Progress Report No. 34, LLL, UCRL-50007-69-2 (1969).

[3] Elliott, Jack H., "Operation of the Hazards Control Calibration Facility Neutron Generator," LLL, UCID-17215 (1976). 
[4] Elliott, Jack H., "Shonka Chamber Calibrations Procedures," LLL, UCID-17788 (1978).

[5] Slaughter, D. R. and Rueppel, D. W., "Calibration of a dePangher Long Counter from $2 \mathrm{keV}$ to $19 \mathrm{MeV}, "$ Nucl. Instr. and Meth., 145, 315 (1977).

[6] Cate, J. L., "Transmission Anode X-ray Tube Development," Hazards Control Progress Report No. 53, LLL, UCRL-50007-76-2 (1976).
[7] Elliott, Jack H., "Neutron Source Calibration Procedure by Activation Comparison," LLL, UCID-17216 (1976).

[8] Boggs, J. V., "The Hazards Control Instrument Calibration Facility," LLL, UCRL-51049 (1971).

[9] "Handbook on Calibration of Radiation Protection Monitoring Instruments," IAEA, Vienna, 1971. 

Maury Neuweg

Division of Radiation Protection

Inlinois Department of Public Health

Springfield, Illinois 62761

\begin{abstract}
The State of Illinois, Department of Public Health, is engaged in a pilot project with the National Bureau of Standards to establish a regional calibration facility. The objective of this project is to provide calibration services for state radiation control programs for radiation measurement instruments utilized in the diagnostic $x$-ray energy range. Rationale for the pilot project and the design and implementation phases of the calibration laboratory facility are discussed.
\end{abstract}

(Facility design, future plans, implementation, objectives, purpose)

\section{Introduction}

One of the most fundamental requirements in the conduct of state radiation control programs which protect the public from the hazards of excessive and unnecessary exposure to radiation is the capability to make measurements of radiation fields with adequate accuracy and reliability. This requires the use of measuring instruments with calibration traceable to the national measurement standards maintained by the National Bureau of Standards (NBS). The calibration chain which provides traceability to NBS standards for state radiation control programs should be short and direct because of the major impact which measurements made in state programs have on public health and safety.

Ideally, radiation measuring instruments used in state radiation programs should have no more than 2 calibration steps between them and the NBS standards. The first step is represented by an instrument calibration against MBS standard. This instrument plays the role of a transfer standard, and serves as a secondary reference standard in a regional standards laboratory. The second step is to calibrate field instruments against the secondary reference standard, some of which could serve as tertiary standards.

To complete the chain of traceability in a satisfactory manner, the calibration system must be tested periudically to verify that al1 calibrations are being performed satisfactorily with adequate accuracy. This measurement assurance function is a necessary part of a satisfactory calibration and measurement system. Unfortunately, a system which will provide the needed calibration traceability to NBS standards does not exist at this time. As a result, many measurements are made in state radiation control programs with unknown and unspecified accuracy. In many cases, such measurements are made with instruments that have no verified traceability to NBS standards.

\section{Purpose}

Realizing this very important void in our radiation control program, we agreed to enter into an agreement with NBS to design and implement a regional calibration laboratory as a pilot project. The laboratory is designed to serve the calibration needs for the Illinois Radiation Control Program, specifically relating to measurements of $x$-ray meachines unker $150 \mathrm{kVp}$. It wi11 also provide calibration services for other state radiation control programs, especially, for the states surrounding Illinois and in the Midwest region who desire to take advantage of this service. It is clearly indicated that one of the most serious applications of radiation, in terms of significant exposure of a relatively large percentage of the public, is the practice of diagnostic radiology. Therefore, the laboratory will concentrate on the range of $x$-ray energies and intensities utilized for that purpose. However, this range also covers many additional applications of $x$-rays in other medical and industrial applications. Once the procedures and techniques are established for calibrating instruments within the diagnostic $x$-ray range, it is proposed that an expansion of the laboratory will be necessary to calibrate instruments measuring energies and intensities above the $150 \mathrm{kVp}$ range.

\section{Objectives}

In cooperation with NBS, this project will test the concept of having a state radiation control program serve as a regional calibration laboratory. The laboratory will also serve as a model facility which could be duplicated in other states or regions in an attempt to provide crucial traceability standards for radiation measuring instruments. It is not the intent of our Department either to duplicate or interfere with commercial companies or other organizations or private entities regarding calibration of radiation instruments. But rather, to provide a supplement to the existing calibration services available either locally in Illinois or throughout the nation. The Department of Public Health is placing major emphasis on this project, since it was the only new initiative approved by the Bureau of the Budget for an appropriation to fund the project during FY 80 within the Department. The Director of the Department has been personally involved in project negotiations, and the Governor 
is also aware of the project and supports this new initiative.

\section{Implementation of the Project}

Administrators with NBS and the State Health Department formulated the ideal of initiating a regional calibration laboratory in 1978. Department administrative staff was extremely supportive in promoting the project, since the need for such service has been demonstrated numerous times through diagnostic $x$-ray inspection and enforcement activities. In 1973, the Department initiated a rather innovative approach to reduce unnecessary radiation exposure to patients from diagnostic $x$-ray procedures. This approach relates to the concept of placing a limit on the exposure per radiographic film for certain diagnostic $x$-ray examinations. Illinois was the first state to initiate this method to reduce unnecessary patient exposure by limiting exposures for dental bitewing examinations. In 1975, I1linois became the first state to establish limits on 4 specific medical radiologic examinations. Compliance with these limits is determined by making actual measurements at medical and dental facilities throughout the State with appropriate radiation measuring instruments. It is easily recognized that accuracy and reliability of the instrument readings are paramount to regulate and enforce the exposure limit standards properly. If radiation measuring instruments are not calibrated and traceable to a national standard, enforcement action could be challenged and subject to possible legal proceedings. This was the Department's prime reason for initiating the calibration laboratory within the State of Illinois.

Other states, and the Federal Environmental Protection Agency, have since either established patient exposure limits or recommendations utilizing the rationale developed within the Illinois State Health Department. The Conference of $\mathrm{Ra}$ diation Control Program Directors, Inc., and the Food and Drug Administration, Bureau of Radiological Health, are currently interested in the development of patient exposure guidelines as a method of reducing unnecessary patient exposure throughout the nation. Measurement results, however, are only as good as the reliability and accuracy of the measuring instrument. Therefore, calibration within the diagnostic $x$-ray range is critical in properly assessing exposure to patients and accurately determining compliance through regulatory activities. Since it is neither possible nor practical for NBS to calibrate all instruments used in field application, especially if other states implement this concept, it is appropriate to establish regional calibration centers for the convenience of the states desiring these services. Thus, the Illinois pilot project is especially important because it will test the viability of this concept. If it is successful, it will then serve as a model for similar facilities in other regions of the country.

\section{FACILITY DESIGN AND OPERATION}

The agreement to develop the calibration laboratory with NBS specified that the Department of Public Health would be responsible for providing the necessary space for and components of the structure, including construction of a shielded room, adequate electricity and water supply, and of course, appropriate temperature, humidity and ventilation control. The Department would also provide the operating staff to perform the calibrations and handle the accountability and record keeping procedures.

NBS would provide all equipment necessary to implement the laboratory, including a $150 \mathrm{kVp}, 20$ $\mathrm{mA}$ constant potential industrial $x$-ray unit and all auxiliary equipment such as electrometers, standard ion chambers, power supplies, laser system, visual monitoring system, etc. The Bureau would also provide training for the operating staff, conduct periodic comparisons of the Illinois standard with the national standard for exposure measurement, and conduct periodic testing of performance of the laboratory to maintain quality control.

The laboratory is located within the Department of Public Health office complex at 525 West Jefferson, Springfield, I11inois, on the ground floor level. Two existing walls of the outside structure of the building provide excellent environmental shielding since one side wall is solid concrete, approximately 18 inches thick at the bottom, and tapers to approximately 10 inches at the ceiling of the shielded room. The other wall has approximately 15 feet of compacted earth, sand and concrete which provides excellent shielding. The shielded room was constructed so that the direct beam of the radiation source would be aimed toward this end wa 11 . To reduce radiation scatter, we also constructed a $7^{\prime} \times 7^{\prime}$ sheet of onequarter-inch lead on the inside of the end wall which was then covered with plaster board. The interior walls of the shielded room consist of one-quarter-inch thickness of lead sheeting impregnated onto sheet rock which extends to the ceiling. All openings cut in the lead shielding for electrical outlets, and all nail and screw holes to support the shielding, were individually covered with additional lead to provide necessary exposure reduction and radiation protection. The floor above the shielded room within the structure consists of a 6 -inch thickness of concrete. An oversized door to the shielded room is steel constructed and leads into a maze to further reduce environmental exposure. The entire iaboratory consists of approximately 800 square feet. The shielded room is approximately 250 square feet. The remaining area of the laboratory contains an office, x-ray control area, and work area for instrument maintenance and repair, and sufficient space for radiation survey instrument shipments.

The x-ray unit was installed in January, 1980. However, the optical bench and auxiliary supporting equipment have not yet been received from NBS. We expect to receive the additional equipment within the next month so we can begin operation by June or July. Once all the quipment is installed, a thorough, detailed environmental monitoring of the shielded room and the laboratory will be conducted, utilizing themoluminescent dosimeters (TLD), to verify integrity of the 
shielding and conformance to state and national radiation protection standards.

\section{FUTURE PLANS AND EXPECTATIONS}

Calibration procedures and methodology wi11 be formatted into standard operating procedures with assistance from NBS staff. We plan to perfect the system utilizing our own radiation measuring instruments prior to initiating calibration services for other state radiation control programs. Once the procedures and techniques have been developed, tested and approved by the National Bureau of Standards, we will then contact state radiation control program directors advising them of the services available. We expect to assess nominal fees to other state programs to offset operating expenses the Department will incur through personal services, overhead expenses and transportation costs. The fee structure has not as yet been determined.

The Bureau has expressed interest in obtaining a Cesium-137 source of approximately 3-5 curies to provide calibration services for instruments of higher energy ranges. It is anticipated this will be the second phase of the project to provide a broader range of calibration capabilities on a regional basis.

There will be routine evaluations of the operating procedures by the Department and NBS to assure quality control of the calibration system. Operating staff of the facility will be provided with the best training available through NBS. Continuing education will also be stressed to assure that the calibration system will be conducted with high quality standards in the everincreasing complexity and technological advancement in the radiation protection field, especially as it relates to radiation measuring instrumentation utilized by state radiation control programs. 

THE AMERICAN ASSOCIATION OF PHYSICISTS IN MEDICINE'S REGIONAL CALIBRATION LABORATORY SYSTEM

\author{
Robert J. Shalek, Leroy J. Humphries and William F. Hanson \\ Physics Department \\ The University of Texas System Cancer Center \\ M. D. Anderson Hospital and Tumor Institute \\ Houston, Texas
}

\begin{abstract}
Three Regional Calibration Laboratories have been established primarily for the dissemination of national radiation standards for radiation therapy. The National Bureau of Standards together with the regional laboratories have a calibration capacity in rough equilibrium with the demand. However, if a 1$]$ instrument users had field instruments calibrated regularly the demand might exceed present calibration capacity. Various data are adduced to demonstrate that commercially available field instruments can maintain calibrations for periods longer than the generally recommended 2 year interval.
\end{abstract}

\section{Introduction}

It is estimated that there are 1322 radiation therapy facilities in the United States and that a minimum of 1057 field instruments require calibration in order to service these facilities [1]. At present the National Bureau of Standards calibrates less than 100 field instruments per year. In order to close the gap between need and calibration capacity, it was suggested that secondary radiation standardizing laboratories be established just as secondary laboratories exist for the dissemination of electrical and other standards. Robert Loevinger of the National Bureau of Standards recommended that the American Association of Physicists in Medicine (AAPM) become the accrediting agency for the establishment of Regional Calibration Laboratories (RCL) [2]. The AAPM accepted the suggestion in 1970 and appointed Task Group \#3 of the Radiation Therapy Committee to establish criteria for the initiation and operation of the laboratories, to review applications for laboratory accreditation, to select laboratories and to continue in the supervision of the laboratories.

To date, three Regional Calibration Laboratories have been accredited by the AAPM. These facilities are located at Memorial SloanKettering Cancer Center (MSK) in New York, The University of Texas System Cancer Center M. D. Anderson Hospital and Tumor Institute (MDA) in Houston, and Victoreen Instrument Division (VIC) in Cleveland. It has been recommended that at least one additional $\mathrm{RCL}$ be established at a distance from the other laboratories [1].

In the discussion here, some of the requirements and capabilities of the regional laboratories will be considered together with an indication of the quality assurance pro- cedures between the National Bureau of Standards and the regional laboratories. The distribution of work load between the laboratories and the types of instruments now used as field instruments will be discussed. In addition, the frequency of calibration of field instruments used for the calibration of radiation therapy machines will be considered from the view of what is occurring and what may be required for the satisfactory use of the instruments.

The information derives from Task Group \#3 reports, from a Report of the Committee on Radiation Calibration Needs in Therapy of the American Association of Physicists in Medicine (L. Lanz1, Chairman) [1], from the operating experience of the $M$. D. Anderson RCL, and from data collected by the Radiological Physics center (RPC). The latter organization reviews radiation measurements and calculations relating to radiation therapy at institutions participating in interinstitutional clincial trials and thus has the opportunity for observing the operation of field instruments by the user.

\section{Requirements For and Operation of Regiona] Calibration Laboratories}

The specific requirements for operation of an RCL are presently being reviewed by a subcommittee of Task Group \#3 [3]. It is likely that the RCLs will be required to provide instrument calibrations that agree with the national standards to within the limits specified in Table I. These overall requirements will replace present specific requirements upon various steps in the calibration process. In this paper only instruments for the calibration of therapy machines will be considered. 
Proposed Criteria for Calibration Agreement Between

an RCL and NBS
Radiation Beam Qualities Available at NBS and the RCLs (1980)

$\underline{\text { Lab }{ }^{60} \mathrm{Co}} \times \underline{\text { Ray (HVL/KV) } \quad \text { Filt. }}$
Reference-class instruments suitable for calibration of other instruments to a precision of $0.1 \%$

Field-class instruments suitable for therapy beam calibration

Field-class instruments suitable for diagnostic $x$-ray calibration

Field-class instruments suitable for health physics survey measurements

\section{$\underline{{ }^{60} \mathrm{Co}} \times \underline{\mathrm{ray}}$}

$\pm 0.5 \% \quad \pm 1.0 \%$

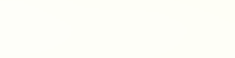

$\pm 1.0 \% \quad \pm 2.0 \%$



Table II

\section{Secondary Standard Instrumentation at the MDA RCL}

Exposure Standards: (NBS calibration biennially) Shonka-Wyckoff, $3.6 \mathrm{cc}, 0.25 \mathrm{~mm} A E$ wa 11

Exradin Model A-3,3.6cc, 2.54mm AE wall Victoreen Model 415A. 2cc, 2 mil mylar window Nuclear Enterprises Model 2561 (NPL Secondary Standard), $0.3 \mathrm{cc}, 0.5 \mathrm{~mm}$ graphite wall

Capacitance Standards: (NBS traceable calibration biennial7y)

General Radio Type 1404-A, 1000 pF

General Radio Type 1404-B, 100 pF

Voltage Standards: (*NBS traceable calibration biennially)

Keithley Model 240A, Regulated HV supply, 0 to $1.2 \mathrm{kV}$

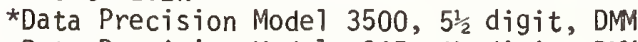

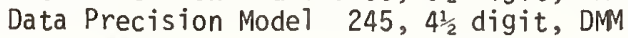

*Eppley Model 100, Standard Cell

Other RCL Instruments:

Keithley Model 602 electrometers

Keithley Model 261 picoampere source

Taylor Model 6204M aneroid barometer

Fisher Model 15-043A thermometer, 1 to $51^{\circ} \mathrm{C}$, $0.1{ }^{\circ} \mathrm{C} / \mathrm{div}$.

Aluminized-mylar transmission monitor chamber

$0.03-2.78 \mathrm{~mm} \mathrm{A1/10-100} \mathrm{kVcp}$

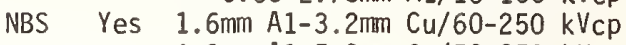
4.2mm A1-5.2mm Cu/50-?50 kVcp

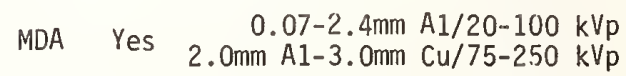

$0.03-1.95 \mathrm{~mm} \mathrm{A1} / 10-60 \mathrm{kVp}$

MSK Yes

3. $0 \mathrm{~mm} A 1-2.1 \mathrm{~mm} \mathrm{Cu} / 60-250 \mathrm{kVcp}$

$0.9-1.6 \mathrm{~mm} \mathrm{A1} / 50-75 \mathrm{kVp}$

VIC Yes

$2.8 \mathrm{~mm} \mathrm{~A} 1-3.2 \mathrm{~mm} \mathrm{Cu} / 60-250 \mathrm{kV} c \mathrm{p}$

$\mathrm{L}$

M

$\mathrm{H}$

L

L

M

L

* Filtration: Light, L; Moderate, M; Heavy, H NBS also calibrates at ${ }^{13^{7}} \mathrm{Cs}$ energy

Table IV

RCL Measurement Assurance Tests by NBS

\begin{tabular}{|c|c|c|c|c|c|}
\hline Year & RCL & $\begin{array}{r}\text { Medium Er } \\
\text { Dev } \\
\text { Mean }\end{array}$ & $\begin{array}{l}\text { rgy } \\
\text { tion } \\
\sigma(c\end{array}$ & $\begin{array}{l}x \operatorname{Ray}(b) \\
\text { (a) } \\
\operatorname{Max}\end{array}$ & $\begin{array}{l}{ }^{60} \mathrm{Co} \\
\text { Deviation (a) }\end{array}$ \\
\hline 1976 & $\begin{array}{l}\text { MDA } \\
\text { MSK } \\
\text { VIC }\end{array}$ & $\begin{array}{l}-1 \\
+2 \\
-7\end{array}$ & $\begin{array}{l}3 \\
1 \\
2\end{array}$ & $\begin{array}{l}-4 \\
+4 \\
-11\end{array}$ & $\begin{array}{l}-3 \\
-1 \\
+1\end{array}$ \\
\hline 1977 & $\begin{array}{l}\text { MDA } \\
\text { MSK } \\
\text { VIC }\end{array}$ & $\begin{array}{l}-5 \\
-3 \\
+2\end{array}$ & $\begin{array}{l}-- \\
-- \\
3\end{array}$ & $\begin{array}{r}-5 \\
-3 \\
+8\end{array}$ & $\begin{array}{l}-1 \\
+3 \\
+2\end{array}$ \\
\hline 1978 & $\begin{array}{l}\text { MDA } \\
\text { MSK } \\
\text { VIC }\end{array}$ & $\begin{array}{l}-4 \\
-2 \\
+3\end{array}$ & $\begin{array}{l}5 \\
1 \\
2\end{array}$ & $\begin{array}{l}-11 \\
-4 \\
+6\end{array}$ & $\begin{array}{r}+2 \\
0 \\
+1\end{array}$ \\
\hline 1979 & $\begin{array}{l}\text { MDA } \\
\text { MSK } \\
\text { VIC }\end{array}$ & $\begin{array}{l}-5 \\
+2 \\
-6\end{array}$ & $\begin{array}{l}2 \\
4 \\
4\end{array}$ & $\begin{array}{l}-8 \\
+9 \\
-12\end{array}$ & $\begin{array}{l}+2 \\
-1 \\
-4\end{array}$ \\
\hline
\end{tabular}

(a) Deviation: Parts per thousand [(RCL/NBS $)-1] \times 1000$

(b) $60-250 \mathrm{kV} ; 1.86 \mathrm{~mm} \mathrm{A1}$ to $3.2 \mathrm{~mm}$ Cu HVLs

(c) One standard deviation

Intercomparison Instrument

1976: Shonka $3 \mathrm{~cm}^{3}$ ion chamber

1977: Victoreen $2 \mathrm{~cm}^{3}$ 415B chamber

1978: NEL Dosemeter and Farmer Chamber

1979: PTW $1 \mathrm{~cm}^{3}$ 30-349 chamber 
In Table II, the equipment employed at the MDA RCL is listed. This equipment is commercially available and for the most part capable of performing with a reproducibility of $0.1 \%$. The range of beam qualities available for calibaration at NBS and at each RCL are shown in Table III.

The ionization chambers maintained as secondary standards by an RCL are calibrated at NBS at least biennially for each calibration energy offered by an RCL. Other instruments such as standard capacitor, standard voltage cell, barometer, thermomether and voltmeter have calibrations documented as traceable to NBS. In addition NBS circulates a chamber or dosimeter system with undisclosed calibration annually to each RCL for calibration. The results from four years of these measurement assurance tests are shown in Table IV. In each year the calibration at coba $1 t-60$ and the mean of the calibrations in the $x$-ray range were within the criteria defined in Table I. In two isoloated $x$-ray cases, the deviation from the national standard exceeded the $1 \%$ proposed for reference-class instruments, however, the worst case was only $1.2 \%$.

Table $V$ shows the distribution of instrument calibrations among the various laboratories. Data comes from two sources, the questionnaries circulated by the Lanzl committee [1] and from RCL records. $80 \%$ of the responders to the Lanzl committee questionnaire had calibrations from NBS or an RCL. Although the word regional appears in the name of the secondary laboratories, instruments come for calibration to the RCLs from distant parts of the country and some foreign countries.

\section{Table $V$}

Laboratory of Last Calibration and RCL Workload

\begin{tabular}{lcc}
\hline Laboratory & $\begin{array}{c}\text { Respondents (a) } \\
\%\end{array}$ & $\begin{array}{c}\text { \#Instruments }(\mathrm{b}) \\
7 / 78-6 / 79\end{array}$ \\
\cline { 2 - 3 } & 19 & - \\
NBS & 24 & 102 \\
MDA RCL & 21 & 65 \\
MSK RCL & 16 & 75 \\
VIC RCL & 20 & - \\
Manufacturer & &
\end{tabular}

(a) Number of respondents to this question was 520; number of radiotherapy centers is approximately 1,322 .[1]

(b) From $\mathrm{RCL}$ reports
Directly Traceable to NBS

The first definition of directly traceable appeared in the 1971 protocol of the AAPM Scientific Committee on Radiation Dosimetry (SCRAD) [4] as follows, "for the purposes of this protocol, an instrument with a calibration factor directly traceable to the National Bureau of Standards has been calibrated either at NBS or against a reference instrument which has itself been calibrated at NBS." Robert Loevinger of NBS has proposed that the definition of directly traceable be tightened as follows [5]. A field instrument with a calibration factor directly traceable to the National Bureau of Standards has been calibrated against the national standard maintained at NBS or against a secondary standard maintained at a Regional Calibration Laboratory. Implicit in this definition is the recognition that a secondary standard is more than a reference-class instrument calibrated at NBS because of the quality assurance requirements placed upon an RCL by the AAPM.

\section{The Frequency of Calibration of Field Instruments}

The Nuclear Regulatory Commission requires that 1 icencees of cobalt-60 teletherapy units perform calibrations with dosimetry systems calibrated by NBS or an RCL within the previous two years [6]. Some states and other agencies require annual recalibration. A time period of two years between calibrations of field instruments accords reasonably well with current practices as shown in Table VI.

\section{Table VI}

Frequency of securing a calibration

\begin{tabular}{|c|c|c|c|}
\hline \multicolumn{2}{|c|}{ From Lanz1 Report } & \multicolumn{2}{|c|}{ From MDA RCL Data } \\
\hline $\begin{array}{c}\text { Time } \\
(\text { years })(a)\end{array}$ & Frequency & $\begin{array}{c}\text { Time } \\
(\text { years) }\end{array}$ & Frequency \\
\hline$<1$ & 3 & 0.5 & 9 \\
\hline 1 & 33 & 1 & 29 \\
\hline 2 & 30 & 1.5 & 32 \\
\hline 3 & 13 & 2 & 18 \\
\hline 4 & 7 & 2.5 & 4 \\
\hline 5 & 4 & 3 & 4 \\
\hline 6 & 4 & 3.5 & 3 \\
\hline 7 & 2 & 4 & 1 \\
\hline 8 & 2 & & \\
\hline$>8$ & 3 & & \\
\hline
\end{tabular}

Average time: 2.5 year

1.5 year

Mean time : 1.5 year

1.2 year

a) Time since last calibration

b) Time between calibrations by an institution 
The median time indicated by respondents to the Lanz] questionnaire [1] or users of the MDA RCL is approximately 1.5 years. Despite the agreement between the practices of users and the federal regulation, the frequency of calibration necessary for field instruments is worth consideration. Information to be addressed here suggests that the time period between the calibrations of field instruments could be longer than two years if suitable other tests upon the instrument are performed by the user.

During visits to institutions to review measurements and calculations relating to radiation therapy, the RPC usually makes an intercomparison in air in a 60 Co beam between the institution's field instrument and the RPC instrument. Since September, 1970 the RPC instrument consisted of one of several Farmer chambers and a Keithley 602 electrometer. As an indication of RPC precision, seventy-five constancy checks over a three-year period using the RPC field instrument showed a standard deviation of $0.4 \%$ for individual measurements, with a maximum deviation $8 f 1 \%$, where 60 Co irradiator or a commercial ${ }^{90} \mathrm{Sr}$ checker was the radiation source [7]. In some intercomparisons prior to September 1970, the RPC used a Farmer Secondary Standard model 2502 electrometer and chamber that showed a standard deviation of $0.7 \%$ for individual measurements in 17 measurements over a twoyear period [7].

In Figure 1 a bar graph indicates the types of chambers the institutions visited by the RPC employed during various two-year intervals from 1968 to 1979. It is clear that Farmer-type chambers are being used more and that Victoreen R-Meters are being used less as time passes. However, the stability of the

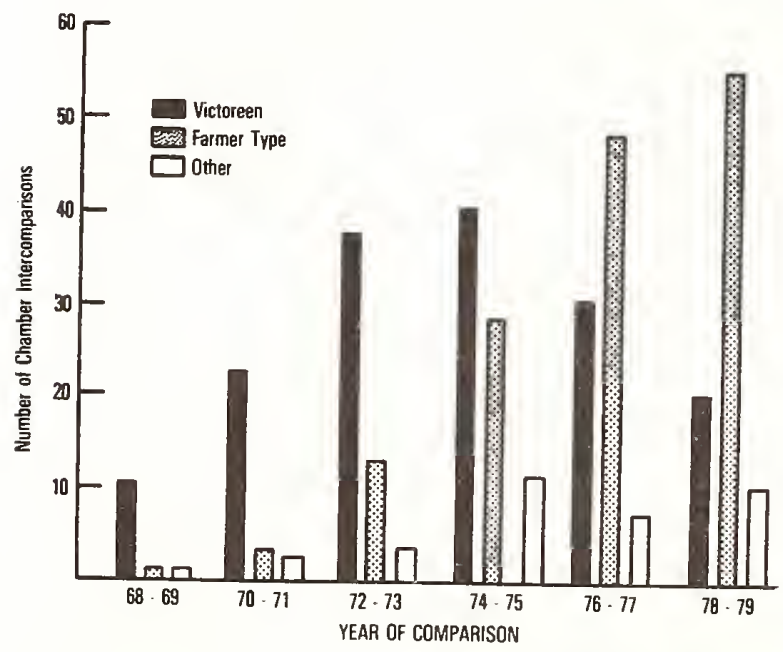

Figure 1: Number of chamber intercomparisons performed by the RPC, by year, for Victoreen R-Meters, 0.6cc Farmer type chambers and for other chambers. various instruments in holding their calibration appears to be comparable as is shown in Table VII. Here RPC intercomparisons with instruments which had calibrations from NBS or an RCL show no great difference according to instrument type. The lapsed time between the calibration of the instrument and the intercomparison with RPC was a median 13 months for Victoreen R-Meters and 10 months for Farmer type instruments. In tables which follow, no distinction is made between different types of instruments.

In Table VIII, the results of RPC intercomparisons are shown according to calibration source before 1976 and after 1976. It is clear that prior to 1976 instruments which were calibrated by a manufacturer or had an uncertain calibration history (other) were suspect; after 1976 few instruments with suspect calibrations were found regardless of the method of calibration; however, there are not enough manufacturer or other calibrations after 1976 to demonstrate a conclusive improvement. It is noteworthy that field instruments intercompared with other instruments which were calibrated at NBS or an RCL appear to have calibration factors which are not significantly less reliable than those calibrated by NBS or an RCL. Many of these instruments were an institution's instrument for everyday use which has been compared to the institution's standard instrument calibrated at NBS or an RCL. Prior to about 1976, intercomparison with the institution's chamber was usually made only when the RPC differed by more than $2 \%$ in the calibration of a therapy machine. After that time intercomparisons were made whenever the institution's instrument was available during review visits. Thus some bias in the direction of causing the earlier data to appear less consistent has been introduced by RPC procedures.

\section{Table VII}

Intercomparison of the RPC instrument with instruments calibrated at NBS or an $\mathrm{RCL}$, distinguishing the type of instrument $(1968-1980)$

\begin{tabular}{|c|c|c|c|c|}
\hline Instrument & $\begin{array}{l}\text { Number of } \\
\text { Intercom- } \\
\text { parisons }\end{array}$ & $\begin{array}{c}\text { Mean } \\
\text { RPC/Inst } \\
\end{array}$ & $\sigma^{(a)}$ & $\geq 3 \%$ (b) \\
\hline $\begin{array}{l}\text { Victoreen } \\
\mathrm{R} \text { Meters }\end{array}$ & 57 & 1.000 & 0.014 & 1 \\
\hline $\begin{array}{l}\text { Farmer-type } \\
\text { chambers }\end{array}$ & 56 & 1.000 & 0.009 & 0 \\
\hline Other & 10 & 1.016 & 0.033 & 1 \\
\hline
\end{tabular}

a) One standard deviation

b) Number of chambers whose factor differed from the RPC by more than $3 \%$ 
Properly maintained therapy field instruments appear to maintain their calibration factors over long periods of time. The time since instrument calibration does not seem to play a role in the reliability of the chamber calibration factor as seen in RPC intercomparisons in Table IX. These instruments were calibrated at NBS or an RCL and thus started with a calibration directly traceable to NBS.

Further data on long term stability of instruments comes from the MOA RCL. Table $X$ shows data on 5 chambers which have been calibrated by MDA RCL 3 times or more since 1976 . The checks indicate the year of initial calibration and the values are the ratio of the calibration factor determined in subsequent

Table VIII

Intercomparison of the RPC instrument with institution's instruments calibrated by various laboratories

\begin{tabular}{|c|c|c|c|}
\hline $\begin{array}{l}\text { Calibration } \\
\text { Source }\end{array}$ & $\begin{array}{l}\text { Number } \\
\quad \text { of } \\
\text { Intercom- } \\
\text { parisons }\end{array}$ & $\begin{array}{l}\text { Mean } \\
\text { RPC/ } \\
\text { Inst. } \quad \sigma^{(\mathrm{a})}\end{array}$ & $\begin{array}{l}\text { Number } \\
>3 \%\end{array}$ \\
\hline
\end{tabular}

Instruments calibrated before 1976

$\begin{array}{lllll}\text { NBS } & 29 & 1.001 & 0.017 & 1 \\ \text { RCL } & 35 & 1.003 & 0.020 & 1\end{array}$

Compared to

chamber cali-

brated at NBS

or $\mathrm{RCL}$

20

$1.005 \quad 0.013$

0

Chamber

manufacturer

44

$1.016 \quad 0.030$

13

other

25

$\begin{array}{lll}1.009 & 0.031 \quad 6\end{array}$

Instruments calibrated in 1976 or later

NBS

$9 \quad 1.000 \quad 0.009 \quad 0$

$\mathrm{RCL}$

40

0.999

0.011

Compared to chamber calibrated at NBS or $\mathrm{RCL}$

24

$0.998 \quad 0.018 \quad 1$

Chamber

Manufacturer

4

$\begin{array}{lll}1.017 & 0.053 \quad 1\end{array}$

Other

5

1.005

0.014

a) One standard deviation.

b) Number of instruments with calibration factor differing from the RPC by more than $3 \%$ calibrations relative to that determined in the original calibration. The maximum deviation seen in the calibrations was $0.3 \%$.

Forty-two other chambers were calibrated twice by MDA RCL since 1976. The time interval between calibrations varied from one to three years. The results are shown in Figure 2. The mean ratio between the new and original cali-

Table IX

Intercomparison of the RPC instrument with institution's instrument as a function of the time since instrument was calibrated at NBS or an RCL

\begin{tabular}{|c|c|c|c|c|}
\hline $\begin{array}{l}\text { Time since } \\
\text { cal ibration } \\
\text { (months) } \\
\end{array}$ & $\begin{array}{l}\text { Number of } \\
\text { Intercom- } \\
\text { parisons }\end{array}$ & $\begin{array}{c}\text { Mean } \\
\mathrm{RPC} / \text { inst. }\end{array}$ & $\sigma^{(a)}$ & $\begin{array}{l}\text { Number } \\
>3 \%\end{array}$ \\
\hline $0-12$ & 60 & 1.003 & 0.018 & 2 \\
\hline $13-24$ & 29 & 0.997 & 0.010 & 0 \\
\hline $25-36$ & 10 & 0.996 & 0.008 & 0 \\
\hline $37-48$ & 10 & 1.008 & 0.016 & 0 \\
\hline $49-60$ & 1 & 0.990 & & 0 \\
\hline$>60$ & 3 & 0.993 & 0.021 & 0 \\
\hline \multicolumn{5}{|c|}{ a) One standard deviation. } \\
\hline \multicolumn{5}{|c|}{$\begin{array}{l}\text { b) Number of instruments with calibration } \\
\text { factor differing from RPC by more than } 3 \% \text {. }\end{array}$} \\
\hline
\end{tabular}

Table $X$

Repeated Calibrations by MDA RCL (new calibration factor)/ (original calibration factor)

\begin{tabular}{|c|c|c|c|c|c|c|}
\hline \multicolumn{2}{|l|}{ Dosimeter } & 36 & 177 & 178 & 179 & $' 80$ \\
\hline \multicolumn{2}{|l|}{$K-F$} & $\checkmark$ & .999 & .999 & 999 & 1.000 \\
\hline \multicolumn{2}{|l|}{$\mathrm{K}-\mathrm{F}$} & $\sqrt{ }$ & & 1.000 & & 0.999 \\
\hline \multicolumn{2}{|l|}{ K-F } & $\checkmark$ & & 1.000 & & 1.002 \\
\hline \multicolumn{2}{|c|}{$F$} & & $\checkmark$ & & 0.999 & 1.002 \\
\hline \multicolumn{2}{|l|}{ Vict $R$} & $\checkmark$ & & 0.999 & & 1.000 \\
\hline$K-F$ & \multicolumn{6}{|c|}{$\begin{array}{l}\text { - Farmer } 0.6 \mathrm{cc} \text { graphite chamber with } \\
\text { Keithl ey model } 602 \text { or } 616 \text { electrometer }\end{array}$} \\
\hline $\mathrm{F}$ & \multicolumn{6}{|c|}{ - Farmer $0.6 \mathrm{cc}$ graphite chamber } \\
\hline \multicolumn{7}{|c|}{$\begin{array}{l}\text { Vict } R \text { - Victoreen model } 131 \text { chamber with } \\
\text { model } 570 \text { electrometer }\end{array}$} \\
\hline
\end{tabular}


bration factors was 1.002 with a standard deviation of $0.3 \%$. A maximum deviation of $0.7 \%$ was seen in three chambers. There was no difference between the results for Victoreen R-Meters and Farmer type instruments.

The MDA RCL data indicate that instruments are even more stable and reliable than indicated by the RPC data above. These differences stem from several factors including: the RPC data are from field intercomaprisons with field instruments, the institution may be using the instrument in a different manner from that employed by the calibrating laboratory, or the instrument may have been modified since calibration. Although the data indicate good long term stability, there are two $0.6 \mathrm{cc}$ Farmer chambers (with nylon thimbles), belonging to the authors, each of which have experienced unexplained changes in calibration of 1 to $2 \%$.

\section{Discussion of the Time Between Calibrations of Field Instruments}

If NBS and each RCL presently in operation were to calibrate 85 instruments per year, the 1057 instruments requiring calibration [1] could on the average be calibrated every 3.1 years. If another RCL was activated the average time between calibrations could be 2.5 years. However, there are a number of calibrations required following repair of instruments or purchase of new instruments. The fact that the average time between calibrations by an institution at the MDA RCL is 1.5 years suggests that some institutions or individuals may be overly conscientious in calibration of instruments while others allow longer periods of time between calibrations of their instruments.

From the instrument user's view, an instrument calibration is essential if he feels uncer-

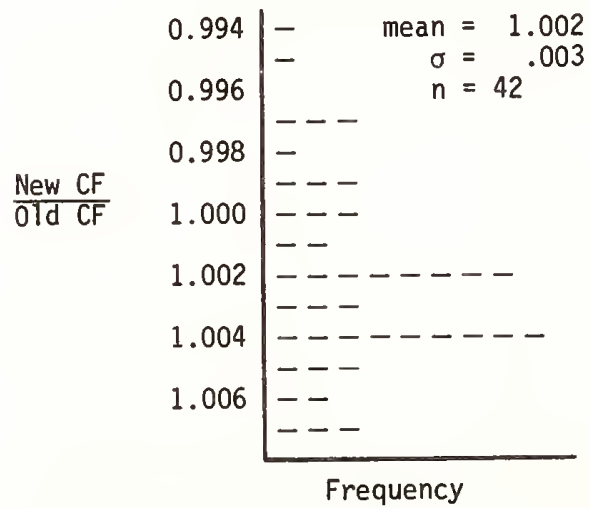

Figure 2: Histogram of the ratio of the calibration factor assigned by the MDA RCL on a subsequent calibration, relative to that assigned when the chamber had been previously calibrated by MDA RCL one to three years earlier. tain about his current calibration. However, if the user is confident of his instrument calibration, a recalibration according to a time schedule is usually not welcome, since there is risk to the instrument in transport and the absence of the instrument may be a serious inconvenience. In addition, the cost of calibration is sometimes a problem.

\section{Techniques Available to Assure Reliability of Assigned Calibration Factors}

Since therapy field instruments appear to maintain their calibration factors over extended periods of time, the instrument user can maintain confidence in his instrument calibration through periodic constancy checks. Grant, et al. [7] discuss the use of a cobalt-60 therapy unit or a strontium-90 constancy check source device to perform routine checks on the performance of the instrumept. Both techniques appear comparable. The ${ }^{5} \mathrm{Sr}$ data are reproduced in Figure 3 , showing all checks to be within $\pm 1 \%$ of the mean.

Another important constancy check proedure is an intercomparison with instruments from other institutions that have chambers calibrated by NBS or an RCL. Table XI shows the results of intercomparisons carried out in conjunction with meetings of Southwest, Midwest and Missouri Valley chapters of the AAPM $[8,9,10]$. These intercomaprisons uncovered erroneous factors on two chambers whose factors were from questionable sources, and verified suspected problems with two RCL calibrated chambers. Periodic intercomparisons of several chamber electrometer systems (1ast 5 lines of Table XI) again demonstrate the long term stability of these dosimetry system.

It is important to remember that any calibration laboratory can provide an erroneous calibration factor and that instruments may

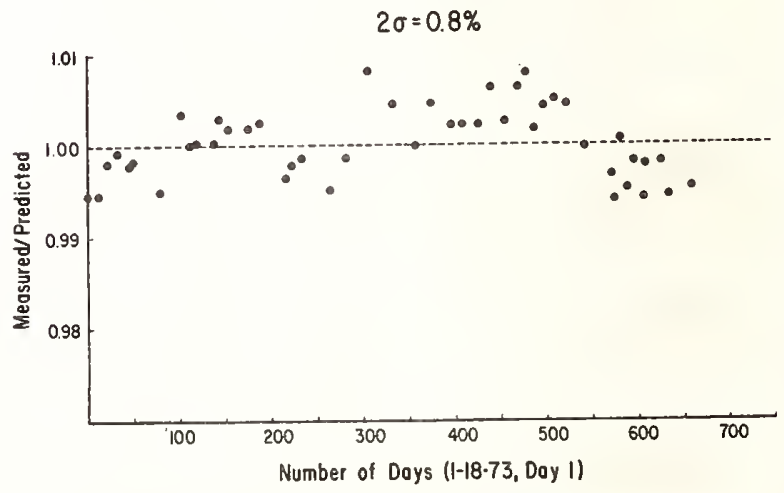

Figure 3: Constancy check of an RPC FarmerKeithley dosimetry system over a 21 month period using a $90_{\mathrm{Sr}}$ constancy check device. From Grant et al. [7]. 
undergo change during transport. A physicist should therefore challenge, in every way possible, any calibration factor obtained from NBS and an RCL. These challenges can include; comparing the new factor with the old factor, a constancy check on the instrument before and after calibration, and intercomparison with other instruments calibrated at NBS or an RCL.

\section{Conclusions and Recommendations}

The Regional Calibration Laboratories appear to be sucessfully filling an important need in the radiological community. The users of therapy field instruments who respond to

\section{Table XI}

Intercomparison of Chambers with

a Reference Chamber that had been Recently Calibrafed by NBS or an RCL (a)

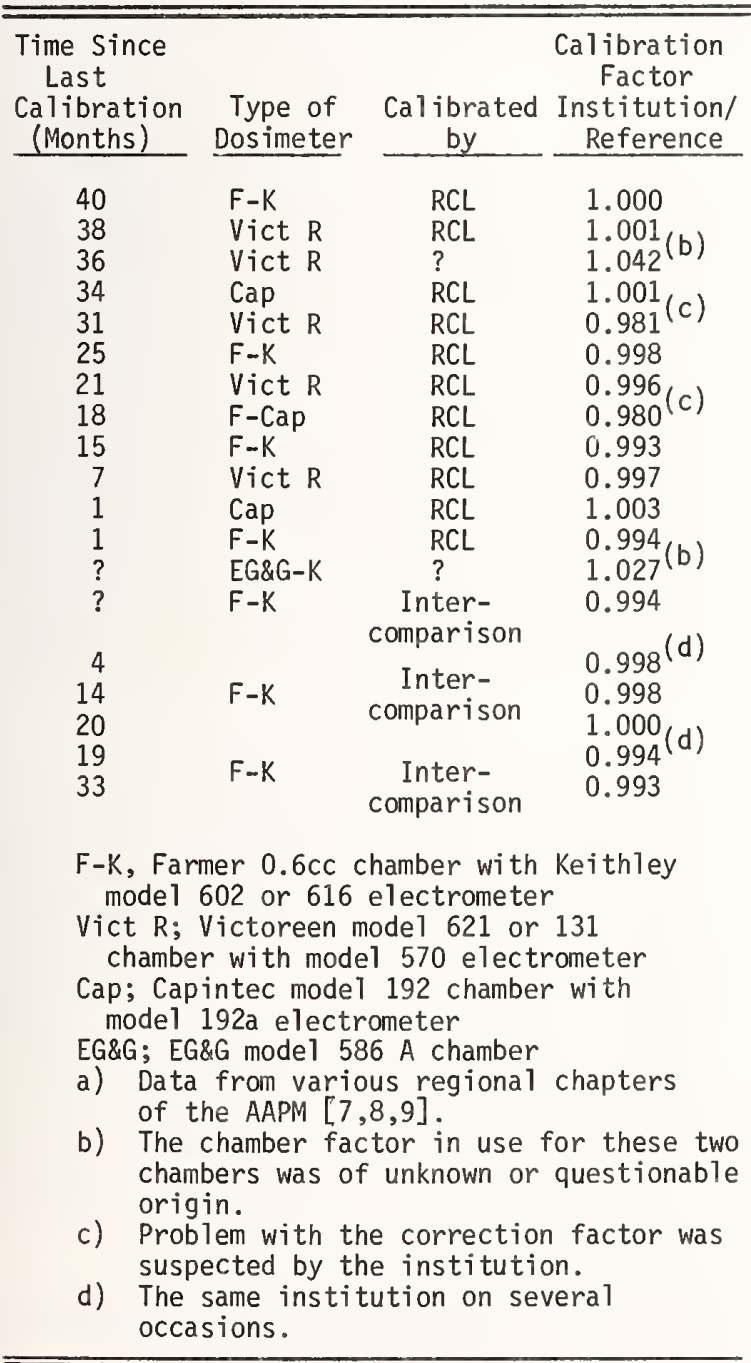

questionnaires and have their instruments calibrated regularly have calibrations at a mean interval of about 1.5 years. However, from an estimate of potential users and the current capacity of NBS and 3 RCLs it is suggested that only one calibration every three years would be possible for each user if a 11 of the instruments were calibrated at the same interval.

Data from various sources support the conclusion that commerical field instruments are capable of maintaining their calibrations for many years. It is suggested here that there be a reconsideration of the time interval between calibration required by federal or state policy. If a user who has a calibration factor directly traceable to NBS verifies the constancy of this instrument monthly by measurements on a cobalt-60 irradiator or strontium-90 constancy checker and if he verifies the instrument constancy at least every two years by an intercomparison with other instruments with calibrations directly traceable to NBS, it should be possible to space calibrations at NBS or an RCL to periods of 3 to 5 years. The user would always use the factor assigned by NBS or an RCL and employ the monthly constancy checks and biennial intercomparison checks as indications for recalibration of his instrument when consistent discrepancies of $2 \%$ are found in the checks. This suggestion seems warranted by the performance characteristics of the available instruments if coupled with reliable checks and adequate documentation.

\section{References}

[1] Lanzl, L. H. (Principal Investigator) Report of the Committee on Calibration Needs in Therapy of the American Association of Physicists in Medicine, Chicago, Illinois (1979).

[2] Rosenfeld, M. (Chaiman), Task Group \#3 of the American Association of Physicists in Medicine. It has been recommended that the regional laboratories be renamed, Accredited Dosimetry Calibration Laboratory $(A D C L)$, but the AAPM has not as yet approved the name change.

[3] McCarthy, W. A., Chairman of Subcommittee of Task Group \#3 of the American Association of Physicists in Medicine. Report in draft (private communication).

Scientific Committee on Radiation Dosimetry (SCRAD) of the American Association of Physicists in Medicine. "Protocol for the Dosimetry of $X$ - and Gamma Ray Beams with Maximum Energies between 0.6 and $50 \mathrm{MeV} . "$ Phys Med Biol 16 (1971): 379-396.

[5] Loevinger R., NBS, Private Communication.

[6] Federal Register 44, 5, 1722-1725, (Janaury 8,1975 ). 
[7] Grant III, W., Cundiff, J., Hanson, W., Gagnon, W., and Shalek, R., Calibration Instrumentation used by the AAPM Radiological Physics Center. Med Phys 3, p. 353-4, (1976).

[8] Southwest chapter of AAPM (Humphries, L. J.) unpublished data.

[9] Missouri Valley chapter of AAPM (Purdy J. A.I and Feldman, A.) unpublished data.

$[10]_{\text {Midwest chapter of AAPM (Hrejsa, A. F.) }}$ unpublished data.

This work supported in part by DHEW NCI grant CA 10953. 


\title{
NBS TRACEABILITY PROGRAMS FOR RADIATION THERAPY
}

\author{
Christopher G. Soares and Margarete Ehrlich \\ National Bureau of Standards \\ Washington, D.C. 20234
}

\begin{abstract}
Traceability of the calibration of radiation therapy machines to the national dosimetry standard may be verified by means of a measurement assurance program. Such a program often involves the use of rugged dosimetry systems for establishing a direct link between the user and the primary calibration laboratory without personal visits. In this paper, procedures common to this type of therapy dosimetry survey systems are discussed. Then, to illustrate these procedures, three of these systems are treated in detail: (1) the ferrous sulfate (Fricke) dosimetry system used at NBS in an ongoing survey of electron-therapy dosimetry, (2) a TLD system that was used by NBS in a one-time study of cobalt-60 teletherapy dosimetry, and (3) a second TLD system proposed for surveying megavoltage bremsstrahlung therapy dosimetry.
\end{abstract}

(Cobalt-60 gamma radiation; dosimetry; ferrous sulfate dosimetry; high-energy bremsstrahlung; high-energy electrons; measurement assurance; radiation therapy; survey; teletherapy; thermoluminescence dosimetry; traceability)

\section{Introduction}

Users of teletherapy equipment rely on a calibration chain for an assessment of the radiation output from their units. The steps in this chain involve calibration of a secondary standard instrument against a primary standard and then a measurement of the therapy beam output either with this secondary standard or with a tertiary instrument calibrated against the secondary standard. It is the aim of NBS measurement assurance programs to test this chain by a direct comparison between the primary standards laboratory and the user, with a suitable detector. Such a comparison may be carried out initially by means of shipped dosimetry systems sufficiently rugged and compact to withstand rough handling and variations in ambient conditions likely to be encountered during shipment. Subsequent follow-ups through personal contacts may be required.

A11 suryeys involving shipped dosimeters have certain features in common in their conception and execution. First, a survey objective must be stated, defining what is to be measured and to what accuracy. Then an administrative procedure for obtaining participants and reporting results must be set up. In developing the mechanism for the survey, an irradiation protocol must be decided upon and its feasibility tested. Along with this goes the selection of a suitable dosimeter. Handling and readout procedures for the dosimeter must be developed and tested, and some information about the accuracy of dose determination must be gathered. Once these preliminary steps have been completed, the survey can be performed.

In actual practice, each round of a typical survey (such as those described here) contains three distinct phases. They are (a) a dosimeter characterization phase, in which the relative response of all dosimeters is determined prior to shipment; (b) shipment in suitable irradiation holders of the dosimeters required by the survey participants, and calibration of the remaining dosimeters in the surveying facility; and (c) after return of the shipped dosimeters, readout of all dosimeters in one session and evaluation, from the dosimeter responses, of doses delivered by the participants. Each of these phases is discussed in greater detail below.

\section{(a) Dosimeter Characterization Phase}

Dosimeters may be characterized by their response to a known irradiation level. If, in a given batch, dosimeter identity is maintained, this response may be used to correct for variations in the response characteristics of individual dosimeters during the survey. This procedure may be referred to as individual dosimeter characterization. If, on the other hand, dosimeter identity is not maintained, the batch of dosimeters may be characterized by the mean and the standard deviation from the mean of the responses of the members of the batch. This procedure may be referred to as batch characterization. The way in which dosimeters are characterized determines overall uncertainty in dose interpretation. Batch characterization is sufficient when dosimeters have similar response characteristics. However, when the spread in response among the dosimeters within the batch is comparable to or larger than the reproducibility of the response of individual dosimeters in the batch, then the increased effort involved in maintaining dosimeter identity and using individual characterizations often pays off in increased accuracy. Examples are discussed in a later section. 
(b) Dosimeter Shipping and Calibration Phase

Participants are shipped dosimeters each consisting of a passive radiation measuring device in a holder of a material with atomic number close to water (and soft tissue). They are also given instructions for the irradiation of these dosimeters in their therapy beams. A portion of the characterized dosimeters remain in the surveying facility for calibration during the survey round. This calibration consists of delivering known absorbed doses to individual dosimeters in a geometry identical to that to be used by the participants. A sufficient number of different absorbed-dose levels are used to establish a calibration curve over the range of doses likely to be delivered by the participants. This calibration curve forms the basis for the dose interpretation from the response of the dosimeters irradiated by the participants.

\section{(c) Dosimeter Readout and Dose Evaluation Phase}

When dosimeters have been returned to the surveying facility, they are "read out" along with the dosimeters that remained for calibration (i.e., the radiation effect is measured). Readout of al1 dosimeters at the same time is important since it eliminates corrections for possible dayto-day variations in readout apparatus. Dose interpretations may then be made from dosimeter responses via the calibration curve, if necessary after appropriate corrections.

This completes a single survey round. If the survey consists of several rounds and the same dosimeters are to be used throughout, recharacterization of the dosimeters may be required between consecutive rounds.

To illustrate how these procedures work in practice, traceability surveys with three types of mailable dosimeters are discussed in the following sections. First, the NBS ferrous sulfate (Fricke) dosimetry service of megavoltage electron therapy dosimetry is discussed in detail Next, a one-time thermoluminescence dosimetry (TLD) traceability survey of cobalt-60 teletherapy dosimetry is discussed and finally, a second TLD system is described which has been tested for use in a proposed traceability survey of megavoltage bremsstrahlung dosimetry.

\section{Megavoltage-Electron Dosimetry Traceability}

The ferrous sulfate (Fricke) system is used in an ongoing NBS service to provide users with assistance with absorbed-dose measurements in high-energy electron beams. This is a fee service, performed twice a year. It is not meant to take the place of a beam calibration, but is only to provide information on uniformity of dose del ivery throughout the country.

\section{Procedure}

Megavoltage electron beam users contact NBS if they wish to receive dosimeters for the next survey round. Fresh dosimeter solution is pre- pared for each survey round and each dosimeter is characterized individually. The desired number of dosimeters is shipped to the participants along with a shipping control and the rest kept at NBS as in-house controls. Most dosimeters are returned within the next six weeks. All dosimeters are then read out together and dose interpretations are made. Results for all dosimeters shipped and irradiated by the participants in one round are reported to each participant, with only his own identified.

The sensitive volume of the dosimeter is $2.5 \mathrm{~cm}^{3}$ of Fricke solution. This is contained in a ground-glass stoppered quartz spectrophotometer cell, encased securely in a polystyrene block as shown in figure 1. The participants are instructed to insert this block into an appropriate cutout in a $30 \mathrm{~cm} \times 30 \mathrm{~cm} \times 30 \mathrm{~cm}$ polystyrene phantom as prescribed in the Protocol of the Therapy Committee of the American Association of Physicists in Medicine [1]. The center of the block is to be at the center of a $10 \mathrm{~cm} \times 10 \mathrm{~cm}$ field, at a depth in the phantom at or slightly beyond that corresponding to maximum depth dose. (The prescribed depth is $1 \mathrm{~cm}$ for electrons of energy between 5 and $10 \mathrm{MeV}, 1.5 \mathrm{~cm}$ for electrons between 10 and $25 \mathrm{MeV}$, and $3.5 \mathrm{~cm}$ for electrons between 25 and $50 \mathrm{MeV}$.) The participants are further instructed to deliver 50-80 Gy (5000$8000 \mathrm{rad})$ to water to all but one of the dosimeter blocks and then to return all blocks to NBS, along with their assessment of dose delivered. The change in ferric-ion concentration in the returned dosimeter solution is evaluated spectrophotometrically and related to absorbed dose. The report mailed to each participant includes a record of the G-value used in the dose interpretation.

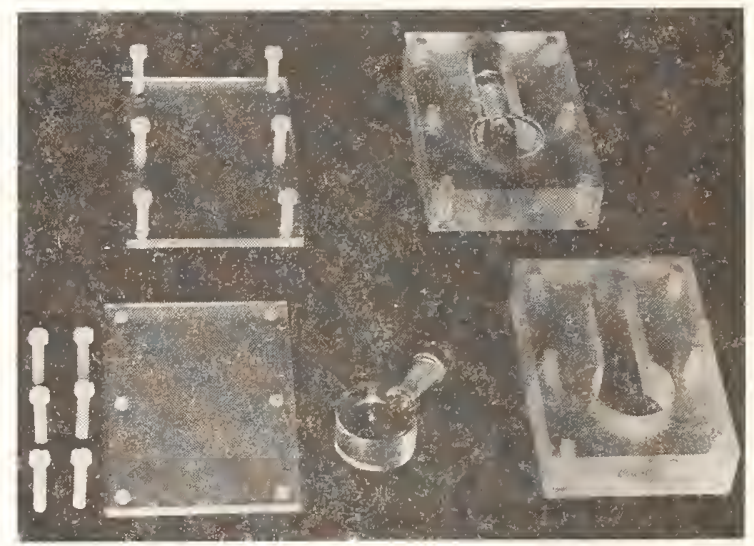

Figure 1 Ferrous Sulfate (Fricke) Dosimeter Assembly

\section{Principle of Fricke Dosimetry}

The radiation-chemical yield, or G-value (defined as the number of stable atoms or ions formed per $100 \mathrm{eV}$ of absorbed energy), is one of the quantities of fundamental importance in the use of the ferrous sulfate (Fricke) dosimeter. For the ferrous-ferric reaction initiated by irradiation, $\mathrm{G}\left(\mathrm{Fe}^{+++}\right)=100 \mathrm{n} / \mathrm{D}$, where $\mathrm{n}$ is the 
number of $\mathrm{Fe}^{+++}$ions formed in à unit mass and $D$ is the radiation energy in $\mathrm{eV}$ absorbed in the same unit mass. When expressed in terms of molar concentration $M$ (in moles per liter) and absorbed dose D (in grays), this becomes

$$
\mathrm{G}\left(\mathrm{Fe}^{+++} \mathrm{L}=0.9426 \times 10^{7} \frac{\mathrm{M}}{\mathrm{D}}\right.
$$

when the density of the Fricke solution is set equal to $1.024 \mathrm{~g} / \mathrm{cm}^{3}$. The raoiation chemistry of the Fricke system has been studied in detail and the G-yalue of the reactions leading to the oxidation of the ferrous ions has been determined over a relatively wide range of 1 inear energy transfers [2].

Since the change in ferric-ion concentration causes a marked change in the ultraviolet absorption spectrum of the Fricke solution, a chemical evaluation of this change may be replaced by a simple spectrophotometric measurement of the change in the absorption properties in the main absorption peak (304 $\mathrm{mm}$ ). Absorbance, A (which is the transmission density corrected for losses through scattering in the optics of the spectrophotometer), is related to the molar concentration, $M$, by Beer's law

$$
A=\varepsilon M d
$$

where $d$ is the optical path length, and $\varepsilon$ the molar extinction coefficient.

$$
\begin{aligned}
& \text { Combining equations (1) and (2) yields } \\
& D=0.9426 \times 10^{7} \frac{\Delta A}{\Delta \varepsilon G\left(\mathrm{Fe}^{+++}\right) \mathrm{d}}
\end{aligned}
$$

where $\triangle A$ is the change in absorbance before and after irradiation to an absorbed dose $D$ and $\Delta \varepsilon=\varepsilon\left(\mathrm{Fe}^{+++}\right)-\varepsilon\left(\mathrm{Fe}^{++}\right)$. When the measurement is made at the conventional wavelength of $304 \mathrm{~nm}, \varepsilon\left(\mathrm{Fe}^{++}\right) \simeq 0$ and, as a consequence, $\Delta \varepsilon \simeq \varepsilon\left(\mathrm{Fe}^{\mathrm{f++}}\right)$.

Rather than to rely on the theoretical value for the molar extinction coefficient, it is good practice to measure this coefficient for one's own spectrophotometer, using $\mathrm{Fe}^{+++}$solutions of * a number of different known molar concentrations. Temperature control during optical density measurements is important since the extinction coefficient has a temperature dependence of w0.7 percent per ${ }^{\circ} \mathrm{C}[3]$.

\section{Dosimeter Preparation}

The Fricke solution used at NBS consists of

$$
\begin{aligned}
& 0.001 \mathrm{M} \mathrm{Fe}\left(\mathrm{NH}_{4}\right)_{2}\left(\mathrm{SO}_{4}\right)_{2} \text {, dissolved in } \\
& 0.8 \mathrm{~N} \mathrm{H}_{2} \mathrm{SO}_{4} \text {, well aerated, and } \\
& 0.001 \mathrm{~N} \mathrm{NaCl}^{\text {. }}
\end{aligned}
$$

\footnotetext{
*Having recently replaced our spectrophotometer with a new model, we made this measurement in our new instrument and obtained a value of $2188 \mathrm{M}^{-1} \mathrm{~cm}^{-1}$ at $25.0^{\circ} \mathrm{C}$, which agrees well with the theoretical value of $2197 \mathrm{M}^{-1} \mathrm{~cm}^{-1}$.
}

The $\mathrm{NaCl}$ is added to desensitize the system against organic impurities. Because the addition of $\mathrm{NaCl}$ causes an increase in the rate dependence of the G-value, we recommend that the participants do not exceed instantaneous dose rates of $10^{3} \mathrm{~Gy} / \mathrm{s}$. Irradiation of this solution produces free radicals and molecular products which cause oxidation of $\mathrm{Fe}^{++}$to $\mathrm{Fe}^{+++}$. Spontaneous oxidation also occurs at room temperature even in the absence of organic impurities. This must be taken into account when there are delays of more than two or three days between the initial dosimeter readout during the characterization phase and the final dosimeter readout, as is usually the case in a mailed suryey.

Cleanliness of glassware used in preparing and storing the solution is of great importance. organic contaminants cause massive spontaneous oxidation of stored solution rendering it useless for dosimetry. At NBS the spectrophotometer cells were initially cleaned with detergent in an ultrasonic cleaner and since then have been kept filled with Fricke solution. Other glassware was initially cleaned with hot concentrated sulfuric acid and since then has been kept filled with either Fricke solution or distilled water. No plastics are ever allowed in contact with the Fricke solution.

The purity of the water used both in cleaning and making the Fricke solution is crucial to the performance of the system, freedom from organic impurities being one of the main requirements. Satisfactory water has been obtained at NBS by permanganate distillation [4]. Over the years, NBS has also had a number of satisfactory commercial sources for water.

\section{Dosimeter Characterization}

The cleaned and filled cells are all irradiated with cobalt-60 gamma radiation to a level of $\sim 50$ Gy to water and read out spectrophotometricaliy. These readings characterize each individual dosimeter in the batch and furnish the base line from which changes in optical density due to irradiation are measured, as well as the base line from which corrections for the spontaneous growth of optical density are determined. The procedure also identifies dosimeters with anomalous characteristics, which then are eliminated from further use; it also provides for a rough check on the G-value of the particular Fricke batch for cobalt-60 gamma radiation, calculated from the average of the optical densities of the irradiated cells and a knowledge of the dose delivered. No further calibration is performed.

\section{Dosimeter Evaluation}

The returned dosimeters are read out together and the change in optical density is determined for each dosimeter. Correction of the readings of the irradiated dosimeters for spontaneous density growth is made by subtracting the average density growth of all unirradiated control dosimeters (shipped and unshipped). Since growth varies somewhat with individual dosimeters, this procedure adds an additional uncertainty to the 
dose interpretations, which in our procedure amounts to about 1 percent. Finally, the dose delivered to the dosimeters is determined from the corrected change in optical density by eq (3) using the molar extinction coefficient measured for the spectrophotometer employed, and publ ished G-values.*

\section{Uncertainty}

We estimate that the total uncertainty in dose interpretation in the NBS survey procedure is about 4 percent. We fee] that this uncertainty could be reduced by using a sealed Fricke dosimetry system instead of the present open system. We are presently attempting to adapt such a system to our program.

\section{Results}

Overall performance of the participants did not improve noticeably between 1967, when the service was initiated, and 1975. Table 1 shows that, through 1975, only 58 percent of the dose interpretations were within 5 percent of the dose assigned by participants. In the last four years, this fraction is seen to have risen to 73 percent. This improvement has been accompanied by a large increase in the number of dosimeters shipped, which indicates an increased awareness in the radiation-therapy community of the importance of accurate dosimetry.

Table 1

Perfomance Results of All Participants in Electron Beam Dosimetry Uniformity Study

\begin{tabular}{ccccc} 
Calendar Year & $\begin{array}{c}\text { Number of } \\
\text { Oosimeters }\end{array}$ & $|\Delta| \leqslant 5 \%$ & $\begin{array}{c}\text { Number of Dosimeters with } \\
\text { Difference } \Delta \text { of }\end{array}$ \\
\hline 1967 & 50 & $33(66 \%)$ & $14(28 \%)$ & $3(\Delta) \leqslant 10 \%$ \\
1968 & 81 & $39(48 \%)$ & $24(30 \%)$ & $18(22 \%)$ \\
1969 & 55 & $25(45 \%)$ & $16(29 \%)$ & $14(25 \%)$ \\
1970 & 61 & $34(56 \%)$ & $12(20 \%)$ & $15(25 \%)$ \\
1971 & 58 & $30(52 \%)$ & $13(22 \%)$ & $15(26 \%)$ \\
1972 & 47 & $35(74 \%)$ & $5(11 \%)$ & $7(15 \%)$ \\
1973 & 60 & $38(63 \%)$ & $9(15 \%)$ & $13(22 \%)$ \\
1974 & 49 & $38(78 \%)$ & $6(12 \%)$ & $5(10 \%)$ \\
1975 & 74 & $38(51 \%)$ & $24(32 \%)$ & $12(16 \%)$ \\
1976 & 99 & $76(77 \%)$ & $19(19 \%)$ & $4(4 \%)$ \\
1977 & 109 & $77(71 \%)$ & $21(19 \%)$ & $11(10 \%)$ \\
1978 & 142 & $107(75 \%)$ & $25(18 \%)$ & $10(7 \%)$ \\
1979 & 148 & $103(70 \%)$ & $29(20 \%)$ & $16(11 \%)$
\end{tabular}

\section{Cobalt-60 Teletherapy Dosimetry Traceability}

The major objective of the cobalt-60 teletherapy survey was to assess the ability of users to deliver a requested absorbed dose. This was accomplished-by a survey of teletherapy dosimetry, conducted by the National Bureau of Standards (NBS), supported in part by the Bureau of Radiological Health (BRH). Similar studies have been (and are being) performed, elsewhere [5-8].

\footnotetext{
"Presently, we are using a G-value of 15.5/100 ev for both cobalt-60 gamma and high-energy electron irradiations.
}

Names and addresses of licensees were supplied to NBS by BRH, and each licensee was sent an invitation to participate free of charge. If there was no response, a single follow-up invitation was sent. In this way, over 700 or about two-thirds of all licensed users agreed to participate in the survey.

Because of limited facilities, NBS could only survey about 40 participants at a time, which made dosimeter re-use mandatory. Dosimeters were shipped every six weeks, being kept at NBS for readout and re-characterization only one week between mailings. Also shipped with the dosimeters was a three-page information form, which asked for calibration details of the unit surveyed and for steps in the calculation of the dose to be delivered. This information was used by NBS to check the participants' dose calculations. The results of this check as well as the dose interpretations from the response of the irradiated dosimeters were sent to participants in a report covering all dosimeters involved in each mailing. A11 results were kept confidential; the participant to whom the report was sent had only his own dosimeters identified. Results and information from returned forms, which were given to $\mathrm{BRH}$ without participant identification, formed the data base for a later BRH statistical study [9].

Each participant was sent six dosimeter blocks. Five were to be irradiated in separate exposures, the sixth was to be left unirradiated as a control. The participants were to place one block at a time on the shipping container and position the center of the block at their normal treatment distance, with a $10 \mathrm{~cm} \times 10 \mathrm{~cm}$ field size. They were to calculate the time necessary to deliver 3 Gy to water at this distance, at a depth of $1 \mathrm{~cm}$ in a water phantom, and then to irradiate the block in air for the calculated time. Setups and irradiations were to be performed by persons routinely involved in patient irradiations.

\section{Choice of Dosimeters}

Several considerations went into the choice of the type of dosimeter for use in this survey. The necessity for dosimeter re-use with minimal re-calibration, the limited manpower available for performing the work at NBS, and the need to restrict overall uncertainty in dose interpretation to less than 5 percent, all pointed towards the use of thermoluminescence dosimetry (TLD) for the survey. $\mathrm{CaF}_{2}:$ Mn was chosen as the $\mathrm{TL}$ phosphor because of the relatively small dependence of its response on annealing and irradiation history. Also, because all irradiations were to be performed with cobalt-60 gamma rays, one could ignore the energy dependence of its response which is large compared with that of other commonly used but otherwise less desirable phosphors (such as $\mathrm{LiF}$ and $\mathrm{Li}_{2} \mathrm{~B}_{4} \mathrm{O}_{7}$ ). Normal handling difficulties involved in TLD work were overcome by obtaining the TLD phosphor in a commercially available configuration in which two pieces of hot-pressed $\mathrm{CaF}_{2}: \mathrm{Mn}$, held in contact with a metallic heating strip, are sealed in a glass bulb 
containing a neutral atmosphere. Each dosimeter consisted of the commercial TLD bulb enclosed in a black polystyrene block. The block protected the bulb during shipment and participant handling, shielded it from ultraviolet radiation, and provided electron equilibrium during cobalt-60 gamma irradiation. An exploded view of the dosimeter is shown in figure 2.

The TLD readout system consisted of a commercial unit in which the metallic strip of the TLD bulb was heated resistively, and the resulting thermoluminescence emission was collected by a cooled photomultiplier tube (PMT). The current signal from the PMT was fed to a current integrator, which was gated by a timer to allow cutoff of integration after readout was complete, but prior to emission of the thermal signal generated during subsequent annealing. On completion of the readout, the integrated signal was punched on paper tape for off-line analysis.
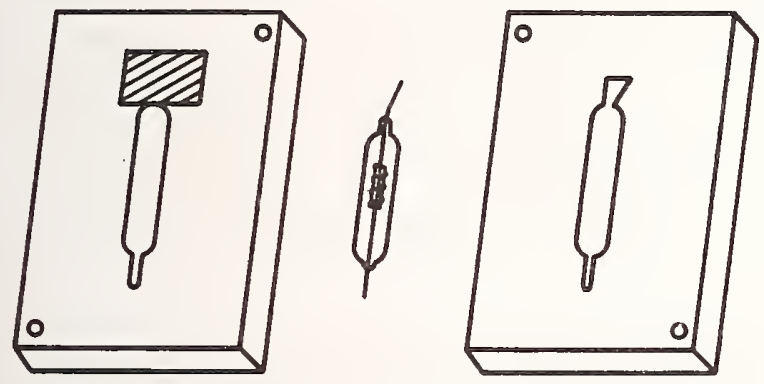

Figure 2 Schematic Diagram of Bulb Dosimeter Assembly

Principle

The crystal lattice of some solids--in particular those containing certain impurity centers--are capable of storing radiation energy and, upon subsequent heating, releasing it in the form of light or ultraviolet radiation. This phenomenon is referred to as thermoluminescence (TL). In many phosphors, TL output increases monotonically--and over a limited range essentially linearily--with the amount of radiation energy stored, prior to the onset of saturation effects. This is one of the major prerequisites for the application of $T L$ in radiation dosimetry. Intensive research and development over the past decades has led to a number of TLD phosphors suited for the practical dosimetry of electrons, photons, and neutrons over a wide range of radiation energies and irradiation levels, a subject that has been extensively treated in the literature [10].

Repeated use of most TL phosphors requires some form of heat treatment (annealing) after readout, particularly at dose levels above a few hundredths of one gray. Insufficient annealing causes accumulation of unwanted residual response in subsequent readouts. This is a problem particularly when a low dose is used in the laboratory to characterize the dosimeter response and then a high dose is delivered in the field. For this survey, in which $\mathrm{CaF}_{2}: \mathrm{Mn}$ was used up to dose levels of about $3.0 \mathrm{~Gy}$, it was found to be sufficient to anneal the TLD bulbs in the reader for a few seconds after readout. The temperatures developed during this procedure were found to reduce residuals sufficiently to necessitate only minor corrections (discussed below).

\section{Characterization}

Dosimeter identity was maintained throughout the entire survey, permitting the characterization of the response of each individual TLD bulb. Initially, a base-line characterization was obtained in terms of the average response of each bulb to identical reference irradiations ( $3-5 \mathrm{R})$ and subsequent readouts. This also yielded the information on the reproducibility of the TLD system required for an estimate of the uncertainty in the dose interpretation from the response to irradiations by the participants. Since some residual response had been found to be present after irradiation at the 3.0-Gy level and subsequent readout with annealing, all bulbs were read out twice after each mailing (the second readout five days after the first) to establish the level of the residual response. This procedure was followed by two further sets of identical reference irradiations and readouts. The average relative response of the bulbs to these irradiations, suitably adjusted for residual response, was used as a correction in the computation of the dose interpretations from the response of each of the dosimeters irradiated in the preceding survey round. Throughout the survey, a record was kept of any change in the bulb characterization from the initial base line.

\section{Mailing and Calibration}

A11 but about 40 of the 300 bulb dosimeters were mailed to participants for irradiation. The remainder were used at NBS for establishing the current response-versus-dose relationship, and to monitor fading characteristics of the batch.

Initially, the calibration was done at several levels around $3.0 \mathrm{~Gy}$, and a second order polynomial was fitted to the individually corrected responses. Dose interpretations were then made via this curve. In later rounds of the survey, calibration was done only at the 3.0-Gy level, since in the narrow range in which most of the bulbs were irradiated (within $\pm 10 \%$ of $3.0 \mathrm{~Gy}$ ), response was proportional to dose.

In order to be able to correct for fading between irradiation and readout, dosimeters also were irradiated at a known level at several different times during each survey round, and read out with the other dosimeters at the end of the round. Also, a record was kept of the participants' irradiation dates. With a knowledge of these dates and of response as a function of fading time, we were able to correct the dose interpretations for fading. The fading function reproduced well over the entire survey, with typical corrections for four weeks of fading having been of the order of 5 percent. 
After readout, corrections were applied for variations in individual response and for fading of the response between irradiation and readout. Because of changes in PMT response during the two to three hours required for readout of the 300 dosimeter bulbs (probably caused by insufficient PMT cooling), a further correction, amounting to up to 2 percent, was necessary.

Dose interpretations were made from the corrected readings via the results of the similarly corrected calibration data (response-versus-NBS delivered dose relationship). Establishing a new calibration for each survey round made it possible to eliminate the influence of reader variations and changes in dosimeter response.

\section{Uncertainty}

Sources of uncertainty in the dose interpretation are shown in table 2. The systematic uncertainties shown are estimated upper bounds. The random uncertainties are taken as three times the relative standard deviation of the mean of dosimeter readings after repeated irradiations and readouts. This table is discussed in detail in the comprehensive report on this survey published elsewhere [11]. We feel that the quoted overall uncertainty of 4 percent is probably conservatively high.

\section{Table 2}

Uncertainties in NBS Method of Determining Absorbed Dose from Dosimeter Response

\begin{abstract}
Systematic Uncertainty
NBS exposure calibration of $\mathrm{C}_{0}-60$ gamma-ray source . . . . . D.7\%

Uncertainty in dosimeter calibration ........... . . . . . . . . .

Uncertainty in dosimeter fading correction . . . . . . 1.0\%

Total (surmed linearly) ........... $2.4 \%^{*}$

Total (summed in quadrature) ......... 1...
\end{abstract}

Random Uncertainty

Reproducibility of individual dosimeter response ... 2.4\%

Correction for sensitivity variation between dosimeters $2.4 \%$

Total for corrected individual dosimeter response $3.4 \%$

Total for average corrected response of five

dosimeters (summed in quadrature) ...... 1.5\%

Total uncertainty in dose interpretation from average of

five dosimeters (sumured linearly) ........... $4.0 \%^{\star}$

(sunmed in quadrature) ......... 2...

* Chosen for NBS evaluation

\section{Results}

The overall results of the survey are shown in figure 3. Plotted are percent differences between individual dose interpretations and the dose to be delivered (3.0 Gy). Eighty-three percent of the dose interpretations were within

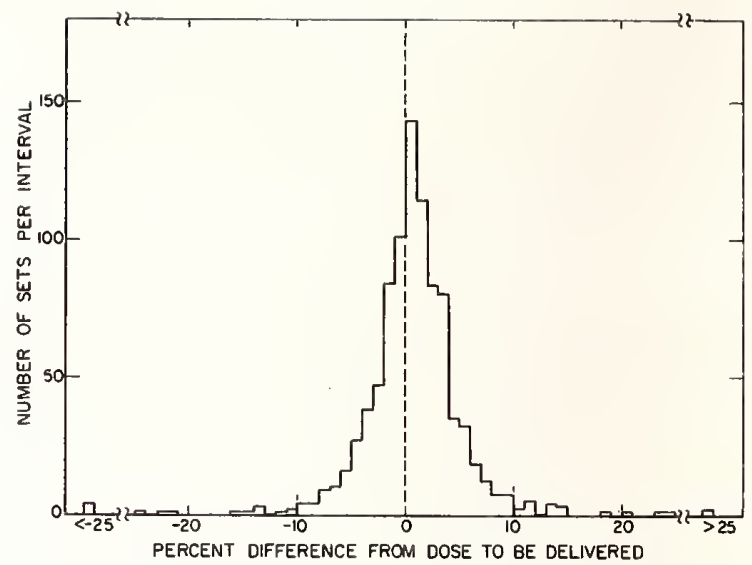

Figure 3 Performance of Participants Involved in the Cobalt-60 Teletherapy Survey. Shown is the difference, in percent, between the dose to be delivered by the participants and the NBS dose interpretation from the average of the responses of the five irradiated dosimeters. Total number of participants: 812 ; total number of sets: 906.

5 percent of the requested dose, with only 4 percent differing by more than 10 percent. From the figure it is apparent that there is a positive bias in the data, the average deviation for all dosimeters shown being +0.7 percent. This could be significant, and has been explained by the fact that most participants used the conversion factor from exposure to absorbed dose to soft tissue $(0.957)$ rather than that to water $(0.965)$, which was used in the NBS dosimeter calibrations.

\section{Follow-up}

Two follow-up studies were performed as statistical checks on the results of the initial study. The first of these studies involved resurveying a random sample (about one-fifth) of the original participants. The second involved a survey of a random sample (about one-tenth) of the initial non-participants. The results of these follow-up studies, while of limited statistical validity, tended to confirm the results of the initial study.

\section{Preparations for a Survey of High-Energy Bremsstrah7ung Therapy Dosimetry}

There has long been interest in extending the survey of therapy dosimetry to include megavoltage bremsstrahiung. Because of the much wider variation in spectral quality of these bremsstrahlung sources as compared to cobalt-60 gamma-ray sources, energy dependence of the dosimeter response becomes an important consideration. Therefore it was feit that a different system than that used in the cobalt-60 teletherapydosimetry survey would have to be developed. 
Procedure, Choice of Dosimeters and Irradiation Protocol

This study will be carried out by BRH. While the administrative procedure for this survey has yet to be worked out by $\mathrm{BRH}$, an irradiation protocol has been developed and its feasibility tested by NBS at some length [12]. At this time, it is envisioned that participants will be sent a cubic polymethyl methacrylate (PMMA) phantom with sides $20 \mathrm{~cm}$ in 1ength, loaded at several depths with hot-pressed LiF samples. The participants will be asked to deliver a certain dose $(1.0 \mathrm{~Gy})$ to water at a 10- cm depth, treating the phantom for dose calculation as if it were water. This procedure will provide information on accuracy of dose delivery and may also yield some information obtained with the aid of TLD response at the different depths.

The response of Lif has a relatively low energy dependence; this makes LiF desirable for a suryey involving wide spectral variations. Advances in reader technology have overcome difficulties once encountered with this phosphor, such as spurious readings. For use in the medical dose range (> $0.1 \mathrm{~Gy})$, furnace annealing was required with the chosen reader. We investigated this system using the conventional annealing cycle of one hour at $400^{\circ} \mathrm{C}$, cooling for one-half hour, followed by one hour at $100^{\circ} \mathrm{C}$. In addition, all samples were given a post-irradiation anneal at $100^{\circ} \mathrm{C}$ for 10 minutes prior to readout. They were never exposed to direct sunlight or other sources of illumination containing a large ultraviolet component. A vacuum pickup was used for all sample manipulations. For readout, an automated reader was employed, in which the samples are heated by hot nitrogen and which allows the readout of 50 samples in rapid sequence. The readout signals were fed directly into a microcomputer system for storage and later retrieval for off-line analys is.

Several investigations were carried out to assess the feasibility of such a system using the protocol described. Fading under laboratory conditions was found to be almost negligible, with only about 2 percent being evident over a period of three weeks. Also investigated was the influence of phantom dimensions upon dosimeter response at the depth of interest. Several phantom sizes and shapes from $15 \mathrm{~cm}^{3}$ to 20 $\mathrm{cm}^{3}$ were investigated, and no significant effect was measured. The influence on the response of samples at a $10-\mathrm{cm}$ depth in the presence of samples located on the axis above and below this depth was investigated as a function of phantom size and beam energy. The results of these investigations are shown in table 3. Response of dosimeters at a depth of $10 \mathrm{~cm}$ in the presence or absence of dosimeters at other depths is compared. There is a trend towards slightly reduced responses in the presence of other dosimeters, however its significance is questionable. In view of these results it was concluded that it was feasible to irradiate dosimeters at more than one depth simultaneously.

BRH plans to have the first phase of the survey include sources of up to $10 \mathrm{MeV}$ in photon energy. We therefore made measurements of the response of LiF as a function of absorbed dose with bremsstrahlung produced at exciting potentials of 4,6 , and 10 MV as well as with cobalt-60 gamma radiation. Dose-versus-response data from this determination are shown in figure 4. The samples show the same degree of supralinearity, regardless of energy. Of particular interest is a comparison of response for dif-

Table 3. Influence on Dosimeter Response of the Presence of Dosimeters in 0ther Depths

\begin{tabular}{|c|c|c|c|c|c|c|}
\hline \multirow[t]{2}{*}{$\begin{array}{c}\text { TYPE } \\
\text { OF } \\
\text { RADIATION }\end{array}$} & Cube, $15 \mathrm{~cm}$ side & $\begin{array}{l}\text { AVERAGE OOSIMET } \\
\text { with dosimeters at }\end{array}$ & $\begin{array}{l}\text { ER RESPONSE FOR DO } \\
\text { Cube, } 20 \mathrm{~cm} \text { sides }\end{array}$ & $\begin{array}{l}\text { SIMETERS AT A } 10-\mathrm{cm} \\
\text { with dosimeters at }\end{array}$ & $\begin{array}{l}\text { DEPTH IN } \\
\text { Parallelepiped, } \\
\text { is cm } x 15 \mathrm{~cm} \text { x } \\
\text { with dosimeters }\end{array}$ & $20 \mathrm{~cm}$ deep \\
\hline & $10-\mathrm{cm}$ depth only & $\begin{array}{l}2.5-, 5-\text { and } 10-\mathrm{cm} \\
\text { depths }\end{array}$ & $\mid 0-\mathrm{cm}$ depth only| & $\begin{array}{l}2.5-, 5-, 10-\text { and } \\
15-\mathrm{cm} \text { depths }\end{array}$ & $\begin{array}{l}\text { 10-cm depth } \\
\text { only }\end{array}$ & $\begin{array}{l}2.5-, 5-, 10- \\
\text { and i5-cm } \\
\text { depths }\end{array}$ \\
\hline $\begin{array}{l}\text { Cobalt-60 } \\
\text { gamra rad. }\end{array}$ & $0.581 \pm 0.002$ & $0.578 \pm 0.006$ & $0.589 \pm 0.003$ & $0.588 \pm 0.004$ & - & \\
\hline 4 kiv bremsstr. & $\longrightarrow$ & - & $0.607 \pm 0.003$ & $0.601 \pm 0.004$ & & \\
\hline 6 MV bremsstr. & - & $\longrightarrow$ & $0.552 \pm 0.003$ & $0.552 \pm 0.003$ & 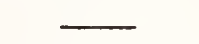 & \\
\hline 10 MV bremsstr. & $0.681 \pm 0.003$ & $0.680 \simeq 0.004$ & $0.685 \pm 0.009$ & $0.683 \pm 0.005$ & $0.683 \pm 0.004$ & $0.685 \pm 0.003$ \\
\hline
\end{tabular}




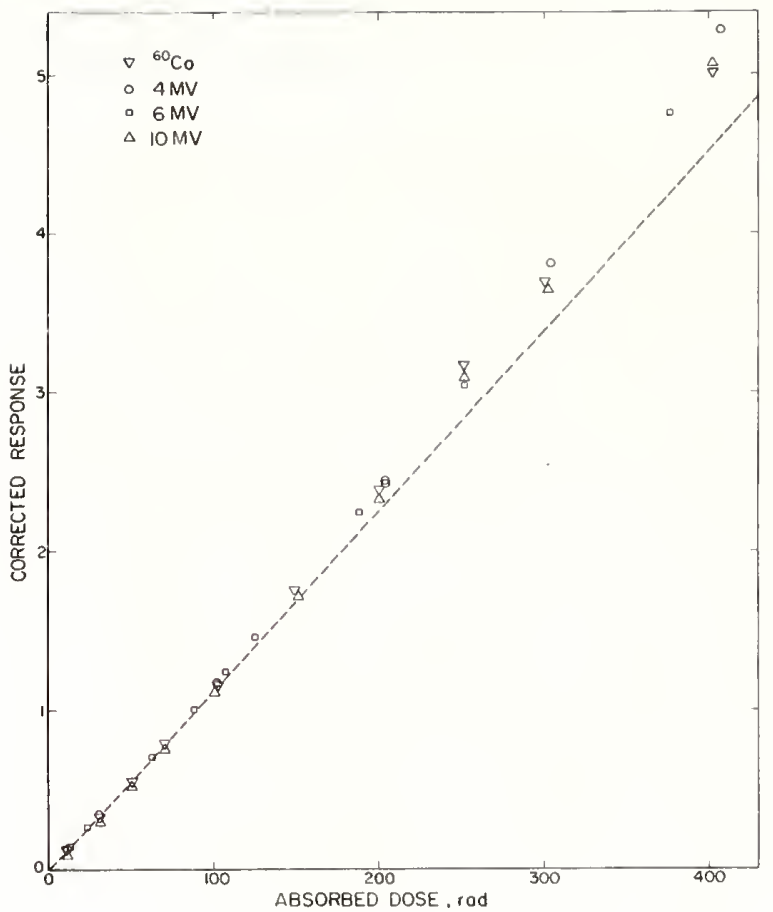

Figure 4 LiF Response in PMMA as a Function of Absorbed Dose. Dashed 1 ine - 1inear relationship between response and $a b-$ sorbed dose.

ferent beam energies at one particular dose level. The level used was $1 \mathrm{~Gy}$, chosen because higher levels induce residual TL signal which is difficult to remove with conventional annealing techniques. Table 4 shows measured values of the ratio of responses to 1 Gy irradiations of high-energy bremsstrahlung and cobalt-60 gamma radiation. As is seen from the table, the ratio is unity within the uncertainty of the determination. Therefore, no correction for beam energy (at least up to $10 \mathrm{MeV}$ ) will be required in the survey. In addition, it will be possible to perform calibrations during the mailing round with cobalt-60 gamma rays, without any further corrections.

Finally, exposures were made to assess the feasibility of measuring depth-dose profiles using the planned irradiation geometry. Results of these measurements are shown in figure 5 . Data were normalized to those at the $10-\mathrm{cm}$ depth, and are seen to be adequate--at least in

Table 4

Ratio of Dosimeter Response in PMILA to Megavoltage Bremsstrahiung and Dosimeter Response in PMMA to Cobalt-60 Gamma Rays, for 1 Gy Absorbed Dose to Water

\section{Radiation Source}

Varian $\mathrm{Clinac}-4$

Siemens Mevatron VI

Varian Clinac-18

Siemens Mevatron XII

\section{Nominal Peak Energy}

$4 \mathrm{MeV}$

$6 \mathrm{MeV}$

$10 \mathrm{MeV}$

$10 \mathrm{MeV}$
Ratio

0.991

1.001

0.979

1.000 principle--for distinguishing between the energies employed.

\section{Expected Uncertainty}

The number of dosimeters to be included per measurement point greatly influences the overall uncertainty in dose interpretation. Of importance also is whether the dosimeters are calibrated individually or as a batch. We have determined that associated with the response of individually calibrated dosimeters is a standard deviation of about 1 percent, as compared with a practical lower limit of 1.5 percent associated with batch-calibrated dosimeters. Since the survey will be performed by BRH personnel using large numbers of dosimeters, batch calibration probably will be used. In this case, nine dosimeters per measurement point lead to a combined random and systematic uncertainty of about 4 percent in dose interpretation [12]. Individual calibration would lower this value by about 1 percent.

\section{Plans for Extension of Current Programs}

Our future plans in therapy dosimetry traceability include extensions of the proposed high-energy survey to bremsst,rahlung energies up to $50 \mathrm{MeV}$. This will involve further phantomsize and energy-dependence studies.

We are presently involyed in preliminary work on devising a TLD system for use in a highenergy electron dosimetry survey. As a first step, we are trying to determine whether a system similar to that employed for the highenergy bremsstrahlung survey would be satisfactory or whether charge-up effects will make it necessary to switch from a plastic to a water phantom.

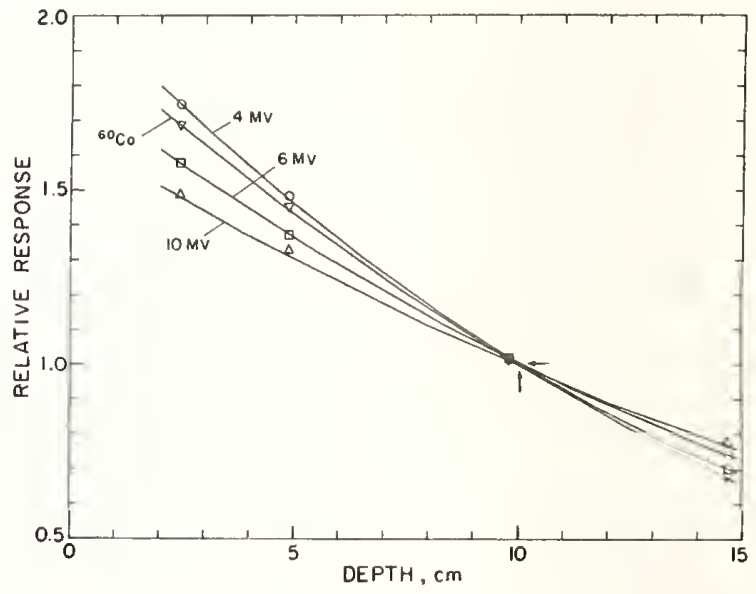

Figure 5 Absorbed Dose to Water as a Function of Depth in the PMMA Phantom, Computed from Dosimeter Response. The absorbed dose data were normalized to those obtained at a depth of $10 \mathrm{~cm}$ in PMMA (arrows). 
[1] The Subcommittee on Radiation Dosimetry of the AAPM (SCRAD), "Protocol for the Dosimetry of High Energy Electrons", Physics in Medicine and Biology 11, 505 (1966).

[2] See e.g., Fricke, H., and Hart, E.J., "Chemical Dosimetry" in Radiation Dosimetry, Vol. II, Attix, F.H., Roesch, W.C., editors, Academic Press, New York (1966) or SCRAD Protocol (ref. 1) or "Radiation Dosimetry: Electrons with Initial Energies Between 1 and $50 \mathrm{MeV} "$, I.C.R.U. Report 21, International Commission on Radiation Units and Measurements, Washington, D.C. (1972).

[3] Scharf, K., and Lee, R.M., "Investigations of the Spectrophotometric Method of Measuring the Ferric Ion Yield in the Ferrous Sulfate Dosimeter", Radiation Research 16, 115 (1962).

[4] Chesler, S.N., Gump, B.H., Hertz, H.S., et al., "Trace Hydrocarbon Analysis", p. 49, Appendix A, NBS 889 , U.S. Department of Commerce, National Bureau of Standards (1976).

[5] Shalek, R.J., Kennedy, P., et al., "Quality Assurance for Measurements in Therapy", Proceedings of the Symposium on Measurements for the Safe Use of Radiation, NBS SP 456, 111-118, U.S. Department of Commerce, National Bureau of Standards (1976).

[6] Sundara Rao, I.S., Naik, S.B., et al., "Evaluation of Dosimetry Accuracy and Uniformity for ${ }^{60} \mathrm{Co}$ Radiation Therapy", Proceedings of the International Symposium on National and International Standardization of Radiation Dosimetry, Atlanta, Ga. (1977).
[7] Eisenlohr, H.H., and Jayaraman, J., "IAEA-WHO Cobalt-60 Teletherapy Dosimetry Service Using Marked Dosimeters. A Survey of Results Obtained during 1970-75", Phys. Med. Biol. 22, 18-28 (1977).

[8] Dicey, B.B., Moe, H.J., and Tongue, T.M., "Nationwide Evaluation of ${ }^{60} \mathrm{Co}$ Teletherapy Calibrations", Medical Physics $\underline{5}, 434$ (1978).

[9] Thompson, D., Kearly, F., Wyckoff, H., and Gitlin, J., "Nationwide Survey of ${ }^{\circ} \mathrm{Co}$ Teletherapy: Final Report", to be published as a Bureau of Radiological Health Technical Report.

[10] See, e.g., Fowler, J.F., and Attix, F.H., "Solid State Integrating Dosimeters", in Radiation Dosimetry, Vol. II, Attix, F.H., Roesch, W.C., editors, Academic Press, New York (1966).

[11] Soares, C.G., and Ehrlich, M., "Nationwide Survey of Cobalt-60 Teletherapy Dosimetry", NBS TN 978, U.S. Department of Commerce, National Bureau of Standards (1978).

[12] Ehrlich, M., and Soares, C.G., "A Thermoluminescence Dosimetry System for Use in a Survey of High-Energy Bremsstrahlung Dosimetry", NBS TN 1119, U.S. Department of Commerce, National Bureau of Standards (1980). 

TRACEABILITY PROGRAMS FOR NUCLEAR MEDICINE

\author{
D. B. Golas \\ Atomic Industrial Forum, Inc. \\ Washington, D.C. 20014 \\ and \\ National Bureau of Standards \\ Washingt on, D.C. 20234
}

\begin{abstract}
The National Bureau of Standards (NBS) supervises and administers two measurements assurance programs: one on behalf of the Atomic Industrial Forum (AIF), representing several manufacturers of radiopharmaceuticals; and the other with the College of American Pathologists (CAP), representing hospitals and final users of radiopharmaceuticals. Each program is described and the results of measurements of samples of known, but undisclosed, activity are presented.
\end{abstract}

(Assurance; measurements; radioactivity; radiopharmaceutical; standards; traceability)

\section{Introduction}

The National Bureau of Standards (NBS) currently supervises and administers two programs for measurements assurance in the field of nuclear medicine. The research-associate program of the Atomic Industrial Forum (AIF) involves several of the major bulk suppliers of radiochemicals and producers of radiopharmaceuticals; the College of American Pathologists (CAP) quality assurance "Q" program involves the hospitals and nuclear pharmacies which comprise the users of radiopharmaceuticals. Together, these two programs encompass the radiopharmaceutical spectrum from manufacture to use. The programs are a help in satisfying the increasing regulatory requirements to demonstrate traceability to NBS, through the distribution of samples

(Standard Reference Materials) of known, but undisclosed, activity ("blinds") which are measured by the participants. The comparison of the participant's measured activity to that certified by NBS is a measure of the competence of the participant to quantify an unknown amount of radioactive material accurately. In the case of the AIF researchassociate program, a Report of Measurement is then issued which states the difference between the participant's reported value and the NBS certified value, thereby establishing traceability to within that limit, for that particular radionuclide, at that time. In the CAP program, a Report of Calibration giving the NBS certified activity value is sent to each participant upon return of their results, and when all values are in, a report is issued which gives the results for the entire group of participants. If a participant has a problem measuring the unknown, the activity value is usually given by telephone, in advance of sending a certificate, so that the participant can make use of the NBS reference material to derive a calibration factor for his dose calibrator or other measuring system.

The AIF-NBS research-associate program is of great value to the manufacturers of radiopharmaceuticals because it helps to minimize measurement uncertainty and demonstrate traceability to NBS.
This in turn reduces some of the problems they have in satisfying application requirements when filing New Drug Applications with the Food and Drug Administration (FDA), as well as saving time and paperwork when complying with requirements of the Nuclear Regulatory Commission (NRC) and other Federal and State agencies. Participation in the program also helps the participants when questions arise between the companies and their customers. For example, when the quantity of radioactive material measured by the customer does not agree with that of the supplier, the supplier often uses results of measurement tests to defend its value.

The CAP " $Q$ " program is valuable to the users of radiopharmaceuticals because it enables them to determine if the calibration of their dose calibrator or other measuring system is correct for each radionuclide that they receive. In addition they can obtain help if they have problems in the measurement of these radioactive materials. The CAP program is limited, however, by the number of participants who receive the samples for measurement. This will become more apparent later, when this program is described in detail.

\section{AIF-NBS Standards Program for the Radio- Pharmaceutical Industry}

The AIF-NBS radioactivity measurements-assurance program evolved in response to a number of problems facing the commercial suppliers of radionuclides. In 1973, Seidel and Brant ley [1] described some of these problems: lack of standard reference materials for about 75 percent of the more than 100 radionuclides commercially produced at that time, the sometimes inconvenient physical form, and the insufficient activity levels of some of the standards that were available. Another reason, important economically, was that one company's activity differed from that of another due to the use of different decay-scheme parameters. After several pilot distributions begun in 1972, and at the request of two AIF committees, 
namely the Committee on Radioisotope Production and Distribution and the Committee on Radiopharmaceuticals, the Atomic Industrial Forum entered into an agreement with the National Bureau of Standards in November 1974. The agreement established a research-associate program to help satisfy the needs of the radiopharmaceutical industry and solve the problems described above. Past and present industry participants are listed in Table 1 . Concurrently, the FDA is provided with similar services through an interagency agreement.

\section{TABLE I}

PARTICIPANTS IN THE AIF-NBS STANDARDS PROGRAM FOR THE RADIOPHARMACEUTICAL INDUSTRY

Food and Drug Administration

Bureau of Drugs

Division of Drug Chemistry

Washington, D. C.

Atomic Industrial Forum Participants

Atomic Energy of Canada, Ltd. Ottawa, Canada

General Electric Companya Pleasanton, California

Mallinckrodt Nuclear St. Louis, Missouri

Medi-Physics, Inc. Emeryville, California

New England Nuclear North Billerica, Massachusetts

E. R. Squibb \& Sons, Inc. New Brunswick, New Jersey

Union Carbide Corporation Tuxedo, New York

Amersham/Searle Corporation b Arlington Heights, Illinois

acurrently a partial member

bparticipation terminated November 1975

The major objectives of the AIF-NBS researchassociate program are to: 1) provide a monthly distribution of both high-level (multi-millicurie) and low-level (multi-microcurie) Standard Reference Materials (SRMs); 2) provide current decay-scheme data through the Evaluated Nuclear Structure Data File at the Oak Ridge National Laboratory; and 3) assist participants with any difficulties or problems in the measurement of these SRMs.

The SRMs consist of approximately 5 milliliters of solution in standard NBS borosilicateglass ampoules, except for xenon-133 which is distributed as an uncompressed gas in a pyrex ampoule having a volume of approximately $5 \mathrm{milli-}$ liters. The activity ranges are from 1 to 300 millicuries for the high levels and from approximately 50 microcuries to 5 millicuries for the low levels depending on the radionuclide and its half Tife. A steering committee composed of one representative from each participating company and NBS, and the AIF-NBS research associate selects the radionuclides to be distributed each year. Several radionuclides currently more important in nuclear medicine, such as molybdenum-99, technetium-99m, jodine-125, iodine-131, and xenon-133 are distributed yearly and others of lesser importance are supplied every other year. Table 2 1 ist those radionuclides which have been issued by NBS through Apri] 1980.

\section{TABLE 2}

\begin{tabular}{|c|c|}
\hline \multicolumn{2}{|c|}{$\begin{array}{c}\text { STANDARD REFERENCE MATERIALS PREPARED FOR } \\
\text { THE AIF-NBS STANDARDS PROGRAM } \\
\text { FOR THE RADIOPHARMACEUTICAL INDUSTRY } \\
\text { FROM APRIL } 1975 \text { TO APRIL } 1980\end{array}$} \\
\hline SRM NO. & RADIONUCLIDE \\
\hline $4400-C^{*}$ & ${ }^{51} \mathrm{Cr}$ \\
\hline $4401-F$ & $131 \mathrm{I}$ \\
\hline $4402-B$ & ${ }^{113} \mathrm{Sn}-113^{\mathrm{m}} \mathrm{In}$ \\
\hline 4403-B & ${ }^{85} \mathrm{Sr}$ \\
\hline 4404-C & $201 \mathrm{Tl}$ \\
\hline 4405-B & ${ }^{198} \mathrm{Au}$ \\
\hline 4406-D & $32 \mathrm{p}$ \\
\hline 4407-E & $125 \mathrm{I}$ \\
\hline 4408-B & ${ }^{57} \mathrm{Co}$ \\
\hline $4409-C$ & ${ }^{75} \mathrm{Se}$ \\
\hline $4410-E$ & 99m Tc \\
\hline $4411-B$ & ${ }^{59} \mathrm{Fe}$ \\
\hline 4412-E & $99 \mathrm{Mo}$ \\
\hline 4413 & $197 \mathrm{Hg}$ \\
\hline 4414-B & $123 I$ \\
\hline 4415-D & ${ }^{133} \mathrm{Xe}$ \\
\hline 4416 & ${ }^{67} \mathrm{Ga}$ \\
\hline 4417 & $111 \mathrm{In}$ \\
\hline 4418 & $203 \mathrm{Hg}$ \\
\hline 4419 & $169 \mathrm{Yb}$ \\
\hline 4420 & $203 \mathrm{~Pb}$ \\
\hline 4421 & ${ }^{195 \mathrm{Au}}$ \\
\hline 4422 & ${ }^{36} \mathrm{Cl}$ \\
\hline
\end{tabular}

*The letter after the SRM number indicates the number of times the radionuclide has been distributed since the beginning of the program. ( $B$ means it has been distributed twice; $C$, three times; etc.) 
The SRMs are usually dispatched as "knowns" the first time, and as "blinds" subsequently. A questionnaire is included with each blind in order to check the measuring procedures used by each participant. If the reported activity value is great ly different from the NBS value, it is often possible to ascertain where an error occurred or what caused the discrepancy, by examining the questionnaire. As previousiy stated, the "blinds" are used to demonstrate traceability to NBS within stated limits prescribed by the U.S. Pharmacopeia. Although the particpants have the option of not receiving the SRMs as blind sources if they do not produce or market the particular assessment. Participants have usually submitted a radionuclide that they have had difficulty measuring in the past; one whose activity value has been claimed to be incorrect by a customer or another producer; or one that they market but which has not been distributed by NBS for some time.

Figure 1 shows how the participants" reported values compared with the NBS-measured activity values for both the high-level and low-level samples distributed since the beginning of the program. Twenty-eight of the 429 values used in the histogram are beyond the 10-percent

FIGURE 1

AIF High and Low Lovel Roculte for Rounds I Through XLIV All Values Reported As Of $4 / 23180$

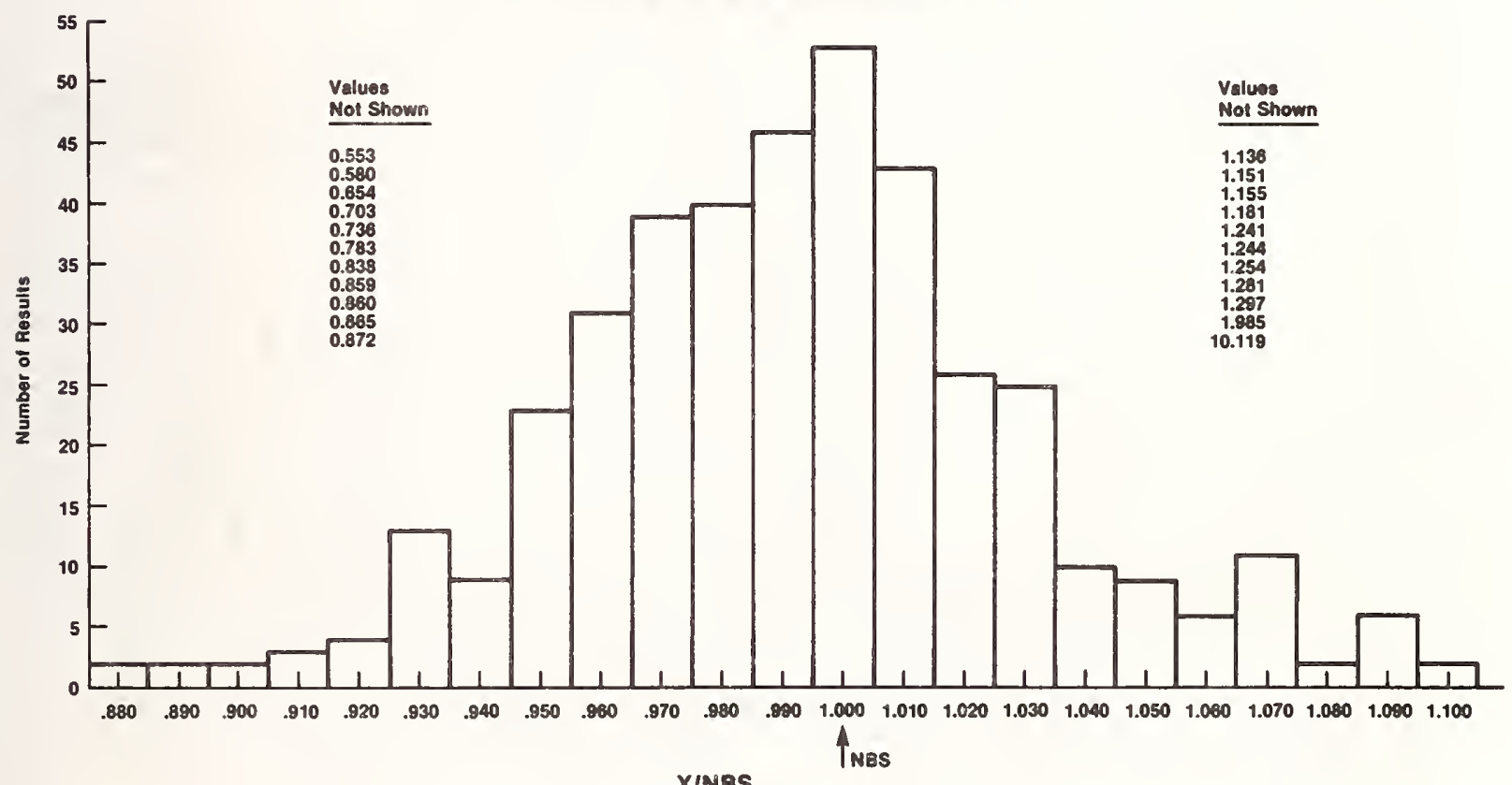

XINBS

radionuclide, many companies elect to receive them as blinds to test their instrument response or measuring procedures. The first radionuclide distributed as a part of this program was chromium-51 issued in Apri1 1975. A different SRM has been distributed almost every month since then, usually as a blind. The results of the blind distributions, with the exception of those from the FDA and Amersham/Searle Corporation, are summarized in Tables 3,4 , and 5 and in Figures 1 , 2 , and 3 . The results are not given in the same order as the listing of companies in Table 1.

Beginning in 1979, two distributions per year were replaced by two "open" months to allow participants greater flexibility in their choice as to what radionuclide they would like to measure. During the open months, each participant submits a calibrated sample of their choice giving the activity, solution composition, and impurity limit ( 5 percent for iodine-125) imposed by the U.S. Pharmacopeia for radiopharmaceuticals. This is 6.5 percent of the values, a higher percentage than would be expected if the differences were strictly random; however, the trend has been toward a reduction in the number of outliers. For example: in 1975 and 1976, there were 6 values outside the 10-percent limits; in 1977, there were 7 ; in 1978, 5; in 1979, 4; so far in 1980, none. Some of these outliers occurred when the participants asked for the SRMs as blinds during the first distribution of that particular radionuclide, so that the values reported were not based on any previous NBS standard. The negatively skewed distribution indicates that there is a bias in the results and that the participants tend to measure less activity in the SRM than is certified by NBS. This bias can be seen even more clearly in Figure 2 , where the average results are presented chronologically. 
In Figure 2 the results are averages presented for the group of AIF participants as a whole, for each radionuclide distributed each month. Except in a few cases, the results are lower than the NBS certified value; one or two large outliers which are not representative of the group as a whole are usually responsible for results greater than those of NBS. For example, the difference between the high-level and low-level results for tin-113-indium-113m (SRM 4402B) is caused by one low-level outlier which was almost 100 percent greater than the NBS value. Figure 2 shows that there is little difference between the results for the high-level and the low-level blinds; this tends to indicate that the differences are due to calibration errors or source-preparation techniques rather than to problems in making dilutions.

Figure 3 is similar to Figure 2 except that the direction of the deviation from the NBS value is eliminated by taking the absolute value of the difference before averaging the participants' values. The results show that the average absolute deviation from the NBS value has not noticeably improved with time, and is generally within five percent. Table 4 shows, however, that there are

FIGURE 2

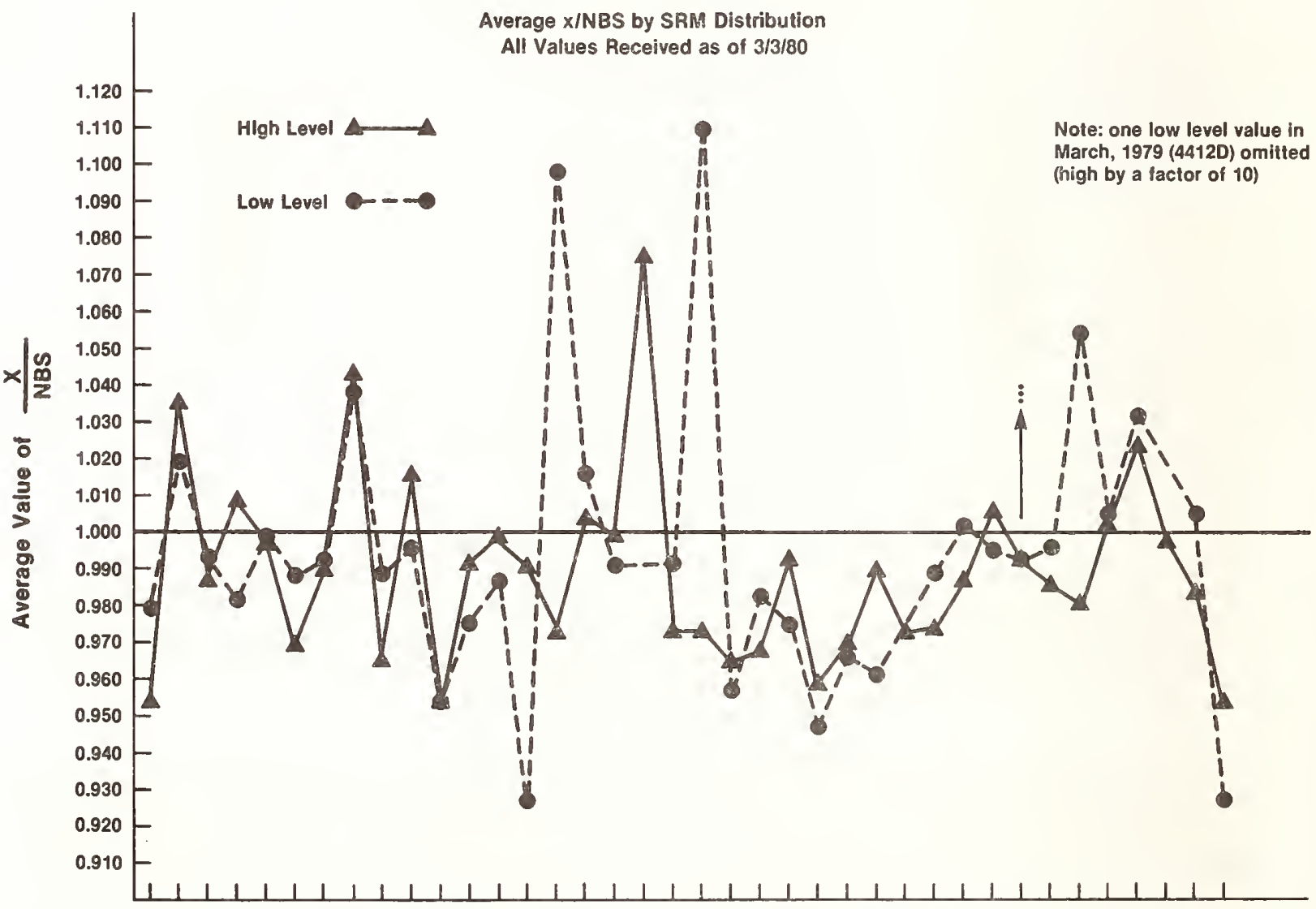

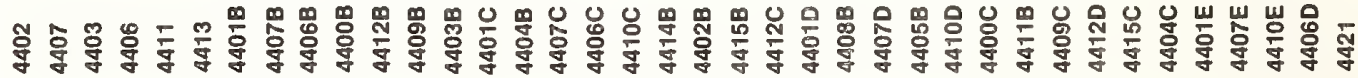

SRM Number 


\section{FIGURE 3}

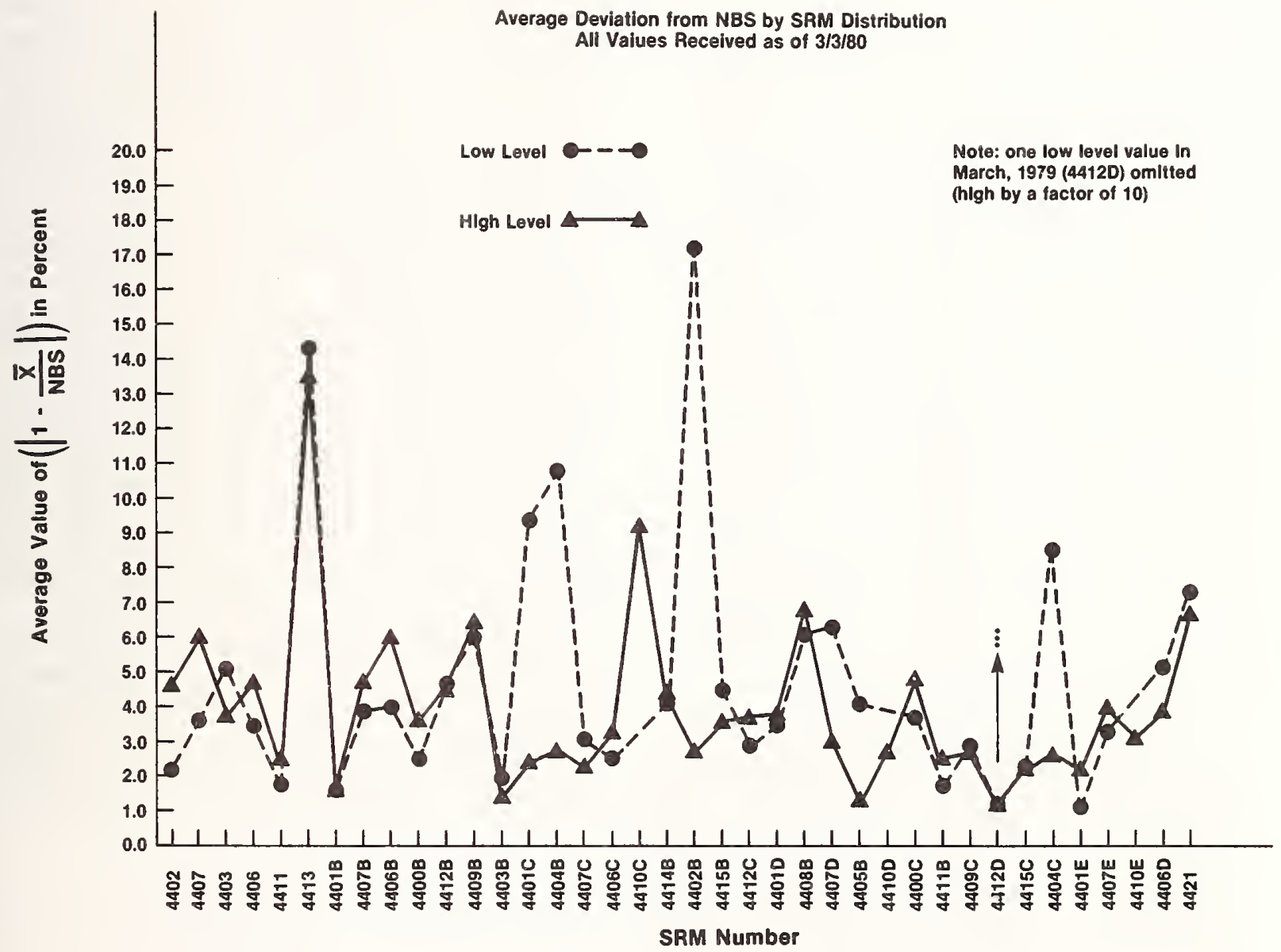


cases where the results have improved with time. The sharp peaks in certain areas of Figure 3 are again usually caused by one or two large outliers and are not representative of the group as a whole. Figure 3 shows that the participants usually do slightiy better with the high-level blinds.

This could be due to the fact that the high-level blinds are closer to the usual activity levels measured by inost participants. Table 3 illustrates this trend more clearly.

TABLE 3

\begin{tabular}{|c|c|c|}
\hline \multicolumn{3}{|c|}{$\begin{array}{c}\text { AVERAGE DEVIATION FROM NBS VALUE } \\
\text { FOR ROUNDS I THROUGH XLI } \\
\text { (Results received as of February 28, 1980) }\end{array}$} \\
\hline PARTICIPANT & HIGH LEVEL & LOW LEVEL \\
\hline ALL & $\begin{array}{l}3.892 \% \\
(215)^{\star}\end{array}$ & $\begin{array}{l}4.616 \% \\
(191)\end{array}$ \\
\hline A & $\begin{array}{l}3.58 \% \\
(48)\end{array}$ & $\begin{array}{l}2.81 \% \\
(41)\end{array}$ \\
\hline B & $\begin{array}{l}3.34 \% \\
(19)\end{array}$ & $\begin{array}{l}3.79 \% \\
(17)\end{array}$ \\
\hline C & $\begin{array}{l}7.45 \% \\
(43)\end{array}$ & $\begin{array}{l}6.20 \% \\
(40)\end{array}$ \\
\hline$D$ & $\begin{array}{l}2.91 \% \\
(32)\end{array}$ & $\begin{array}{l}3.96 \% \\
(32)\end{array}$ \\
\hline$E$ & $\begin{array}{l}2.36 \% \\
(37)\end{array}$ & $\begin{array}{l}2.53 \% \\
(34)\end{array}$ \\
\hline $\mathrm{F}$ & $\begin{array}{l}1.68 \% \\
(19)\end{array}$ & $\begin{array}{l}1.66 \% \\
(16)\end{array}$ \\
\hline G & $\begin{array}{l}4.06 \% \\
(17)\end{array}$ & $\begin{array}{c}19.52 \% \\
(11)\end{array}$ \\
\hline${ }^{\star}$ Number of & s in aver & \\
\hline
\end{tabular}

The overall deviation for the participants is approximately 4 percent for the high-level blinds and 4.6 percent for the low-level blinds. The results for individual participants listed by letter in Table 3 show that some participants do a better job than others. The order of the participants in this table is not the same as that in Table 1. The high value for the low-level results of participant $G$ is due to one or two outliers, and to the small number of results reported to NBS by the participant. However, these numbers do not show that the participant's performance has improved with time, and that the average is still largely affected by some earlier bad results. Currently, more time is being expended to find and suggest changes in each participant's measuring procedure that could give better results. In most cases, however, suggestions would not be implemented unless the cost or time spent in making the measurement is similar to that presently being used. Substantial changes in the amount of training required by the personnel making the measurements would also hinder any changes from taking place.
Tables 4 and 5 give the ratios of each participant's value to that of NBS for individual radionuclides and show how they have changed with repeated distributions. Only molybdenum-99 and iodine-131 are tabulated as examples. When more than one value is shown for a particular company for a single distribution, it indicates that the participant reported the activity measured in two different ways.

The values in Table 4 show that there has been some improvement with time for molybdenum-99, and the deviation has leveled off in the past two years so that it is less than 1.5 percent different from the NBS value for the group as a whole. There is no guarantee however that the results in subsequent years will remain as good. The ratios for iodine-131 in Table 5 illustrate this; the average for the first year is better than those for the next two years. From this, one could conclude that any new improvement would have to be the result of a change in the method or technique used to perform the measurements. For example, most of the participants determine the activity by counting sources which are made from a dilution of the solution in the ampoule. The dilutions in most cases are made by volume using pipets which are quite often uncalibrated. Improvements could be made by calibrating the pipets using solutions which are the same density as the solutions in the SRMs, by applying volume corrections for changes in temperature and pressure, or better yet, by making the dilutions by mass. Most participants, however, cannot justify the changes that NBS would suggest, because some of these improvements might take more time than the methods currently employed. If they are already within the requirements imposed by the regulatory agencies, there is no economic incentive to improve. This is one reason why it is un likely that there will be any significant change in the future unless the regulatory agencies demand an improvement. Secondly, companies that have employees who belong to certain unions must see that the radiation exposure is divided equally among the personnel performing the measurements. This results in many different people making the measurements, which means that relatively simple procedures must be used. This must not be interpreted, however, to mean that only a minimum of training is necessary. Unfortunately, training is frequent $7 y$ inadequate. 
TABLE 4

AIF-NBS STANDARDS PROGRAM FOR THE RADIOPHARMACEUTICAL INDUSTRY INDIVIDUAL RESULTS FOR MOL YBDENUM-99

PARTICIPANTS' REPORTED ACTIVITY VALUES/NBS ACTIVITY VALUE $(X / N B S)$

\begin{tabular}{|c|c|c|c|c|c|}
\hline $\begin{array}{l}\text { PARTICIPATING } \\
\text { COMPANY }\end{array}$ & $\begin{array}{l}\text { SRM } \\
\text { DATE }\end{array}$ & $\begin{array}{r}4412 B \\
2 / 77 \\
\end{array}$ & $\begin{array}{r}4412 C \\
4 / 78 \\
\end{array}$ & $\begin{array}{r}4412 D \\
3 / 79 \\
\end{array}$ & $\begin{array}{r}4412 \mathrm{E} \\
3 / 80 \\
\end{array}$ \\
\hline A & $\frac{H^{b}}{L}$ & $\frac{0.9355,0.9394}{0.9260,0.9600}$ & $\frac{0.8651,0.9262}{0.9354,0.9833}$ & $\frac{0.9924}{0.9932}$ & $\frac{0.9730}{0.9934}$ \\
\hline B & $\frac{H}{L}$ & $\frac{0.9946}{0.9885}$ & $\frac{1.0109}{0.9981}$ & $\frac{1.0016}{0.9976}$ & $\frac{1.0256}{0.9984}$ \\
\hline c & $\frac{H}{L}$ & $\frac{0.9485}{0.9591}$ & $\frac{0.9825,0.9528}{0.9673,0.9540}$ & $\frac{0.9894}{0.9872}$ & $\frac{0.9690}{0.9845}$ \\
\hline D & $\frac{H}{L}$ & $\frac{0.9448}{0.9541}$ & $\frac{0.9947}{0.9927}$ & $\frac{1.0128}{1.0138}$ & $\frac{0.9930}{1.0126}$ \\
\hline E & $\frac{H}{L}$ & $\frac{0.9609}{0.9592}$ & $\frac{1.0081}{--}$ & $\frac{0.9593}{0.9716}$ & $\frac{1.0061}{1.0090}$ \\
\hline$F$ & $\frac{H}{L}$ & $\frac{0.9297}{0.9061}$ & $\frac{0.9838}{1.0471}$ & $\frac{0.9986}{10.119}$ & $\frac{0.9805}{--}$ \\
\hline G & $\frac{H}{L}$ & $\frac{0.9877}{0.9970}$ & $\frac{0.9842}{0.9862}$ & $\frac{1.0039}{0.9927}$ & $\frac{1.0008}{0.9874}$ \\
\hline \multicolumn{2}{|l|}{ Average $\mathrm{X} / \mathrm{NBS}$} & 0.9557 & 0.9748 & $0.9934^{c}$ & 0.9949 \\
\hline \multicolumn{2}{|c|}{$\begin{array}{l}\text { Average absolute deviation } \\
\text { from NBS }\end{array}$} & $4.43 \%$ & $3.29 \%$ & $1.15 \% \mathrm{c}$ & $1.35 \%$ \\
\hline
\end{tabular}

a. The order of the participants does not correspond to that in Table 1.

The FDA and Amersham/Searle are not represented in this tabulation.

b. $\quad H=$ High Level. $L=$ Low Level.

c. 10.119 out Tier not included. 
TABLE 5

AIF-NBS STANDARDS PROGRAM FOR THE RADIOPHARMACEUTICAL INDUSTRY INDIVIDUAL RESULTS FOR IODINE-131 PARTICIPANTS' REPORTED ACTIVITY VALUES/NBS ACTIVITY VALUE
(X/NBS)

\begin{tabular}{|c|c|c|c|c|c|}
\hline $\begin{array}{l}\text { PARTICIPATING } \\
\text { COMPANYa }\end{array}$ & $\begin{array}{l}\text { SRM } \\
\text { DATE }\end{array}$ & $\begin{array}{r}4401 \mathrm{~B} \\
5 / 76 \\
\end{array}$ & $\begin{array}{r}4401 \mathrm{C} \\
5 / 77 \\
\end{array}$ & $\begin{array}{r}4401 D \\
5 / 78 \\
\end{array}$ & $\begin{array}{r}4401 \mathrm{E} \\
7 / 79 \\
\end{array}$ \\
\hline A & $\frac{H^{b}}{L}$ & $\frac{0.9866,0.9599}{0.9859,} 0.9908$ & $\frac{0.9798}{1.0100}$ & $\frac{1.0439}{0.9625}$ & $\begin{array}{l}0.9785 \\
1.0006\end{array}$ \\
\hline B & $\frac{H}{L}$ & $\frac{1.0036}{1.0012}$ & $\frac{0.9586}{0.9538}$ & $\frac{1.0137}{0.9964}$ & $\frac{1.0138}{1.0081}$ \\
\hline c & $H$ & $\frac{0.9923}{--}$ & $\frac{1.0290}{1.0280}$ & $\frac{1.0083}{0.9937}$ & $\frac{1.0258}{1.0081}$ \\
\hline D & $\frac{H}{L}$ & $\frac{1.0067}{1.0145}$ & $\frac{1.0166}{1.0239}$ & $\frac{1.0094}{1.0108}$ & $\begin{array}{l}1.0289 \\
1.0297\end{array}$ \\
\hline E & $\frac{H}{L}$ & $\frac{0.9603,0.9919}{0.9760,0.9637}$ & $\frac{0.9888}{0.9917}$ & $\frac{1.0319,0.9337}{1.0219,0.9621}$ & $\frac{0.9602}{0.9836}$ \\
\hline $\mathrm{F}$ & $\frac{H}{L}$ & $\frac{--}{--}$ & $\frac{0.9742}{0.5534}$ & $\frac{0.9078}{0.8767}$ & $\frac{1.0013}{1.0024}$ \\
\hline Average $X / N B S$ & & 0.9872 & $\begin{array}{c}0.9590 \\
(0.9959)^{c}\end{array}$ & 0.9838 & 1.0034 \\
\hline $\begin{array}{l}\text { Average absolut } \\
\text { from NBS }\end{array}$ & leviation & $1.68 \%$ & $\begin{array}{l}5.89 \% \\
(2.37 \%)^{c}\end{array}$ & $3.62 \%$ & $1.64 \%$ \\
\hline
\end{tabular}

a. The order of the participants does not correspond to that in Table 1. The FDA and Amersham/Searle are not represented in this tabulation.

b. $H=H i g h$ Level. $L=$ Low Level.

c. 0.5534 outlier not included. 
College of American Pathologists Quality Assurance "Q" Program

The College of American Pathologists qualityassurance program was developed as a result of a survey taken in 1970 by the Nuclear Medicine Subcommittee of the College. Out of 1300 laboratories responding to a questionnaire, 560 users of radioactive materials were identified, and an interest in quality assurance was seen.

In the fall of 1970 a pilot study was conducted with 25 participants who responded to the questionnaire. NBS was asked to prepare and distribute solution standards of iron-59 and participants were asked to identify and quantify the radionuclide. Fourteen laboratories identified the material correctly, six incorrectly, two said that they were too busy to participate, one had no interest, one was unable to identify the peaks and one did not respond. No one reported a cobalt-60 impurity in the sample. Nine of the fourteen correct identifications were within five percent of the NBS value. The results of this exercise showed that identification of the radionuclide presented a larger problem than the assay of the activity.

In 1972, a new pilot study was performed to determine the accuracy with which a measured quantity of radioactivity could be administered to a patient. The purpose of this exercise was to determine how good the participant's laboratory performance was on a routine basis. Seventy-six percent of the participants that completed this study indicated that the procedure used in the test was indeed routine.

Participating laboratories were asked to inject a known activity of approximately 50 microcuries of chromium-51 into a serum bottle (the "patient") and return the bottle, syringe, and needle to NBS. Data were received from 33 out of 46 participants. Reported activities were based either on dose-calibrator measurements and, or, the value supplied on the vial by the manufacturer. Eighty-one percent of the reported values were

TABLE 6

OVERVIEW OF THE CAP QUALITY ASSURANCE "Q" PROGRAM

\begin{tabular}{|c|c|c|c|c|c|c|}
\hline YEAR & RADIONUCLIDE & $\begin{array}{c}\text { SAMPLES } \\
\text { DISPATCHED }\end{array}$ & $\begin{array}{c}\text { PARTICIPANTS } \\
\text { REPORTING } \\
\text { RESULTS }\end{array}$ & $\begin{array}{l}\text { CORRECT } \\
\text { IDENTIFI- } \\
\text { CATIONS }\end{array}$ & $\begin{array}{c}\text { VALUES } \\
\text { WITHIN } 10 \% \\
\text { OF NBS VALUE }\end{array}$ & $\begin{array}{c}\% \text { OF REPORTED } \\
\text { VALUES WITHIN } \\
10 \% \text { OF NBS }\end{array}$ \\
\hline \multirow{2}{*}{1972} & ${ }^{131} \mathrm{I}$ & 50 & 28 & 25 & 20 & $71 \%$ \\
\hline & ${ }^{125} \mathrm{I}$ & 56 & 38 & 37 & 11 & $29 \%$ \\
\hline \multirow{2}{*}{1973} & ${ }^{57} \mathrm{Co}$ & 50 & 24 & 23 & 12 & $50 \%$ \\
\hline & ${ }^{203} \mathrm{Hg}$ & 51 & 27 & 17 & 10 & $37 \%$ \\
\hline \multirow{2}{*}{1974} & ${ }^{75} \mathrm{Se}$ & 48 & 25 & 21 & 12 & $48 \%$ \\
\hline & $59 \mathrm{Fe}$ & 45 & 22 & 21 & 14 & $64 \%$ \\
\hline \multirow{2}{*}{1975} & ${ }^{60} \mathrm{Co}$ & 117 & 39 & 27 & 16 & $41 \%$ \\
\hline & ${ }^{85} \mathrm{Sr}$ & 110 & 38 & 32 & 17 & $45 \%$ \\
\hline \multirow{2}{*}{1976} & ${ }^{75} \mathrm{Se}$ & 123 & 48 & 46 & 26 & $54 \%$ \\
\hline & ${ }^{125} \mathrm{I}$ & 120 & 43 & 41 & 15 & $35 \%$ \\
\hline \multirow{2}{*}{1977} & $133 \times e$ & 83 & 42 & - & 20 & $48 \%$ \\
\hline & $201 \mathrm{Tl}$ & 83 & 55 & - & 28 & $51 \%$ \\
\hline \multirow{2}{*}{1978} & ${ }^{67} \mathrm{Ga}$ & 80 & 40 & - & 30 & $75 \%$ \\
\hline & $169 \mathrm{Yb}$ & 82 & 43 & - & 24 & $56 \%$ \\
\hline \multirow{2}{*}{1979} & 111 In & 63 & 38 & - & 31 & $82 \%$ \\
\hline & ${ }^{131} \mathrm{I}$ & 68 & 42 & - & 40 & $95 \%$ \\
\hline
\end{tabular}


within twenty percent of the NBS-measured values. Noticeable differences from NBS were seen among participants who used the same type of dose calibrator, and consistently low values were reported from participants that purchased their material from one particular supplier. The results ranged from 0.60 to 1.36 of the NBS-measured values with one extreme of 3.68. Careless arithmetic and reporting of results or incorrect decay corrections were found in one-third of the reported results. Eighty-two percent stated that they never checked for radionuclidic impurities and six percent never checked the suppliers' values.

In 1972, as a result of these two studies, the CAP quality-assurance "Q" program was begun, and continues in much the same form today. Two calibrated radioactivity samples are provided by NBS per year to each subscriber. For the first ten distributions ( 5 years), the participants were asked to identify and quantify the unknown radionuclide, but beginning with xenon-133 (distributed in saline solution) in the spring of 1977 , the participants were asked only to quantify the amount of radioactive material present. A summary of these distributions is presented in Table 6.

The data in the table show that a large number of participants do not report results. Some of the explanations for not completing the exercise after receipt of the material range from "not enough time to measure the sample", to "no setting on the dose calibrator for the particular radionuclide", to "the ampoule was too big to fit in the $\mathrm{NaI}\left(\mathrm{T}_{1}\right)$ well crystal". The results in the last three columns indicate that there is much room for improvement in both identification and quantification of an unknown radionuclide. It is important to know that the patient receive the correct material for a specific study, and that the patient be administered only the amount necessary for that study. Better training of the personnel, better equipment, and more careful computation and reporting skills would all help to improve the results.

\section{TABLE 7}

COLLEGE OF AMERICAN PATHOLOGISTS 1979 RADIONUCLIDE STUDY SERIES Q-B

IODINE-131

\begin{tabular}{|c|c|}
\hline SUMMARY OF ALL PARTICIPANTS & $\begin{array}{c}\text { NUMBER OF } \\
\text { PARTIC IPANTS }\end{array}$ \\
\hline Number of Participants & 43 \\
\hline $\begin{array}{l}\text { Participants suspecting } \\
\text { radionuclidic impurities }\end{array}$ & 7 \\
Selenium-75 & 3 \\
Cobalt-57 & 2 \\
Iodine-125 & 2 \\
Cobalt-60 & 1 \\
Indium- 113 & 1 \\
\hline
\end{tabular}

No photon-emitting impurities were found by NBS.

* Two participants noted the presence of xenon-131m which is, however, a decay product of iodine-131.

131|: June 1972

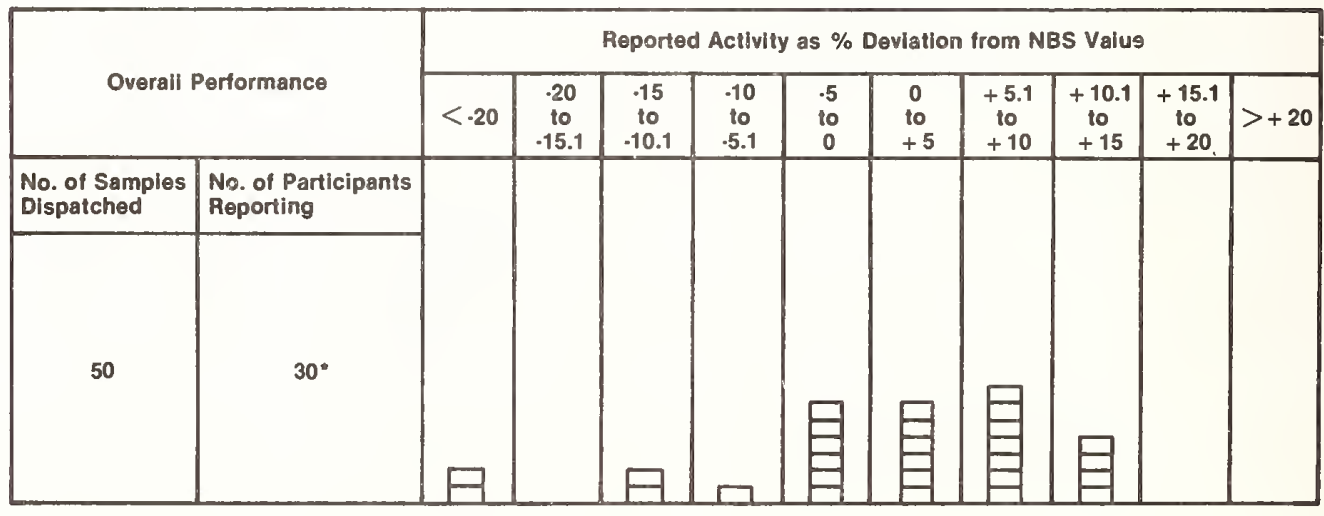

- 1 identifled sampie as ${ }^{51} \mathrm{Cr}$

1 identified sampie as ${ }^{133} \mathrm{Ba}$

$42.86 \%$ of results reported were within $5 \%$ of NBS value.

$71.43 \%$ of resuits reported were within $10 \%$ of NBS vaiue. 
Table 7 shows some of the results of radionuclidic-impurity identification for the iodine-131. samples distributed in 1979. Little improvement has occurred in the identification of impurities since the first pilot study in 1970. In fact, in 1979, sixteen percent found radionuclidic impurities in the iodine-131 when there were none.

Tables 8 and 9 give a comparison between results for iodine-131 distributed in 1972 and again in 1979. The overall performance seems to have improved in the past seven years but this could be a coincidence as the participants reporting their -esults in 1979 may not be the same as those rejorting in 1972. In the past seven years, however, :he equipment has most likely improved, and as the ld equipment is replaced by the new, results should improve as well. Whether or not the people who nade the measurements were better trained in 1979 is a matter of speculation. The results obtained vith dose calibrator $S$ would tend to indicate that :he equipment and not the personnel, is in juestion, but the results of the impurity assessient would suggest just the opposite. In any case, improved training of personnel and calibration of :he dose calibrators would substantially improve the results. It is probable that the participants in this program are more aware of the need for making accurate measurements than the average user of radiopharmaceuticals due to their interest in participation in the program. Even so, the results show much room for improvement and one can only guess as to how well the other 97 percent of the 3200 [2] or more hospitals with diagnostic radioisotope facilities can measure a given amount of radioactive material.

\section{Conclusion}

The AIF-NBS Research Associate Program and the CAP Quality Assurance "Q" Program are beneficial for those associated with the practice of nuclear medicine because they provide both hospitals and radiopharmaceutical suppliers with SRMs for the calibration of their measuring systems, and at the same time, help them to satisfy the increasing regulatory requirements for traceability to the National Bureau of Standards. However, 85 percent of the diagnostic procedures performed utilize technetium-99m-1abeled compounds and the measured dose is usually determined in the hospital's nuclear-medicine department or nuclear pharmacy.

\section{TABLE 9}

131J: November 1979

\begin{tabular}{|c|c|c|c|c|c|c|c|c|c|c|c|}
\hline \multirow{2}{*}{\multicolumn{2}{|c|}{ Overall Performance }} & \multicolumn{10}{|c|}{ Reported Activity as \% Doviation from NBS Value } \\
\hline & & \multirow{2}{*}{$<-20$} & \multirow{2}{*}{$\begin{array}{c}.20 \\
10 \\
-15.1\end{array}$} & \multirow{2}{*}{$\begin{array}{c}-15 \\
\text { to } \\
-10.1\end{array}$} & \multirow{2}{*}{$\begin{array}{c}.10 \\
10 \\
.5 .1\end{array}$} & \multirow{2}{*}{$\begin{array}{c}.5 \\
\text { to } \\
0\end{array}$} & $\begin{array}{c}0 \\
10 \\
+5 \\
\end{array}$ & $\begin{array}{r}+5.1 \\
10 \\
+10 \\
\end{array}$ & $\begin{array}{c}+10.1 \\
10 \\
+15 \\
\end{array}$ & \multirow{2}{*}{$\begin{array}{c}+15.1 \\
10 \\
+20\end{array}$} & \multirow{2}{*}{$>+20$} \\
\hline $\begin{array}{l}\text { Doses } \\
\text { Callbrator }\end{array}$ & $\begin{array}{l}\text { Number of } \\
\text { Particlpants }\end{array}$ & & & & & & & & & & \\
\hline $\mathbf{R}$ & 30 & & & & & & 日 & & & & \\
\hline A & 4 & & & & & & & & & & \\
\hline D & 5 & & & & & & & & & & \\
\hline $\mathbf{S}$ & 3 & & & & & & & & & & \\
\hline $\begin{array}{l}\% \text { of } \\
\text { Partlelpants }\end{array}$ & & $2 \%$ & & & & $14 \%$ & $62 \%$ & $19 \%$ & $2 \%$ & & \\
\hline
\end{tabular}

$\mathbf{7 6 . 1 9 \%}$ of results reported were within $5 \%$ of NBS value.

$95.24 \%$ of results reported were within $10 \%$ of NBS value. 
The AIF program is limited in this area because technetium-99m is not sold in its final prepared form due to its six-hour half life, but rather milked from a molybdenum-99-technetium-99m generator in a hospital laboratory. The CAP "Q" program is limited due to the fact that less than 100 hospitals out of the approximately 3200 hospitals with diagnostic radioisotope facilities participate in the program. Also, the radionuclide which is presently of greatest importance in diagnostic nuclear medicine, technetium- $99 \mathrm{~m}$, has not been distributed to the CAP participants due to the cost and the great effort required to supply it to each participant in a short enough time for it to be useful. In spite of the shortcomings, these programs are important steps toward assuring that the correct dose is given to a patient for a diagnostic procedure. Because of the AIF-NBS research-associate program, the suppliers of radiopharmaceuticals can give greater assurance to their customers that the products they sell contain the amount of activity stated on the label, and this helps the hospital pharmacist provide more accurate doses. The participants in the AIF-NBS Research Associate Program and the CAP program are helped by being able to assess their routine measuring techniques with each blind received from NBS, and are benefited by having a standard to calibrate their instruments once the activity is disclosed.

From the patient's point of view, to ensure that the correct dose of a radiopharmaceutical is given, important steps would be (1) improve

training of the personnel in the nuclear-medicine departments across the country and (2) involve the companies that manufacture dose calibrators in one of these traceability programs administered by the National Bureau of Standards.

\section{References}

[1] C. W. Seidel and J. C. Brantley, "Activities of Commercial Radionuclide Producers" in Activities and Needs Related to Radioactivity Standards for Environmental Measurements, Environmental Protection Agency Rpt. No. EPA-670/4-75-006, 39 (U.S. Printing Office, Washington, D.C., 1975).

[2] Hospital Statistics, American Hospital Association Hospital Data Center (1979). 


\author{
Thomas F. Gesell and Mary Feild Jones \\ The University of Texas School of Public Health \\ P.O. Box 20186 \\ Houston, Texas 77025 \\ and \\ Gail de Planque \\ U. S. Department of Energy \\ Environmental Measurements Laboratory \\ 376 Hudson Street \\ New York, N.Y. 10014
}

\begin{abstract}
The nature of the environmental radiation field is briefly reviewed and its complexity of composition and energy emphasized. The needs and appropriate standards for environmental dosimetry are discussed and calibration procedures are examined. The international environmental dosimeter intercomparison program is reviewed. Data from the intercomparison program are used to show that only a small part of the error associated with environmental TLD measurements is likely to be due to uncertainty in the calibration standard. Other problems of the calibration process are discussed.
\end{abstract}

(Calibration; dosimetry; environmental; intercomparison; standards; thermoluminescence).

\section{Introduction}

Penetrating Environmental Radiation

Penetrating environmental radiacion arises from several sources, naturally occurring primordial radionuclides and their daughter products, cosmogenic radionuclides generated in the atrnosphere by cosmic radiation, cosmic radiation itself, and man-made radionuclides and radiation devices (1). The primoridal radionuclides and their daughter products give rise to a complex penetrating component of the environmental radiation field consisting of gamma rays, $x$-rays and beta particles. These radiations arise not only in the rocks and soils but also in the atmosphere because there is transport of naturally occurring radon isotopes from the soil to the atmosphere. Another major component of penetrating environmental radiation arises from cosmic rays. Although primary cosmic radiation consists almost entirely of protons, few of these reach ground level due to attenuation in the atmosphere. Instead nuclear reactions in the atmosphere produce high energy muons and electrons which reach ground level. The ground level air ionization produced by these muons and electrons is roughly equivalent to that produced by typical soil concentrations of the primordial radionuclides. Cosmogenic radionuclides do not make a significant contribution to penetrating environmental radiation field. In addition to radiation arising from natural radionuclides distributed in a natural fashion, there are manmade contributions. These anthropogenic con- tributions arise from man-made radioisotopes and devices as well from the re-distribution of naturally occurring isotopes (2). Anthropogenic sources contribute gamma rays, $x$-rays and beta particles to the penetrating environmental radiation field.

Measurement of penetrating environmental radiation is required for a number of reasons which include basic and applied research, regulatory compliance and health effects studies. When the requirement is for an integrated measurement over a period of time of a few days to a year or so, passive environmental dosimeters, usually thermoluminescence dosimeters (TLDs) are often employed. These devices are well described in the literature $(3,4)$ and are widely employed. While no exact ccunt of the users of these devices is available, approximately 100 laboratories throughout the world have participated in the series of voluntary environmental dosimetry intercomparisons conducted over the last several years by the University of Texas School of Public Health and by the U. S. Department Energy. Environmental TLDs are in universal use around U.S. nuclear facilities and figured prominently in the assessment of the population radiation dose to the residents in the vicinity of Three Mile Island Nuclear Station (5).

\section{Standards for Environmental TLD}

The complexity of the radiation fields to which environmental TLDs are exposed as well as the often harsh environmental conditions in which they are used create special problems for 
their calibration and handling. These special problems have been addressed in the American National Standards Institute Standard ANSI N 545-1975, "performance, testing, and procedural specifications for thermoluminescence dosimetry (environmental applications)" (6). This standard has been adopted with minor changes by the United States Nuclear Regulatory Commission (7) and therefore serves as guidance to the Commission's licencees. The ANSI standard specifies (among other things) that the calibration exposure given to a TLD shall be known to within 5\% and that acceptable methods of calibration include comparison with calibrated equipment or radioactive sources traceable to the National Bureau of Standards (U.S.A) or similar national institutions in other countries.

The purposes of this paper are to examine how environmental TLDs are calibrated, the degree of agreement that exists among users of environmental TLDs, the problems of calibration and the importance of standards in the overall accuracy of environmental TLD measurements. This paper draws heavily on the several international intercomparisons of environmental dosimeters, $(8,9,10,11)$ especially the most recent (11) in addressing these questions.

\section{Calibration of Environmental TLDs}

While TIDs in the environment are subject to a variety of kinds and energies of charged particles and a rather broad spectrum of photon energies, calibration is usually performed with one or at best a few photon sources. Cesium-137, Cobalt-60 and Radium-226 are specifically mentioned in the ANSI standard (6) and reported as being used by most of the intercomparison participants. The calibration is usually expressed in exposure units, Roentgens or more recently Grays. The environmental measurements on the other hand cannot be strictly expressed in exposure units because exposvre is strictly defined only for photon radiation. Thus when an environmental measurement is expressed in exposure units it is understood that the result is equivalent to that obtained from a specified exposure from the calibration source. Theoretical and some experiment evidence indicates that TID phosphors underrespond to cosmic ray muons (12). The packaging of typical environmental dosimeters is sufficiently thick to exclude some to all of the environmental beta particles. Many users however utilize a package of sufficient thickness to exclude all beta particles. This approach has the additional advantage of assuring charged particle equilibrium for garma rays during calibration. In this case, only the photon and cosmic radiations are being measured however.

Another intrinsic problem with TLDs concerns energy dependence. While some phosphors such as those whose major component is $\mathrm{LiF}$ and $\mathrm{Li}_{2}$ $\mathrm{B}_{4} \mathrm{O}_{7}$ are nearly energy independent, the more sensitive phosphors such as those based on $\mathrm{CaSO}_{4}$ and $\mathrm{CaF}_{2}$ exhibit a severe over-response to photon radiation at low energies. Some users compensate for this over-response with an energy compensating shield or filter. The following discussion of calibration should be interpreted with the above limitations in mind.

Basic calibration is effected in one of two ways. In one technique an NBS traceable instrument is used to measure the radiation exposure rate in some small volume in a radiation field and a calibration dosimeter substituted for the instrument for an appropriate length of time to achieve the desired exposure. In another approach an NBS traceable source is arranged with the calibration dosimeter in an approximation of "free aiṛ" geometry. The calibration exposure is then calculated using the known source strength, the gamma ray constant of the source and the inverse square law. Within this basic frame-work a variety of calibration schemes are employed. Some laboratories calibrate each dosimeter individually; others select batches of dosimeters with similar response and calibrate only a random sample of the whole batch; others combine these techniques and perform batch calibrations but use individual dosimeter correction factors.

\section{The International Environmental Dosimeter Intercomparison Program}

\section{Procedures}

Much of the information contained in this paper derives from the series of international intercomparisons of environmental dosimeters so a discussion of them is appropriate. The intercomparisons originated in 1973 with a highly informal pilot intercomparison at Oak Ridge National Laboratory involving 12 sets cf dosimeters from 5 labboratories (13). The poor results of this informal study were sufficiently alarming that a more formal study with good control for radiation exposure acquired in transit was conducted in 1974 (8). Dubbed the "first international intercomparison of integrating environmental dosimeters" it has been followed by three others using similar protocols. The fifth intercomparison is to be held in Idaho Falls in 1980. The recent intercomparisons have typically attracted 125 sets of dosimeters from 100 laboratories located in 25 countries. For each set to be tested in the intercomparisons, each participant sends several pairs of dosimeters to the test location. One pair of dosimeters is designated as "control", one pair is designated as "field" and the third and sometimes fourth pairs are designated as "laboratory". Upon receipt at the test site the dosimeters are stored in a low background radiation shield until the beginning of the field test period. At the beginning of the field test period the "field" dosimeters are removed from the storage shield and deployed in close physical proximity in an environmental radiation field. Both natural (first, second, fourth intercomparisons) and artificially enhanced (pilot, third intercomparisons) fields have been employed. Usually a field test period of three months is used but shorter times have occasionally been employed. Except for the pilot study, high pressure ionization chambers have been operated at the field site for the entire duration of the field exposures to give an independent assessment of the field exposure. Approximately half way through the field period, 


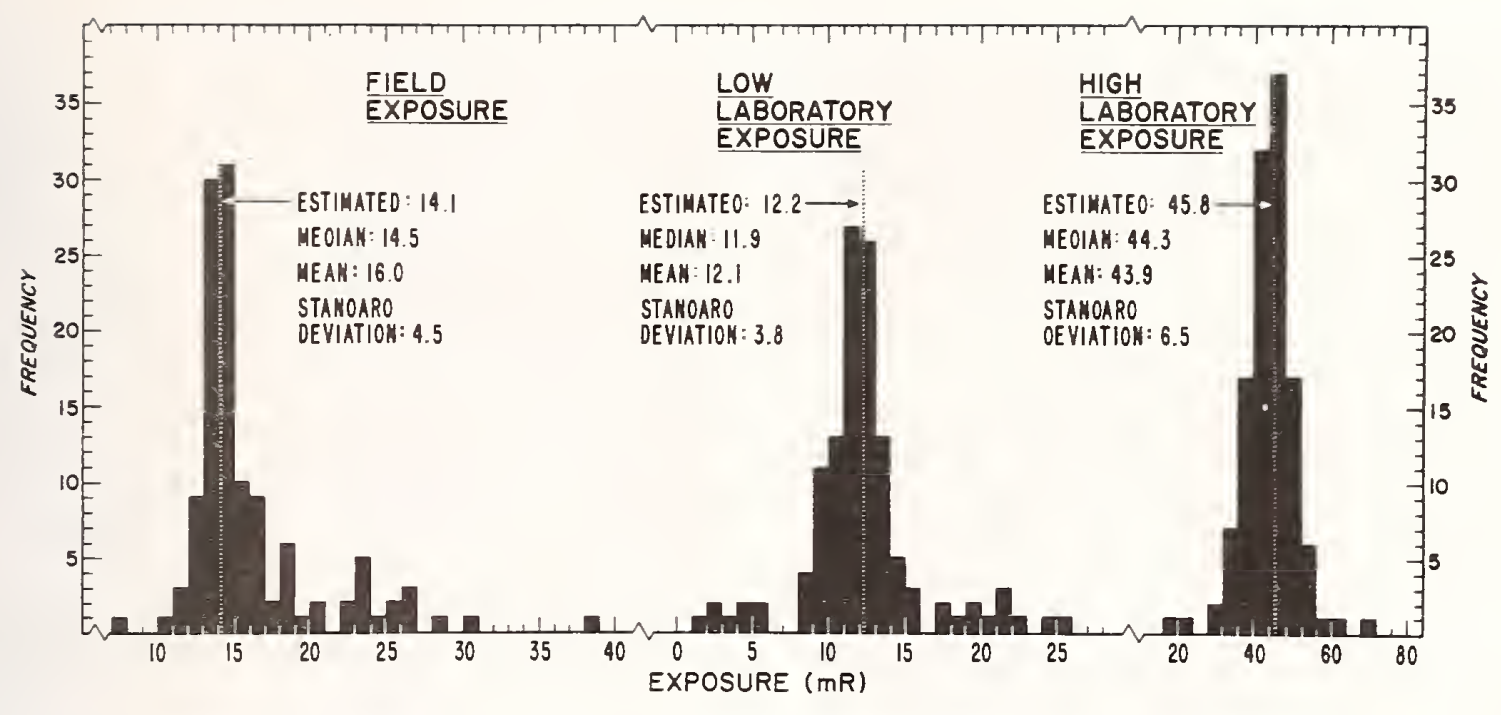

Figure 1. Frequency distributions of measured exposures reported bu participants for all dosimeters in the field and laboratory tests of the fourth intercomparison (II).

the "laboratory" dosimeters are removed and exposed to a known but unrevealed quantity of gamma radiation. Cobalt-60, Cesium-137 and Radium-226 have been employed in the several intercomparisons. In the fourth intercomparison, two laboratory pairs of dosimeters were solicited from the participants. One set was given a "low" exposure on the order of a typical field period exposure to natural radiation; the other pair was given a "high" exposure approximately four times the "low" exposure. In all but the pilot study, control dosimeters were used to isolate the actual laboratory and field exposures from the exposures acquired in transit and storage. The control dosimeters also allowed estimation of the transit exposures. The results of the intercomparisons have been analyzed statistically and a number of factors contributing to random and systematic errors identified.

\section{Selected Results of the Intercomparisons}

The general results of the fourth intercomparison are shown in figure 1. The estimated delivered laboratory and field exposures are shown for comparison. Two levels of laboratory exposure were used to help determine if previously observed differences in dispersion of the results could be related to exposure level, to differences between laboratory and field conditions or to improved performance. These data on dispersion are combined with data from the previous intercomparisons, and presented in figure 2. These results strongly suggest that the dispersion is related to the exposure level. The only point not lying on the smooth curve is the value for the field exposure during the third (Oak Ridge) intercomparison. This particular field exposure involved an artifically enhanced source with a large low energy scattered radiation component causing unusual response problems.

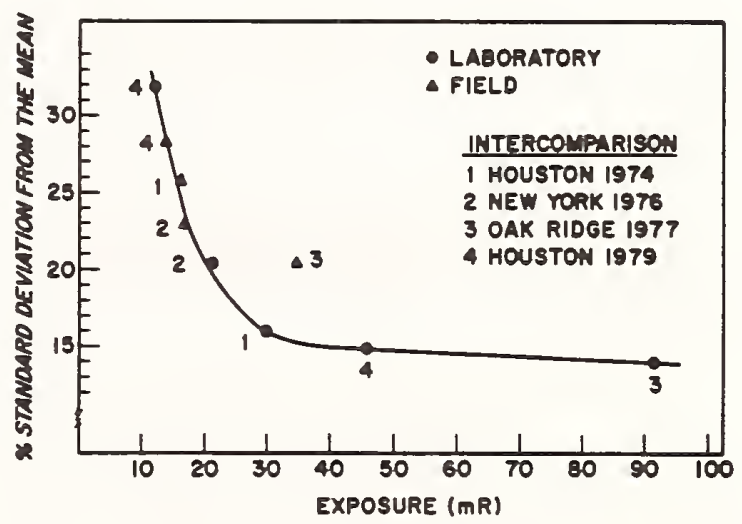

Figure 2. Relationship between percent standard deviation and delivered exposure for all tests in four intercomparisons.

\section{The Importance of the Calibration Source In Environmental TLD Measurements}

The importance of the sccuracy of the calibration source in environmental TLD can be illustrated using data from the fourth intercomparison (11). Figure 3 shows the degradation of estimated accuracy from the standard itself to the field measurement. The uppermost histogram is the hypothetical distribution of accuracies of laboratory standards available to participants. For purposes of illustration it is assumed that all users could have a laboratory standard with an accuracy of $2 \%$. This could be either a calibrated source or a calibrated instrument. The next lower histogram is the distribution of overall calibration accuracy estimated by participants (participants were asked to estimate accuracy as two standard deviations). This distribution is clearly much broader and reflects additional uncertainties in the calibration process beyond the uncertainty of the source. These 
additional uncertainties are introduced by errors of positioning of the calibration dosimeters, timing of the exposure, and; especially with calibrated sources, errors associated with scattered radiation. The lower three histograms represent the distribution of estimated accuracy reported by the participants for the "high" laboratory test, the "low" laboratory test, and the field test (participants were again asked to estimate accuracy as two standard deviations). Those distributions are in turn broader than the distribution of accuracy of calibration. The additional breadth results from known additional sources of measurement error such as random variation of dosimeter response, energy dependence, directional dependence, signal fading, and self irradiation (14) as well as the additional error introduced by the requirement for subtracting transit exposures.
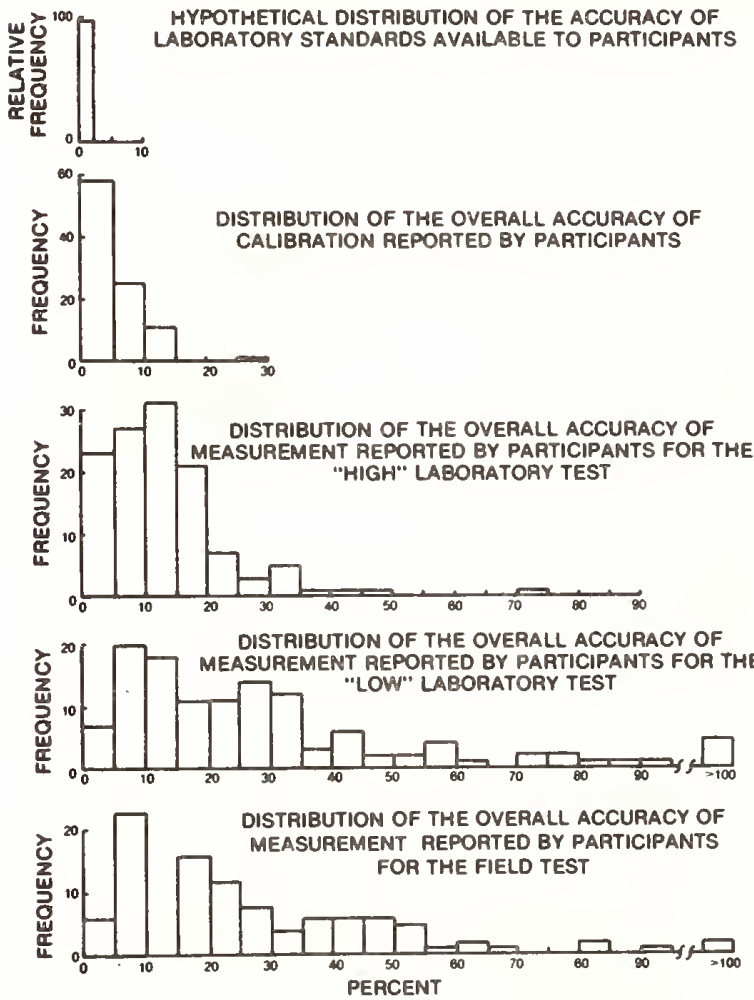

Figure 3. Frequency alstributions showing the hypothetical distribution of accuracy of laboratory standards available to environmental TLD users, the distribution of reported overall calibration accuracies and the distributions of reported overall accuracies of measurement for the three tests carried out in the fourth intercomparison.

It should be stressed that figure $3 \mathrm{dis}-$ cussed above consists of a hypothetical distribution of laboratory standard accuracies plus distributions of estimated accuracies reported by environmental TLD users. At this point we can turn to actual performance in the intercomparison tests. Figure 4 illustrates the absolute percent difference between participants'
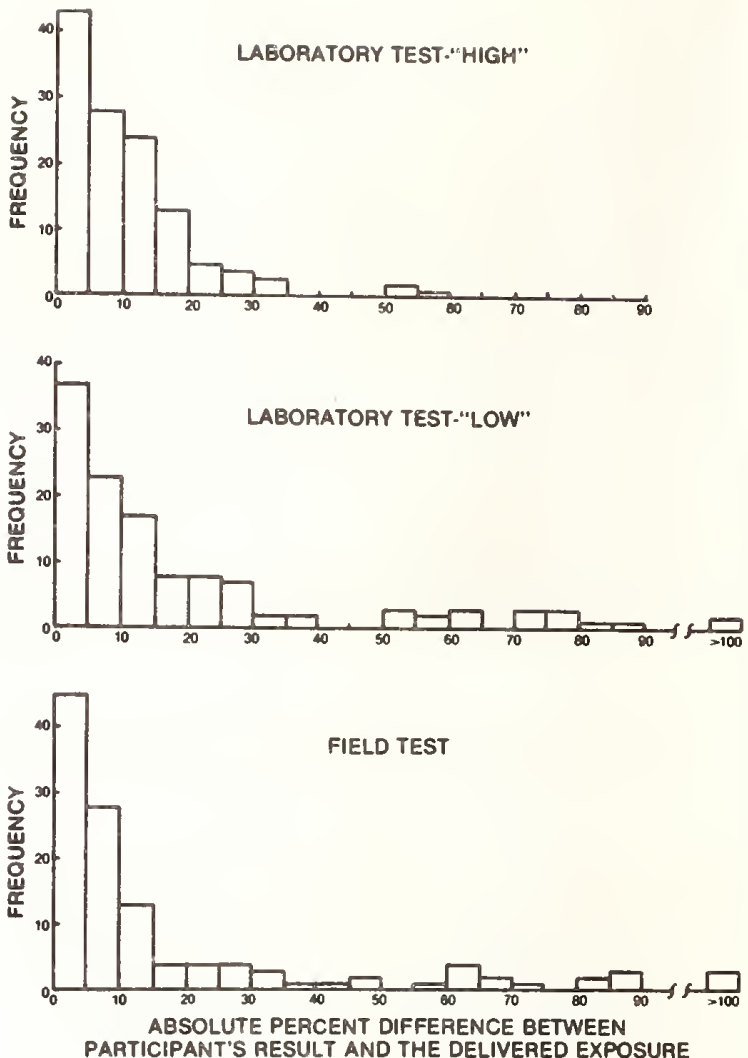

Figure 4. Frequency distributions showing actual deviations ( in \%) of the participants' results from the delivered exposures for the three tests carried out in the fourth intercomparison.

results and the estimated delivered exposure for all three tests. Performance is seen to be better for a the "high" laboratory test than for either the "Iow" laboratory of "field" tests. This performance is in general consistant with the estimated accuracies shown in figure 3 .

Figure 5 examines more directly the ability of users to estimate the error of their laboratory and field measurements. The quantity displayed on the abcissa is the error estimated by the participants ( in $\%$ ) subtraced from the actual difference ( in $\%$ ) between the participants' results and the estimated delivered exposure. Positive results occur when the actual error exceeds the estimated error. These cases of underestimating of error are shaded for emphasis. Approximately 30 percent of the participants' results differed from the delivered exposure by more than their estimated error. The estimated accuracy of the delivered exposures was $10 \%$.

The uncertainties estimated by environmental TLD users (figure 3 ) as well as the deviations from the delivered exposures (figure 4) are much larger than the estimated uncertainties of currently available laboratory standards traceable to the National Bureau of Standards or equivalent standards groups in other countries 

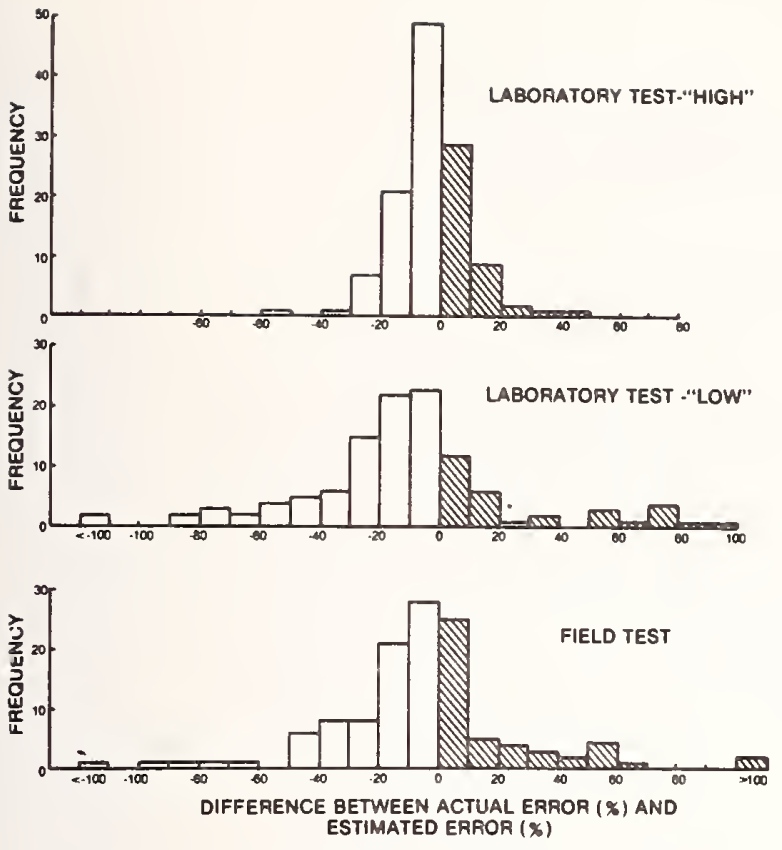

Figure 5. Frequency distributions of the differences between the errors estimated by the participarts (in \%) and the actual deviations of the participants'results from the delivered exposures ( in \%). The positive (shaded) results represent cases in which the deviation from the delivered exposure was greater than the error estimated by the participant.

Furthermore many users are apparently underestimating their overall uncertainties (figure 5). It thus appears that little would be gained by improving the 1-2\% accuracy already available in the calibration standards.

There are however several problems associated with calibration which have been elucidated by the intercomparison program, but which are not necessarily connected directly with the accuracy of the calibration source. When the data for the second intercomparison (9) was analyzed it was noted that the standard deviation of the results of participants who calculated their calibration exposures from known source strengths was larger by a factor of two than the standard deviation of the results of participants who measured their calibration exposures directly. It was believed that this additional error may be due to unaccounted -for room scattering, air attenuation and effects of the source capsule or support. This effect was somewhat diminished in the subsequent intercomparisons, but still persisted.

Another calibration problem which has persisted through the four international intercomparisons is the systematic difference in re- sults among uses of the three most common calibration isotopes. Users of Cobalt-60 calibration sources typically exhibit average laboratory test results a few percent higher than those using Cesium-137. Users of Radium-226 calibration sources exhibit average laboratory test results a few percent lower than either Cobalt-60 or Cesium-137 users. No satisfactory explanation has been found for these differences.

\section{Conclusions}

At the present time the collective errors associated with making environmental TLD measurements are much larger than the error associated with laboratory staniards traceable to the National Bureau of Standards or equivalent standards groups in other countries. It would therefore seem that the standard sources and standardized instruments available to the users are of sufficient accuracy in view of the state of the art. Use of standard sources rather than standardized instruments can lead to additional calibration errors due to uncertainties in scatter, attenuation and source holder effects. While environmental TLD users will nearly always wish to use a locally available calibration facility for routine operations, it may be desirable to have a service similar to that provided by the international program available to users at their convenience rather than at the fixed and rather infrequent intervals presently available. This service could conceivably be provided by the National Bureau of Standards, another government agency or a contractor. This scheme could allow users to test the effectiveness of their own calibration systems at reasonable expenditure of time and money.

\section{References}

(1) National Background Radiation in the United States, National Council on Radiation Protection and Measurements Report NCRP 45, Washington, D.C. (1975).

(2) The Technologically Enhanced Natural Radiation Environment, T. F. Gesell and H. M Prichard, Health Physics 28 361-366 (1957).

(3) Thermoluminescent Dosimetry, J. R. Cameron, N. Suntharalingam, and G. N. Kenney, The University of Wisconson, Press, Madison, wisconson (1968).

(4) Solid State Dosimetry, K. Becker, CRC press, Cleveland, Ohio (1973).

(5) Staff Reports to the Presidents Commission on the Accident at Three Mile Island; Reports of the Public Health and Safety Task Force, ed. Jacob I. Fabricant, Sup. Doc. Washington, D.C. (1979).

(6) Performance, testing and procedural specifications for thermoluminescence dosimetry (environmental applications), ANSI N 545-1975. 
American National Standards Institute, 1430 Broadway, New York (1975).

(7) Performance, testing and procedural specifications for thermoluminescence dosimetry; environmental applications, U.S. Nuclear Regulatory Commission, Regulatory Guide 4.13, Washington, D.C. (1976).

(8) An International Intercomparison of Environmental Dosimeters, Thomas F. Gesell, Gail de Planque Burke and Klaus Becker, Health Physics 30, p. 125-133 (1976).

(9) Second International Intercomparison of Environmental Dosimeters, Gail de Planque and Thomas F. Gesell, Health Physics 36 p. 221-233 (1979).

(10) Third International Intercomparison of Environmental Dosimeters under Field and Laboratory Conditions, T. F. Gesell, R. B. Gammage and G. de Planque, Presented to the 23rd Annual Meeting of the Health Physics Society, Minneapolis, Minnesota, 18-23 June, 1978 Abstract: Health Physics 35, p. 909-910 (1978).

(II) Highlights of the Fourth International Intercomparison of Environmental Dosimeters under field and laboratory conditions, Thomas F. Gesell and Gail de Planque, Nuclear Instruments and Methods (in press).

(12) The Response of LiF Thermoluminescence Dosimeters to Natural Environmental Radiation, Wayne M. Lowder and Gail de Planque, Energy Research and Development Agency Report HASL-313 New York, N.Y. (1977).

(13) Tenth Dosimetry Intercomparison, H. W. Dickson, F. F. Haywood and K. Becker, Oak Ridge National Laboratory Report \#ORNL-TM-4566, Oak Ridge, Tennessee (1975).

(14) Error Analysis of Environmental Radiation Measurements made with Integrating Detectors, Gail de Planque Burke and Thomas F. Gesell, Proceedings of the Symposium on measurements for the safe use of radiation, ed. S.P. Fivozinsky, National Bureau of Standards Special Publication 456, p. 187-198 (1976). 
THE NATIONAL BUREAU OF STANDARDS

LOW-LEVEL RADIOACTIVITY-MEASUREMENTS PROGRAM

K. G. W. Inn

J. R. Noyce

National Bureau of Standards

Washington, D.C. 20234

The National Bureau of Standards low-level radioactivity measurements program is oriented towards the production of reference materials for environmental radioactivity measurements needs. These reference materials are used 1) for calibration of instruments, and 2) as test sources for analytical procedure evaluation. These endeavors are designed to provide the nation with a means of assessing the quality of environmental radioactivity measurements and relating them to national and international radioactivity standards. The present status of these efforts is discussed along with possible future plans.

(Calibration, environment, natural material, radioactivity, radionuclide, standard, traceability)

\section{Introduction}

The need for environmental radiological studies has been and will continue to be of great importance to the public. The protection of the puitic from excessive exposure to radiation and basic scientific understanding of the environment are the two primary reasons for these studies. Some of the programs that are concerned with environmental radiological studies are listed in Table T. Regulatory requirements have been established for public safety and require radiation monitoring around nuclear-power plants, uranium mines, nuclearfuel manufacturing plants, nuclear-waste repositories, as well as the air we breath, the water we drink, and the food we eat. Basic scientific environmental investigations, on the other hand, use radioactive tracers as a sensitive means for studying the environment. Careful radiometric measurements have aided in transport studies of the atmosphere, oceans, and the 1ithosphere, dating studies as well as cosmological and biological studies. The objective of the low-level radioactivity-measurements program at the National Bureau of Standards (NBS) is to produce reference materials suitable for environmental radioactivity-measurements needs. These materials are used for 1) calibration of instruments and 2) as test sources for analytical-procedure evaluation. In this paper the status and requirements regarding reference materials and test samples needed in traceability programs will be discussed.

Table 1

General categories of low-level radioactivity measurements with examples.

Public Safety:

Routine monitoring:

Radioactive waste studies:
Coal-burning power plants, uranium mines, uranium mills, nuclear-power plants, Clean Water Act, Clean Air Act.

High-level contaminated sites, nuclear-waste repositories, uranium-mill tailings and slag.

\section{Scientific Knowledge:}

Transport studies:

\author{
Meteorology, oceanography, water resources. \\ Archeology, geology, cosmology. \\ Lunar samples, polar ice, deep-sea sediments, meteorites.
}




\section{Radioactive Standard Reference Materials}

The selection of radioactive Standard Reference Materials (SRM) to be produced has been, to a large degree, influenced by requests from agencies such as the Environmental Protection Agency (EPA) and the Nuclear Regulatory Commission (NRC), reports from knowledgeable groups such as the International Comittee for Radiological Metrology (ICRM), NBS questionnaires, evaluation of regulations and surveys of the literature. Table 2 lists some of the users of the resulting NBS SRMs.

\section{Table 2}

NBS standards users and examples.

Operating nuclear-power stations

Preoperational nuclear-power stations

Research reactors

Major nuclear facilities:

Nevada Test Site

Idaho National Engineering Laboratory

Richland, Washington

Oak Ridge National Laboratory

Savannah River Plant

Rocky Flats Plant

Mound Laboratory

Paducah, Kentucky

Cimarron, Oklahoma

Federal Agencies:

Environmental Protection Agency

Nuclear Regulatory Commission

Department of Energy

States with active environmental

surveillance programs:

New York, Pennsylvania, South Carolina

University based research projects:

Berkeley

Miami

Arkansas

Institutions:

Woods Hole Oceanographic Institution Scripps 0ceanographic Institution Battelle NW

Environmental radiation consulting firms: Radiation Management Corporation Nuclear Environmental Services United States Testing Company West inghouse NES

Cities, counties, other sub-state governmental bodies:

New York City
Presently, approximately seventy radioactive SRMs of nearly forty radionuclides are available from NBS [1], many of which are useful for environmentally related work [2]. -Table 3 includes the various types of SRMs produced by the Radioactivity Group at NBS. These sources come in various forms namely as liquids, point sources, gases and solids. Most of these SRMs are used to calibrate instruments for detection efficiencies while some are useo to monitor the stability of instrumental response [3]. These SRMs also play an important role in traceability considerations.

Table 3

Types of National Bureau of Standards radioactivity Standard Reference Materials and examples.

\section{Source Type \\ alpha-particle, solution \\ beta-particle, solution \\ photon-emitting, solution}

a]pha-particle, point

photon-emitting, point

beta-particle, photonemitting, gas

solid

\section{Examples}

${ }^{239} \mathrm{pu}, 242 \mathrm{pu}$

$3 \mathrm{H},{ }_{\mathrm{S}}{ }^{14} \mathrm{C}, \mathrm{C}_{\mathrm{Y}}, 63_{\mathrm{Ni}}$,

$54 \mathrm{Mn},{ }^{60} \mathrm{Co},{ }^{109} \mathrm{Cd}$

${ }^{137} \mathrm{Cs}-137 \mathrm{mBa}, 226 \mathrm{Ra}$

$148 \mathrm{Gd}, 238 \mathrm{Pu},{ }^{241} \mathrm{Am}$

$55 \mathrm{Fe}, 85 \mathrm{Kr}, 133 \mathrm{Ba}$,

$139 \mathrm{Ce}, 152 \mathrm{Eu}$

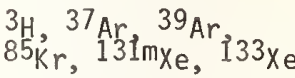

River Sediment

\section{Measurements Traceability}

In environmental measurements, one is interested in establishing the ability to make consistently accurate assays. That is to say, the goal is to establish a consistently accurate analytical scheme which begins with the collection of samples and continues until the data are finally reported. Measurements-traceability programs for environmental radioactivity provide a basis by which laboratory measurements can be related to national radioactivity standards. Through a traceability program, data quality can be assessed, and a firm foundation for policy decision and scientific discussion can be established. In many cases traceability may be recomended or required under regulations, agreements, regulatory guides, licensing, or recommended practices. One can visualize a three-phase traceability scheme which would test: 
1) Instrument calibration

2) Radiochemical procedures

3) Sampling, preparation, and storage methods.

The first phase of traceability is concerned with the accuracy of instrumental response. The second phase of traceability evaluates radiochemical procedures for significant chemical biases. And finally, the third phase provides some assurance that a laboratory is able to collect and prepare samples for assay, and store them without affecting their integrity.

\section{Calibrations of Instruments}

The first phase, instrumental traceability, is propagated through the Traceability System $[4,5,6,7,8,9]$ shown in Figure 1. NBS maintains traceability internationally through interaction with the International Bureau of Weights and Measures, the International Atomic Energy Agency and other national laboratories. Domestically, NBS establishes instrumental traceability to Quality Assurance (QA) laboratories through Measurements-Assurance Programs $[10,11,12,13]$. Some of the SRMs produced by the Radioactivity Group at NBS are used in these programs as test samples, of undisclosed value, to establish the traceability link between NBS and QA organizations.

The Environmental Protection Agency (EPA) is responsible for radiological monitoring of the environment outside nuclear-fuel-cycle facilities. To assist in the accomplishment of EPA's mission, the EPA-NBS traceability program consists of both implicit and explicit [14] traceability measurements for alpha- and beta-particle and gamma-ray-emitting nuclides. Tests on twentyeight radionuclides have been made so far, and EPA's performance demonstrates its instrumental traceability to NBS for these radionuclides (Figure 2). Because it has been able to assay a variety of radionuclides accurately, it has developed a reputation for consistent and competent activity-concentration measurements. Nuclides which may be added to its list of traceable nucl jides by the end of 1980 are ${ }^{46} \mathrm{Sc},{ }^{57} \mathrm{Co}$, and $125 \mathrm{Sb}$.

In addition to EPA's traceability program, a Radiological Pollutant Quality Assurance Program was established in 1975 to provide NBS reference materials for radionuclides released to the environment by coal-burning and nuclear power plants. The sources, produced in quantity for EPA's distribution as calibrated materials [15] or as test samples in their Environmental Radioactivity Laboratory Intercomparison Studies Program (cross-check program) [16], are listed in Table 4. When used in EPA's cross-check program, these materials provide traceability to the user level for nuclides that have not been included in the formal traceability program between NBS and EPA. Several of the calibrated radioactivity sources in this list are environmental matrix materials. A more complete discussion on the natural material sources follows in the next section.

\section{INTERNATIONAL AND NATIONAL RADHOACTIVITY MEASUREMENTS "TRACEABILITY TREE"}

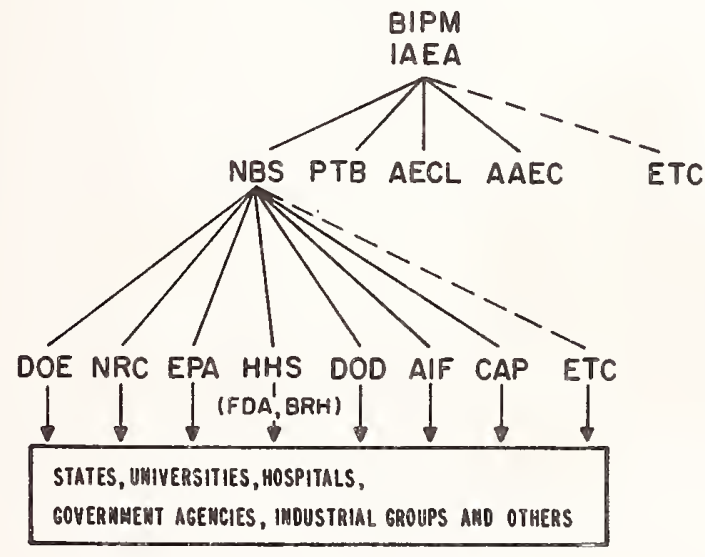

INTERNATIONAL

NATIONAL LABORATORIES

QUALITY CONTROL AND REGULATORY BODIES

Figure 1 
Table 4

Radioactivity-calibrated materials prepared by the National Bureau of Standards for the Environmental Protection Agency under the Radiological Pollutant Quality Assurance Program (1976-1980).

$$
\begin{array}{r}
\text { Solutions: } \\
210 \mathrm{Po} \\
232 \mathrm{Th} \\
239 \mathrm{Pu} \\
241 \mathrm{Pu}
\end{array}
$$

Mixed Radionuclide Solutions:

$$
\text { Mixed gamma-ray emitting } \left.{ }_{65}{ }^{51}{ }^{5 n}, 8 r_{y},{ }^{37} \mathrm{Cs}-137 \mathrm{~m}_{\mathrm{Ba}},{ }^{139} \mathrm{Ce}\right)
$$

Natural uranium $(234 \mathrm{U}, 235 \mathrm{U}, 238 \mathrm{U})$

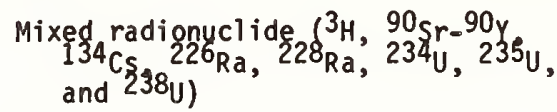

Solids:

$$
\begin{aligned}
& \text { Mancos Shale }\left({ }^{226} \mathrm{Ra} \text { and }{ }^{228} \mathrm{Ra}\right) \\
& \text { Pottery } \mathrm{Clay}\left({ }^{65} \mathrm{Zn},{ }^{88} \mathrm{Y},{ }^{113} \mathrm{Sn}-\right. \\
& \left.113 \mathrm{~m}_{\mathrm{In}},{ }^{13} \mathrm{Cs}-13 \mathrm{~m}_{\mathrm{Ba}} \text {, and }{ }^{139} \mathrm{Ce}\right) \\
& \text { Fly Ash from coal combustion } \\
& \text { (226 } \left.\mathrm{Ra} \text { and } 228_{\mathrm{Ra}}\right)
\end{aligned}
$$

The responsibility of the NRC is to monitor nuclear-fuel-cycle facilities, and its traceability program with NBS is implemented through the Radiological and Environmental Sciences Laboratory (RESL) at Idaho Falls.
Since the program was established in 1974, calibrated sources of forty-six radionuclides have been commonly measured by NBS and RESL and the results of the measurements are shown in Figure 3. RESL has demonstrated throughout the program a high level of instrumental reproducibility and stability, and operator competence for a broad range of alpha-, beta-particle, and photon-emitting nuclides, some of the radionuclides being assayed more than once. Scandium-46, $133 \times$ e, $228 \mathrm{Th}-208 \mathrm{Tl}$, and $240 \mathrm{Pu}$ are included in the RESL traceability program for 1980 .

Another program in the national traceability effort was established by agreement between EPA and NRC. The NRC Regulatory Guide 4.15 [17] requires the nuclear-power plants in the United States to participate in interlaboratory comparison programs, such as the EPA cross-check program for environmental samples [16], to establish links to the national traceability program [18]. To evaluate the level of analytical performance of the power plants, EPA has agreed to develop a number of test samples for the NRC. Calibrated samples of radionuclides such as 131 , natural uranium, $210 \mathrm{~Pb}, 210_{\mathrm{Po},} 226_{\mathrm{Ra}}$, and $230 \mathrm{Th}$ in air, food and water are desired. NBS may prepare some of these standards to help implement the EPA-NRC agreement.

The College of American Pathologists (CAP) and the Atomic Industrial Forum (AIF) also have traceability programs with NBS. These programs have previously been discussed by Golas [19], and will not be addressed here.

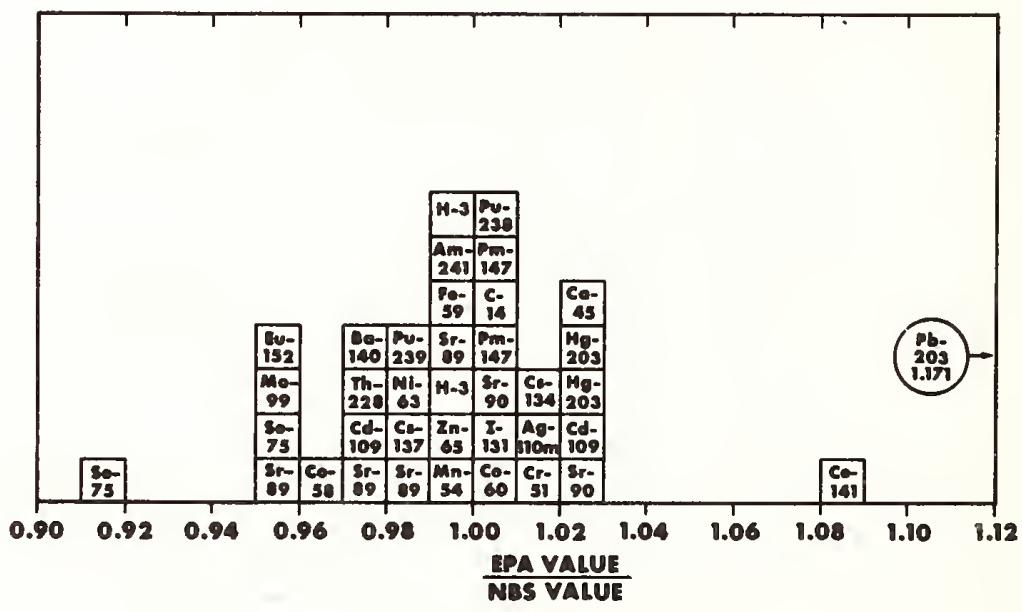

Figure 2

Results of the EPA-NBS Radioactivity-Measurements Traceability Program from its inception through March, 1980. 


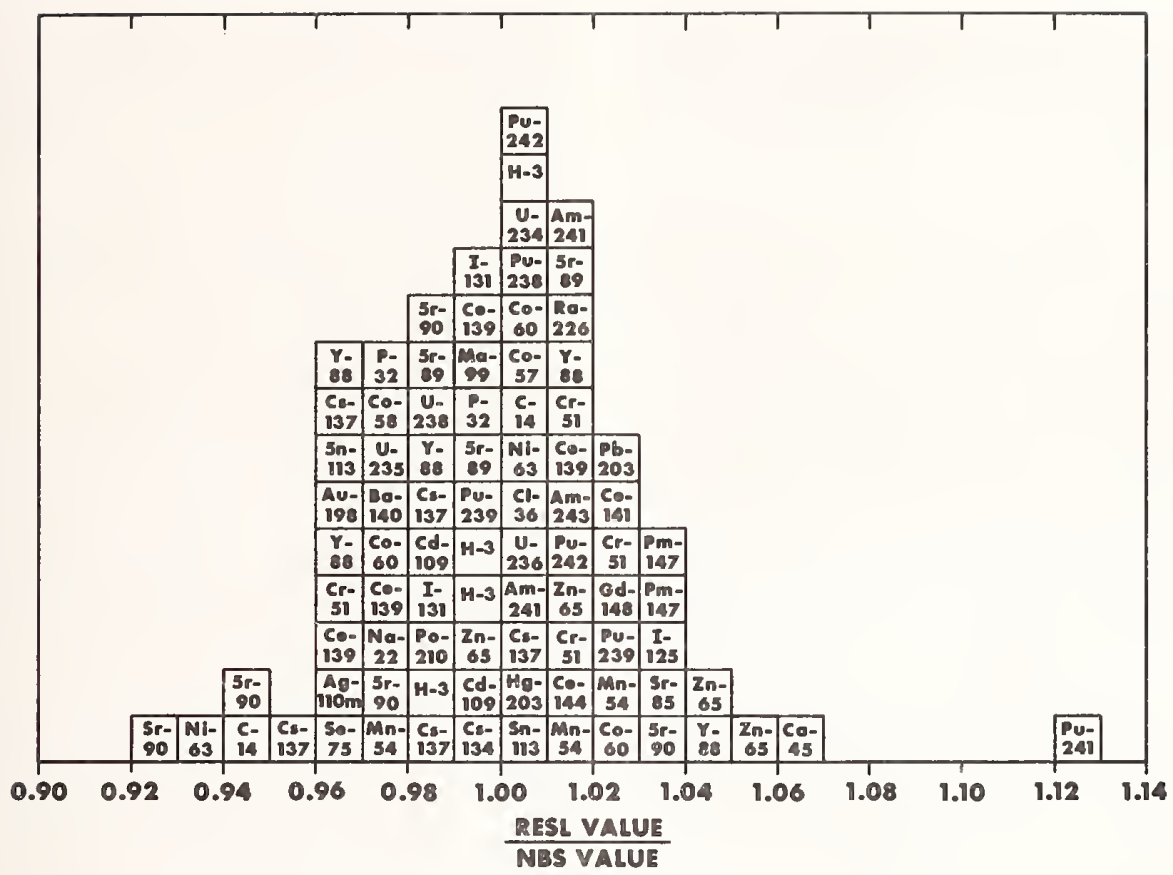

Figure 3

Results of the RESL-NBS Radioactivity Measurements Traceability Program from its inception through March, 1980 .

NBS provides two additional services that are designed to provide implicit instrumental traceability to interested parties. First, SRMs can be obtained by customers, for a small extra fee, as "blind" test sources. These "blinds" are issued without disclosure of their certified emission-rate or activity-concentration values. The purchaser measures one or other of these quantities and reports his value to NBS, which then issues a Report of Measurement giving the certified value, the purchaser's value, and the percentage difference from the certified value. By using the "blinds" the purchaser can test the performance of his instrumentation, but not necessarily his radioanalytical techniques.

NBS also provides traceability services for a large number of radionuclides submitted by the customer. Sources must be submitted in forms which meet certain criteria for chemical composition, geometry, and activity. The customer provides his measured value for the calibration of the emission rate or activity concentration. After NBS completes the calibra$t i o n$ of the source, the supplier receives a Report of Calibration which states the certified emission rate or activity concentration of the source, the customer's value, the percentage difference, the uncertainties in the NBS assay, and the methods and nuclear parameters used.
In addition, NBS provides an explicit traceability mechanism to other laboratories, that produce and distribute radioactivity standards, through their submission of a few samples of each batch to NBS for corroborative measurement. In the past NBS produced SRMs which contained a mixture of nine photon-emitting radjonuclides: ${ }^{57} \mathrm{Co},{ }^{60} \mathrm{Co},{ }^{85} \mathrm{Sr},{ }^{88} \mathrm{y},{ }^{109} \mathrm{Cd},{ }^{113} \mathrm{Sn},{ }^{137} \mathrm{Cs}$, ${ }^{139} \mathrm{Ce}$, and $203 \mathrm{Hg}$. This mixture was provided in the forms of point sources and as solutions in 5-, 50-, and 450-ml containers. These SRMs have found wide application in calibrating detectors for gamma-ray spectrometry $[20,21]$. Recently, similar standards or reference sources have been distributed by the Amersham Corporation and Analytics, Incorporated. Whenever these companies have produced a set of such standards, they have sent several randomly selected samples from the set to NBS for confirmation of emission rates per gram at 10 or 11 gamma-ray energies. The explicit traceability mechanism, therefore, provides for the continual availability of mixed gammaray-emitting reference sources that are traceable to NBS.

NBS is presently working on another mixed gamma-ray-emitting reference source consisting of the relatively long-lived radionuclides $125 \mathrm{Sb}$ $\left(t_{1 / 2}=2.77 \gamma^{*}\right),{ }^{154} \mathrm{Eu}\left(t_{1 / 2}=8.6 \mathrm{r}\right)$, and

* One mean tropical year equals 365.2422 days. 
${ }^{155} \mathrm{Eu}_{\mathrm{U}}\left(\mathrm{t}_{1 / 2}=4.69 \mathrm{Y}\right)$. The new mixture will provide more gamma-ray photopeaks in the lowerenergy region than the earlier mixture and a longer usable life.

\section{Tests of Radiochemical Procedures}

The second phase of environmental traceability is implemented through calibrated test samples containing specific radioanalytical problems. These test samples fall into two general catagories: 1) SRM solutions with particular chemical challenges and 2) NaturalMatrix Standards (NMSs) which present peculiar matrix problems. Several test samples with chemical and other interferences have been distributed in the past by NBS and are listed in Table 5.

Table 5

Test sources with interferences.

Assayed

radionuclides

${ }^{89} \mathrm{Sr}$, solution

Interferences

${ }^{90} \mathrm{Sr}-90 \mathrm{Y}$, solution

${ }^{90} \mathrm{Sr}, \mathrm{Ca}^{2+}$

${ }^{232}$ Th, solution

${ }^{133} \mathrm{Ba}, \mathrm{Ca}^{2+}$

${ }^{230} \mathrm{Th}$

Natural uranium, solution

$$
\begin{aligned}
& { }^{234} U,{ }^{235} U, 238_{U} \\
& \text { (interfere with } \\
& \text { each other) }
\end{aligned}
$$

Mixed photon-emitting spiked pottery clay

Matrix

Although these test sources with interferences present considerable challenges to the analyst's skill, they are relatively "clean" samples. Environmental samples, on the other hand, are very complex materials and contain an abundant store of insidious difficulties. Some of the obstacles facing the analyst are: interfering ions [22], chelating ligands [22], grain size of the host matrix, organic decomposition [23], mineralogical variability, radionuclide volatility $[23,24]$, contamination of the samples $[22,25]$, density variability, varying chemical species and valence states of the nuclides [e.g.,26], and the variability of the radionuclide distribution in the matrix.

Particularly important is the attainment of equilibrium between the radionuclides in the matrix and the tracers and carriers being used as radiochemical yield monitors. Without this condition, quantitative assays of the radionuclides will be forfeited before the analyst has had the opportunity to work the sample. Gorsuch [23], for example, warned against selective losses of material during dry ashing. Losses of material may be the result of selective volatilization, co-precipitation, or even diffusion into the container wall. Hamilton et al. [27] observed selective volatilization of As in spiked serum. When the serum was spiked in vitro, $28 \%$ of the As volatilized during ashing, but when the serum was spiked in vivo, as much as $86 \%$ of the As volatilized. This showed that metabolized As was considerably more volatile than As added as a yield monitor. Thus, if a tracer is added in vitro as a radiochemical yield monitor for As determination in serum, chemical equilibration between the sample and the tracer would not be achieved during ashing, thereby resulting in unreliable data.

Accordingly, reference materials closer in composition to environmental samples should provide more rigorous tests of analytical systems. Natural-Matrix Standards (NMSs) serve as test samples for environmental radiochemical assays. An NMS has been defined by Noyce [28] as

\section{... a solid, liquid, or gas found in or} closely derived from nature. It is homogeneous and contains one or more radionuclides, present from environmental processes or by addition in the laboratory, whose concentrations have been rigorously assayed and certified...

For those materials in which the radionuclides were introduced into the matrix by environmental processes we further designate here as Environmentally Quasi-equilibrated Materials (EQMs) while those materials in which the radionuclides were introduced by delibrate addition in the laboratory we call Spiked Materials (SMs). The NMSs can be used to develop new wet-chemical procedures, to evaluate chemical procedures already in use, calibrate instruments, act as materials for interlaboratory comparisons, test the competence of technicians to do chemical assays, and demonstrate that data outputs are reliable [28].

To date, NBS has produced four NMSs: the River Sediment, Mancos Shale, Pottery Clay, and Fly Ash from coal combustion (from Tables 3 and 4). SRM 4350, the River Sediment, is an example of an EQM. The radionuclides certified by NBS include the alpha-particle emitters $239 \mathrm{pu}$ plus ${ }^{240} \mathrm{Pu}$, the pure beta-particle emitters $90 \mathrm{Sr}$ and $90 \mathrm{\gamma}$, and the gamma-ray emitters $40 \mathrm{~K},{ }^{4} \mathrm{Mn},{ }^{60} \mathrm{Co}$, ${ }^{65} \mathrm{Zn},{ }^{137} \mathrm{Cs},{ }^{152} \mathrm{Eu},{ }^{154} \mathrm{Eu}$, and $228 \mathrm{Ac}$ [29].

The Mancos Shale and Fly Ash are also EQMs, and both are certified for ${ }^{226} \mathrm{Ra}$ and ${ }^{228} \mathrm{Ra}$ radioactivity concentrations.

An example of a calibrated Spiked Material is the Pottery Clay mixed-gamma-ray emission-rate standard. In this case, the material was quantitatively spiked with calibrated solutions of five radionuclides $\left(65 \mathrm{Zn}, 88 \mathrm{y},{ }^{113} \mathrm{Sn},{ }^{3} 7 \mathrm{Cs}\right.$, and $\left.{ }^{139} \mathrm{Ce}\right)$. 
There has been some discussion about which type of NMS is preferable for presenting radioanalytical problems. Some of the factors affecting the suitability of EQMs and SMs will now be addressed.

When using NMSs, it is important to keep in mind the mechanism of nuclide addition to the material $[29,30,31,32,33]$. For EQMs, it is presumed that if the radionuclides have been in the environment for some time, natural processes would have brought them into chemical equilibrium. Strontium-90 and cesium-137, for example, require only a relatively short time to reach an equilibrium state in the environment. Many radionuclides, however, require long periods of exposure to the environment to attain chemical equilibrium. Plutonium dioxide, for example, is highly resistant to weathering and is likely to require extremely long exposure times before it could be considered equilibrated with the environment.

Other problems concerned with the produc$t i$ on of EQMs are that the desired matrix material may be limited in quantity, the activity levels may not be suitable, there is no prior knowledge of the concentration of the radionuclides, and because of the low radioactivityconcentrations the possibility of confirmation by independent methods is limited.

The SMs, in principle, have considerably greater flexibility than EQMs. There is control over the concentration and composition of the radionuclides being added (particularly useful for short-lived radionuclides), known analytical problems can be "built into" the material, and the cost may be lower because the calibration and characterization of the material may require less effort.

Does the chemical form of the radionuclides in an environmental sample significantly affect the assay? Herein lies a presumed limitation of SMs as test samples which are to be subjected to destructive analysis. In most cases it is probable that spiking results in chemical species which do not correspond to those found in the environment. Furthermore, since environmental speciation of the radionuclides are often not well known or characterized, duplication of the chemical forms of the radionuclides in environmental samples by spiking may not be possible. Thus, the spiked radionuclides may not behave in the same way during radiochemical analysis as those nuclides which were incorporated by natural processes.

For some purposes, chemical equivalence is of no consequence. For example, if the material is to be assayed by $\mathrm{NaI}(\mathrm{Tl})$ - or $\mathrm{Ge}(\mathrm{Li})$ detector spectrometry, the chemical speciation of the radionuclides does not significantly affect the quality of the assay. However, if se- lective chemical leaching is the method of choice, it is important that the radionuclide of interest be as close to its environmental state as possible to justify the validity of the assay. Even with these limitations on EQMs and SMs, we feel that NMSs will still serve as valid test samples for many environmental-radioassay methods.

The calibrated River Sediment, Fly Ash, Mancos Shale, and Pottery Clay, of course, cannot cover all the existing needs for environmentalradioactivity-reference materials. Other NMSS are also needed. The Low-Level Techniques Working Group of the ICRM is comprised of representatives from a number of national and international metrology and standards laboratories. The Working Group held an international symposium in Paris, in 1976, to identify problems in $10 \mathrm{w}-1$ evel radioactivity measurements $[34,35]$. I1977, another conference was convened at Woods Hole Oceanographic Institution (WHOI). The needs for NMSS and assignment of priorities for their production were the topics of this meeting. The list of highpriority materials as human organs, foods, water, sediments, soils, and air particlulates. These materials are to be calibrated for activation and fission products as well as a number of natural radionuclides, and alpha-particle emitters when found to be present.

One of the more important considerations was that these materials provide a long-term comparison base for measurement quality-assurance programs. Consequently, quantities of materials of the order of several-hundred kilograms are needed. The production of such large quantities of calibrated materials by individual QA laboratories would have been nearly impossible not only because the requirements for manpower, time, and calibration equipment would be prohibitive, but also specialized materials-handling equipment and expertise would also be needed. NBS, therefore, has undertaken the responsibility for producing some of the requested NMSs with the cooperation of other domestic and national Taboratories.

From the initial list of requested materials in Table 6 , seven materials were selected to be produced first. These materials are listed in Table 7 , along with their production progress [36]. The Human Lung and Liver are plutonium-contaminated tissue. The Rocky F? ats Soils - East and West - are low-calcium soils with moderate levels of plutonium. The Columbia River Sediment is a fresh water, low-calcium river sediment containing activation and fission products and alphaparticle emitters at low concentrations. Gyttja is a freshwater-lake sediment of high-organic content that contains moderate levels of activation and fission products. And, the Peruvian Soil will represent a background "blank" because it is expected to be nearly free of fallout radionuclides. All of the collecting, milling, bottling, and homogeneity measurements 
Table 6

Calibrated materials needed for environmental radioactivity measurements.

\begin{tabular}{lll} 
Matrix & $\begin{array}{l}\text { Radio- } \\
\text { nuclides }\end{array}$ & $\begin{array}{l}\text { Ten-year } \\
\text { requirements }\end{array}$ \\
\hline
\end{tabular}

Soil:

High $\mathrm{Ca}$ alpha-particle $\quad 5,000$

$\begin{array}{ccc} & \text { emitters } & \text { aliquants } \\ \text { Low Ca } & 90 \text { Sr, } 137 \mathrm{Cs}, & (1-\mathrm{kg} \\ & 210 \mathrm{pb} & \text { samples })\end{array}$

Sediments:

High Ca

Low Ca

alpha- and betaparticle emitters, photonemitters

1,600

al iquants

(100-g

samples)

Mill

tailings

Water:

$$
\begin{aligned}
& \text { natural radio- } \\
& \text { nuclides, } \\
& \text { alpha-particle } \\
& \text { emitters, }{ }^{60} \mathrm{Co}, \\
& 90 \mathrm{Sr}-90 \mathrm{H}{ }^{3} \mathrm{H}, \\
& 106 \mathrm{Ru},{ }^{34} \mathrm{Cs}, \\
& 137 \mathrm{Cs}
\end{aligned}
$$

Several thousand aliquants

(50- to

$100-\mathrm{ml}$

samples)

Biological:

Lung

Liver

Bone

Food

Milk

Sea clam

Sea hare

Seaweed

alpha-partiçle

emitters, ${ }^{3} \mathrm{H}$,

products,

activation

products

\section{Severa 1}

hundred

al iquants

Air:

Filters natural radionuclides

have been completed for these materials.

Assays of the various radionuclides is just beginning and will be a fairly lengthy process. Confirmatory and additional assays will be carried out by other domestic and national laboratories such as Battelle NW, Environmental Monitoring Laboratory, Los Alamos Scientific Laboratory, RESL, Service Central de Protection Contre les Rayonnements Ionisants, and WHOI. We are grateful for the efforts of these moral and financial support of the EPA, NRC, and the U.S. Department of Energy.
Tests of Sampling, Preparation, and Storage Procedures

The third phase of the traceability scheme has not yet been implemented and will be left for future discussion.

\section{Future Plans}

Future efforts by the low-level radioactivity measurements group at NBS will include continuing traceability programs with RESL and EPA, particularly for those radionuclides that they distribute but are not as yet traceable to NBS. We hope to develop new solution SRMs of ${ }^{99} \mathrm{Tc}, 208 \mathrm{po}$ or $209 \mathrm{Po}, 210 \mathrm{~Pb}, 227 \mathrm{Ac}$, and $232 \mathrm{U}$. There will also be continued development of NMSs which may include matrices such as animal bone, vegetation, air filters, and uranium-mill tailings. It is also anticipated that reference sources of noble gases for the calibration of thermoluminescent dosimeters (TLDs) will be developed. Charcoal traps containing ${ }^{85} \mathrm{Kr}$, $133 \mathrm{Xe}$, and $135 \mathrm{Xe}$ will be produced in addition to the present gaseous SRMs. And lastly, methods are to be developed for exposing TLDs to $85 \mathrm{Kr}$ and $133 \mathrm{Xe}$.

\section{Acknowledgments}

The authors thank Dr. J.M.R. Hutchinson, who is the coordinator of the Low-Level MeasurementTechnique Group, ICRM, and Dr. W. B. Mann for their comments on the manuscript.

\section{References}

[1] L.M. Cavallo, National Standards for Radioactivity Measurements, Traceability for Ionizing Radiation Measurements, May 8-9, 1980 , National Bureau of Standards, U.S. Department of Commerce, these proceedings.

[2]

B.M. Coursey, J.M.R. Hutchinson, L.L. Lucas, W.B. Mann, T. Matsumura, and J.R. Noyce, Radioactivity Standards for Environmental Monitoring, J. Radioanal. Chem., 43, 451, (1978).

[3]

J.M.R. Hutchinson, W.B. Mann, and R.W. Perkins, Low-Level Radioactivity Measurements, Nucl . Inst. Methods, 112, 305 (1973). 
TABLE 7

Status of Callbrated Enviromental Material

\begin{tabular}{|c|c|c|c|c|c|c|c|c|}
\hline & $\begin{array}{l}\text { Rocky Flats } \\
\text { Soll-Hest }\end{array}$ & $\begin{array}{r}\text { Stat } \\
\text { Rocky Flats } \\
\text { Soil-East } \\
\end{array}$ & $\begin{array}{c}\text { tus of cal } \\
\text { Peruvian } \\
\text { Soil }\end{array}$ & $\begin{array}{c}\text { 1brated Environ } \\
\text { Columbia River } \\
\text { Sediments }\end{array}$ & Gyttja & $\begin{array}{l}\text { Laterial } \\
\text { Ituman } \\
\text { Liver } \\
\end{array}$ & $\begin{array}{l}\text { Human } \\
\text { Lung } \\
\end{array}$ & Renarks \\
\hline Collected & 7 & $\frac{1}{2}$ & 7 & 7 & 1 & 7 & 1 & Several hundred kilograns \\
\hline Dried & 1 & 1 & 7 & $\begin{array}{l}\text { Frefze } \\
\text { Oried }\end{array}$ & $\begin{array}{l}\text { Frétze } \\
\text { Oried }\end{array}$ & $\begin{array}{l}\text { Frkeze } \\
\text { Oried }\end{array}$ & $\begin{array}{l}\text { Frbeze } \\
\text { Oried }\end{array}$ & $\begin{array}{l}\text { Air dried or freeze dried at } \\
<38^{\circ} \mathrm{C} \text { shelf temperature }\end{array}$ \\
\hline Milled & ! & 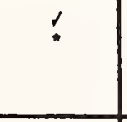 & $\vdots$ & $\vdots$ & $:$ & $\because$ & 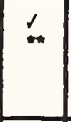 & 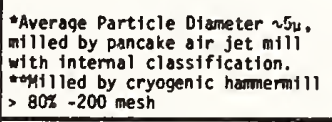 \\
\hline 8lended & $109^{\prime} \mathrm{kg}$ & $132^{\prime} \mathrm{kg}$ & $50^{\prime} \mathrm{kg}$ & $190^{\prime} \mathrm{kg}$ & $59^{\prime} \mathrm{kg}$ & $34^{\prime} \mathrm{kg}$ & $10^{\prime} \mathrm{kg}$ & $\begin{array}{l}\text { ay blender used w/intenstfiter } \\
\text { bar, blended for } 30 \mathrm{~min} \text {. }\end{array}$ \\
\hline $\begin{array}{l}\text { NaI } \\
\text { Homogeneity } \\
\text { Determination }\end{array}$ & 1 & 1 & 1 & 1 & $\checkmark$ & W/A & N/A & Inhomogenet ty < $0.3 \%$ (3s) \\
\hline $\begin{array}{l}\text { Preliminary } \\
\text { Assay }\end{array}$ & 8 & 1 & 1 & 1 & $\checkmark$ & H/A & $M / A$ & $\begin{array}{l}\text { Ge(L1) spectroscopy \& } \\
\text { radiochemistry }\end{array}$ \\
\hline Bottled & $r$ & $\checkmark$ & 1 & 1 & $\checkmark$ & $\checkmark$ & $\checkmark$ & \\
\hline $\begin{array}{l}\text { Semi-Quantitative } \\
\text { Elenental } \\
\text { Determiniation }\end{array}$ & 1 & 1 & $\checkmark$ & 1 & 1 & N/A & N/A & $\begin{array}{l}\text { Measurements by emission } \\
\text { spectroscopy }\end{array}$ \\
\hline Assay & & & & & & & & \\
\hline
\end{tabular}

[4] L.M. Cavallo, M. Ehrlich, and J.M.R. Hutchinson, Traceability in Ionizing Radiation Measurements Systems, Proceedings of "IAEA International Symposium on National and International Standardization of Radiation Dosimetry," At lanta, Georgia, December 5-9, 1977, IAEA-SM-222/18, Vienna (1978).

[5]

W.B. Mann, Radionuclide Metrology and Quality Assurance, Environmental Monitoring Series, EPA-670/4-75-006 (June, 1975), Proceedings of "Activities and Needs Related to Radioactivity Standards for Environmental Measurements", U.S. Environmental Protect i on Agency, Washingt on, D.C., August 21, 1973.

[6]

L.M. Cavallo, B.M. Coursey, S.B. Garfinkel, J.M.R. Hutchinson, and W.B. Mann, Needs for Radioactivity Standards and Measurements in Different Fields, Nucl. Inst. Methods, $112,5(1973)$.

\section{[7]}

W.B. Mann, and J.P. Cali, Traceability and Standard Reference Materials, Proceedings of "Standardization, Performance and Quality Control in Nuclear Medicine", June 12-14, 1975, National Bureau of Standards, Washington, D.C., The C.V. Mosby Company, Saint Louis, Missouri, (1975).
[8]

W.B. Mann, Reliability and Traceability in Radioactivity Measurements, Proceedings of "Southeastern Workshop on the Utilization and Interpretation of Environmental Radiation Data", Orlando, Florida, March 1-3, 1976.

[9]

W.B. Mann, The Radioactivity Standards Program of the National Bureau of Standards, Proceedings of "IAEA International Symposium on National and Internationa 1 Standardization of Radiation Dosimetry," At lanta, Georgia, December 5-9, 1977, IAEA-SM-222/11, Vienna (1978).

[10]

B.M. Coursey, J.R. Noyce, and J.M.R. Hutchinson, Interlaboratory Intercomparisons of Radioactivity Measurements using National Bureau of Standards Mixed Radionuclide Test Solutions, National Bureau of Standards Technical Note 875, U.S. Department of Commerce, Washington, D.C. (1975).

[11]

H.L. Volchok and M. Feiner, A Radioanalytical Laboratory Intercomparison Exercise, EM-366, Environmental Measurements Laboratory, U.S. Department of Energy, New York, New York (October, 1979). 
A.N. Jarvis, The EPA National Quality Assurance Program, Traceability for I onizing Radiation Measurements, May 8-9, 1980 , National Bureau of Standards, U.S. Department of Commerce, these proceedings.

\section{[13]}

L.K. Cohen, NRC Traceability Concerns in its Inspection and Enforcement Program, Traceability for Ionizing Radiation Measurements, May 8-9, 1980, National Bureau of Standards, U.S. Department of Commerce, these proceedings.

[14]

National Council on Radiation Protection and Measurements, A Handbook of Radioactivity Meaurements Procedures, NRCP Report No. 58, Chapter 8, Nat1. Council Radiat. Protection Measurements, Washington, D.C.

(1978).

[15]

L.H. Ziegler, Radioactivity Standards Distribution Program 1978-1979, EPA-600/4-78033, U.S. Environmental Protection Agency, Environmental Monitoring and Support Laboratory, Las Vegas, Nevada (1978).

[16]

Quality Assurance Branch, Environmental Radioactivity Laboratory Intercomparison Studies Program 1978-1979, EPA-600/4-78-032, U.S. Environmental Protection Agency, Environmental Monitoring and Support Laboratory, Las Vegas, Nevada (1978).

[17]

U.S. Nuclear Regulatory Commission, Quality Assurance for Radiological Monitoring Programs (Normal Operations) - Effluent Streams and the Environment, Regulatory Guide 4.15, Office of Standards Development, U.S. Nuclear Regulatory Commission, Washington, D.C. (February, 1979).

[18]

L.K. Cohen, Quality Assurance for Effluent and Environmental Monitoring - A Nuclear Regulatory Commission Overview, ASTM Special Technical Publication 698, J.J. Kelly, ed., Amer. Soc. Testing Materials, Philadelphia, Pennsylvania, 282 (1980).

[19]

D. Golas, Traceability Programs for Nuclear Medicine, Traceability for Ionizing Radiation Measurements, May 8-9, 1980, National Bureau of Standards, U.S. Department of Commerce, these proceedings.
[20]

B.M. Coursey, J.M.R. Hutchinson, and M.P. Unterweger, Calibration of Ge(Li) Gamma-Ray Spectrometers for the Measurement of Radioactive Noble Gases, Int. J. Appl. Rad. Isotopes, 28, 551 (1977).

[21]

B.M. Coursey, Use of NBS Mixed-Radionuclide Gamma-Ray Standards for Calibration of $\mathrm{Ge}(\mathrm{Li})$ Detectors Used in the Assay of Environmental Radioactivity, Proceedings of "Symposium for the Safe Use of Radiation", National Bureau of Standards Special Publication 456 (November, 1976), U.S. Department of Commerce, 173, March 1-4, 1976.

[22]

C.W. Sill, Problems in Sample Treatment in Trace Analysis, Accuracy in Trace Analysis: Sampling, Sample Handling, Analysis, NBS Special Publication 422, P.D. LaFleur, ed., U.S. Department of Commerce, Washington, D.C., Vol. 1, 463 (1976).

[23]

T.T. Gorsuch, Dissolution of Organic Materials, Accuracy in Trace Analysis: Sampling, Sample Handling, Analysis, NBS Special Publication 422, P.D. LaFleur, ed., U.S. Department of Commerce, Washington, D.C., Vol. 1, 491 (1976).

[24]

International Atomic Energy Agency, Reference Methods for Marine Radioactivity Studies, Technical Reports Series No. 118, Vienna (1970).

[25]

T.J. Murphy, The Role of the Analytical Blank in Accurate Trace Analysis, Accuracy in Trace Analysis: Sampling, Sample Handling, Analysis, NBS Special Publication 422, P.D. LaFleur, ed., J.S. Department of Commerce, Washington, D.C., Vol. 1, 509 (1976).

[26]

K.M. Wong, T.A. Jokela, and V.E. Noshk in, Problems Associated with Transuranium Determination of Suspended Solids in Seawater Samples, Radioelement Analysis Progress and Problems, Proceedings of "Twenty-Third Conference on Analytical Chemistry in Energy Technology", W.S. Lyon, ed., Ann Arbor Science Publishers Inc., Ann Arbor, Michigan, 207 (1967). 
[27]

E.I. Hamilton, M.J. Minski, and J.J. Cleary, The Loss of Elements During Decomposition of Biological Materials, with Special Reference to Arsenic, Sodium, Strontium and Zinc, Analyst, 92, 257 (1967).

[28]

J.R. Noyce, Standards for the Assay of Radionuclides in Solid Environmental Samples, Effluent and Environmental Radiation Surveillance, ASTM Special Technical Publication 698, J.J. Kelly, ed., Amer. Soc. Testing Materials, Philadelphia, Pennsylvania, 309 (1980).

[29]

J.R. Noyce, J.M.R. Hutchinson, W.B. Mann, and P.A. Mullen, Development of a National Bureau of Standards Environmental Radioactivity Standard: River Sediment, Proceedings of "International Conference on Environmental Sensing and Assessment", Las Vegas, Nevada, Sept. 15-19, 1975, IEEÉ, Inc., Annals No. 75CH1004-I 19-5.

[30]

V.T. Bowen, Natural Matrix Standards, Environment Internationa $1,1,35$ (1978).

[31]

C.W. Sill, The Case Against Natural

Matrix Standards, Twenty-Fifth Annual Conference on Bioassay, Environmental, and Analytical Chemistry, Las Vegas, Nevada, October 31 - November 1, 1979.

[32]

V.T. Bowen and H.L. Volchok, Spiked Sample Standards: Their Uses and Disadvantages in Analytical Quality Control, Environmental Internationa 1, in press (1980).

[33]

D.G. 01son, Synthesized Standards in Natural Matrices, Environment International, in press (1980).
[34]

J.M.R. Hutchinson and W.B. Mann, ed., Metrology Needs in the Measurement of Environmental Radioactivity, Environment Internationa 1, 1, 1 (1978).

[35]

J.M.R. Hutchinson, Possible Areas of Effort by the International Committee on Radionuclide Metrology in the Field of Low-Leve 1 Radioactivity, Environment International, 1, 11 (1978).

[36]

H.L. Volchok, M. Feiner, K.G.W. Inn, and J.F. McInroy, Development of Some Natural Matrix Standards - Progress Report, Environment International, in press (1980). 


\title{
NRC TRACEABILITY CONCERNS IN ITS INSPECTION AND ENFORCEMENT PROGRAM
}

\author{
Lawrence K. Cohen \\ U. S. Nuclear Regulatory Commission \\ Washington, D.C. 20555
}

\begin{abstract}
This paper discusses NRC's traceability requirements in the licensing process and in its inspection programs. It describes the approach and direction NRC has taken to achieve traceability for its own program and to provide a means for the licensee as well.
\end{abstract}

(Enforcement; inspections; NRC; radiation measurements; regulations; regulatory guides; traceability)

\section{Introduction}

In the area of radiation measurements, the U.S. Nuclear Regulatory Commission (NRC) has imposed upon their licensees technical specifications and license conditions to protect the radiation worker and general public from excessive radiation exposure from facilities. Among these requirements, it is stated that radiation standards and measurements systems be "traceable." This requirement of traceability, however, is not limited to only NRC licensees. NRC has also invoked similar requirements on its own radiation measurements programs being conducted by the NRC Office of Inspection and Enforcement (OIE).

"Traceability" is a term that often triggers a spectrum of responses, especially from licensees, ranging from confusion and perplexity on the one hand to frustration on the other. We all know that traceability is perhaps a noble, idealistic goal for which one should strive and achieve, but many people are unsure what needs to be done, how to do it, or what traceability really means. The concept of traceability is mostly undefined, vague, often generating misunderstanding. There is an abundance of discussions, definitions, and papers covering the subject, with no apparent consensus of opinion.

\section{Traceability}

Traceability Requirements in the Regulatory Process

When writing regulations, technical specifications, and regulatory guides, regulators feel compelled to include, for example, some ambigwous statement about traceability to the National Bureau of Standards Radiation Measurement System. Figure 1 provides a sampling of some of the statements that have been found in earlier regulatory guides and technical specifications.

Regulatory Guide 1.21 (on measuring effluents from power reactors), P. 5, Section 11C:

"Calibrations of measuring equipment should be performed using reference standards certified by the National Bureau of Standards or standards that have been calibrated against standards certified by the National Bureau of Standards."

Regulatory Guide 4.14 (on measuring effluents from uranium mills), P. 4, Section 4.3:

"To the extent possible, calibrations of measuring equipment should be performed by using radioactive sources that have been calibrated by a measurement system traceable to the National Bureau of Standards' radiation measurements system. ... Functional tests, i.e., routine checks performed to demonstrate that a given instrument is in working condition, may be performed using sources that are not calibrated by a system traceable to the National Bureau of Standards."

Regulatory Guide 4.15 (on quality assurance for radiological effluent and environmental monitoring), P. 4, Section 6.1: "Radionuclide standards that have been certified by the NBS, or standards that have been standardized using a measurement system that is traceable to that of the NBS, should be used when such standards are available. Otherwise standards should be obtained from other reputable suppliers."

Figure 1. Statements concerning calibrations, traceability, and NBS in NRC Regulatory Guides and Technical Specifications. 
Regulatory Guide 4.15 (on quality control for continuous effluent monitoring systems), P. 7, Section 7:

"Initial calibration of each measuring system should be performed using one or more of the reference standards thai are certified by the National Bureau of Standards or that are calibrated by a measurement system that is traceable to that of the National Bureau of Standards."

10 CFR 50, Appendix I, Technical Specifications for PWRs, Table 4.3-11, Radioactive Liquid Effluent Monitoring Instrumentation Surveillance Requirements, P. 3/4 3-53:

"The CHANNEL CALIBRATION shall include the use of a known (traceable to the National Bureau of Standards radiation measurement system) liquid radioactive source positioned in a reproducible geometry with respect to the sensor and emitting beta and gamma radiation with fluences and energies in the ranges measured by the channel during normal operation." (A similar statement is made regarding gaseous effluent monitoring.)

Example of a type of statement no longer being used by NRC:

"All liquid effluent radiation monitors shall be calibrated at least quarterly by means of a radioactive source which has been calibrated to a National Bureau of Standards source."

Figure 1 (continued)

For those who are responsible for the inspection and enforcement of these requirements and ensuring that the licensee is complying with them, namely the NRC inspectors, these requirements present a very difficult burden. There have been many attempts to solve this problem. One solution was to replace the word "traceable" with "relatable;" i.e., "Standards that are relatable to the NBS, etc." As one would expect, this was no solution. It merely produced additional confusion.

In February 1979, the revision to Regulatory Guide 4.15, "Quality Assurance for Radiological
Monitoring Programs (Normal Operations) - Effluent Streams and the Environment," was issued to ensure that radiation reference standards used by the licensee were indeed traced back to NBS. We believe that this is an important aspect of a good quality assurance program. To prevent confusion, we deleted the term "traceable" in reference to standards and replaced it with a paragraph that, although more wordy, was more meaningful, practical, and useful. The paragraph spelled out exactly what had to be done. This paragraph is shown in Figure 2. Similar phrasing was used, incidentally, in the Standard Effluent Technical Specifications shown in Figure 3.

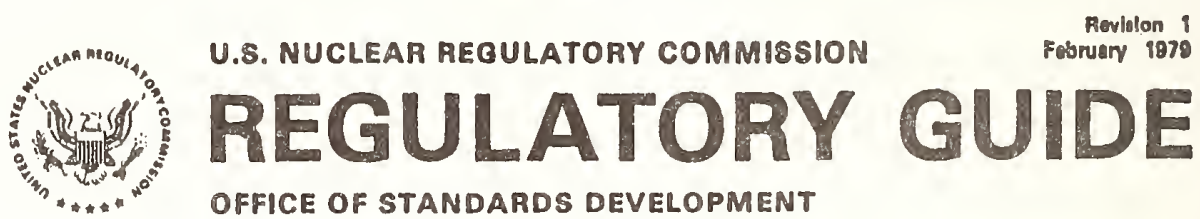

REQULATOAY GUIDE 4.15

QUALITY ASSURANCE FOR RADIOLOGICAL MONITORINO PROQRAMS (NORMAL OPERATIONS) - EFFLUENT STREAMS AND THE ENVIFONMENT

" RADIONUCLIDE STANDARDS tHAT HAVE BEeN CERTIFI由 BY NBS OR STANDARDS THAT HAVE BEEN OBTAINED FROM SUPPLIERS WHO PARTICIPATE IN MEASUREMENT ASSURANCE ACTIVITIES WITH NBS"

\section{A FOOT NOTE FOLOWING THIS PHRASE DESCRIBES THE MEASUREMENT ASSURANCE PROGRAM (MAP):}

(1) The SUPPLier SUBMitS A CALIBRATED RADIOACTIVITY SOURCE TO NBS FOR CONFIRMATION,

(2) NBS PROVIDES CALIBRATED RADIOACTIVITY SOURCES OF UNDISCLOSED ACTIVITY TO THE SUPPLIER.

Figure 2. Standard statement from Regulatory Guide 4.15. 
(3) The initial CHANNEL CALIBRATION shall be performed using one or more of the reference standards certified by the National Bureau of Standards or using standards that have been obtained from suppliers that participate in measurement assurance activities with NBS. These standards shall permit calibrating the system over its intended range of energy and measurement range. For subsequent CHANNEL CALIBRATION, sources that have been related to the initial calibration shall be used. (Operating plants may substitute previously established calibration procedures for this requirement.)

Figure 3. Standard statement from Standard Effluent Technical Specifications.

In subsequent discussions with suppliers of radioactive standards, they appeared to understand procedures and mechanisms. However, they did complain about the cost of the service. Several speakers have already discussed the Measurement Assurance Program (MAP) to which this paragraph refers, so I do not see any need for a further elaboration. I would like to thank NBS for their assistance in writing this section of the guide.

\section{Traceability in the NRC Measurement Program}

It is very important that radiation measurements made by NRC in the course of an inspection, investigation, or in response to emergencies be accurate and reproducible. We must be able to demonstrate that our values are correct and will withstand a rigorous technical and judicious review. We must be able to establish a level of credibility with the public. Those considerations are becoming more and more important as NRC expands its Independent Measurements Program (IMP) in the Office of Inspection and Enforcement. Increasing emphasis is being placed on independent measurements to complement the traditional inspection techniques of records and procedures review, evaluation, discussion, and direct observation. Independent measurements provide convincing direct evidence of the licensee's performance and are congruent with the other techniques. Independent measurements are being included in all routine inspections at all NRC-licensed facilities. They cover reactors, fuel facilities, byproduct material processors and users, and medical users. At these facilities, inspectors or NRC contractors take and analyze inplant samples, such as effluents, or collect environmental media samples in the environs. Similarly, they also take direct radiation measurements in the plant and environs.

\section{The RESL Connection}

Since the beginning of a quasi-formal measurements program in 1972, the Radiological and Environmental Sciences Laboratory (RESL) in Idaho Falls (formerly HSL) acted as the NRC reference laboratory and performed the radiological analyses. At the present time, RESL performs over 2000 analyses of over 800 samples a year submitted by the regional inspectors. It was realized at the beginning of the program that some assurance was needed to demonstrate that the analytical results were accurate.
In January 1973, NRC entered into a contract with NBS to develop the traceability of the NRC reference laboratory (RESL) to the NBS system [National Radioactivity Measurements System (NRMS)]. Here we are talking about "direct traceability." The mechanism to achieve this was by means of a predetermined program of tests. This program required the NRC reference 1 aboratory to annually assay 8 to 12 prepared NBS solutions of preselected radionuclides of unknown activity. Included in the selection were alpha emitters, beta emitters, and single gamma-ray emitters. Under the agreement between RESL and NBS, RESL will report its measurements to NBS. NBS will then issue a report of the test presenting the ratio of the RESL-to-NBS radioactivities concentration values. If the ratio lies within the range of 5 percent, the report will state that RESL has demonstrated traceability to the NBS to within 5 percent. Figure 4 shows a histogram of the results of past tests since the inception of the program. The graph shows that the RESL measurements have consistently clustered within 1 percent of the NBS value.

As part of the agreement with the NRC,. NBS measures randomly selected samples from batches of standards provided by RESL to regional offices and NRC contractors (i.e., States). Periodically, NBS also distributes to RESL, NRC contractors, and regional offices special standards such as $\mathrm{Kr}-85, \mathrm{Xe}-127$ and $\mathrm{Xe}-133$ gas samples. However, all of these types of samples sent to RESL are blind samples that are used in calibration and testing.

\section{The NRC Indirect Traceability Connection}

In the last two years, NRC has been developing its own capability to perform radiation measurements. We have provided each of the five regions with mobile laboratories and propose to equip each regional office with additional laboratory instrumentation. RESL will play an important role in a rigorous quality assurance program, as well as provide the radiochemical capability that is required.

Interrelationship Between NRC, NBS, RESL and Other Laboratories

Figure 5 shows the interrelationship that exists between the various laboratories. Although the intercomparisons and other efforts do not constitute traceability, they help to improve the quality of the measurements performed. 


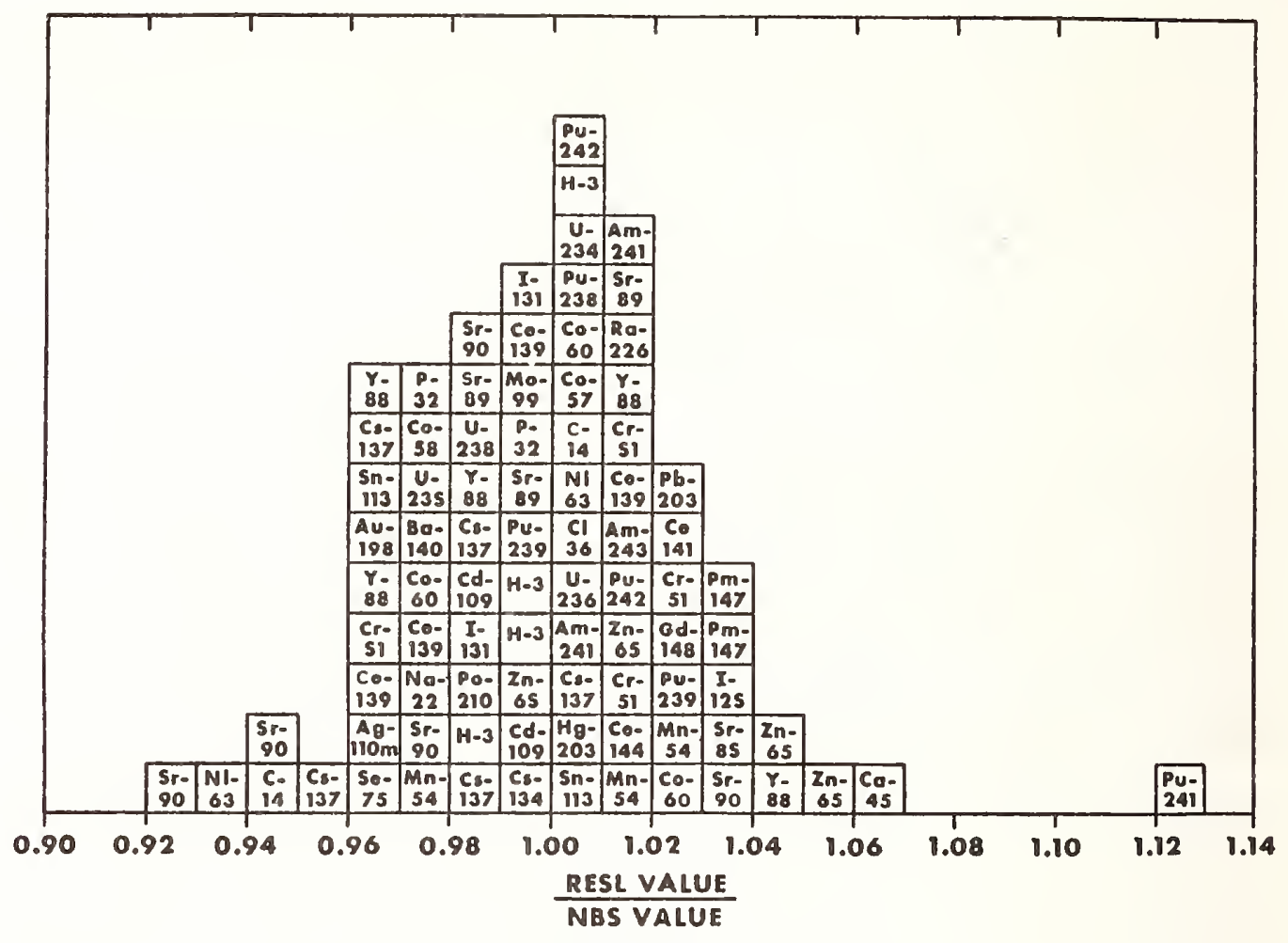

Figure 4. Historical comparison of traceability measurements.

\section{Traceability in the Area of Direct Radiation Measurements}

As previously indicated, we have also developed our capability to perform radiation surveys in the plant and monitor the facilities environs. It became apparent after losing an enforcement case over the inadequate calibration of an NRC survey meter that a similar arrangement was needed in the field of direct radiation measurements. I would like to divide the subject into the calibration of radiation protection instruments and the thermoluminescent dosimeter (TLD) devices. For radiation protection instruments, I would like to see the establishment of regional calibration facilities directly traceable to NBS as was done for medical instrumentation. At present, we are looking into the establishment of an NRC calibration facility to handle our needs. Another speaker will discuss the question of traceability of these instruments. Figure 6 shows the proposed traceability pathways.

After the accident at TMI, the OIE initiated an NRC TLD Direct Radiation Monitoring Network, which was a departure from our previous position. In this program, up to fifty dosimeters will be placed around all operating reactor sites and eventually will apply to other major licensees. This will provide, for the first time, consistent and accurate measurements of the ambient radiation levels throughout the country. To ensure the accuracy of this statement, I an developing a direct traceability protocol with NBS.

\section{Conclusion}

In conclusion, our interest in the subject of traceability is our desire to improve the quality of radiation measurements performed by licensees as well as by NRC employees. We approach this objectivity by the following means:

1. Imposing upon radiation users wellwritten, clear, and meaningful regulations and requirements.

2. Developing an effective and efficient inspection program.

3. Establishing a mechanism for users of radioactivity to enter into a program to demonstrate the accuracy of these measurements. 


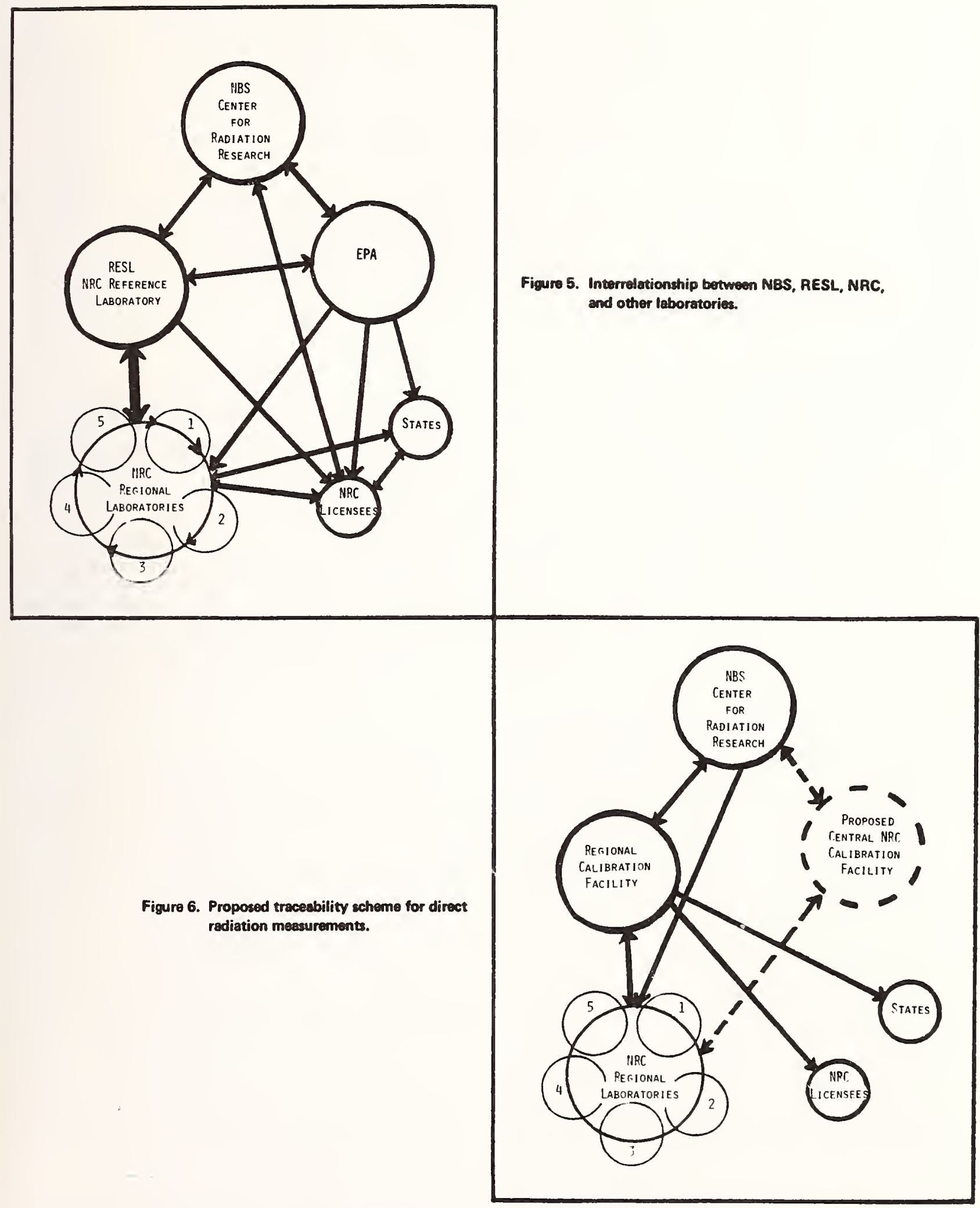


RADON AND RADON DAUGHTER FIELD MEASUREMENTS

\author{
Andreas C. George \\ Environmental Measurements Laboratory \\ U. S. Department of Energy \\ New York, NY 10014
}

\begin{abstract}
Practical methods for measuring the concentration of radon and radon daughters in air are reviewed, and procedures and instruments are recommended for reliable field measurements.
\end{abstract}

(environmental measurements; radon; radon daughters)

\section{Introduction}

Radon and its daughters is causing increasing concern to many investigators involved in research and situations where diagnostic measurements for source identification and quantification are needed.

While radon-222 and 1 ts daughters contribute the highest fraction of the natural radiation dose to man, we have been more concerned by certain special cases of exposure. These include the occupational exposure of uranium miners and uranium mill workers, the general public in and around areas of enhanced radiation, and more recently inside houses built with materials with high radium-226.

The concentration of radon and its daughters and their contribution to human dose cannot be adequately measured and assessed unless all components of measurement systems are accurately calibrated. Little has been published describing the different calibration methods of all the equipment presently used for radon and radon daughter measurements. The American National Standards Institute (ANSI) issued a standard [1] with specific application in radiation protection in uranium mines. The ANSI procedures do not specify any accuracy requirements. A more comprehensive publication dealing with calibration procedures for radon and radon daughter measurement equipment was issued by the Department of the Interior. [2] The report stresses the necessity for the proper calibration of the radon and radon daughter measurement instrumentation to assure accurate evaluation of the radiation hazard. Although the publication was intended for uranium mining it is very useful for other enviromments.

The instrumentation developed for measurements in uranium mines has evolved with respect to sensitivity and convenience. The widespread need of these instruments in other environments with much lower concentrations necessitated further improvement.

Knowledge of the various kinds of errors encountered in physical measurements is necessary for reliable data interpretation and comparison. In this report I will describe some methods and instruments employed in the determination of radon and radon daughters as well as their applications and limitations so one may be able to choose one method over another for a particular application.

Importance of Radon and Radon Daughter Measurements

The main reason for the high interest in radon and its daughters is their effect on human health. An important stimulus for this interest is the radon releases from the nuclear fuel cycle. Although studies of radon and radon daughters provide us with natural radiation data which can be used as a standard to evaluate health effects to human populations from man-made radionuclides, recently there have been extensive measurement programs in al1 sources of radon in the environment. Some of the areas of interest are:

Nuclear. Energy Industry

Uranium and its decay products are found in a11 industrial activities associated with uranium mining and milling operations. Although the biological hazard data from the uranium mine population were investigated extensively, the evaluation of possible radiological hazards from the waste products of uranium mill tailings is just beginning. Radon measurements are important for determining the adequacy of reclamation programs at uranium tallings.

\section{Phosphate Mining and Processing}

The concentration of natural uranium in 
phosphate ores ranges from 10 to $400 \mathrm{ppm}$. [3] The assessment of the radiological impact of phosphate mining, processing and use is being investigated and appropriate standards and guides will be established. In Florida more than 25,000 acres of mined lands have been reclaimed for residential development and the potential higher levels of alrborne radiation warrant additional studies to define the scope and extent of this problem.

\section{Radon In Natural Gas}

Radon 18 being considered as another source of exposure of inhabitants of buildings as a result of combustion of natural gas in unvented appliances. The concentration of radon in natural gas depends on the well head concentration and transmission time to consumption point. Concentrations of radon ranging from 1 to $l, 500 \mathrm{pC} 1 / \ell$ have been reported.[4]

\section{Radon In Natural Caves}

Every year in the United States an excess of 1 million persons visit some of the large caves. Usually exposure to tourists will not be large but measurements show that the radiation dose to regular cave workers is likely to reach or exceed the maximum permissible dose. [5]

\section{Radon and Geotherma1 Resources Application}

High radon concentrations in the waste streams of geothermal electric power plants were measured. It is suspected that elevated exposures to radon and 1 ts daughters would occur at the plant and in the surrounding vicinity. Nonelectrical applications of geothermal resources are widespread especlally in the western United States [6] for space heating, domestic hot water sources and for recreational purposes. Their radiological health implications should be investigated by measuring radon concentrations inside structures which use geothermal fluids.

\section{Earthquake Prediction}

Radon measurements in sub-surface waters are being investigated in earthquake prediction. It Is suggested that the tectonic strain of the rock formations may increase the rate of release of radon to the ground water.[7]

\section{Radon In Atmospherlc Tracer Studies}

Since the half-1ife of radon is sufficiently long to allow transport over thousands of miles, It is used to trace continental air masses over the oceans for as long as two weeks. It is also used to study air currents, diffusion and cloud formation and behavior.[8,9]

\section{Radon In Indoor Environments}

Radon diffuses out of building materials (brick, concrete, stone and interior wa11s) and to a greater extent from the soll under the floor and from the domestic water supply.[10] In regions with large deposits of radioactive materials, indoor levels become elevated. In recent years, the construction of energy-efficlent homes resulted in elevated concentrations of radon and other pollutants, many times over that found outdoors. In the late $1970^{\prime} \mathrm{s}$, active solar heating systems were installed in residential and comerclal structures for space heating. To make the system more efficient, the heat is stored in rock bins until needed. Since the natural radioactivity of rocks in different geographical areas differs, the Impact of these rocks on the concentration of indoor radon levels must be investigated.

\section{Instruments and Methods for Radon and Radon Daughter Measurements}

Measurements of the alrborne concentrations of radon and radon daughters are usually categorized by application. Technology is sufficiently deve1oped to meet most demands encountered in field measurements. Choice of the instrument and method depends on the levels to be measured, the accuracy required, equipment availability and convenience. There is an abundance of available instruments for routine laboratory and fleld applications and recently complex instruments have been introduced for research purposes.

There are methods for prompt or instantaneous or grab sampling, continuous, and time-integrating that yleld average concentrations for an extended time period usually for a week or more. Tables 1 and 2 list the most commonly used instruments and methods for radon and radon daughter measurements. Detalled procedures of each method are described in the listed references.

How We11 Can Radon and Radon Daughter Measurements be Made in the Fleld?

The errors of most monitoring techniques are acceptably sma11, when instruments are callbrated and operated properly. The basic errors encountered in environmental measurements are:

Personal errors due to human fallure. This can be traced to deviation from prescribed procedures. In the field, shortcuts in operating procedures usually result in errors which can be eliminated through experience.

Statistical errors due to the random nature of radioactivity. The resulting random errors cannot be prevented but they can be reduced and be accounted for by the application of the proper 
TABLE 1. INSTRUMENTS AND METHODS FOR MEASURING RADON

\begin{tabular}{|c|c|c|c|c|}
\hline $\begin{array}{l}\text { Instrument } \\
\text { and Method }\end{array}$ & Appllcation & Principle of Operation & Sensitivity & Reference \\
\hline Sclntillation flask & $\begin{array}{l}\text { Grab or continuous } \\
\text { saopling }\end{array}$ & Scintillation alpha count & $<0.1 \mathrm{pCl} / \mathrm{l}$ & 11,12 \\
\hline Two filter & $\begin{array}{l}\text { Grab or continuous } \\
\text { sampling }\end{array}$ & $\begin{array}{l}\text { Decay of radon and collection } \\
\text { of daughter producta on second } \\
\text { f1lter; alpha count }\end{array}$ & $0.01-5 \mathrm{pC} 1 / \mathrm{l}$ & 13,14 \\
\hline Pulse Ion 1zation & Grab (laboratory only) & $\begin{array}{l}\text { Sample transferred fato Ion } \\
\text { chamber; pulse ion count }\end{array}$ & $<0.05 \mathrm{pCl} / \mathrm{l}$ & 15 \\
\hline Track etch & Continuous & $\begin{array}{l}\text { Alpha senoltive flims regloter } \\
\text { tracks when etched in NaOH }\end{array}$ & $0.2 \mathrm{pC} 1$ - month $/ \mathrm{L}$ & 16,17 \\
\hline Passive & Continuous & $\begin{array}{l}\text { Radon diffurion Into sensitive } \\
\text { volume. Po-218 collected on } \\
\text { scintiliation counter } \\
\text { electrostatically }\end{array}$ & $0.5 \mathrm{pC} 1 / 2$ & 18 \\
\hline Plastic bag & Time integrating & $\begin{array}{l}\text { Collection of amblent alr } \\
\text { in bag. Transfer in ocintilla- } \\
\text { tion flask; alpha count }\end{array}$ & $<0.1 \mathrm{pC} 1 / \ell$ & 19 \\
\hline Passive monitor & Time integrating & $\begin{array}{l}\text { Radon diffusion Into sensitive } \\
\text { volume. Po-218 collection on } \\
\text { TLD electrostatically }\end{array}$ & $0.03 \mathrm{pC1} / \mathrm{L}$ & 20 \\
\hline
\end{tabular}

TABLE 2. INSTRUMENTS AND METHODS FOR MEASURING RADON DAUGHTERS

\begin{tabular}{|c|c|c|c|c|}
\hline $\begin{array}{l}\text { Ins trument } \\
\text { and Method }\end{array}$ & Application & Principle of Operation & Sens 1t $1 \mathrm{v} 1 \mathrm{ty}$ & Reference \\
\hline Rusnetz and Rolle & $\begin{array}{l}\text { Grab sample for } \\
\text { working level only }\end{array}$ & $\begin{array}{l}\text { Collect sample on filter; } \\
\text { alpha count }\end{array}$ & $0.0005 \mathrm{WL} \star$ & 21,22 \\
\hline $\begin{array}{l}\text { Ts Ivoglou and } \\
\text { modifications }\end{array}$ & $\begin{array}{l}\text { Grab oample for } \\
\text { Individual radon } \\
\text { daughters and working } \\
\text { level }\end{array}$ & $\begin{array}{l}\text { Collect sample on filter } \\
\text { alpha count }\end{array}$ & $\begin{array}{l}0.1 \mathrm{PC} 1 / \mathrm{l} \text { each } \\
\text { of } \operatorname{RaA}, \mathrm{RaB} \text { and } \\
\operatorname{RaC}-0.0005 \mathrm{WL}\end{array}$ & $\begin{array}{l}23,24,25 \text {, } \\
\text { and } 26\end{array}$ \\
\hline Alpha spectrometry & $\begin{array}{l}\text { Grab sample for indi- } \\
\text { vidual radon daughters } \\
\text { and working level }\end{array}$ & $\begin{array}{l}\text { Collect oample on filter, } \\
\text { count in alpha } \\
\text { spectrometer }\end{array}$ & $\begin{array}{l}0.5 \mathrm{pC} 1 / \ell \text { each } \\
\text { of } \mathrm{RaA}, \mathrm{RaB} \text { and } \\
\operatorname{RaC}-0.002 \mathrm{WL}\end{array}$ & 27,28 \\
\hline $\begin{array}{l}\text { Instant working } \\
\text { level monitor }\end{array}$ & $\begin{array}{l}\text { Grab sample for Indi- } \\
\text { vidual radon daughters } \\
\text { and working levels }\end{array}$ & $\begin{array}{l}\text { Automatic sample collectlon, } \\
\text { alpha or alpha and beta count }\end{array}$ & $\begin{array}{l}1 \mathrm{pC} 1 / \mathrm{l} \text { each of } \\
\mathrm{RaA}, \mathrm{RaB} \text { and } \mathrm{RaC}- \\
0.01 \mathrm{WL}\end{array}$ & 29 \\
\hline $\begin{array}{l}\text { Working level } \\
\text { monitor }\end{array}$ & $\begin{array}{l}\text { Time-integrating radon } \\
\text { daughter concentration }\end{array}$ & $\begin{array}{l}\text { Collect sample on filter } \\
(1-2 \text { weeks). Detect with } \\
\text { therwoluminescent matertal }\end{array}$ & $\begin{array}{l}0.0005 \text { WL in a } \\
\text { week }\end{array}$ & $30,31,32$ \\
\hline
\end{tabular}

*1 WL (working level) is the concentration of radon daughters in $1 \&$ of alr that will release $1.3 \times 10^{5} \mathrm{MeV}$ of alpha energy upon complete decay through Po-214. 
statistical methods. In measuring environmental levels of radioactivity, the primary goal is to accumulate statistically meaningful counts within a reasonable period of time. By using the best combination of sensitive volume, pumping rate and counting times we can obtain the required precision. Measurement precision can be determined experimentally by comparing the results of a series of replicate measurements. Usually, measurement precision between $10 \%$ and $20 \%$ is satisfactory.

Systematic errors usually result from malfunctioning instruments and from improper calibration of equipment. The accuracy of a method is measured by calibration against a standard method or by a reliable method traceable to NBS as near as possible to the actual deployment use in the field. Test calibrations should be conducted in large chambers in which the ambient conditions of temperature, relative humidity and dust loading can be simulated for different times of exposure. Our experience at the Environmental Measurements Laboratory (EML) is not to accept the calibration of an instrument as received from a supplier. Although instruments are usually constructed well, we found that they are not necessarily calibrated proper ly.

\section{Radon Measurements}

\section{Scintillation Flask}

For grab samples, the scintillation flask method is one of the oldest, most reliable and widely used both in the laboratory and in the field. Basic equipment consists of a scintillation flask, a vacuum system or pump and a photomultiplier tube counter. Measurement errors with this method may arise due to the following.

Improper flask calibration. In intercalibration exercises in which several agencies and universities participated, we found that the disparity of some of the data was the result of improper calibration. In one exercise in.which 12 groups took part, the reported values of four participants were $10 \mathrm{w}$ by 20 to $35 \%$ and in another two cases were $20 \%$ higher than the expected value.

Leaking flasks. Scintillation flasks from the same production batch that deviate substantially from the ideal calibration are associated with leakage. This is more common with the evacuated type. It is essential that flasks should be leak-tested before calibration and that they be recounted for several days after calibration to observe any deviation from the expected value.

Alpha counting equipment. A radon scintillation flask should be calibrated with the counting equipment intended for the fleld application. Flasks counted on different counters can differ substantially because of different operating vol tage plateaus and their accompanying noise levels. This can be very troublesome when measuring environmental levels of radon.

\section{Two-Filter Method for Radon}

Although this method is not used as much as the scintillation flask it can be designed for a variety of specific applications. The two-filter sensitive volume may range from $.05 \ell$ to $1000 \ell$ depending on the required sensitivity. By varying the sampling flow rate, tube volume, and sampling time, radon concentrations as low as $.01 \mathrm{pCi} / \mathrm{h}$ can be determined.

The common errors encountered are: any leakage around the front filter will tend to increase the radioactivity on the exit filter and overestimate the radon concentration. To avoid this, it is prudent to push rather than draw air through the two-filter device; in this manner the leaks are outwards from the device. The front filter should have essentially $100 \%$ collection efficiency for radon daughter products and the exit filter should have good surface characteristics for the collection of Po-218.

The counting equipment should be standardized with an alpha standard that has the same geometric configuration as the exit filter and approximately the same alpha energy emission. Calibration under different conditions of flow rate, collection time and concentration should be conducted to test the linearity of the system before it is deployed in the field.

\section{Continuous Measurement of Radon}

Continuous reading radon monitors have been found useful for measuring varying concentrations of radon over a long period of time. These types of measurements are more meaningful than grab samples in estimating average exposures. Several kinds of continuously reading radon monitors have been developed to serve this purpose. However, this extra information is derived at a considerable increase in instrument size, complexity and additional cost. The most commonly used continuous radon monitors are:

Radon flask monitor. This instrument is based on the counting of alpha disintegrations produced from radon circulated through a scintillation flask mounted on a PM tube. Previous monitors neglected to take into consideration deposition of radon daughters in the scintillation flask and this resulted in questionable measurements. To avoid this discrepancy, the monitor must be calibrated taking into consideration the total number of counts obtained in 
successive equal time intervals, the detection volume of the scintillation flask, counting efficlency, and correction for the previously deposited radon daughters. $[14,33]$ When this procedure is applied, the radon flask monitor is capable of measuring varying radon concentrations accurately for an indefinite length of time.

Two-filter monitor. The instrument can be designed to measure environmental levels of radon (as low as $0.01 \mathrm{pC} 1 / \mathrm{l}$ ). Like the scintillation flask monitor, it must be calibrated in the same manner as intended for fleld measurements. Corrections for the radioactivity from the previous samples must be made for accurate radon determination. A source of error ts that which arises from the contribution of thoron activity on the fixed exit filter. This can be eliminated by passing the ambient air containing radon and thoron through a delay chamber upstream from the twofilter sensitive volume, which it will allow thoron ( $T \frac{1}{2}=55$ seconds) to decay but will have no effect on the radon.

A modification [34] of the two-filter continuous radon monitor uses an automatic drive that changes the exit filter every hour and transports it into a scintillation counter, thus eliminating the accumulation of thoron daughter products and the need for corrections from the previous hourlong sample.

Passive electrostatic monitor. In principle the monitor is continuously detecting the ambient radon concentration. But as in the case of the scintillation flask and the two-filter monitors, the changes in ambient radon concentration are masked by the previously deposited radon daughters. So far a procedure for correction for the activity associated with radon daughters deposited in previous counting intervals has not been incorporated in the calibration of this instrument. Another deficiency in this instrument that may result in error is the dependence of the instrument on humidity. Tests at EML with similar monitors showed a humidity dependence, namely a $6 \%$ decrease in sensitivity for a $10 \%$ increase in relative humidity.[35]

\section{Time-Integrating Radon Monitor}

Another type of instrument that measures radon concentration over long periods of time is the time-integrating monitor which obtains a single number representing the average concentration during the period of observation.

Plastic bag method. Alr is sampled continuously for 48 hours by pumping ambient air into a $40 \mathrm{l}$ bag at a rate of $10 \mathrm{ml} / \mathrm{min}$. [19] This method requires additional analytical steps by transferring the radon from the bag into a scintillation flask. In addition to errors encountered by the flask method, correction for the decay of radon during the course of sampling are somewhat difficult to make since it is not known exactly when the radon was accumulated in the bag.

Passive environmental monttor. Its principle of measurement [20] is similar to the passiveelectrostatic monitor in that it samples by molecular diffusion. Alr diffuses through a desiccant into the sensitive volume thus elimtnating the effect of humidity on the instrument's performance.

The alpha activity that accumulates on the electrode is detected continuously during exposure by a thin thermoluminescence detector (TLD). After exposure the TLD chip is read in a thermoluminescence reader and its reading is proportional to the time-integrated radon concentration. Calibration of the monitor under different conditions simulating field atmospheres is necessary.

The response of the monitor lags about 5 hours, which is the diffusion period through the desiccant, but over long monitoring periods (usually one week or more) the average concentration in the sensitive volume will equal the average ambient concentration even in varying radon atmospheres.

\section{Radon Daughter Measurements}

A11 measurement methods for radon daughters are based on collecting a known volume of air through a filter in a known time and by counting the activity on the filter during or after sampling. A number of different samplingcounting regimes may be used and the choice depends on the amount of information one seeks. The simplest methods involve a single alpha count and yield a result in WL only. The more sophisticated methods involve several counts and yleld the Individual air concentrations of the three daughter products, Including the WL.

The methods 1isted in Table 2 for measuring radon daughter concentrations by grab sampling are well established. Details of each method are given in the references.

Errors in determining individual radon daughter and WL concentrations result from:

1. measurement of sample volume,

2. filter media characteristics,

3. measurement of collected radioactivity directly on a filter or indirectly on a detector close to the filter.

Al1 three are subject to several sources of errors. 
Inaccuracies in measurements of air sample volume results from lmproper calibration of flowmeters, unstable air samplers, filter holder integrity and incorrect timing period.

Air pump flowmeters should be calibrated for each application. Their calibration is density dependent and care must be taken when used at different altitudes. The pump-flowmeter-train assembly should be calibrated at the same conditions of elevation and at the same resistance caused by the filter and the other component parts in the sampling train. During field sampling an open face filter or filter holder assembly suitable for particulates should be used to prevent radon daughter losses due to plate out. Plate-out losses may be significant in atmospheres with low concentrations of particles (less than 5,000 particles per $\mathrm{cm}^{3}$ ). Some instruments tested by EML were found to be unsuitable for radon daughter sampling. Plate out was high either because the filter was situated at the wrong place during sampling or because of plate out on surfaces upstream from the filter.

Sample timing is very important in the usually short sampling periods used for grab sampling. Errors may be significant if an operator relies on his wristwatch and on his memory. A one-minute mistake in timing causes a $20 \%$ error in air volume alone for a nominal five-minute sample.

The sensitivity of the different grab sampling methods depend on sampling rate, the delay between sampling and counting, and the counting interva1. For low concentrations of radon daughters, such as those encountered outdoors, the precision of the measurement can be improved considerably by sampling a larger volume of air. This can be accomplished by increasing the flowrate and the size of the collection surface. Sample flowrates from $10 \mathrm{l} / \mathrm{min}$ to 300 $\ell / m i n$ can be achleved with available commercial air samplers, and filters ranging in size from 4 $\mathrm{cm}^{2}$ to $80 \mathrm{~cm}^{2}$ can be accommodated with existing samplers and alpha counters. Buildup of filter resistance from dust loading is unimportant for the short sampling periods of 5 to $10 \mathrm{~min}$.

If alpha spectrometry is used for counting, the volume of air is limited because solid state detectors are very small and can handle sma11 filters only. Better sensitivity can be achieved when counting total alpha as in alpha scintillation detectors which are not limited to sample volume. A word of caution in using high volume samplers indoors - if one wants to measure the ambient air, care should be taken not to disturb it during sampling. A high volume sampler, operating at $300 \mathrm{l} / \mathrm{min}$ in a small room, will introduce particulates from its exhaust air. This will disturb the state of equilibrium and attachment of the radon daughiers, although it will not affect the radon concentration. However, with the proper positioning, high volume samplers can be used inside large rooms and outdoors.

\section{Filtex Media Characteristics}

Filters for radon daughter sampling Should have high collection efficiency and good surface deposition characteristics. Membrane filters, $<0.8 \mu \mathrm{m}$ pore size, were found to be suitable. Tests done at EML with both membrane, $0.8 \mu \mathrm{m}$ pore size, and glass fiber filters showed collection efficiencies of virtually $100 \%$ for radon daughters. Any other type of filter should be investigated similarly before deployment in the field.

\section{Measurement of Collected Radioactivity}

Errors in counting radon daughter samples result from incorrect calibration of the counting equipment and from counting errors.

Several types of laboratory and field counters are commerclally avallable; some have more desirable features than others. Scintillation type detectors are the most popular. Alpha spectrometry is used in special research applications with limited use in the field.

The counting efficiency of a detector is a function of geometry and energy level. The geometric configuration of the counter depends on the distance of the detector from the sample and the relative size and shape of the detector and sample. It is essential that alpha counters be calibrated with an alpha standard having the same size and shape as the sample to be counted. Usual1y, Po-218 and Po-214 sampled on a membrane filter offer the most suitable alpha source. Instruments with thick windows were found to be energy dependent and their detection efficiency with a monoenergetic alpha calibration source of $5 \mathrm{MeV}$ to be as low as half of that for radon daughters from Po-218 and Po-214. Alpha counters with windows need to be calibrated with radon daughters against a windowless counting system. Once the counting efficiency of a counter is determined with radon daughters collected on a membrane filter, any alpha standard may be used as a reference check source to verify the instrument's counting efficiency in the field.

Alpha self-absorption in membrane filters counted with alpha scintillation counters was found to be nil. Comparative measurements made by EML on glass fiber and membrane filters show selfabsorption in glass fiber filters to be $<5 \%$ if the linear velocity across the filter is maintained below $100 \mathrm{~cm} / \mathrm{s}$. If any other filter is used, the alpha energy attenuation in the filter 
should be investigated by making comparative measurements with thin membrane filters or by using the procedure described in the ANSI standard. [1]

Counting errors result because of the random nature of radioactive decay and the larger the number of counts detected the smaller the uncertainty of the measurement. In most of the methods listed on Tables 1 and 2, there is room for flexibility to reduce counting errors. This can be accomplished by sampling a larger volume of air on a larger filter, by using a larger or more sensitive detector, and by counting during and after sampling.

\section{Radon and Radon Daughter Measurements with Thermoluminescent Detectors}

Thermoluminescence dosimetry (TLD) is gaining wide acceptance in environmental measurements. There is an abundance of scientific papers in the literature that cover dosimetry using TLDs and an ANSI standard [36] was issued which considers the performance of TLD systems when used to measure $\mathrm{x}$ and gamma radiation. To our knowledge, there are no recommended procedures for TLD systems used for measurement of radon and radon daughter radiation exposures. However, the same performance specifications and testing procedures used in $\mathrm{x}$ - and gamma dosimetry w111 apply equally well in alphadosimetry.

In alpha dosimetry the phosphors that have been widely used are $\mathrm{LiF}, \mathrm{CaF}_{2}$ and $\mathrm{CaSO}_{4}$. These materials in combination with manganese or dysprosium as activators have adequate sensitivity for monitoring radon and radon daughters.

The short range of alpha rays in matter insures total deposition of the incident $\alpha$-ray energy in the TLD material. Energetic beta and gamma rays deposit only a portion of their energy and this prejudices the registered signal in favor of $\alpha$-ray energy deposition - a desirable characteristic.

At EMi, alpha TLD work began in the late 1960 's during testing and evaluation of personal dosimeters for uranium miners. We selected LiF because it has adequate sensitivity and found it to be less troublesome in environmental measurements. $\mathrm{CaF}_{3}$ and $\mathrm{CaSO}_{4}$ have better sensitivities but require energy response and fading corrections - both undesirable characteristics. Since TLD respond to beta and gamma radiation, it is desirable to minimize this response by using a thin dosimeter chip. Our tests indicate that LiF-700 ( $\left.\frac{1}{8} \times \frac{1}{8} \times .015 \mathrm{in.}\right)$ minimized response to beta and gamma radiation, and in field measurements the gamma radiation is readily corrected for by a second control TLD chip which is not exposed to the alpha radiation.

Besides the practical reasons for choosing a TLD system, such as cost and system flexibility, a system with adequate sensitivity over the anticipated range of exposures should be selected. The ANSI standard [36] recommends testing and calibration procedures which are invaluable in selecting the appropriate TLD system. The key to proper testing is the simulation of the environmental conditions under which the system will be used.

The EML Procedures Manual [15] devotes a whole section to thermoluminescence dosimetry procedures which will be of particular help to those who plan to incorporate TLD dosimetry in their programs. One of the most critical parameters that can affect the measurements of radon and radon daughters is uniformity of TLD response among dosimeters. At EML we found that LiF-700 chips from the same supplier but from different production lots can vary by as much as a factor of two. Response of TLD chips from the same lot is usually very good (standard deviation $\pm 5 \%$ ). The uniformity is usually measured by exposing TLD chips to alpha radiation for the same length of time. From our experience, we found it less troublesome to purchase a large quantity of chips from the same production lot and use them in our entire program.

Both of the integrating monitors designed by EMI for measuring radon and radon daughters, using LiF-700 chips $\left(\frac{1}{8} \times \frac{1}{8} \times .015\right.$ in.) as the sensing devices, are calibrated in the exact configuration in which they are used in the field. Calibrations are performed in a large chamber $\left(20 \mathrm{~m}^{3}\right)$ in which radon and radon daughter exposure conditions can be simulated. By varying the concentration over periods of one week or more and the normal length of the fleld exposure, the sensitivity of the system over a range of exposures can be achleved.

\section{Traceability of Measurements}

\section{Radon Measurements}

The common methods for measuring radon concentration are usually calibrated against a secondary standard traceable to a primary NBS standard; this is usually done in large laboratories. At EML, the pulse ionization chamber is the standard against which all other methods are compared. The $2 \&$ pulse ionization chamber is standardized several times a year with radon from an NBS SRM Ra-226 solution. The solution is diluted (by weight), split into aliquots and placed in radon bubblers from which the radon standard is transferred to the pulse ionization by emanation. The chamber has an overall counting efficiency of $85 \%$. 
Standard electrodeposited alpha sources of the same size as the filters are usually used to obtaln the counting efficiency of the alpha detector. At EML, the detection efficiency of $2 \pi$ proportional counters is determined by measuring an NBS certified $\mathrm{U}_{3} \mathrm{O}_{8}$ standard source. The activity strength of other sources prepared at EML or procured conmerclally is calculated based on the detector efficiency determined with the NBS standard source. The counting effictency of radon daughter detectors is readily determined by counting $\mathrm{RaC}^{\prime}$ (Po-214) collected on a filter alternately in a windowless counter and in the detector to be tested.

\section{References}

[1]

Radiation Protection in Uranium Mines, American Nationa 1 Standards Institute, ANSI N13.8 (1973).

[2] Calibraţion Procedures for Radon and Radon Daughter Measurement Equipment, R. T. Beckman, Mining Enforcement Safety Administration Report MESA I.R. 1005 (1975).

[3] Radiation Exposures in the Florida Phosphate Industry, W. A. Mills, R. J. Guimond and S. T. Windham, Proceedings IV International Congress, IRPA, Paris, April (1977).

[4] Assessment of Potential Radiological Health Effects from Radon in Natural Gas, G. W. Johnson, D. E. Bernhardt, D. E. Nelson and H. W. Calley, U. S. Environmental Protection Agency Report EPA 520/1-75-004 (1973).

[5] Measurements of Seasonal and Daily Radon Daughter Concentration Fluctuations in National Park Service Caves, K. A. Yarborough, Radon Workshop, ed. A. J. Breslin, U. S. Energy Research and Development Administration Report HASL-325, New York (1977).

[6] Radioactivity Associated with Geothermal Waters In the Western United States, M. F. O'Connel1 and G. A. Gilgan, U. S. Environmental Protection Agency Report ORP/LV-75-8B, Apr11 (1978).

[7]

Investigation of Radon-222 in Subsurface Waters as an Earthquake Predictor, R. A. Smith, H. R. Bowman and D. F. Moster, JEFE Transaction on Nuclear Sclence, NS-23, 694-698 (1976).

[8] Vertical Distribution of Radon-222, Radon220 and Their Decay Products in the Atmosphere, W. Jacob1 and K. Andre, J. Geophys. Res., 68, 3799 (1963).

[9]

Radon-222 Concentrations in the Convective Patterns of a Mountain Environment, M. H.
[10]

The Distribution of Amblent Radon and Radon Daughters in Residential Buildings in the New Jersey-New York Area, A. C. George and A. J. Breslin, Presented at the DOE/UT Symposium on the Natural Radiation Environment III, Houston, Texas, Apri1 23-28 (1978).

[11] Improved Low-Leve1 Alpha Scintillation:Counter for Radon, H. F. Lucas, Review Sci. Instrum., $\underline{28}, 680$ (1957).

[12] Scintillation Flasks for the Determination of Low Leve1 Concentrations of Radon, A. C. George, Proceedings of Ninth Midyear Health Physics Symposium, Denver, Colorado, Feb. (1976).

[13] A Study of the Two-Filter Method for Radon-222, J. W. Thomas and P. C. LeClare, Health Phys., 18,113 (1970).

[14]

Development and Operation of Continuous Radon Monitors 1974-77, J.W. Thomas, U. S. Department of Energy, Environmental Measurements Laboratory, unpublished report (1977).

[15] EML Procedures Manua1, ed. John H. Harley, U. S. Department of Energy Report HASL-300, updated annually (1972).

[16]

Dosimetry of Environmental Radon. Methods and Theory for Low-Dose Integrated Measurements, R. L. Fleischer, General Electric Research and Development Center, Schenectady, NY, unpublished report (1980).

[17] Improved Type Track Etch Detector Calibration Results, H. W. Alter, Terradex Corp., Walnut Creek, CA, unpublished report (1980).

[18]

Design and Application of a Continuous, Digital-Output Environmental Radon Measuring Instrument, H. Spitz and M. W. Wrenn, Radon Workshop, ed. A. J. Breslin, U. S. Energy Research and Development Administration Report HASL-325, New York (1977).

[19] An Integrating Air Sampler for Determination of Radon-222, C.W. Sill, Health Phys., 16, 371 (1969).

[20]

Measurement of Environmental Radon with Integrating Instruments, A. C. George and A. J. Breslin, Workshop of Methods for Measuring Radiation in and Around Uranium Mills, ed. E. D. Harward, Atomic Industrial Forum, Inc., Program Report, Vo1. 3 (1977).

[21] Radon Daughters in Mine Atmospheres - A Field Method for Determining Concentrations, H. L. Kusnetz, Am. Ind. Hyg. Assoc. J., 17, 85 (1956). 
[22]

Rapid Working Level Monitoring, R. Rolle, Health Phys., 22, 233 (1972).

[23] Occurence of Nonequilibrium Atomospheric Mixtures of Radon and Its Daughters, E. C. Tsivoglou, H. E. Ayer and D. A. Holaday, Nucleonics, 1,40 (1953).

[24] Measurement of Radon Daughters in Air, J. W. Thomas, Health Physics, 23, 783 (1972).

[25] A Radon Daughter Monitor for Use in Mines, A. C. James and J. C. Strong, Proceedings 3rd Internationa 1 Congress, IRPA, Washington, D.C., USAEC CONF-730907, p. 932 (1973).

[26] Analysis of the Activity of Radon Daughter Samples by Weighted Least Squares, O. G. Raabe and M. E. Wrenn, Health Phys., 17, 593(1969).

[27] Analysis of Atmospheric Concentrations of RaA, RaB and RaC by Alpha Spectroscopy, D. E. Martz, D. F. Holleman, D. E. McCurdy and K. J . Schlager, Health Phys., 17, 131 (1969).

[28] The Measurement of Low-Concentrations of the Short-Lived Radon-22 Daughters in the Air by Alpha Speccroscopy, N. Jonassen and E. I. Hayes, Health Phys., 26, 104 (1974).

[29] A Microprocessor-Assisted Calibration for a Remote Working Leve1 Monftor, W. B. McDowe11, D. J. Keefe, P. G. Groer and R. T. Witek, IEEE Trans. Nuc1. Sci., NS-24:1, Feb. (1977).

[30] Integrating Radon Progeny Air Sampier, K. J Schiager, Am. Ind. Hyg. Assoc. J., 35, 165 (1974).

[31] A Working Level Dosimeter for Uranium Miners, A. J. Breslin, S. F. Guggenheim, A. C. George and R. T. Graveson, U. S. Department of Energy Report EML-333, New York (1977).

[32]

A Time-Integrating Environmental Radon Daughter, S. F. Guggenheim, A. C. George, R. T. Graveson and A. J. Bresin, Health Phys., 36,452 (1979).

[33] Interpretation of the Response of Continuous Radon Monitors to Transient Radon Concentrations, A. Busigin, A. W. Van Der Vooren and C. R. Phillips, Health Phys., 37, 659 (1979).

[34] A Two-Filter Environmental Monitor with an Automatic Drive that Changes the Exit Filter, V. C. Negro, U. S. Department of Energy Report EML-367, p. 244 (1979).
[35] FUNGI - A Radon Measuring Instrument with Fast Response, V. C. Negro and S. Watnick, IEEE Trans. Nuc1. Sci., NS-25, p. 757 (1978).

[36] Performance, Testing and Procedural Specifications for Thermoluminescence Dosimetry (Environmental Applications), American National Standards Institute, ANSI N545 (1975). 


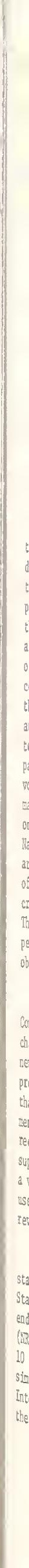




\author{
Phillip A. Plato \\ C. Glenn Hudson \\ The University of Michigan \\ Ann Arbor, MI 48109
}

\begin{abstract}
From 1977 to 1979, The University of Michigan conducted a pilot study of a dosimetry performance testing standard that the Nuclear Regulatory Commission is considering as the basis of a mandatory testing program for dosimetry processors that service their licensees. This paper discusses the traceability of the radiation sources used in the pilot study to the National Bureau of $S$ tandards and summarizes the results of the pilot study.
\end{abstract}

(dosimeters, NRC, pilot study, sources, standard, traceability)

\title{
Introduction
}

There have been many attempts during the past twenty years to test the performance of personnel dosimetry processors in the United States. Customers and competitors of commercial dosimetry processors continuously design tests to examine the competence of a given processor. Unfortunately, the competence of the testing group has often been worse than the competence of the processor being tested, which created more problems than were solved. The National Sanitation Foundation [1] (NSF) has operated an annual dosimetry testing program since 1966. However, participation in the NSF testing program is on a voluntary basis and, as a result, attracts a maximum of only a half dozen commercial processors on a regular basis. In 1972, the American National Standards Institute published a standard [2] that could be used to test the performance of film badge processors. Due to a variety of criticisms [3], the standard was never used. Thus, in reviewing the past efforts to test the performance of dosimetry processors, one common observation is apparent; none was successful.

In 1975, the Health Physics Society Standards Committee (HPSSC) formed Working Group 1.4, chaired by Dr. Margarette Ehrlich, to prepare a new standard that could be used to test dosimetry processors. There was one primary reason to hope that this standard would succeed as a useful document whereas other similar dosimetry standards had received either modest support nationally or no support at all. That reason was cooperation among a variety of regulatory agencies that would make use of the HPSSC Standard once it had passed peerreview processes.

The impetus for the development of a new standard came initially from the Conference of State Radiation Program Directors. The idea was endorsed by the US Nuclear Regulatory Commission (NRC) which expressed an interest in amending 10 CFR 20 to require performance testing of dosimetry processors that serve NRC licensees. An Interagency Policy Committee was formed to monitor the progress of Working Group 1.4 and to coordin- ate the efforts of the various regulatory agencies concerning future mandatory testing of processors. The Interagency Policy Committee included members of the NRC, the Department of Energy (DOE), the Department of Defense, the National Bureau of Standards, the Bureau of Radiological Health, and a representative from the States. Although no regulatory agency could commit itself in 1975 to the adoption of the standard that would be produced by Working Group 1.4, it was the hope of many people that the standard would someday be adopted by all the regulatory agencies involved as the basis of a uniform, nationally-recognized, mandatory testing program for all personnel dosimetry processors in the United States.

By late 1976, the first draft of the HPSSC Standard [4] was available for public comment. In a public meeting held at the end of 1976, concern was expressed by a number of people that regulatory agencies might adopt the 3tandard without first seeing how it would work in a test situation. Thus, the NRC sponsored a two-year pilot study of the Standard beginning in October, 1977. The contract to conduct the pilot study was awarded to The University of Michigan. Any organization in the United States that processed personnel dosimeters used for primary dose records was permitted to pariicipate in the pilot study on a voluntary basis at no charge. A total of 59 organizations chose to participate. These included large and small commercial processors, most of the National Laboratories, a number of prime DOE contractors, many nuclear power plants, the military, and a few medical facilities and universities.

The purpose of this paper is to discuss the traceability of the radiation sources used in the pilot study to the National Bureau of Standards (NBS), and to summarize the results of the pilot study. 


\section{Radiation Sources}

Table 1 is a summary of the radiation sources used during the two-year pilot study and the procedures used to determine if a processor passed or failed any radiation category (type of radiation) within the Standard. A detailed description of calibration and irradiation procedures has been published [5]. Four types of radiation are required for the Standard as shown in Table 1: gamma-rays (cobalt-60), standard NBS X-ray techniques (specific combinations of voltage and filtration), beta particles (strontium-90), and neutrons (californium-252). When the NRC contract was awarded to The University of Michigan, we had seven months to obtain the required sources, calibrate the sources, and develop the operational and administrative procedures required to test each processor according to the Standard. At the same time the NRC awarded the contract to The University of Michigan, they awarded a second contract to NBS to provide calibrations and other technical services to The University of Michigan to insure that all irradiations done for the pilot study would be accurate to within $\pm 5 \%$ as specified in the Standard.

Two cobalt-60 sources, $5 \mathrm{Ci}$ and $2700 \mathrm{Ci}$, were used for the pilot study. Two Shonka-Wyckoff ionization chambers, $3 \mathrm{~cm}^{3}$ and $100 \mathrm{~cm}^{3}$, were calibrated to cobalt -60 by NBS. These chambers were then used to calibrate the exposure rate from the two University of Michigan sources. Half-life corrections were made on a daily basis after each source was calibrated.

The same two ionization chambers were also calibrated by NBS to several standard NBS X-ray techniques. The chambers were used to calibrate an X-ray beam before and after dosimeters were irradiated on a given day. A beam monitor connected to a strip chart recorder was used to determine if the exposure rate of the beam changed during the working day.

A $40 \mathrm{mCi}$ strontium-90 beta-particle source was calibrated by both NBS and The University of Michigan using extrapolation chambers. Half-life corrections were made on a monthly basis after calibration.

The californium-252 neutron source was calibrated by NBS with their manganese sulphate bath calibrator. The neutron emission rate determined by NBS was combined with a dose conversion factor given in the standard to calculate a dose equivalent rate at a given distance from the source.

\section{Results}

Each processor was permitted to be tested twice during the pilot study. In each test, a processor could choose to be tested in any or all of the radiation categories shown in Table 1 . To pass each category, a processor had to pass each depth of each interval (dose range) shown in Table 1. Thus, to pass Category IV, a processor had to pass only two statistical tests. However, to pass Category II, a processor had to pass seven statistical tests. The statistical criteria are summarized on the bottom of Table 1 and are discussed in detail in the Final Report [6] of the pilot study.

The results of the pilot study showed that only about one-third of the categories tested were passed. The passing rate for the intervals tested was considerably better, although a processor passes a category only if all the dose intervals within the category are passed.

As part of an additional analysis of the results of the pilot study, the performance of each individual dosimeter irradiated during the pilot study was examined. This analysis, which is discussed in detail in a Supplementary Report [7] following the completion of the pilot study, is not part of the statistical requirements of the Standard. However, this analysis permits an observation of the percent of dosimeters that had a reported dose within $\pm 10 \%$ of the actual delivered dose, $\pm 30 \%, \pm 50 \%$, etc. The results of this analysis showed that approximately $80 \%$ of the 23,000 dosimeters irradiated during the twoyear pilot study had a reported dose that was within $\pm 50 \%$ of the delivered dose.

\section{Conclusion}

The NRC and the other relevant regulatory agencies are currently evaluating the results of the pilot study to determine if a mandatory testing program is necessary and feasible for all dosimetry processors in the United States. Operationally, a mandatory testing program appears to be feasible. The radiation sources required by the Standard can be calibrated and used to provide delivered doses within $\pm 5 \%$ requirement of the Standard. The cost of a mandatory testing program does not appear to be prohibitive, probably around $\$ 3,000$ for a complete test of a processor. Administratively, the problems are immense. Answers are currently being sought to questions such as;

How many tests should a processor be required to pass within a given time period?

What should be the qualifications of a testing laboratory?

How many testing laboratories should be permitted?

How should a testing laboratory be monitored technically to insure credability?

Who should mediate a dispute between a testing laboratory and a processor? 
Should a processor that falls a test be given a probationary period to correct probiems while still being permitted to provide dosimeters to radiation workers?

The relatively easy work of the pilot study has tren completed. The difficult task of implementing the Standard is now at hand.

\section{$\underline{\text { References }}$}

[1] National Sanitation Foundation Standard No. 16 Relating to Dosimetry Services. The National Sanitation Foundation, P.0. Box 1468, Ann Arbor, MI, 48106 (1966).

[2] American National Standards Institute, Inc., American National Standard Criteria for Film. Badge Performance, ANSI N13.7 - 1972. 1430 Broadway, New York, NY (1972).

[3] Plato, P. Evaluation of "Criteria for Film Badge Performance" ANSI N13.7 - 1972. Am. Ind. Hygiene Assoc. Journal, 38:41-45 (1977).

[4] Criteria for testing personnel dosimetry performance. Proposed standard prepared by the Health Physics Society Standards Committee, 4720 Montgomery Lane, Suite 506, Bethesda, MD 20014 (November 30, 1977). This Standard is also published by the American National Standards Institute as Draft ANSI N13.11.

[5] Plato, P. and Hudson, G. Procedures manual for performance testing of personnel dosimetry services, NUREG/CR-1063, National Technical Information Service, Springfield, Virginia 22161 (January, 1980).

[6] Plato, P. and Hudson, G. Final report for performance testing of personnel dosimetry services, NUREG/CR-1064, National Technical Information Service, Springfield, Virginia 22161 (January, 1980).

[7] Plato, P. and Hudson, G. Supplementary report for performance testing of personnel dosimetry services, NUREG/CR-1304, National Technical Information Service, Springfield, Virginia 22161 (April, 1980). 
Table 1. Summary of the HPSSC Standard used in the pilot study.

$\frac{\begin{array}{l}\text { Radiation } \\ \text { Category }\end{array}}{\text { I. } \quad \begin{array}{l}\text { Gama } \\ (\text { Co-60) }\end{array}}$

II. X Ray

$(30-300 \mathrm{keV})$

III. X Ray

$(15-30 \mathrm{keV})$

IV. Beta

$(S I-90)$

V. Neutrons

(Cf-252)

VI. Photon Mixtures

(Cat. I \& II)

\begin{tabular}{|c|c|c|}
\hline Interval & \multicolumn{2}{|c|}{ Iest Range } \\
\hline 1 Accident: & $\begin{array}{l}10-800 \\
30-100\end{array}$ & rad \\
\hline 3 & $101-300$ & mrem \\
\hline 4 & $301-10,000$ & mrem \\
\hline
\end{tabular}

1 Accident: $\quad 10-800$ rad

2

3

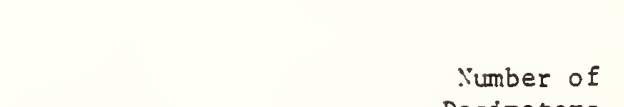

lumber of

Dosimeters

Per Test

10

10

10

10

10

10

10

10

Tolerance Level (I)

(see Eoztnotes)

\begin{tabular}{|c|c|c|}
\hline \multicolumn{2}{|c|}{$\begin{array}{r}\text { Shallori } \\
\left(7 \mathrm{mg} / \mathrm{cm}^{2}\right) \\
\end{array}$} & \multirow[t]{2}{*}{$\begin{array}{c}\text { Deep } \\
\left(1000 \mathrm{ma} / \mathrm{cm}^{2}\right) \\
\end{array}$} \\
\hline no & test & \\
\hline no & test & $b$ \\
\hline no & test & b \\
\hline no & test & b \\
\hline no & test & a \\
\hline & c & c \\
\hline & c & c \\
\hline & c & $c$ \\
\hline
\end{tabular}

Accident: no test

1 Protection: 150-300 mrem

2 301-10,000 mrem

10

10

$c$

c

Accident: no test

1 Protection: $150-300$ mrem 10

2 301-10,000 mrem 10

$c$

c no test

c no test

Accident: no rest

1 Protection: 100-300 mrem 10

2 301-5,000 mrem 10

no test

no test

c.

c

Accident: no test

1 Protection: 50-100 mrem 10

2 101-300 mrem 10

$3 \quad 301-10,000$ mrem 10

VII. Photon and Beta Mixtures

Accident: no test

1 Protection: 200-300 mrem 10

(Cat. I or II\&IV)

$301-10,000$ mrem $\quad 10$

VIII. Photon and Neutron Accident: no test

Mixtures 1 Protection: 150-300 mrem 10

(Cat. I \& V) 2 301-5,000 mrem 10

$\begin{array}{ll}c & c \\ c & c \\ c & c\end{array}$

For each dosimeter, a performance index is calculated by:

$$
P=\frac{H^{\prime}-H}{H} \quad \text { where: } \begin{aligned}
& H=\text { delivered quantity } \\
& H^{\prime}=\text { reported quantity }
\end{aligned}
$$

For each depth of each interval, an average performance index, $\bar{P}$, and its standard deviation, $S$, are calculated.

A processor passes a category if, for each depth of each interval:

$$
|\bar{P}|+2 S \leq L
$$

where:

$$
\begin{array}{ll}
\text { a: } & L=0.3 \\
\text { b: } & L=0.3 \text { or } 6 / \sqrt{\bar{H}} \text { whichever is larger } \\
c: & L=0.5 \text { or } 15 / \sqrt{\bar{H}} \text { whichever is larger }
\end{array}
$$


OCCUPATIONAL EXPOSURE MEASUREMENTS IN NRC REGULATORY GUICES*

\author{
Allen Brodsky \\ Occupational Health Standards Branch \\ Office of Standards Development \\ U.S. Nuclear Regulatory Commission \\ Washington, D.C. 20555
}

\begin{abstract}
Since the formation of the Nuclear Regulatory Commission (NRC), a series of guides on occupational radiation protection standards have been developed. These guides include information on acceptable accuracy and quality control of most types of radiation survey measurements for internal and external exposure assessment. However, more complete specifications of precision, accuracy, and traceability requirements are under development, and programs are underway to establish measurement systems for monitoring and certifying licensee compliance with quality control and accuracy standards. Many fundamental measurement principles and radiation protection concepts are involved in these developments, and they must be better understood and applied to properly establish these systems.
\end{abstract}

(Accuracy, bioassay performance, occupational radiation protection standards, performance criteria, quality control, radiation instrument performance, radiation measurements, ragulatory standards)

\section{Introduction}

In recent years, a fairly extensive body of NRC regulatory guides $[1-31]$ has been published to assist the NRC licensee in establishing acceptable ways of meeting regulatory standards for radiation protection and the measurements and surveys required to ensure compliance with the exposure standards [32]. However, the specific accuracy and quality control performance criteria for the radiation or radioactivity measurements to be made for occupational health protection still require further development, al though considerable progress has already been made -- particularly in regard to the development of personnel dosimetry performance criteria. Preceding papers have described some of this development, but some more recent progress in developing bioassay performance criteria will be summarized here. NRC programs for implementing performance testing of personnel dosimetry are already underway [33-37], and similar programs for implementing the performance testing of survey meter calibrations and radiobioassay services are planned. Many of the agencies and scientists participating in this meeting have been very helpful to NRC in the development of these programs and standards.

In developing its guidance, the NRC has encouraged public and licensee participation, and has followed the government policies of supporting the development of national consensus standards through the American National Standards Institute (ANSI) wherever possible $[38,39]$. A number of these standards $[40-73]$, in addition to the recommendations of professional and scientific organizations [74-80], are now available to guide the establishment of good radiation measurement and survey practices. Where appropriate for regulatory purposes, some of the provisions of the ANSI have been incorporated by reference into NRC guides. The NRC staff is supporting and participating in the development of further ANSI standards that are expected to be used in regulatory guidance and rule making on measurement accuracy and performance. The participation of all government agencies in the development and use of consensus standards, in order to expedite the development of reasonable and effective regulatory requirements without unnecessary duplication of effort by the Federal agencies, has been further encouraged by a recent office of Management and Budget circular [81]. Considering the complexities of scientific methods, measurement principles, radiation protection philosophies, government-industry employee-public relations, and radiation protection management principles, which a11 interact in the developinent of adequate performance testing systems, it is essential that participation of all concerned and expert parties be well coordinated during the implementation of these systems. Thus, this is a subject worthy of considerable further discussion. Only a few current developments can be mentioned here. There are also many technical and policy questions that must be answered before the complete implementation of a comprehensive national system of performance testing can be accomplished, which will ensure the reliability and accuracy of measurements used for radiation protection purposes. Hopefully, the talks and discussions at this conference, and their publication for further study, will stimulate progress in answering these questions.

\footnotetext{
*Presented at the Seminar on Traceability for Ionizing Radiation Measurements, National Rureau of Standards, Washington, D.C. 20234, May 8-9, 1980, to be published. This paper was prepared by an employee of the U.S. Nuclear Regulatory Commission. It presents information that does not necessarily currently represent an agreed-upon staff position, but the author believes it to be consistent with current NRC plans and policies. NRC has neither approved nor disapproved its technical content.
} 
II. Types of Occupational Exposure Measurements Required for Employee Health Protection

The types of radiation exposure measurements required by NRC regulations [32] to ensure compliance with regulatory 1 imits of exposure may be divided into the following categories: personnel dosimetry for external exposure monitoring; bioassay measurements for estimating internal exposures (including in vivo or whole body counting); air monitoring (measurements of concentrations of radioactivity in air in work areas); and surveys of external radiation levels and surface contamination. The regulatory guides related to occupational protection and license application requirements [1-31] now provide rather comprehensive information and references that identify acceptable radiation protection and survey practices for many different types of installations, although the series is not complete in all respects. Most of the guidance is procedural so far, but some information on accuracy requirements over necessary ranges of measurement have been developed based on recommendations of professional consensus standards and regulatory experience. The present status of NRC efforts to define, and subsequently monitor compliance with, accuracy requirements for occupational exposure measurements will be reviewed. However, the NRC programs to improve measurement accuracies will either depend upon or will be assisted by, the current national and international efforts to define and improve both "artifact traceability" and "measurement traceability" as described by Eisenhower [111], or equivalently "direct" and "indirect" traceability (including documentation) as defined by Kathren [112]. Thus, some remarks will also be made about the NRC's interest in the subject of traceability, and its relationship to the overall quality control of radiation protection measurements of various types.

\section{A. Personnel Monitoring}

The development of standards of performance for personnel monitoring services, and the completion of tests of the feasibility of establishing a laboratory to certify compliance with such standards, represents in my opinion a major advance in recent years toward national systems to assure the best state-of-the-art accuracy in field measurements for radiation protection purposes. Dr. Plato has ably described the progress of this program in the preceding paper of this seminar, and in his reports [34-36]. He and Dr. Margarete Ehrlich, who chaired the Health Physics Society WG that produced the recent draft performance standard [37], deserve commendation and gratitude for their scientific and professional leadership in these projects.

Also, much credit is due R. E. Alexander and R. B. Minogue who recognized the need for NRC initiative in providing the funding and technical direction to implement this important program. Despite so many years and so many previous scientific efforts to develop performance criteria [82-86], the implementation of a nationwide program to certify personnel dosimeter processors had foundered until now. Hopefully, the forthcoming public meeting [33] on personnel dosimetry will help resolve the remaining technical and operational questions, and a national system of quality assurance for personnel dosimetry will be established and operating within the next few years. This system may then serve as a model for establishing national quality control over the other measurements made for radiation protection: bioassay measurements for internal exposure assessments; measurement of air concentrations of radioactivity to evaluate and control sources of internal radiation exposure in the work environment; and surveys with field instruments to measure ambient external radiation exposure levels or surface contamination in work areas.

\section{B. Bioassay}

Al though a formal system of certifying the accuracy and quality control of bioassay services has not yet been implemented, there has been considerable progress in establishing a consensus of good pracice in the form of draft or final ANSI standards for the important nuclides encountered in industry and medicine. These ANSI standards have been prepared by working groups of the Health Physics Society Standards Committee (HPSSC).

Information in one of the earlier drafts of the uranium bioassay standard was used in preparing NRC Regulatory Guide 8.11 [11], published together with an NRC NUREG report [126], which provides analytical methods for evaluating internal radiation exposures from uranium bioassay data. Additional experimental work is underway at the University of Rochester to provide data that will allow the extension of these analytical methods in cases of exposure to $U_{6}$ or its hydrolysis products.

One of the earijer working groups, composed of health physicists involved in radiochemical bioassay and wholebody counting from various types of reactor installations, industry users, commercial analytical laboratories, and the NRC, completed development of an ANSI standard on bioassay of fission products and activation products [4.3]. This standard provides conditions requiring bioassay, advice on selection of personnel to be bioassayed, frequencies of bioassay, and action levels and actions to be taken, for various radionuclides -- both for radiochemical procedures and in vivo counting. It also provides, in appendices, data and information useful for quantitatively converting some types of bioassay data into estimates of internal organ doses. This ANSI standard was well received by NRC technical staff, and was incorporated into a proposed Regulatory Guide, published for comment in 1979 with only minor interpretive additions. Comments received indicate that the parts of the standard dealing with establishing, operating, and quality control of fission product/activation product bioassay services are acceptable, but requests have been made to update information on methods of dose evaluation. Publication of the regulatory guide in final form as Regulatory fuide 8.26 is expected in 1980, with relatively minor revisions and additional references to more recent 1 iterature on internal dose calculations and their relationships to excretion analysis.

Since many detailed refinements in internal dosimetry modeling and calculation methods are underway [104-106], in particular a complete revision of the ICRP 10 series that provides methods of 
relating bioassay data to internal doses [107], the user of the guide will be reminded to examine current literature for new information when examining individual cases with appreciable internal exposure. After al1, in bioassay data evaluation, each case of significant human exposure requires more than a single measurement, and is usualiy a research effort worthy of publication. Although for fission and activation products, in vivo detection 1 imits are usually far below the activities that would deliver maximum permissible internal organ doses, even for equilibrium situations where the internal burdens are continuously maintained (see Table 1 and Reference 43), interpretation of the actual burden of each organ and projected dose commitments still require considerable skill of measurement and analysis. Usually, a number of measurements by several independent methods over time, selection of the proper mathematical models of organ retention and body distribution vs. time, and experienced judgment in pooling results to obtain the best dose commitment estimates, are required. This, combined with the inherent complexity and variability in assessing biological risk factors per unit dose, makes the statement of accuracy and quality control requirements for bioassay of numerous and/or mixed radionuclides extremely difficult. The specification in advance of a single mathematical model for utilizing bioassay data to evaluate internal exposures in individual human cases even with varying parameters for each nuclide and form -- is impossible at the present time.

ANSI standards for bioassay of two other nuclides, plutonium and tritium, have been completed in draft form by Health Physics Society working groups. Again, both of these standards provide recommended methods and programs for: managing bioassay services; deciding which employees are to be bioassayed, under what working conditions, levels of exposure to air concentrations, or quantities of material handled in unsealed form; what frequencies of bioassay are aporopriate; and what actions should be taken when bioassay measurements exceed selected action levels. In both documents, mathematical models and calculation methods for evaluating internal radiation exposures based on the bioassay measurements are presented only as examples of state-of-the-art methods. References are also given to provide an introduction to important published data and methods that may be used in individual human cases to obtain initial and follow up estimates of internal radiation doses and dose commitments. Criteria for evaluating measurement accuracy, and defining and calculating statistical 1 imits of detection are provided in each document. These criteria are based in each case on a judgment of state-of-the-art measurement capabilities, as well as on radiation protection requirements for optimum detection and measurement of internal burdens of $\mathrm{H}-3$ or $\mathrm{Pu}-239$ (and $\mathrm{Am}-241$ ) under the specified programs and frequencies of sampling.

Although both the $\mathrm{H}-3$ and $\mathrm{Pu}-239$ standards have been approved by the Health Physics Society Standards Committee for over a year, neither standard has yet been approved by the ANSI M13 Committee and submitted for ANSI board approval. However, in 1977 the NRC staff utilized some of the earlier work on the H-3 draft standard to develop a concise staff oosition, which is utilized by the Material
Licensing Branch of NRC, and available from that Branch. This staff position provides criteria for judging when it is appropriate to require bioassay for tritium, and provides methods acceptable to NPC staff for selecting: employees to be assayed, frequencies of bioassay, action levels in terms of measured urine concentrations of tritium, and actions to be taken when specified concentrations are exceeded. The draft plutonium standard has also been used informally by NRC 1icensing staff for guidance in evaluating bioassay programs in fuel cycle facilities.

While there are many important differences in the measurement and radioanalytic techniques of bioassay for the many different radionuclides, and their varied physico-chemical forms, there are also many common aspects of bioassay program management: quality control; statistical definitions of accuracy, precision, bias and lower limit of detection: record keeping; and types of actions to be taken in following up exposed employees whose bioassay measurements have exceeded action levels. Thus, in order to establish standards of bioassay performance upon which a uniform national program of performance testing can be based, which will enable NRC to ensure that any radionuclide bioassays required of NRC

licensees are sufficientiy reliable and accurate for internal exposure monitoring purposes, the office of Standards Development requested the Health Physics Society to establish another working group. In 1979, Working Group 2.5, "Criteria for Testina Radiobioassay Performance," was establ ished under the chairmanship of Kenneth Heid. Excellent progress has been made and a first complete draft will be examined for coherence and edited by the full Working Group at the 1980 annual meeting of the Health Physics Society. The purpose and scope of this standard, as currently agreed to and tentatively drafted for the Working Group, is as follows:

\section{"1. PURPOSE AND SCOPE}

\subsection{Purpose}

The purpose of this standard is to provide: quantitative performance criteria for the accuracy of measurements ('radiobioassay') of radioactivity in humans occupationally exposed to the intake of radioactive materials and biological matrices sampled from these humans; procedures for testing radiobioassay service laboratories to determine that their analyses conform adequately to these performance criteria, for a selection of important and representative radionuclides; and selected quality control criteria and procedures of a nonquantitative nature that are necessary to ensure continued reliability of both the radiobioassay source laboratories and the laboratories conducting the testing programs.

\section{"1.2 Scope}

This standard provides quantitative performance criteria for the accuracy and precision of radiobioassays of selected radionuclides in the bodies of, or in biological samples from, persons occupationally exposed to the intake of radioactive materials. It also provides standard quality control procedures for the internal quality assurance programs of radiobioassay laboratories, and procedures to be used by testing laboratories for 
testing the conformance of radiobioassay service laboratories to both the quantitative performance criteria for accuracy and precision and the standard quality control procedures.

"Specifications are given for:

1. Accuracy and precision of both direct (in vivo) and indirect measurements of concentrations and quantities of selected important radionuclides in humans and biological samples.

2. Acceptable detection 1 imits for both routine and emergency analyses, in terms of standard definitions of acceptable 'minimum detectable amounts (MDA).

3. Ranges of concentration and amounts to be mea sured.

4. Acceptable time limits for reporting analytical results.

5. Standard methods of reporting analytical results.

6. Standard procedures for internal quality control in radiobioassay laboratories, including procedures for:

\section{a. obtaining and handling samples}

b. preliminary sample preparation and monitoring for external contamination

c. showering, clothing, and monitoring persons prior to in vivo counting

d. quality control and calibration of radioactivity counting equipment

e. providing suitable 'blank' and 'control' samples of measurement,

f. maintenance of records of all data and procedures used in radiochemical and radiometric ana 1 yses

7. Standard procedures for preparation and distribution of test samples and/or phantoms by the testing laboratories, for both 'blind' and 'nonblind' test programs.

8. Standard procedures for reporting test evaluations to the testing laboratories.

9. Standard procedures for evaluating and reporting of test results by the testing 1aboratories.

"Criteria and procedures pertaining to direct (in vivo) radiobioassay are given in separate sections of this standard from criteria and procedures for indirect radiobioassay, since different testing laboratories may be concerned with the different types of radiobioassay. In addition, examples to clarify concepts and methods described in this standard, and information that may be useful in implementing this standard, are presented in appendices to this standard. The appendices are illustrative and are not a part of the standard. The scope of this standard does not include:
1. detailed radiochemical methods for extracting radionuclides from biological samples,

2. detailed procedures for radiometric measurement of in vivo and in vitro samples.

3. metabolic data and mathematical models for converting radiobioassay results into absorbed dose and dose equivalent,

4. radiation protection program management aspects of radiobioassay sampling and services described in standards for specific nuclides.

"Analytical methods are not currently standardized, but are available in the literature and are provided in summaries and references appended to this standard and to standards for snecific nuclides. Standard methods for converting radiobioassay results into dose and risk estimates are provided in publications of the International Commission on Radiological Protection (ICRP), the National Council on Radiation Protection and Measurements (NCRP), and the International Commission on Radiological Units and Measurements (ICRU). Recommendations of the ICRP, NCRP, and ICRU, and experience with the practical application of these recommendations to the conduct of radiobioassay services and the interpretation and use of bioassay results in radiation protection programs, have been considered in the development of this standard. Appendices to other standards on the provision and management of bioassay programs for specific radionuclides include information useful for interpreting and using bioassay results for radiation protection purposes. The purpose of the present standard is primarily to ensure the accuracy and reliability of the analytical results."

The purpose and scope alone illustrate the complexity of determining the content of a broad performance standard covering the area of bioassay measurements. Anyone wanting to maintain 1 iaison with this working group, or contribute experience or ideas toward its goals, should contact the Chairman [113].

In addition to progress in improving and standardizing bioassay performance through participation in ANSI activities, the NRC develops its own criteria to meet priority needs. Regulatory Guide 8.20 [18] was developed by NRC scientific staff to meet an urgent need for guidance on when I-131 and I-125 bioassay services should be provided to employees, who should be monitored, and what action levels and actions are appropriate when positive indications of internal I-131 or I-125 radioactivity are obtained. Since many of the compounds of iodine nuclides used in medicine, industry and research tend to be more volatile and/or dispersible than compounds of other nuclides, and upon inhalation or ingestion iodine tends to be absorbed into the body and concentrated in the thyroid, the radioactive iodine compounds have been involved in numerous questions regarding the need for, and interpretation of, bioassay measurements in NRC-1 icensed establishments. Thus, the revision of Regulatory Guide 8.20 required not only a consideration of the many comments on the draft version, but visits to many hospitals and industrial establishments to obtain specific information on the likelihood of employee exposure in different situations, and on practicable 
methods of carrying out bioassay programs.

During these visits, it was apparent that the guidance should not include specific measuring equipment, nor radioanalytic or radiochemical procedures, but only some selected references for persons establishing new bioassay measuring systems for I-131 and I-125. Many different systems were found to be in use and adequate for detection and measurements of I-131 and/or I-125, depending in some cases on what equipment or funds were available and what I-containing materials were involved in the exposures. Also, it was evident that a scientist experienced in radiochemical or in vivo measurements would need to be employed by $a$ licensee to at least set up the equipment and procedures for bioassay of radioiodines. This conclusion is similar to those of the ANSI committees, which have each concluded that specific radioanalytic and measurement techniques should not be a part of the standard. General guidance on instrumentation and radioactivity measurements is available in References 78 and 79.

When the development of basic written criteria for accuracy and performance testing of radiobioassay services is complete, the implementation of performance testing will still require answers to many questions, including:

(1) What additional procedures will need to be developed by a testing laboratory to provide "blind" and/or "double bl ind" tests by sending radiochemically spiked samples or phantoms to laboratories around the country?

(2) What additional radiochemical and physical requirements need to be imposed on samples to be prepared for shipment?

(3) What type of laboratory and/or laboratory facilities would be appropriate for assuming the role of the testing laboratory?

(4) How will the performance of the testing laboratory itself be monitored, and how will its own measurements be made "traceable to the National Bureau of Standards"?

(5) What initial trial program of testing will be necessary to ascertain both that the established laboratory is ready to carry out a formal testing and certification program, and that the basic standard of performance is indeed sufficient and appropriate as a basis for testing the variety of laboratories offering bioassay measurement services?

(6) What agencies will participate in the funding and supervision of the implementation of this program, and how will the funding be provided for the several stages of implementation?

Some guidance in answering these questions will come from the professional community of chemists, physicists, and health physicists involved in radiobioassay, some will come from the early experience in NRC's program for performance testing of personnel dosimetry services [34-37], and some will come from programs for testing performance of radioanalytical services in measuring environmental samples [96-103, 114]. However, some additional appljed research in preparation of properly simulating biological samples containing known quantities of radionuclides to be assayed will probably be needed. Also, a pilot program that actually sets up and implements a testing program for a trial perjod of three years will be needed to solve, and weave into a workable system, all of the management, sample preparation, measurement, statistical, and legal questions involved in an on-going radiobioassay performance testing and certification program.

\section{Instrumentation, Surveys, and Air Monitoring}

Regulatory guidance does not so far provide detailed criteria for the accuracy and performance of instruments used in surveys and air monitoring, other than some general statements of accuracy in licensing and survey guides $[4,14,19,21,22,24-$ 31]. Some of these statements are under revision to include suggestions for improvement contained in recent public comments, and can be expected to be more uniform in future guides. However, they do not contain the rigorous statistical definitions of accuracy and performance nor the procedural specifications for instrument usage that would ensure adequate survey measurements.

Calibration frequencies and some limited specification of ranges of calibration required for instruments used to monitor external radiation are contained in these guides. The Occupational Health Standards Branch plans to recommend a rule and guide specifying in more detail NRC's calibration requirements and acceptable ways of calibrating radiation survey instruments. Several acceptable methods of calibration have been drafted, with the advice of National Bureau of Standards staff, and are presented in Appendix A for illustration only. The draft in Appendix A takes into account the facts as explained by Elmer Eisenhower [111] at this conference, that the National Bureau of Standards maintains the standards but does not define methods for making measurements by others "traceable to NBS"; it is each agency's responsibility to define "traceable" for each measurement according to its requirements. Also, as pointed out by Ron Collé [115], one can not define "traceable" without actually stating "what you do" to make a measurement traceable; and when "what you do" is spelled out, the word "traceable" may no longer be needed-unless it is useful for repetitive reference. Some of the examples in Appentix A may suffice to show how the specification of "acceptable methods" of calibration may be used, in lieu of a vague requirement to make measurements (or sources) traceable to NBS. The goal is to define what is to be done to ensure good practice in the calibration of radiation survey instruments. 
The types of procedures in Appendix A for "acceptable calibrations," if carried out regularly by the 1 icensee or company responsible for monitoring its employees, would themselves provide considerable confidence that monitoring instruments used for surveys were operable and sufficiently accurate for radiation hazard assessment. However, an independent testing program might still be necessary for testing independent companies or agencies performing calibration services for NRC 1 icensees, and perhaps for testing a licensee's own capabilities as appropriate. Recently another working group has been formed under the Health Physics Society Standards Committee to develop an ANSI standard on the testing of radiation survey instrument performance. Also, the NRC Office of Standards Development is planning to implement a pilot program for testing the performance of survey instruments against the draft ANSI standard when it becomes available.

General guidance for many aspects of these programs may be obtained from some of the regulatory guides [100-103] and the standards and recommendations [74-80] already available. Specifications and performance standards in some of the current ANSI standards $[41,42,44,45,46,53,54,55,57,59-$ 62] may also be adaptable for use in implementing a national testing program. The experience in the NRC pilot program for testing personnel dosimetry services [33-37], and the British experience and specifications developed for radiation survey meter performance testing $[116,127-130]$ are $1 \mathrm{ikel} y$ to be invaluable in implementing a radiation survey (and monitoring) instrument performance testing program in the United States. Developments in the NRC Inspection and Enforcement programs for quality control of surveys made by NRC inspectors [117] may also be invaluable to implementing certain aspects of quality control programs for 1 icensees.

\section{NRC's Interest in "Traceability" of Radia- tion Sources and Radiation Measurements to NBS}

As implied by the foregoing discussion, the NRC's interest in "traceability" may be broadly translated into an interest in establishing all of the procedures 1 icensees, and those firms who carry out calibrations or measurements for them, should follow to ensure the sufficient accuracy and reliability of radiation measurements made for purposes of protecting employees and the public from radiation exposure, as required by the regulations in Title 10 [32]. These "things that 1 icensees and/or their subcontractors should do" may be outlined as follows:

(1) Procedures carried out by the licensee's own staff for instrument selection, maintenance, calibration, quality control and usage, in order to optimize accuracy and reliability of the 1 icensee's surveys for purposes of radiation protection of employees $[19,21,22,68]$ and the public [100-103], as required in general terms by the regulations 10 CFR Part 20 [32].

(2) Procedures for quality control, calibration, and/or repair carried out in house by commercial companies or independent agencies who supply instruments and/or services related to the 1 icensee's radiation protection program. These are internal qual ity control procedures.

(3) Procedures and requirements to be followed by 1 icensees and/or their subcontractors to participate in a national performance testing and certification program that independently monitors overal1 performance and accuracy of radiation surveys, and to provide any data and information necessary to the continued improvement of radiation monitoring and surveys for protection purposes. These are the external quality control programs that have yet to be implemented.

Is is my impression, from the privilege of participating in some of these developments at NRC during the past 5 years, that major progress has been made in developing the consensus standards and guides necessary for (1) and (2) above. I bel ieve that sufficient information, knowledge, and experience is now at hand within the professional health physics and nuclear science community -- representing government, industry, medicine, and research establishments -- to complete tasks related to (1) and (2) within the next 3-5 years.

However, tasks related to implementation phases of (3) above will, in my opinion, require considerable further technical assistance, applied research, and systems development. This research and development may -- and probably should -- be carried out in parallel with pilot performance testing programs of national scope. These programs should involve all of the managerial and technical aspects -- administrative, measurement science, statistical evaluation, record systems and legal -- that would comprise the ongoing national performance testing and certification programs. When tasks (1)-(3) are accomplished to provide the necessary ongoing quality control of radiation protection measurements for NRC regulatory programs, then these aspects of Minogue's goals [38] for the cooperative "Regulatory-Industry" development of standards for safety will have been accomplis hed.

\section{Some Basic Problems and Considerations Requiring Attention in Implementing Performance Testing Programs}

It should be obvious to this audience that one cannot deal in a sinale article with all the considerations of testing performance of the various radiation measurements made for protection purposes. Many books could be written on this subject. The standards and guides already referenced could fill many volumes, and those that will be written in the next few years would probably fill many more volumes. The publication of this Conference itself will fill a large volume, and this conference has only begun to approach many of the problems that need to be solved. The IAEA handbook [76] describing a laboratory for testing and calibrating radiation survey instruments is a good example of the kind of detail that must be specified just to begin setting up a calibration laboratory. Thus, only a 
few questions will be discussed to stimulate thought on some matters that require further study.

\section{A. Rational Definition of Accuracy Requirements, Limits of Detection}

Statements of the accuracy requirements for radiation survey measuraments, as made in current guides and standards, appear to have been arbitrarily derived based on the judgments of the authors of thèse reports regarding practical feasibility and the state of the art. A more substantial effort to arrive at a rational basis for stating required accuracies and documenting this basis is needed, both for guiding further development of performance requirements, and for explaining the reasons for acceptability of errors or uncertainties to administrators and beneficiaries of radiation protection programs. Stating an "acceptable" level of accuracy implies the acceptance of a certain range of error.

This need for rational derivation of acceptable errors can perhaps be illustrated by posing some cogent questions:

1. What accuracy is needed and justified by the accuracy in assessing biological risks when the exposure is known?

Recently, Warren Sinclair [118] reviewed the estimated ranges of uncertainty in assessing carcinogenic effects of radiation alone, placing "error bars" on the estimated risk (or an estimated confidence level) of a factor of 2 to 10 just for the effects of lowering dose or dose rate in reducing the estimated (average) risk factors obtained from the "linear hypothesis" (which themselves conta in uncertainties often given as a factor of 2-3 when based on linear interpolations from high dose rate [119]). Thus, let us say for purposes of illustration that the 95 percent confidence interval for our best estimate of a risk factor, $R$, for a particular radiation category in the range of doses to be measured (which also needs rational definition) is $R \stackrel{x}{=} 10$ ( $R$ times or divided by 10 ; i.e., $R \times 10$ or $R / 10)$. This would imply that radiation protection standards (exposure limits) should be derived with at least a factor of 10 safety included when based on "best" risk estimates, and that protection measures to maintain exposures within limits as well as ALARA should perhaps generally strive for additional factors of safety of 10-100 below the exposure limits. (This author believes that effective radiation protection practice has sometimes deliberately (and sometimes inadvertently) already converged to this degree of conservatism (purposeful overestimation of risk) over the past eight decades [120].)

Then, a factor of 2 uncertainty in monitoring radiation exposure would seem small on a logarithmic scale compared to the order of magnitude uncertainties of risk estimates and safety factors. Indeed, al though NCRP
Report 57 [78] calls for an "accuracy" of $\pm 30 \%$ at doses approaching maximum permissible level s (MPD) and $\pm 20 \%$ at higher doses, it mentions a factor of 2 uncertainty $(+100 \%,-50 \%)$ as acceptable in the lower range (below $1 / 4$ MPD) (see pp 63-64, Ref. 78). (This factor of 2 statement implies a recognition that monitoring error distributions tend to be lognormal, as indicated below.) However, NCRP Report 57 calls for a precision of $+10 \%$ in personnel monitoring to improve comparisons of trends between persons and time periods.

Even if risk estimates were known with certainty, "biological variations" in responses of different animals from a single strain may vary within a factor of 2 or more even for socalled "non-stochastic" effects. For example, the standard geometric deviation of the 30-day mortality curve for gamma irradiation of mice in Fig. 17, Ref. 90, can be seen to be about $S_{g}=\stackrel{x}{\div} 1.2$. The 95 percent range of variability would be $S_{g}=\frac{x}{\div} 1.44$; i.e., 95 percent of animals would die at doses between $725 \stackrel{\times}{\times} 1.44$ rad, or 503 to 1044 rads. This is about a factor of 2 variation to cover the 95 percent range.

The stochastic (probabilistic) effects of radiation at high and low dose levels al so show a variability of response between animals which may be partly due to inherent biological variations. However, much of the range over which individual animals may respond -- as characterized by the dose-response curve for given experimental conditions -- may in fact be attributable to the stochastic (chance) nature of the cancer induction process [91, 92]. As with chemical agents such as cigarette tars, some individuals may be more resistant (or luckier) and absorb larger. doses over longer time periods before succumbing to cancer. Some may die in old age of other causes without contracting cancer at all -- even at the 1 argest doses. The $95 \%$ ranges of radiation dose for lethality for mammals by cancers of various types generally include doses varying by more than a factor of $2[91,92]$. Carcinogenesis by internal emitters generally exhibits dose-response curves covering a broader range. However, the majority of scientific opinion embraces the belief that the probability of inducing cancer decreases but remains finite down to the lowest doses, without threshold $[118,119]$. At whole-body doses of $1 \mathrm{rem}$ to younger individuals, probabilities of about $2 \times 10^{-4}$ per rem have been estimated by 1 inear extrapolation through the origin from data at high doses and dose rates; for low LET radiation, and for doses below $5 \mathrm{rem} /$ year $[118,119]$, this probability is believed to be reduced another factor of ? to 10 .

Thus, the dose at which any given individual will respond to "non-stochastic" effects can vary by a factor of 2 or more $95 \%$ of the time. The same is true for "stochastic effects," but the probability of an effect is of interest down to the lowest dose levels because of the non-threshold nature of the effect. Yet, this probability can be estimated only to within 
about an order of magnitude.

Thus, a dilemma is created in rationaliy specifying "acceptable" accuracy. Obviously, uncertainties by as much as a factor of 2 in measuring a dose witl not influence very much the order of magnitude of risk estimates. This is particularly true if the dose measurements are made, interpreted and recorded in unbiased fashion, so that the random errors of imprecision (or uncontrolled variation) are partly cancelled according to the statistical laws of large numbers in estimating a cumulative (e.g., annual) dose from many measurements [87]. Yet, our intuitive ideas of "good practice" would often cause us to reject a factor of 2 uncertainty as "unacceptable." We do not consciousTy realize that in the fields of radiation measurement and protection we are usual1y operating on a logarithmic scale $[121,122,130]$, and a factor of two does not represent a large numerical uncertainty range.

Perhaps, looking toward the future for more precise definition of dose-response and measurement phenomena, we should in the meantime satisfy our taste for precision by starting with measurements in the radiation dose range where "non-stochastic" effects are likely, setting the acceptable $95 \%$ confidence band of a measurement at one-tenth the relative ranqe of variation of the 30-day gamma lethality curve for pure-bred mice (Figure 17, Reference $90)$. This would establ ish an accuracy goal for measurements in the "non-stochastic" range of 1.05 , which is just about equivalent to $+5 \%$ since such a narrow distribution may be approximated by either the $10 \mathrm{~g}$-normal or normal shape over the $95 \%$ range $[121,122]$. This accuracy goal is consistent with that for calibration of radiation beams used in radiation therapy [123].

It would be difficult to establish the 1 imits of accuracy of measurements for protection against stochastic effects on a more rational basis before the ranges of uncertainty of risk estimates are more firmly established and understood.

The ICRP (PubTication 12, 1968) (see Reference $76, p$ 54) states "The uncertainties acceptable in routine individual monitoring should be somewhat less than the investigation level and can best be expressed in relation to the annual dose. The uncertainty in assessing the upper limits to the annual dose equivalent to the whole hody or to the organs of the body should not exceed $50 \%$. Wherever these doses are 1 ess than 2 rem, an uncertainty of 1 rem is acceptable." However, these errors will include variations in field measurements due to variations in spectral energy, direction sensitivity, environmental conditions, instrument stability, dose interpretations, and many other factors $[76,78]$. For the moment at least, this author will defer to the judgments in the more recent NCP.P Report 57 [78]. Perhaps a more rational approach witl be discovered during the development and implementation of the performance testing programs described above.
2. What are the lezal requirements for accuracy?

There was considerable discussion about the 1 egal requirements for radiation measurements and record keepinn at the Medical Radiation Information for Litigation Conference [90], and some recognition by the Tawyers present of the difficulties of providing exact numbers to "prove" or "disprove" the causation of diseases by radiation. The proof of causation "beyond reasonable doubt" becomes impossible when the same diseases may also be caused by other agents, when the causation by radiation can only be expressed as a probability that depends upon dose and many other conditions, and when even down to the lowest dose levels there is reason to believe the probability remains small by finite $[91,92]$. I do not bel ieve that a complete legal basis has yet been devised for selecting "acceptahle" accuracies of radiation measurements or assessments. The NRC requlations [32] do not allow for uncertainties of mea surement, and any recorded exposures that exceed 1 imits allowed under 10 CFR Part 20 are deemed to be evidence of the violation of requlations. perhaps the definition of acceptable accuracy is a fertile topic for discussion between scientists and lawyers concerned with radiation protection.

3. How should accuracy (precision and bias) be expressed in rigorous statistical terms?

A brief summary of the considerations in defining detection limits, sometimes better called "minimum detectable amounts or quantities, " is given in section 7 of NCPP Report No. 58 [79]. Further reference to the 1 iterature cited in this report will show that there are many ways of defining detection limits, and lack of standard practice in many areas of radiation measurement has often led to confusion in understanding the limitations of given types of measurement. In the field of radioactivity and environmental measurements, however, the practice has been increasing of utilizing formulations of minimum detectable activity, or lower limit of detection, such as given by the following formula $[102,125]$ :

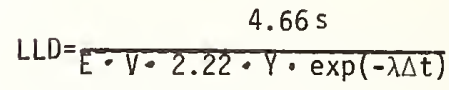

where

LLD is the smallest concentration of radioactive material in a sample that will yield a net count (above system background) that will be detected with 95\% probability with on $1 y$. $5 \%$ probability of falsely con¿luding that a blank observation represents a "real" signal. 
$s$ is the observed standard deviation of the background counting rate or of the counting rate of a blank sample, as appropriate (as counts per minute)

$E$ is the counting efficiency (as counts per disintegration)

$V$ is the sample size (in units of mass or volume)

2.22 is the number of disintegrations per minute per picocurie

$Y$ is the fractional radiochemical yeild (when applicable)

$\lambda$ is the radioactive decay constant for the particular

$\Delta t$ is the elapsed time between sample collection, or end of the sample collection period, and time of counting

This formulation is somewhat different from that adapted in the NRC Report No. 58 [79] from the work of Currie [128]. Currie defines several levels of detection: the decision limit, $L_{C}$, above which the higher count would produce the decision that it was more probable than not that activity above background had been detected; the detection limit, $L_{D}$, at or above which level a true signal is likely to be detected with $95 \%$ probability (i.e., the probability of non-detection at level $L_{D}$ is approximately $5 \%$ ); and a higher level above which a measurement may be made with a given degree of precision. These definitions take into account statistics only and are formulated by the following equations:

$$
\begin{aligned}
& L_{C}=2.32 \sqrt{B} \\
& L_{D}=2.71+4.65 \sqrt{B}
\end{aligned}
$$

As pointed out in NCRP Report No. 58 (pp 276-277), the probability of false detection at the chosen level of $L_{c}$ is approximately $5 \%$ and the probability of non-detection at a level $L_{D}$ is approximately $5 \%$. These formulas are derived under the assumption that the counts of background and total counts are paired observations and no allowance is made for experimental variations due to such factors as variations in back scatter or absorption of some background radiation by the sample. As pointed out in the Report, the procedure calls for a decision of no detection if the net number of counts is less than $L_{C}$, and asks "should the signal level corresponding to $L_{C}$ be called the 'minimum detectable activity'?" As pointed out, at this level the flipping of a coin would give the same results in the long run as the measurements. This condition is unsatisfactory because by minimum detectable activity is meant the activity level that could be detected most of the time, not just occasionally. Yet, one will often find laboratories quoting values calculated by equations similar to that of (2) to be their minimum detectable activity while other more conservative laboratories will use a formula similar to that of (3) or (1).
Thus it is important that definitions of minimum detectable activity or other quantities be defined in standardized ways and be pronerly understood before requirements are made for detection capabilities. There is also a relationship between these definitions and accuracy requirements, because it must be realized that in most radiation measurements one must usually be well above the minimum detectable amounts (MDA) before confidence intervals on the measurements become relatively stable.

In Equation (1), the constant 4.66 is derived under the assumption that when you have an MDA quantity the overlap of the frequency distributions in total counts and backqround counts will be such that there will be exactly a probability $\beta=0.05$ that you will not detect that MnA quantity and have what is called a "Type 2" error. This is also dependent on the previous acceptance of a probability of $\alpha=$ 0.05 that this fluctuation of a background count will not be called a positive measurement. Thus, one can see that any definition of MDA has arbitrary assumptions, and there is no sharp dividina 1 ine below which probability of making an erroneous decision is zero. This must be emphasized because the word "minimum" in the term MDA, or "1imit" in the term LLD, makes the term sound rather absolute. Any definition of MDA or LLn is an arbitrary statement of detection capability under given conditions and counting times (or observation times in the case of the fluctuating needle on a survey meter). However, the adoption of uniform definitions of statistical terms will be very important to the implementation of performance testing programs.

\section{B. Probabilities in Evaluating Measurement Error Distributions}

Another area that deserves attention is the study of the characteristic distributions of error in measurements, where they are made in the same manner that they will need to be made for participation in performance testing programs. This will be necessary in order to properly establish the probabilities of any giver set of mea surements falling outside of defined ranges. Often, error analysis has been carried out under the assumption that errors follow a Normal distribution. Perhaps statisticians should adopt the term "Gaussian" distribution as used by physicists since the elementary statistics courses give the impression that the Gaussian distribution of error, when called "Normal," is the one to assume for most measurements. This has not been found to be the case in radiation measurements; when distributions have been wide enough they have most often shown themselves to be more closely approximated by the log-normal function $[121,122]$.

Figure 1 shows a plot [90] on log-probaility paper of the cumulative distributions of ratios $Y_{i} / X_{i}$, of reported divided by delivered doses, for those film badges of each radiation category that were next to farthest away from perfect performance, for each of 26 companies tested by the National Sanitation Foundation (NSF) in 1965 [83]. These distributions were plotted in order to study the nature of the overall errors in $f i 7 m$ 
dosimetry. When these same points were plotted on a linear-probability paper, they lay on a curve rather than a straight line, showing that a lognormal frequency distribution would be a better description of the data. Figure 1 shows the frequency distribution of error factors for the data pooled for all categories in order to obtain a sufficient sample size for a gross picture of the distribution of errors, without considering any particular weighting of different radiation categories. This approximate fit to a log-normal distribution of errors lends a posteriori support to the fact that NSF selected error bands that were equal distances on a logarithmic scale above and below the 45-degree 1 ine of perfect accuracy (i.e., error limits obtained by multiplying and dividing the median (true) dose value by the same error factor). When error data follow the log-normal distribution, another advantage of this kind of plot is the easy observation of trends in performance. As the performance of the companies or participants improves, the slope of the line in Figure 1 should increase while the median moves closer to 1 .

In Figure 1, the median is 0.88 (half the reported categories included $Y_{i} / X_{j}$ values above $88 \%$ of the true dose and half reported below). The geometric standard deviation $\left(Y_{i} / X_{i}\right.$ at $50 \%$ divided by $Y_{i} / X_{i}$ at $16 \%$ ) is $s_{g}=1.72$, meaning that 68 percent of the $Y_{i} / X_{j}$ values 1 ie between $(88 \times 1.72) \%$ and $(88 / 1.72) \%$ of the true dose; and about $95 \%$ of the deviations 1ie between $88 \times(1.72)^{2} \%$ and $88 /(1.72)^{2} \%$ of the true dose; i.e., within a "factor of $3^{\prime \prime}$ of the true dose. It was interesting to note in this Conference that Dr. Plato's data [124] on error distributions in personnel dosimetry performance tests as it appeared on a linear plot also generally seemed to be skewed in the manner of log-normal distributions and the overall results seem to have a margin of error about the same magnitude as that in the more limited studies of the National Sanitation Foundation [83]. It would be interesting to examine the more recent data to determine the nature of the error distributions in each test category as well as a pooled overview of the performance in general.

It is also interesting that urinary output of a patient [129] under chelation therapy for severa 1 years varied daily according to a log-norma 1 distribution with an $\mathrm{S}_{\mathrm{q}}=1.4$, similar in width to the distribution of personnel dosimetry test errors of Figure 1. Thus, the fundamental single sample measurements of both internal and external dosimetry may have similar inherent error distributions.

\section{Practical Limits to Accuracy of Field Measurements}

References $34-37,76,78,79,83,84,94$, and 95 review many of the sources of error in calibrations and field measurements of external radiation with various types of instruments. References 104-107 provide some further insight on sources of error in interpreting bioassay measurements in terms of internal dose. However, in performance testing programs with specific instruments, specific standardized radiation fields or sources, and specific experimental procedures, the quantitative contribution and frequency distribution of each source of error will need to be determined for each type of instrument and radiation category. This is necessary before the results of performance tests can be completely interpreted, and measures to improve quality control and accuracy can be taken.

\section{Effects of Environmental Conditions on Error Distributions}

The need to test instrument operations and the accuracy of their calibrations under environmental conditions of use has been adequately discussed in a general way in current international and national guides $[76,78,79]$. However, the effects of environmental variables such as temperature pressure, humidity, and ambient radiofrequency electromagnetic radiation under test conditions, must be understood so that conditions can be specified for implementing performance tests for the desired instruments.

In some cases, the time interval of use of dosimeters may influence the degree to which environmental conditions influence the accuracy of exposure determinations. For example, consider the studies of Ron Kathren et. al designed to separate out the effects of the variables temperature, humidity, dose level and wearing interval on the accuracy of film determinations of radiation exposure [87-89]. As it turned out (even for unprotected film packets under high humidity conditions, when they were readable) for weekly exchange intervals, cumulative 12-week exposures in the range of most personnel monitoring results were found to be reliable under all environmental conditions studied. However, for exchange intervals greater than 6 weeks, film fogging under high humidity conditions exceeded latent image fading and produced high erratic dose interpretations.

The effects of temperature and humidity on individual interpretations was examined for badges exposed weekly to $10 \mathrm{mr}$ from a radium-gamma source, for environmental conditions including some of the more extreme environments encountered in the field. The powerful effect of the statistical law of large numbers was experimentally evidenced, showing that when even small and variable measurements are recorded as obtained to within appropriate significant digits, the random variations will tend to cancel over a 12-week period, for each of the environmental conditions, to give a total dose within $10 \%$ of the true total $120 \mathrm{mr}$ dose. Similar results were obtained at other dose levels. Studies with optical density amplification [88] showed that the sensitivity and precision of films may be limited primarily by fluctuations of only a few percent in $f i l m$ emulsion thickness or composition, if the effects of changing environmental conditions can be removed or accounted for. However, when exposure intervals increased beyond 4-6 weeks, high humidities and temperatures tended to produce a large fogging effect that overcompensated the fading of the latent images with time, resulting in large overestimates of exposure [89].

Similar studies that orthogonalize and separate the influence of important environmental variables on other dosimeters and instruments used for 
occupational health protection will probably need to be incorporated in pilot studies of performance testing programs.

\section{E. Problems in Shipping "Standard" or "Unknown" Samples, Sources, Transfer Chambers or Instruments}

Problems and recommendations for preparing radiochemical test samples for shipment for analysis have been addressed in previous analytical performance testing programs [96-99]. Recommendations for shipping and handling sensitive instruments and detectors have been provided by the NCRP [78, 79]. However, studies and tests to validate the conditions for shipping appropriate tests or simulated samples or instruments will need to be an integral part of any specific pilot performance testing program.

\section{F. Selection of Categories of Radiation and Radioactivity Measurements for Testing}

As in the case of the personnel dosimetry testing program, types of measurements or assays to be tested will need to be grouped into cateqories taking into consideration that some laboratories may specialize in services for particular sectors of radiation users. Also, types of instruments, types of assays, various qualities and energies of radiation, and other factors may naturaliy fall into convenient groups for purposes of operating performance testing programs. The selection of categories for testing thus involves the consideration of a complex of many factors -- scientific, statistical, and operational. Thus, the categories to be selected will need to be subjected to pilot testing to optimize the effectiveness of any testing program.

G. Development of Standard Procedures for Statistical Evaluation and Presentation of Program Results and Criteria for Certification

When all other details of performance testing programs are worked out, a standard design for evaluation and presentation of program results, incorporating certification decisions, must be worked out. This is not a trivial consideration, and requires careful and rigorous evaluation of the probabilities of all outcomes, as well as the degree of assurance desired that accuracy goals have been met before certification for a category is made for the appropriate period of time. A simple example may suffice to indicate the importance of these considerations.

Suppose that it has been decided that a $\pm 10 \%$ error, at a 95\% confidence interval, represents good practice and is quite acceptable for radiobioassay samples of a given nuclide. Since each analysis is conducted separately in the laboratory, and since the error may be considered a random variable composed of the sum of a random bias, plus a random uncontrolled variation over time (such as chemical yield), the probability $P_{10}$ that none out of 10 assays of unknowns provided by the testing laboratory will be outside of the \pm $10 \%$ range even for a laboratory that meets the accuracy criteria would be:

$$
P_{10}=\prod_{i=1}^{10} P_{i}
$$

which for al1 $P_{j}=.95$ becomes

$$
P_{10}=(.95)^{10}=0.5987
$$

Thus, unless the random nature of errors is considered in establishing certification criteria, a 10-sample testing in a given category would produce a $40 \%$ chance that even an excellent laboratory would fail the tests for the given radionuc1ide. Now, consider that 10 different radionuclide categories are being tested, and we assume for simplicity that a11 $P_{j}=.95$. The chance that no sample would be outside the $+10 \%$ range would become

$$
P_{100}=(0.95)^{100}=0.00592
$$

In other words, there would be only a .6\% chance that an excellent laboratory would receive certification if perfect adherence to the $95 \%$ error range were required, and the true random nature of errors were not considered in certification criteria. Since the determination of reasonab? accuracy requirements is much more complex and depends upon the type of radiation measurement, the level of radiation or radioactivity and many other factors in any given category, one can see that even experienced judgment will not suffice to arrive at a suitable set of test criteria without actually subjecting a performance testing program to complete pilot testing, including mock runs of certification criteria, and cooperative examinations with the laboratory tested of final results in order to eliminate those sources of error that are correctable.

\section{Summary}

The author hopes that this summary of considerations in providing programs to improve occupational radiation exposure measurements will be supportive of further efforts toward this end. The progress already made in the personnel dosimetry testing program [124] and in the British performance testing and calibration programs [116] lends hope for future progress toward the establ ishment of complete performance testing of al1 of the important types of measurements made for radiation protection purposes in the United States.

As pointed out earlier in this Conference, in order to define "traceability" to the National Bureau of Standards, one must first state: "traceability to what degree of accuracy?" In order to ascertain accuracy, ultimately the independent performance testing programs are required. Thus, the 1 inks between "traceability" and "performance testing" are inseparable. 


\section{Appendix $A^{*}$}

Il ustrative Examples of "Acceptability of Radiation Survey Instrument Calibrations" (4th Draft)

Special Definition for Purposes of NRC Regulations and Guides (Draft)

"Acceptable Calibration" - the calibration of a survey instrument used for surveys to comply with the requirements of 10 CFR Part 20, section 20.201 (b), is defined for purposes of these regulations to be an acceptable calibration if one (or more) of the following conditions is met:

(a) The survey instrument is calibrated hy exposure to a standard radiation field under the follow ing conditions:

(i) Exposure is made in a radiation field emitted by a source of radioactive material that has been certified by the supplier to have: a specified radiation exposure rate at unit distance (e.q., one meter) under specified scattering conditions (for calculation of exposure rates over a range of distances); or specified exnosure rates at various distances under specified scattering and exposure conditions. The certified exposure rates in either case shall be evidenced by a certificated from the supplier including all appropriate information needed for converting instrument readings to the particular exposure or dose units to be used for demonstrating compliance with exposure limits of 10 CFR Part 20;

(ii) The supplier's certificate states that the specified exposure rates are within $\pm 15 \%$ (or some smaller uncertainty) of the true values;

(iii) The source supplier has determined the value(s) of the licensee's calibration source by comparing it with a standard source of radiation maintained in the supplier's laboratory. At least three replicate comparisons with identical equipment-geometry setuos of the radiation measurement system shall be made, in order to avoid errors that might result

\footnotetext{
${ }^{1}$ Certificates shal1 contain any pertinent data on source purity that may over time affect calibration values, as specified in ICRU Report No. 12, "Certification of Standardized Radioactive Sources," International Commission on Radiation Units and Measurements," September 15, 1968.

*This appendix is under further revision for possible use in regulations or regulatory guidance. It is presented here only to provide a more concrete illustration of the details required to specify how "traceable" or acceptable calibrations might be performed for radiation survey instruments.

**In al1 calibration procedures, the radiation field in which the survey instrument is to be calibrated shall be of a type and energy appropriate for the instrument and its intended use.
}

from operator mistakes, instrument drift, or instrument malfunction. The value of the supplier's standard source shall have been certified by the National Bureau of Standards for exposure rate at a fixed distance (e.g., one meter) according to one of its standard calibration services. The changes in value or intensity of the supplier's radiation measurement system are checked on at least a monthly frequency and verified to remain within $+3 \%$ of the value caiculated by correcting the initial National Bureau of Standards certified value for radioactive decay. Records of all source certificates, calibration methods, measured values, and all calculations used by the supplier to certify his sources shall be maintained permanently in the supplier's records and be available for inspection by the NRC.

(iv) The instrument has been calibrated on each ranqe that will be used to comply with requirements of 10 CFP 20 or 1 icense conditions. These ranges shall be calibrated by exposure to a field of the appropriate type and energy of radiation, in field intensities that will produce at least two instrument readings on each scale, one within $20-30 \%$ of the scale range and the other within $70-80 \%$ of the ranqe (in 1 inear distance along the scale, for log or 1 inear scales). Other scales of the instrument shall be checked for oneration, but marked "not of Verified Accuracy" for purooses of compliance with NRC requirements.

(v) Source intensities or values certified by the supplier have been corrected by the licensee for radioactive decay as necessary to maintain calibrations within an accuracy of $+20 \%$, which includes the maximum allowable $+15 \%$ uncertainty in the specified exposure rates for the source (in paragraph (ii) above; and

(vi) The licensee has maintained records available for inspection on source certifications, calibration methods, calibration measurements, and calculations including decay corrections as necessary to compare instrument readings versus administered calibration exposures in units as specified in 10 CFR 20 for the particular type of radiation involved.

(b) The survey instrument is cal ibrated by exposure to a standard source of radioactivity under the following conditions:

(i) Exposure is made to a source that is certified by the supplier to have a given amount of radioactivity, known radionuclidic purity, and a sufficiently known radioactive decay scheme and half-1ife, so that the necessary field intensities as specified in $(a)(i)$ above may be calculated by the licensee from establ ished scientific information. In this case, all calculations of exposure or dose rates from radioactivity units and references used in these calculations shall be maintained for inspection 
with other calibration records.

(ii) The supplier's certificate ${ }^{i}$ states that the specified radioactivity of the source used for calibration is within $+15 \%$ (or some smaller uncertainty) of the true values; and

(iii) Conditions (a) (iii) through (a)(vi) above are also applicable, except that in (a) (iii) the supplier's standard source shall have been certified for radioactivity, rather than the exposure rate at fixed distance, by the National Rureau of Standards.

(c) The survey instrument is calibrated in a radiation field standardized with a secondary standard instrument under the following conditions:

(i) The source used for survey meter calibrations has been provided with an associated set of exposure or dose rates at specified distances, and these values have been provided and certified by a qualified person ${ }^{*}$ using a secondary standard instrument that has been calibrated directly by exposure to standard sources at the National Bureau of Standards, or at one of the Regional Calibration Laboratories accredited by the American Association of Physicists in Medicine with the cooperation of the National Bureau of Standards.

(ii) Conditions (a)(iv) through (a)(vi) also are applicable.

(d) The survey instrument is calibrated by comparison with a secondary standard instrument under the following conditions:

(i) The radiation field used for survey meter calibrations is of appropriate type, energy, geometry, and intensity, and remains stable during the period when calibrations are performed. The survey meter is calibrated by comparison with a secondary standard instrument at a fixed point within the radiation field. At each selected point, a technique involving simultaneous exposure or substitution is used to compare values indicated by the secondary standard instrument and the instrument under calibration. The secondary standard instrument sha11 have been calibrated by the National Bureau of Standards, or by one of the Regiona 1 Calibration Laboratories accredited by the American Association of Physicists in Medicine with the cooperation of the National Bureau of Standards.

\footnotetext{
*Qualified persons include persons offering radiation dosimetry and calibration services who are certified by either: The American College of Radiology in one of the areas of radiological physics; the American Board of Health Physics; or the American Board of Industrial Hygiene in radiological aspects.
}

(ii) The secondary standard instrument is certified to have been calibrated so that its indicated values (after application of any necessary calibration factors) are within $\pm 10 \%$ (or some smaller uncertainty) of the true values.

(iii) Conditions (a)(iv) and (a)(vi) al so are applicable.

(iv) Calibrations of the survey instrument shall be made to within a maximum uncertainty of $\pm 20 \%$ (or less) of the true value. This uncertainty includes the maximum allowable $+10 \%$ uncertainty in the values indicated by the secondary standard instrument, which shall be taken into account in determining survey instrument accuracy. 
Table 1

SENSITIVITIES OF UNIVERSITY OF PITTSBURGH PROCEDURES

FOR SEVERAL NUCLIDES $(1968)^{*}$

\begin{tabular}{|c|c|c|c|}
\hline Radlonuclide & $\begin{array}{l}\text { Lower }(97.5 \% \mathrm{CL}) \\
\text { Limit of Detec- } \\
\text { tion In Lung for } \\
40 \text { Minutes with } \\
\text { Standard Chair } \\
\text { Technlque }\end{array}$ & $\begin{array}{l}\text { Maximum Per- } \\
\text { missible Body } \\
\text { Burden(1) }\end{array}$ & $\begin{array}{l}\text { Fraetlon } \\
\text { of MPBB } \\
\text { Detectable }\end{array}$ \\
\hline $\begin{array}{l}\text { Fission products: } \\
\text { Cs-137 } \\
2 r=95-N b-95 \\
i=131 \\
B a-140-L a-140 \\
C e-144-\operatorname{Pr}=144\end{array}$ & $\begin{array}{l}2 \times 10^{-4} \mu \mathrm{Ci} \\
9 \times 10^{-5} \mu \mathrm{Ci} \\
3 \times 10^{-4} \mu \mathrm{Ci} \\
9 \times 10^{-4} \mu \mathrm{Ci} \\
2 \times 10^{-3} \mu \mathrm{Ci}\end{array}$ & $\begin{array}{l}30 \mu \mathrm{Cl} \\
20 \mu \mathrm{Cl} \\
0.7 \mu \mathrm{Cl} \\
4 \mu \mathrm{Cl} \\
5 \mu \mathrm{Cl}\end{array}$ & $\begin{array}{l}\text { 6. } 6 \times 10^{-6} \\
4.5 \times 10^{-6} \\
4.3 \times 10^{-4} \\
2.2 \times 10^{-4} \\
4.0 \times 10^{-4}\end{array}$ \\
\hline 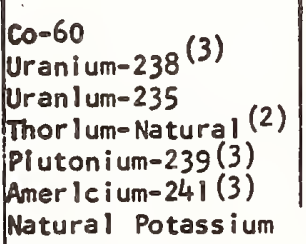 & $\begin{array}{l}4 \times 10^{-4} \mu \mathrm{Ci} \\
4 \times 10^{-4} \mu \mathrm{Mi} \\
1 \times 10^{-4} \mathrm{\mu Ci} \\
6 \times 10^{-4} \mu \mathrm{HC} \\
0.03 \mu \mathrm{MCi} \\
4 \times 10^{-4} \mathrm{\mu Ci} \\
\text { Measurable within }\end{array}$ & $\begin{array}{c}10 \mu \mathrm{Cl} \\
5 \times 10^{-3} \mu \mathrm{Ci} \\
0.03 \mu \mathrm{Ci} \\
0.04 \mu \mathrm{Cl} \\
0.04 \mu \mathrm{Ci} \\
0.05 \mu \mathrm{Cl} \\
\text { 6or adult male }\end{array}$ & $\begin{array}{l}4.0 \times 10^{-5} \\
0.08 \\
0.003 \\
0.015 \\
0.75 \\
0.008 *\end{array}$ \\
\hline Total Gamma Activit & \multicolumn{3}{|c|}{ (Equivalent) $6 \times 10^{-4}$ (cs-137 equivalent) } \\
\hline
\end{tabular}

(1) As given in ICRP Committee II Report, Health Physics 3, 1960, for the total body burden when the most crltical organ is receiving the maxImum permisslble occupational exposure rate.

(2) Evaluated by a procedure similar to that given by LM. Scott, Heaith Physics 12, 101-102, January, 1966.

(3) Counted with a thin-window, I mm thick $\times 2$ 'D Nal erystal agalnst chest for 40 minutes, to detect low energy photons, as in Reference 84.

t $0.0033 \mu \mathrm{Ci}$ for 10 minute count on $8 \times 4$ behind back, assuming $\pm 25 \%$

fiuctuation for uncertainty of $\mathrm{k}-40$ background.

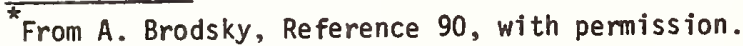




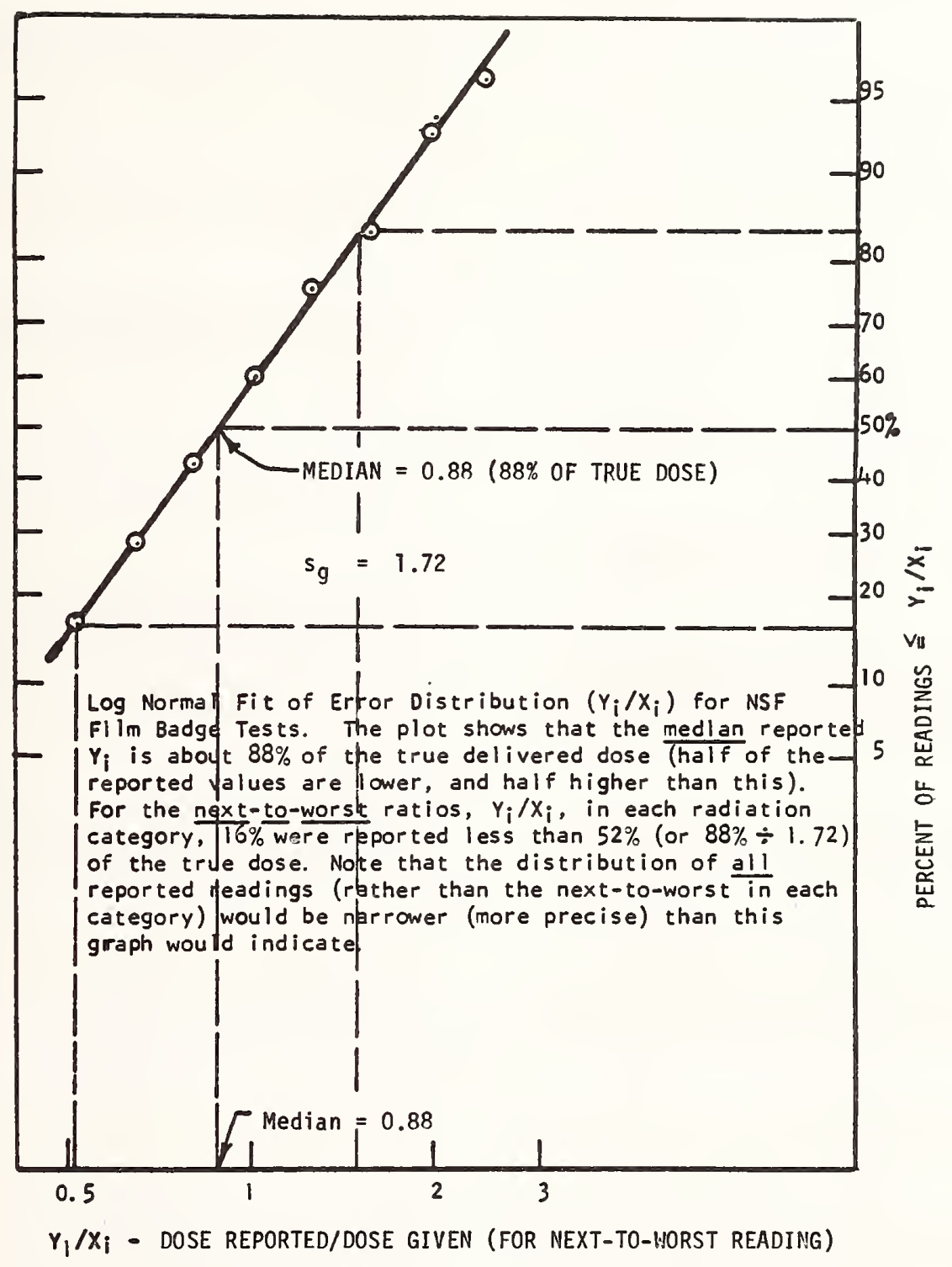

Figure 1 
[1]

USNRC Regulatory Guide 8.1, "Radiation Symbol," $2 / 2 / 73$.

[2]

USNRC Regulatory Guide 8.2, "Guide for Administrative Practices in Radiation Monitoring," $2 / 2 / 73$

[3]

USNRC Regulatory Guide 8.3, "Film Badge

Performance Criteria," 2/2/73.

[4]

USNRC Regulatory Guide 8.4, "Direct-Reading and Indirect-Reading Pocket Dosimeters,"

$2 / 26 / 73$.

[5]

USNRC Regulatory Guide 8.5, "Immediate Evacuation Signal," 2/16/73.

[6]

USNRC Regulatory Guide 8.6, "Standard Test

Procedure for Geiger-Müller Counters," 5/73.

[7]

USNRC Regulatory Guide 8.7, "Occupational Radiation Exposure Records Systems," 5/73.

[8]

USNRC Regulatory Guide 8.8, "Information Relevant to Ensuring that 0ccupational Radiation Exposures at Nuclear Power Stations Will Be As Low As Is Reasonably Achievable," Revision 3, $6 / 78$.

[9]

USNRC Regulatory Guide 8.9, "Acceptable Concepts, Models, Equations, and Assumptions for A Bioassay Program," 9/73.

[10]

USNRC Regulatory Guide 8.10, "Operating Philosophy for Maintaining Occupational Radiation Exposures As Low As Is Reasonably Achievable," Revision $7-R, 9 / 75$.

[11]

USNRC Regulatory Guide 8.11, "Applications of Bioassay for Uranium," 6/74.

[12]

USNRC Regulatory Guide 8.12, "Criticality Accident Alarm Systems," 12/74.

$[13]$

USNRC Regulatory Guide 8.13, "Instruction Concerning Prenatal Radiation Exposure," Revision $1,11 / 75$.

$[14]$

USNRC Regulatory Guide 8.14, "Personnel Neutron Dosimeters," Revision $7,8 / 77$.

[15]

USNRC Regulatory Guide 8.15, "Acceptable Programs for Respiratory Protection," 10/76.
[16]

USNRC Regulatory Guide 8.18 , "Information Relevant to Ensuring that Occupational Radiation Exposures at Medical Institutions Will $\mathrm{Re}$ As Low As Reasonably Achievable," 12/77.

[17]

USNRC Regulatory Guide 8.19, "Occupational Radiation Dose Assessment in Liaght-Mater Reactor Power Plants Design Stage Man-Rem Estimates," Revision 1, 6/79.

[18]

USNRC Requlatory Guide 8.20, "Applications of Bioassay for I-125 and I-131," Revision I, 9/79.

[19]

USNRC Regulatory Guide 8.27, "Health Physics Surveys for Byproduct Material at NRC-Licensed Processing and Manufacturing Plants," Revision $1,10 / 79$.

[20]

USNRC Regulatory Guide 8.22, "Bioassay at Uranium Mi 11s," 7/78.

[21]

USNRC Regulatory Guide 8.23, "Radiation Safety Surveys at Medical Institutions," 2/79.

[22]

USNRC Regulatory Guide 8.24, "Health Physics Surveys During Enriched Uranium-235 Processing and Fuel Fabrication," Revision 1, 10/?9.

[23]

USNRC Regulatory Guide 10.1, "Compilation of Reporting Requirements for Persons Subject to NRC Regulations," Revision 3, 5/77.

[24]

USNRC Regulatory Guide 10.2, "Guidance to Academic Institutions Applying for Specific Byproduct Material Licenses of Limited Scope," Revision 1, 12/76.

[25]

USNRC Regulatory Guide 10.3, "Guide for the Preparation of Applications for Special Nuclear Material Licenses of Less Than Critical Mass nuantities," Revision $7,4 / 77$.

[26]

USNRC Regulatory Guide 10.4, "Guide for the Preparation of Applications for Licenses to Process Source Material," Revision 1, 3/77.

[27]

USNRC Regulatory Guide 10.5, "Guide for the Preparation of Applications for Type A

Licenses of Broad Scope for Ryproduct Material," $9 / 76$.

[28]

USNRC Regulatory Guide 10.6, "Guide for the Preparation of Applications for Use of Sealed Sources and Devices for the Performance of Industrial Radiography," 9/76. 
USNRC Regulatory Guide 10.7, "Guide for the Preparation of Applications for Licenses for Laboratory and Industrial Use of Small Quantities of Byproduct Material," Revision 1, $8 / 79$.

[30]

USNRC Regulatory Guide 10.8, "Guide for the Preparation of Applications for Medical Programs," $1 / 79$.

[31]

USNRC Regulatory Guide 10.9, "Guide for the Preparation of Applications for Licenses for the Use of Gamma Irradiators," 4/80.

[32]

Title 10, Code of Federal Regulations, Part 20, "Standards for Protection Against Radiation," U.S. Government Printing Office, Washington, D.C., 1980.

[33]

Notice to Licensees, Personnel Dosimetry Processors and Other Interested Persons, U.S. Nuclear Regulatory Commission, Washington, D.C. 20555, April 17, 1980.

[34]

Phillip Plato and Glenn Hudson, Performance Testing of Personnel Dosimetry Services: Procedures Manual, NUREG/CR-1063, prepared for U.S. Nuclear Regulatory Commission by University of Michigan, January 1980.

[35]

P. Plato and G. Hudson, Performance Testing of Personnel Dosimetry Services, Final Report of a Two-Year Pilot Study October 1977September 1979, NUREG/CR-1064, prepared for U.S. Nuclear Regulatory Commission by University of Michigan, January 1980.

[36]

P. Plato and G. Hudson, Performance Testing of Personnel Dosimetry Services, Supplementary Report of a Two-Year Pilot Study October 1977-December 1979, NUREG/CR-1304, prepared for U.S. Nuclear Regulatory Commission by University of Michigan, April 1980.

[37]

"Draft American National Standard Criteria for Testing Personnel Dosimetry Performance," N13.11, American National Standards Institute, Inc., 1430 Broadway, New York, N.Y. 10018 , July 1978.

[38]

Robert B. Minogue, "The Regulatory-Industry Interface in Standards Development," presented at the Atomic Industrial Forum Workshop on Reactor Licensing and Sa fety, San Diego, California, December 11, 1974.
[39]

Allen Brodsky, R. E. Al exander, and R. J. Mattson, "NRC's Radiation Protection Regulations," published in the proceedings of the Heal th Physics Society Midyear Topical Symposium, Occupational Heal th Physics, edited by P. L. Carson, W. R. Hendee, and D. C. Hunt, Feb. 9-12, 1976 (available from Central Rocky Mountain Chapter, Heal th Physics Society, P. 0. Box 3229, Boulder, CO 80303).

[40]

Calculation of Absorbed Dose from Gamma

Radiation, Practice For, ANSI/ASTM D2568-70.

[41]

Dosimetry, Definitions of Terms Relating to, ANSI/ASTM El 70-76.

[42]

Gamma or $X$ Radiation, Test for Calculation of Absorbed Dose from, ANSI/ASTM E666-78.

[43]

Internal Dosimetry for Mixed Fission and Activation Products, ANSI N343-1978.

[44]

Neutron and Gamma-Ray Flux-to-Dose-Rate Factors, ANSI/ANS 6.1.1-1977.

[45]

Performance, Testing, and Procedura 1 Specifications for Thermoluminescence Dosimetry: Environmental Applications, ANSI N545-1975.

[46]

Fast-Neutron Flux Measurements by Track-Etch Technique, Method for, ANSI/ASTM E418-73.

[47]

Cobalt-60 and Cesium-137 Teletherapy Equipment, Guidelines for Maintaining, ANSI N449-1974.

[48]

Integrity and Test Specifications for Selected Brachytherapy Sources, ANSI N44.11973.

[49]

Leak Testing Radioactive Brachytherapy Sources, ANSI N44.2-1979.

[50]

Teletherapy Equipment, Procedures for Periodic Inspection of Cobalt-60 and Cesium137, ANSI N449.1-1978.

[51]

Thyroid Radioiodine Uptake Measurements Using a Neck Phantom, ANSI N44.3-1973.

[52]

"Dose Calibrator" Ionization Chambers for the Assay of Radionuclides, Calibration and Usage of, ANSI N42.13-1978. 
Calibration of Germanium Detectors for Measurement of Gamma-Ray Emission Rates of Radionuclides, Method of, ANSI/ASTM E522-78.

[54]

Direct Reading and Indirect Reading Pocket Dosimeters for X- and Gamma Radiation, Performance, Specifications for, ANSI N13.5-1972.

[55]

Geiger-Muller Counters, Test Procedure for, ANSI/IEEE 309-1970.

[56]

Germanium Detectors for Measurement of Gamma Ray Emission of Radionuclides, Calibration and Usage of, ANSI N42.14-1978.

[57]

Germanium Gamma-Ray Detectors, Test Procedures for, ANSI/IEEE 325-1971.

[58]

Germanium Semiconductor Detector Gamma Ray Efficiency Determination Using a Standard Marinel1i (Reentrant) Beaker Geometry, ANSI/ IFEE 680-1978.

[59]

Portable X- or Gamma Radiation Survey

Instruments, Specification of, ANSI N13.41971 (RT 977).

[60]

Radiation Protection Instrumentation Test and Calibration, ANSI N323-i978.

[61]

Semiconductor Radiation Detectors, Test Procedures for, ANSI/IEEE 300-1969.

[62]

Administrative Practices in Radiation Monitoring (A Guide for Management), ANSI N13.21969.

[63]

Dosimetry for Criticality Accidents, ANSI N13.3-1969.

[64]

Film Badge Performance, Criteria for, ANSI N13.7-1972.

[65]

Glossary of Terms Used in Radiation Shielding and Dosimetry, Draft Standard, ANSI/ANS 6.5

[66]

Immediate Evacuation Signal for Use in Industrial Installations Where Radiation Exposure May Occur, ANSI N2.3-1967.

$[67]$

Occupational Radiation Exposure Records Systems, Practice for, ANSI N13.6-1966

(RI 972).
[68]

Sampling Airborne Radioactive Materials in Nuclear Facilities, Guide to, ANSI N13.1-1969.

[69]

Installations Using Non-Medical X-Ray and Sealed Gamma-Ray Sources, Energies Up To 10 MeV, General Safety Standard for, ANSI/NRS 114.

[70]

Packages for Shipment of Radioactive Materials, Leakage Tests On, ANSI N14.5-1977.

[71]

Evaluating Films for Monitoring X-Rays and Gamma Rays Having Energies Up To 3 Million Electron Volts, Method for, ANSI PH2.101965 (R1 979).

[72]

Sensitometry of Industrial X-Ray Films for Energies Up to 3 Million Electron Volts, Method for, ANSI PH2.8-1975.

[73]

Sensitometry of Medical and Dental X-Ray Films, Methods for the, ANSI PH2.9-1974.

[74]

NRCP Report No. 10, "Radiological Monitoring Methods and Instruments," April 7, 1952 .*

[75]

International Atomic Energy Agency (IAEA) Technical Report Series No. 120, "Monitoring of Radioactive Contamination on Surfaces," 1970.*

[76]

IAEA Technical Report Series No. 133, "Handbook on Calibration of Radiation Protection Monitoring Instruments," $1971 . *$

[77]

International Commission on Radiation Units and Measurements (ICRU) Report No. 12, "Certification of Standardized Radioactive Sources," September 15, 1968.*

[78]

NCRP Report No. 57, "Instrumentation and Monitoring Methods for Radiation Protection," 1978.*

[79]

NCRP Report No. 58, "A Handbook of Radioactivity Measurement Procedures," 1978.*

*IAEA reports may be obtained from UNIPUB, Inc., P.0. Box 433, New York, N.Y. 10016.

ICRP reports may be obtained from Pergamon Press, Maxwe 17 House, Fairview Park, Elms ford, N.Y. 10523.

ICRU reports may be obtained from the International Commission on Radiation Units and Measurements, P.0. Box 30165, Washington, D.C. 20074.

NCRP reports may be obtained from NCRP Publications, P. O. Box 30175, Washington, D.C. 20014. 
International Atomic Energy Commission

"Advances in Radiation Protection Monitoring" (ISP494), 1979, $788 \mathrm{pp}$.

[81]

Office of Management and Budget, Office of Federal Procurement Policy, "Federal Participation in the Development and Use of Voluntary Standards; Final Issuance," OMB Circular No. A-119, Federal Register, Vol. 45, No. 14, Monday, January 21, 1980.

[82]

"Notice Regarding Need for Establishment of Film Dosimetry Calibration Laboratory," U.S. Atomic Energy Commission, Federal Register, Document 63-9411, September 4, 1963.

[83]

D. E. Barber, "Report on the National Sanitation Foundation Film Badge Performance Test Program," The National Sanitation Foundation, Ann Arbor, Michigan, June 30, 1965; also, Radiological Health Data and Reports, pp 623626, Nov. 1966.

[84]

C. M. Unruh, H. V. Larson, T. M. Beetle, and A. R. Keene, "The Establishment and Utilization of Film Dosimeter Performance Criteria," BNWL-542, Battelle-Northwest, Richland, WA, 1967.

[85]

First Topical Symposium on Personnel Radiation Dosimetry, Health Physics Society, Chicago, Illinois, Jan. 30, 31, Feb. 1, 1967 (reported in Health Physics, 1968).

[86]

"Employee Radiation Hazards and Workmen's Compensation," Hearings before the Joint Committee on Atomic Energy, U.S. Government Printing Office, Washington, D.C., 1959.

[87]

A. Brodsky, "Accuracy and Sensitivity of Film Measurements of Gamma-Radiation, Part II, Limits of Sensitivity and Precision," Health Physics 9, 463-471, 1963.

[88]

A. Brodsky, "An Optical Device for Extending the Range of Film Measurements of Gamma Radiation," Health Physics 9, 656-663, 1963.

[89]

R. L. Kathren and A. Brodsky, Health Physics 9, 769, 1963.

[90]

"Characteristics of Radiation Monitoring Instrumentation and Methods," by Allen Brodsky, in Medical Radiation Information for Litigation, edited by S. C. Bushong, J. S. Cox, V. P. Collins, J. B. Neibel, and G. B. Murphy, pp 5-59, U.S. Department Health, Education, and Welfare, Document No. DMRE 69-3, July 1969.
[91.]

Allen Brodsky, "A Stochastic Model of Carcinogenesis incorporating Certain Observations from Chemical and Radiation DoseResponse Data," Health Physics 35, 427-428, 1978.

[92]

Allen Brodsky, "Time and Dose Factors in Carcinogenesis," Letter to the Editor, Health Physics $36,468-471,1979$.

[93]

Allen Brodsky, "ALARA -- Radiation Risks and the Need to Keep Exposures 'As Low As Reasonably Achievable'," presented at the Eleventh National Conference on Radiation Control, Sheraton Century Center, OKlahoma City, Oklahoma, May 7, 1979, sponsored by the Conference of Radiation Control Program Directors, to be published by the Bureau of Radiological Health, DHEW, Washington, D.C.

$[94]$

R. L. Kathren, "Instruments in the Field Use, Abuse, and Misuse," Health Physics Operational Monitoring, Vol. 2, C. A. Willis and J. S. Handloser, Eds., Gordon and Breach, New York, 1972 , p. 811 .

[95]

W. P. Howe 11 and R. L. Kathren, "Calibration and Field Use of Ionization Chamber Survey Instruments," Health Physics Operational Monitoring, Vol. 2, C. A. Willis and J. S. Handloser, Eds., Gordon and Breach, New York, 1972 , p. 925.

[96]

Herbert L. Volchok and Melvin Feiner, "A Radioanalytical Laboratory Intercomparison Exercise," EML-366, Environmental Measurements Laboratory, Department of Energy, New York, New York, October 2, 1979.

[97]

"Environmental Radioactivity Laboratory Intercomparison Studies Program 1978-1979, EPA-600/4-78-032, Ouality Assurance Branch, Monitoring Systems Research and Development Division, Environmental Monitoring and Support Laboratory, U.S. Environmental Protection Agency, Las Vegas, NV 89114, June 1978.

[98]

Lee H. Ziegler, "Radioactivity Standards Distribution Program 1978-1979," EPA-600/478-033, Monitoring Systems Research and Development Division, Environmenta 1 Monitoring and Support Laboratory, U.S. Environmental Protection Agency, Las Vegas, NV 89114, June 1978.

"Manual for the Interim Certification of Laboratories Involved in Analyzing Public Drinking Water Supplies, Criteria and Procedures," prepared by the Water Supply nuality Assurance Hork Group, U.S. Environmental Protection Agency, Wash, D.C. 20460, Sept. 1977. 
USNRC Regulatory Guide 4.13, "Performance, Testing, and Procedural Specifications for Thermol uminescence Dosimetry: Environmental Applications," Revision 1, 7/77.

[101]

USNRC Regulatory Guide 4.14, "Measuring, Evaluating, and Reporting Radioactivity in Releases of Radioactive Materials in Liquid and Airborne Effluents from Uranium Mills (For Comment)," 6/77.

[102]

USNRC Regulatory Guide 4.15, "Quality Assurance for Radiological Monitoring Programs (Normal Operations)--Effluent Streams and the Environment," Revision 1, 2/79.

[103]

USNRC Regulatory Guide 4.16, "Measuring, Evaluating, and Reporting Radioactivity in Releases of Radioactive Materials in Liquid and Airborne Effluents from Nuclear Fuel Processing and Fabrication Plants (For Comment)," $3 / 78$.

[104]

M. R. Ford, S. R. Bernard, L. T. Dillman, and S. B. Watson, Internal Dosimetry and Methods of ICRP - Part I, ORNL/NUREG/TM315, Oak Ridge National Laboratory, Oak Ridge, Tennessee 37830, June 1979.

[105]

K. W. Skrable, "Internal Dosimetry and Action Levels Applicable to In Vivo Counting and Other Bioassay Procedures," unpublished, October 1979 (available from Dr. Kenneth W. Skrable, University of Lowe 11, One University Avenue, Lowe11, Massachusetts 01854).

[106]

L. T. Dillman, "EDISTR -- A Computer Program to Obtain a Nuclear Decay Data Base for Radiation Dosimetry," ORNL/TM6689 , Oak Ridge National Laboratory, Oak Ridge, Tennessee 37830, January 1980 (available from the National Technical Information Service, Springfield, VA 22161).

[107]

The ICRP 10 series of reports describing methods of calculating internal dose from bioassay data is under revision and updating. Information on published ICRP reports may be obtained from Pergamon Press, Inc., Maxwe11 House, Elms ford, N.Y. 10523 .

\section{[108]}

USNRC Regulatory Guide 5.58, "Considerations for Establishing Traceability of Special Nuclear Material Accounting Measurements," Revision 1, 2/80.
[109]

R. J. Brouns, F. P. Roberts, and J. A. Merrill, "Monitoring the Random Errors of Nuclear Material Measurements," NUREG/CR0830, Pacific Northwest Laboratory, Richland, Washington 99352, April 1979.

[110]

R. J. Brouns, F. P. Roberts, J. A. Merrill, and W. B. Brown, "A Measurement Control Program for Nuclear Material Accounting," NUREG/CR-0829, Pacific Northwest Laboratory and 0 ffice of Standards Development, U.S. Nuclear Requlatory Commission, Wash. D.C. 20555, September 1979.

[111]

E. H. Eisenhower, "Traceability - A View from the CRR," National Bureau of Standards, this conference, 1980.

[112]

R. L. Kathren, "Traceability - A User's View," Battelle-Northwest, Richl and, Mashington, this conference, 1980 .

[113]

K. R. Heid, Chairman, Working Group 2.5, Health Physics Society Standards Committee," "Criteria for Testing Performance of Radiobioassay Services" (draft), Rattelle Northwest Laboratory, P. 0. Rox 999, Richland, Washington $99352,1980$.

$[114]$

A. N. Jarvis, "The EPA National nuality Assurance Program," this conference, 1980.

[115]

Ron Collé, informal remarks, first session, this conference, 1980.

[116]

W. A. Jennings, "Radiation Measurement Traceability in the U.K.," Mational Physical Laboratory, England, this conference, 1980.

[117]

L. K. Cohen, "MRC Traceability Concerns in its Inspection and Enforcement Proaram," this conference, 1980 .

[118]

Harren K. Sinclair, "The Scientific Basis for Risk Quantification," to be published in the Proceedings of the Annual Meeting of the National Council on Radiation Protection and Measurements, April 2-3, 1980.

[119]

NCRP Report No. 64, "The Influence of Dose and Its Distribution in Time on Dose Fffect Relationships for Low LET Radiation," National Council on Radiation Protection and Mea surements, 1980. 
A. Brodsky, "Radiation Risks: An Historical Perspective," invited talk presented at the Radiation and Health Conference, Hershey, PA, September 1979, available from author.

[121]

J. Shubert, A. Brodsky, and S. Tyler, "The Log-Norma T Function As A Stochastic Model of the Distribution of $\mathrm{Sr}-90$ and Other Fission Products in Humans, "Health Phys. 13, 1187-1204, 1967.

[122]

A. Brodsky, R. P. Specht, R. Brooks, and W. S. Cool, "Log Normal Distributions of Occupational Exposure in Medicine and Industry, " in the proceedings of the Heal th Physics Society Midyear Topical Symposium, Occupational Health Physics (available from Central Rocky Mountain Chapter, P.O. Box 3229, Boulder, CO 80303, 1976.

[123]

R. Loevinger, NBS Standards for Radiation Dosimetry," this conference, 1980.

[124]

P. Plato, "Performance Testing of Personnel Dosimetry Services," this conference, 1980.

[125]

E. Conti, J. S. Bland, J. D. Buchanan, P. J. Magno, W. L. Britz, L. K. Cohen, B. H. Weiss, and E. G. Wright, "Radiological Fnvironmental Monitoring by NRC Licensees for Routine Operations of Nuclear Facilities, " NUREG-0475, 1978.

[126]

R. E. Alexander, "Applications of Bioassay for Uranium," WASH-1251, Superintendent of Documents, U.S. Government Printing Office, Washington, D.C. 20402, 1974.

[127]

The British Calibration Service, Documents: 0021 , November 1977; Document 0802, Jan. 1977 (General Criteria for Laboratory Approval, Provision of Personal Dosimetry Services); Document 0811 , Jan. 1977 (Supplementary Criteria for Laboratory Approval, Calibration of Radiological Protection Level

Instruments: X-, Gamma- and Reta-Rays); Document 0812, Jan. 1977 (Supplementary Criteria for Laboratory Approval, Calibration of Radiological Therapy Level Instruments; X- and Gamma Rays); Document 0813, Sept. 1977 (Supplementary Criteria for Laboratory Approval, Calibration of Radiological Protection Level Instruments: Neutrons); Document 0821, Oct. 1977 (Supplementary Criteria for Laboratory Approval, Provision of Personal Dosimetry Services Using Film Dosimeters for Beta, Gamma, X- and Therma 1 Neutron Radiations); Document 0822 , Oct. 1977 (Supplementary Criteria for Laboratory Approval, Provision of Personal Dosimetry Services Using Nuclear Emulsion, Film Dosimeters for Neutron Radiations); Document 0823, Oct. 1977 (Supplementary Criteria for
Laboratory Approval, Provision of Personal Dosimetry Services Using Thermoluminescent Dosimeters for Beta, Gamma, $X$ - and Neutron Radiations); Document 6601, Jan. 1977

(Calibration of Radiological Instruments at Protection and Therapy Levels), British Calibration Service National Physical Laboratory, Teddington, Middlesex TH 11 OLW, England.

[128]

L. A. Currie, "Limits for nualitative Detection and nuantitative Determination Application to Radiochemistry," Ana 1. Chem. 40, 586-93 (1968).

[129]

A. Brodsky and I. F. Horm, "Removal of ${ }^{241}$ Am from Humans with DTPA," Progress Report, Bureau of Radiological Heal th Grant 2801 EC 00122-03, University of Pittsburgh, 1971.

[130]

A. Brodsky, "Determining Industrial Hygiene Requirements for Installations Using Radioactive Materials, Am. Ind. Hyg. Assn. J. 26, 294-310, 1965 

William L. McLaughlin, Jimmy C. Humphreys, and Arne Miller*

Center for Radiation Research

National Bureau of Standards

Washington, D.C. 20234

\section{ABSTRACT}

In the dosimetry related to sterilization of goods by ionizing photons and electrons, and in other industrial radiation applications, i.e., modification of plastic and other materials, food preservation, and treatment of waste products, it is important to have traceability to standard absorbed dose measurements. The preferred primary methods of dosimetry for large radiation doses (>10 Gy) are: (1) Calorimetry, which is suitable for both electron and photon radiations; (2) Standard chemical dosimetry, in particular, ferrous sulfate dosimetry, which, because of its relatively narrow response range ( 40 - $400 \mathrm{~Gy})$ and rate dependence at dose rates $>10^{7} \mathrm{~Gy} \cdot \mathrm{s}^{-1}$, is mainly suited to $x$ - and gamma radiation. Using these techniques as primary reference methods, it is possible to calibrate the response characteristics of routine dosimeters, such as plastics, dyed plastics, and solid-state sensors in terms of a reproducible signal versus known values of absorbed dose. Dose levels and dose gradients within a sizable irradiated volume, e.g., product packages, are determined within specified values of uncertainty, which may be set in terms of statistical error and precision in making practical interpretation of dose and dose limits.

(Calorimetry; dosimeter calibration; dosimetry; electron beams; gamma radiation; quality control; raidation measurement; radiation processing; radiation sterilization; traceability.)

\section{Introduction}

The radiation processing of industrial goods and the use of radiation in food preservation, waste treatment, and energy research involve large-scale product handling in intense fields of electrons and photons having energies ranging mainly from a few hundred $\mathrm{keV}$ to $210 \mathrm{MeV}[1,3]$. Examples of commercially successful or potentially viable radiation processes are listed in Table I.

\section{TABLE 1}

\section{COMMERCIAL RADIATION PROCESSES}

Sterilization of medical supplies

Recycling of municipal and industrial wastes

Treatment of gaseous effluents and smoke

Water purification

Production of electrical, thermal, and sound insulation

Production of shrinkable films, tape, and tubing

Production of dry lubricants and pressure-sensitive adhesives

Food shelf-life extension

Tire and elastomer manufacture

Curing of inks and paints, plastics, and coil coatings

Manufacture of electronics components and battery separators

Production of improved textiles

Fusion research

Non-destructive testing

Radiation effects studies

Insect population control

Radiation absorbed doses in such applications are generally large, exceeding $10 \mathrm{~Gy}$; and in some cases reach values of $10^{6} \mathrm{~Gy}$. Standardization of dosimetry for such applications, on both national and international levels, has generally been lacking.

In radiation processing that affects public health and safety, it is especially important to standardize the measurement of radiation quantities. Applications in this category include the following: The sterilization of medical supplies, phamaceuticals, cosmetics; disinfestation and preservation of food supplies; treatment of gaseous, liquid and solid wastes; quality assurance and safety of many commodities. In limiting the costs of radiation processing, the improvement of measurement assurance increases quality control, energy saving, and waste and pollution abatement.

This paper is intended to outline means of standardizing large dose radiation measurement, techniques for reducing error and increasing precision in routine dosimetry, and ways of applying certain special dosimetry methods for the mapping of absorbed dose profiles in typical irradiated products and in dosimeter probes and their containers.

\section{Primary Methods of Dose Measurement}

A. Calorimetry

In radiation processing by intense radiation fields, calorimetry is one of the best primary standard means of measuring absorbed dose $[4,6]$. At very large dose rates, ionization methods are not satisfactory because of saturation effects $[7,8]$. The first question that arises in calorimetric dosimetry is how complicated one must be in measuring thermal energy imparted to an irradiated

*Visiting scientist from Accelerator Department, Ris $\varnothing$ National Laboratory, Roskilde, Denmark. 
substance, that is, whether or not the calorimeter must be adiabatic and contain reference calorimetric bodies with calibration heat sources.

Relatively simple heat sensors that lose heat to their surroundings exponentially with time can be used successfully, if the decay factors are determined accurately and are extrapolated to zero time, that is, the time of the beginning of the irradiation $[5,9]$. In the case of pulsed or continuous electron beams, useful designs for calibrating dosimeter response factors include thin foil calorimeters, in which other dosimeter systems are positioned at the location of the displaced calorimetric body [9-11]. Liquid calorimetry is also a useful approach, in which water or organic solvents or solutions can be placed in an insulated Petri dish or larger container with thermocouples or thermistors for measurement of energy deposited locally in the irradiated volume $[5,6$, $12,13]$.

Most calibrations of dosimeters at NBS for radiation processing users involve ${ }^{60} \mathrm{Co}$ gamma radiation in a cylindrically isotropic source of some tens of kilocuries in activity [14]. For traceability to absorbed dose in graphite, all measurements or calibrations with this source are based on calorimetry with a spherical graphite calorimetric body surrounded by spherical graphite shells thick enough to approximate electron equilibrum conditions [15]. The dose rate can also be checked using a graphite ionization chamber of the same dimensions or with ferrous sulfate solution dosimeters (in terms of absorbed dose in water) of similar dimensions [16]. Knowing the approximate photon spectrum in the gamma-ray field, it is possible to estimate within approximately \pm 2 percent absorbed dose in other dosimeters, by applying ratios of mass energy absorption coefficients of different dosimetry materials, weighted over the approximate spectrum [17-19].

\section{B. Aqueous Chemical Dosimetry}

For absorbed doses in the range 40-400 Gy, a convenient standard method of dosimetry involves acidic aqueous solutions of ferrous sulfate or ferrous ammonium sulfate, the so-called "Fricke dosimeter" [19-22]. This may be considered a primary method, since values of chemical yield of ferric ion (G-value) and molar extinction coefficient $\left(\varepsilon_{F_{j}}{ }^{+}\right)$at $305 \mathrm{~nm}$ optical wavelength are well documented, and measureable with high precision (within \pm 1 percent) using quality ultraviolet spectrophotometers. The main limitations are the requirements of ultra pure ingredients, triply distilled water devoid of organic impurities, and extremely clear glass containers.

It is possible to measure larger doses than 400 Gy using other types of aqueous chemical solutions, such as ferrous-cupric sulfate $[20,23]$, or ceric-cerous sulfate $[20,24]$, or "super Fricke" solutions, involving oxygen-saturation and greater concentrations of ferrous ions and $\mathrm{NaCl}$ [22]. In such systems, although G-values and molar extinction coefficients are known, impurities may cause even greater problems than with the ferrous sulfate dosimeter.
III. Establishing Traceability for Absorbed Dose

\section{A. Calibration Services}

Calibration services were instituted at NBS in 1977 for compliance with needs of radiation processing and radiation testing users of highpower electron accelerators and large radionuclide sources of gamma radiation [25]. The aim of these services, as specified in NBS Special Publication 250 , is to allow routine dosimetry practitioners in industrial plants and national laboratories to establish traceability to primary standard methods of dose determination based on calorimetry. The following services are featured.

1. Administer to the user's dosimeters known known absorbed doses (range: 0.1-600 kGy) of electrons or photons of energy range $(0.1 \mathrm{MeV})$.

2. Make dose interpretations in the user's irradiatior (e.g. during processing), by means of transfer radiochromic dye films calibrated at NBS.

3. Intercompare routine dosimeter performance between laboratories.

4. Make spectrophotometry analysis of various high-dose chemical and plastic dosimeters in the ultraviolet and visible spectral region.

5. Determine dose-rate dependence, temperature dependence, and humidity dependence of response of routine dosimeters.

6. Carry out special measurement at the user's facility (e.g. dose mapping or process commissioning).

Results of these services are supplied to the user in the form of an NBS calibration test report.

Statistical evaluation of the ability of the user to meet product specifications may also be included, as 171 ustrated in Figure 1 [25].

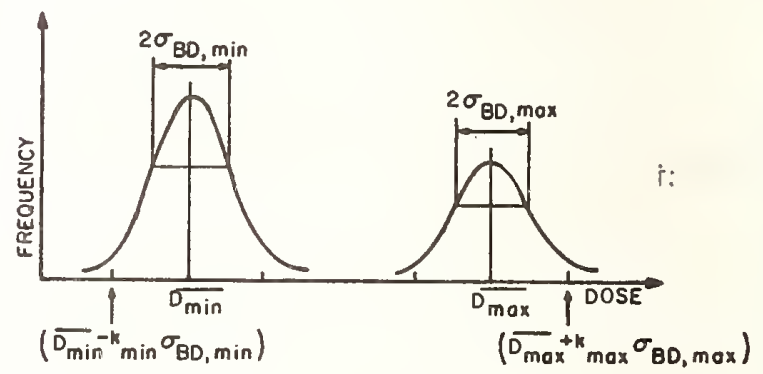

Figure 1 Frequency distribution of absorbed dose in typical product assortment treated in a radiation process, showing variations in minimum and maximum dose due mainly to differences in product bulk density (BD), as measured at positions where minimum and maximum dose have been determined to occur. 
Here are illustrated typical Gaussian-shaped frequency distributions of absorbed dose readings at the minimum dose $\left(\mathrm{D}_{\mathrm{min}}\right)$ and maximum dose ( $D_{\max }$ ) positions in irradiated product of given average bulk density (BD). Such dose interpretations are made by placing in a large sampling of product boxes pairs of calibrated dosimeters of known limits of uncertainty considerably smaller than the values of two standard deviations of dose due to variation in bulk density. (20BP,min and $\left.2 \sigma_{\mathrm{BD}}\right)$. Practical dose limits may thén according to specifications of one-sided tolerance factors, $k_{\min }$ and $k_{\text {max }}$, which determine the factor $\beta$ of product boxes paradiated below or above the limits at a specified probability level $P$, as based on an adequate number of measurement samples, $N$. The tolerance factor can be calculated from Student's t-value tables of $N$ versus $B$ for specified values of $P$. Thus, traceable dosimetry data in an industrial production application can be used to determine whether or not a given radiation process meets specifications of the uniformity ratio $U=D_{\text {max }} / D_{\text {min }}$, say, in terms oi a certain value of limiting uniformity ratio $U_{L}$ :

$$
U<U_{L}=\frac{D_{\text {max }}+k_{\text {max }} \sigma_{B D, \text { max }}}{D_{\text {min }}-k_{\min } \sigma_{B D, \min }}
$$

The determination of detailed absorbed dose distribution in the ${ }^{\circ} \mathrm{Co}$ irradiated chamber at NBS was necessary in order to assure that dose gradients over the volume of dosimeters being calibrated did not exceed \pm 2 percent. The chamber is generally a cylindrical air-filled cavity $30 \mathrm{~cm}$ long and $9 \mathrm{~cm}$ in inner diameter, consisting of a water-tight stainless steel canister lowered manually to a 3 meter depth in water, so that it is surrounded by a cylindrical array of twelve $14 \mathrm{~cm}$ long ${ }^{6}{ }^{\circ}$ Co rods (see elevation view in Figure 2). Nitrogen flow to the dosimeter is also possible, as indicated. In most calibrations the dosimeter is held between layers of polystyrene, aluminum, silicon, etc. (depending on the material of interest) having thicknesses sufficient to approximate conditions of electron equilibrium. The absorbed dose rate is known at this position within approximate uncertaintly limits of \pm 1 percent [15].

Measurements were made using longer strips of radiochromic dye $\mathrm{film}$ dosimeters held in polystyrene layers, in order to map absorbed dose distributions and isodose contours within the irradiation volume of the cannister [27]. Figures 3 and 4 show the results of this mapping study, and reveal that within approximately $2 \mathrm{~cm}$ of the calibration position, namely $6.5 \mathrm{~cm}$ above the inner bottom surface along the cylindrical axis, the absorbed dose rate is uniform to within \pm 2 percent.

\section{B. Means of Achieving Traceability}

The routes to traceability through the NBS high-dose calibration service for intense fields of electrons and photons are illustrated in Figure 5. The approximate uncertainty of each measurement level is given in the left. At NBS primary standardization is provided by calorimetry, and in the case of gamma ray fields, the absorbed

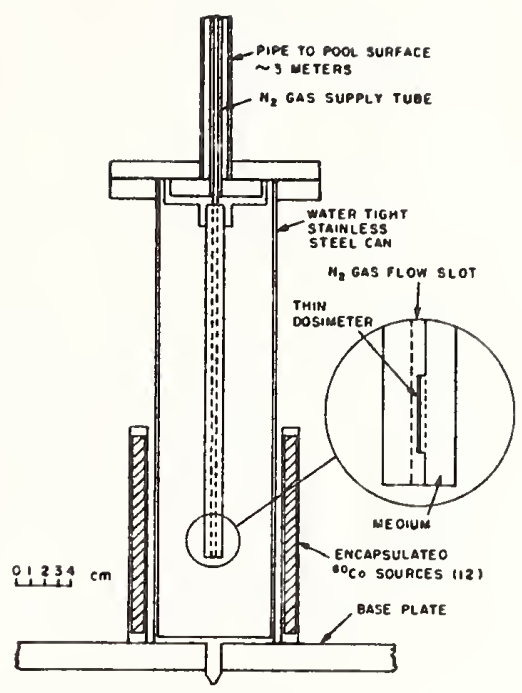

Figure 2 Elevation view of cylindrical stainless steel cannister positioned for dosimeter calibration in cylindrical array of twelve ${ }^{60} \mathrm{Co}$ source rods at bottom of 3-meter deep pool of water. Then thin dosimeters are calibrated either in air or in nitrogen, while held between layers of a medium (plastic, metal, etc.) simulating conditions of electron equilibrium.

dose rate, $\mathrm{D}_{\mathrm{C}}$, is checked periodically with standard graphite ionization chambers matching the dimensions of the graphite calorimeter [15]. In the case of electron beams, the absorbed dose, $D$, in either graphite or metal is measured by means of a thin calorimetric body. Multiplication by ratios of photon energy absorption coefficients over the approximate radiation spectrum makes it possible to determine dose, $D_{i}$, or dose rate, $D_{j}$, in other materials of interest, such as water, plastic, silicon, biological substances, etc. Industrial users generally characterize radiation of standard chemical dosimetry over the absorbed dose ranges indicated. Electron beam users may depend on calorimetry intercompared with that of a national standards laboratory, or they may use transfer dosimeters calibrated against primary standards. The latter is made possible by the calibration service described earlier.

\section{Routine Methods of Dose Determination}

In radiation processing dosimetry, routine procedures require large numbers of commercially 


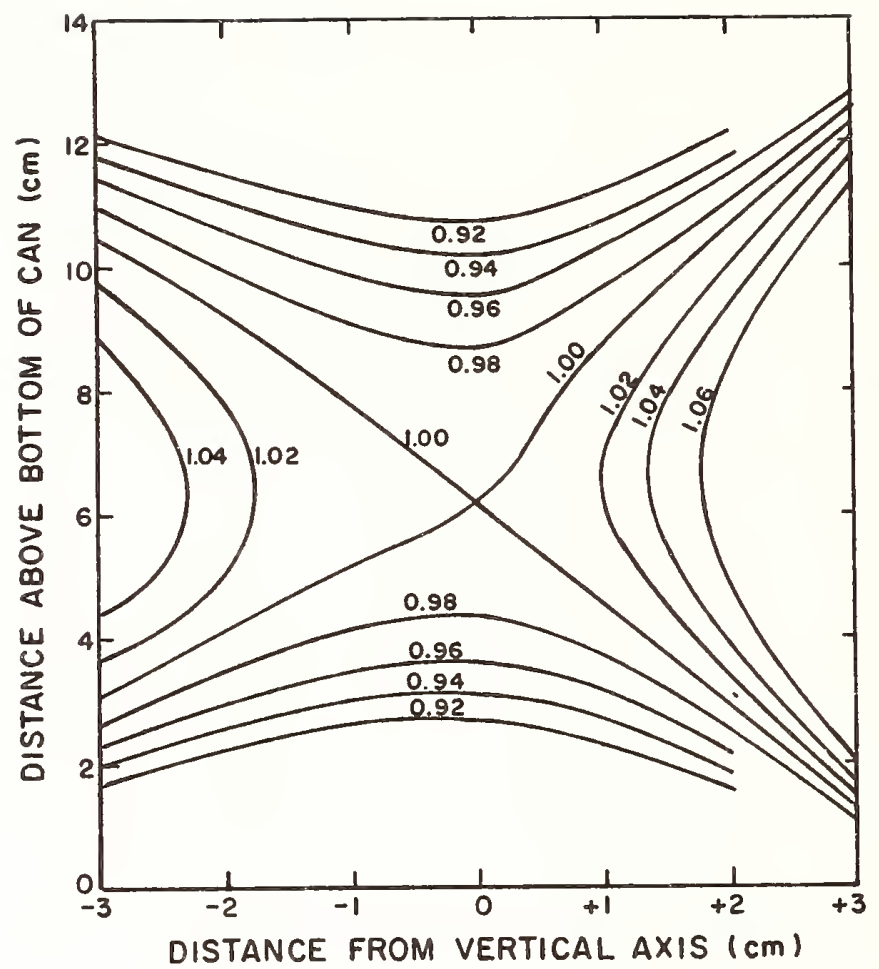

Figure 3 Isodose clirves in a vertical plane bisecting the bottom portion of the volume inside the cannister shown in figure 2, according to measurements by means of strips of calibrated radiochromic dye films.

available measurement systems that must have the following characteristics [28]:

1. Be similar to products of interest in terms of radiation c.bsorption properties.

2. Have linear response in terms of radiation effect yields, or give reproducible characteristics response curves when calibrated in terms of effect-vs.-dose.

3. Be easy to prepare or available in large reproducible commercial batches.

4. Have sufficient response range and precision at dose levels of interest.

5. Show sufficiently small systematic error die to effects of extremes of dose rate and environmental factors during irradiation.

6. Be rugged for production-line use.

7. Be easy to calibrate and analyze for radiation effects of interest.

8. Be readily mailed and have long shelf life.

9. Be stable over time of irradiation and storage before analysis for dose interpretation.

10. Be inexpensive for routine use.
The most widely used and successful methods in industrial applications, for doses in the kilogray and tens of kilogray dose regions are plastic dosimeters, such as red acrylic cylinders (a), red or amber Perspex (b), Perspex HX (c), radiochromic dye film (d), or cellulose triacetate film (e), $[18,25,19]$. Of these, radiochromic dye films were selected by NBS as a transfer measurentent system capable of supplying traceability to the primary standard of absorbed dose in water, graphite, etc. The film consists of a colorless leucocyanide dye derivative dissolved in a clear plastic matrix, and may be supplied in thickness ranging from $8 \mu \mathrm{m}$ to $700 \mu \mathrm{m}$, in order to cover a wide range of absorbed doses $\left(10-10^{6} \mathrm{~Gy}\right)$. Besides this advantage, these films have the following favorable properties:

1. Long shelf 1 ife.

2. Dose rate independence ${ }^{f}[32]$.

(a) Supplied by AECL, Ottawa, Canada

(b) Supplied by AERE, Harwell, UK

(c) Supplied by UK Panel on Electron and Gamma Ray Irradiation, UK

(d) Supplied by Far West Technology, Inc., Goleta, CA, USA

(e) Supplied by CAPRI-Saclay, France

(f) A psuedc low-intensity rate dependence occurs with some types of radiochromic dye films, when irradiated to doses exceeding $\sim 1$ kGy at rates $<5 \mathrm{~Gy} \cdot \mathrm{s}^{-1}$ and relative humidities $<50 \%$ $[30,31]$. 


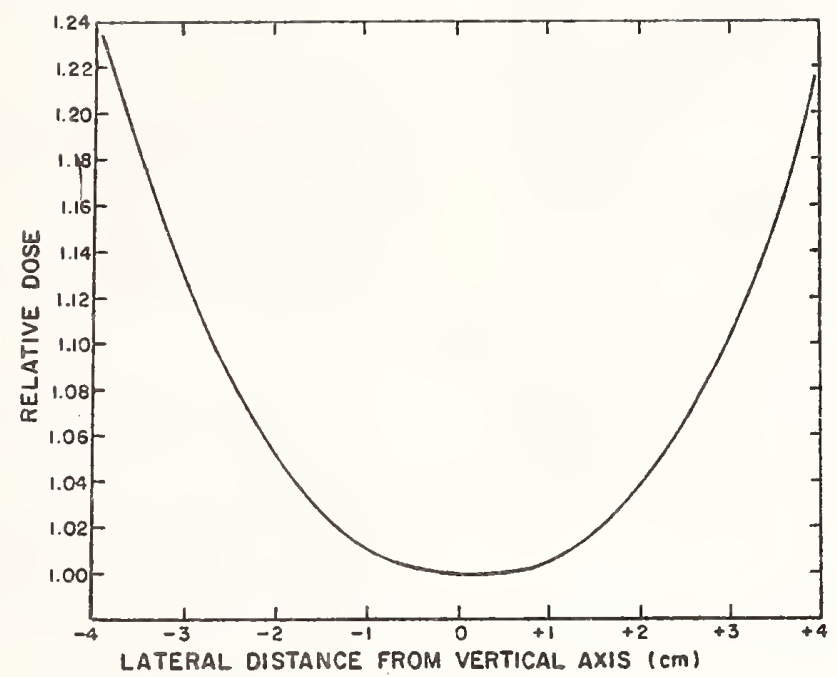

Figure 4 Horizontal dose distribution at a level of the calibration position $6.5 \mathrm{~cm}$ above the bottom surface of the cannister shown in figure 2 [27].

guarded against.

3. Low average atomic number; snaall energy dependence [31].

4. Essentially same response to photons, electrons, protons; low LET dependence [33].

5. Essentially same response in air, vacuum, $N_{2}$, etc. [33].

6. Relatively small and we11-defined temperature dependence of response [35].

7. Relatively stable radiation-induced inteçral signal, i.e., optical density increase that is nearly linear with close and does not chancje appreciably between irradiation and readout (good archival properties) [35].

8. Available in large, reproducible batches of relatively uniform thickness [36].

9. Inexpensive and not very sensitive to the presence of impurities.

10. Relatively simple readout procedures using optical photometers at specified visible iight wavelengths.

There are also certain pitfalls that must be
1. Sensitivity to ultraviolet light, so that a clear plastic film containing a UV blocking agent must be used over windows and fluorescent light fixtures.

2. Sensitivity to wide changes in relative humidity, in particular relative humidities below $\sim 20 \%$ and above $80 \%$ [35]. Best results occur when the films are hermetically packaged in individual polyethylene or foil envelopes.

3. The films nee? to be protected against scratches, fingerprints, and other blemishes.

4. The accuracy and precision of $\mathrm{film}$ response between different batches depends on periodic calibration, in order to make dose interpretatioris traceable to primary standards.

\section{Conclusion}

Although a successful calibration service has been instituted at NBS to partially satisfy the needs of industrial and national radiation users for traceability at high doses, the frogram is still incomplete. This is indicated by the list of needs in Table II. Not only are international standards and intercomparison studies important, but also improved portable calorimeters 


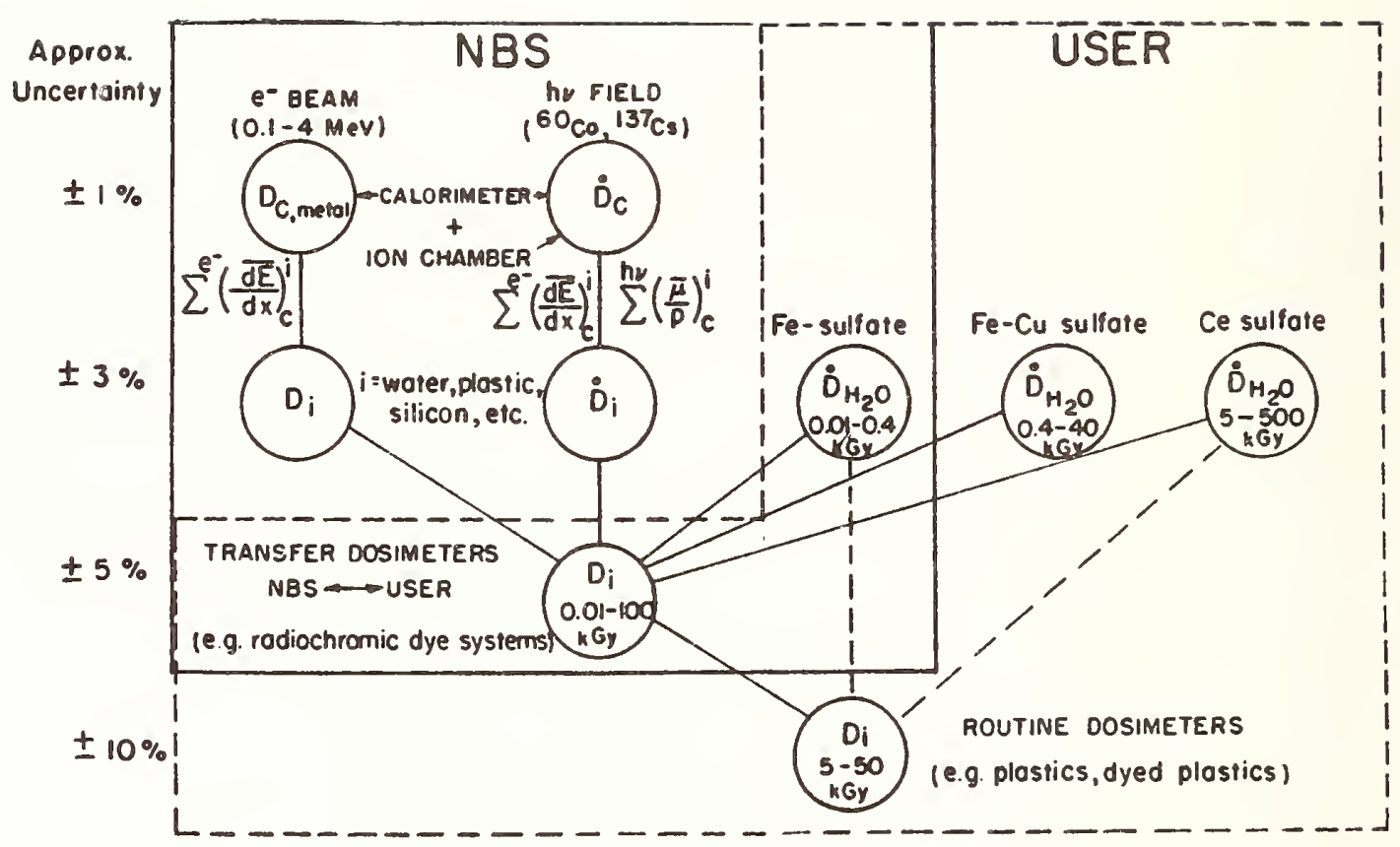

Figure 5 Traceability chart, according to high-dose calibration services at NBS designed for users of intense radiation sources.

based on water vs. tissue-equivāient plastics, better energy dependence data, dosimeter quality control, and continued development of improved measurement systems.

\section{TABLE II}

\section{NEEDS FOR SO VING PROBLEMS OF TRFCEABILITY}

1. International standards

2. Systematic international intercomparisons

3. Transfer calorimeters to reduce number of levels

4. Development of improved water calorimeter

5. Knowledge of radiation sfiectra in both calibration and application

6. Better quality control of transfer dosimeters

7. Development of improved routine dosimeters. 
[1] Radiaticn Processing, Vols. 1 and 2, Silverman, J. and van Dyken, A.R., eds., Pergamon Press, Ltd., 0xford; Radiat. Phys. Chem. 9 (1977)

[2] Advances in Radiation Processing, Vols. 1 and 2, Silverman, J., ed., Pergamon Press, Ltd., Oxford; Radiat. Phys. Chem. 14 (1979)

[3] Advances in Radiation Processing, Vols. 3 and 4, ed., Silverman, J., Pergamon Press, Ltd., Oxford; Radiat. Phys. Chem. (1981) (in press)

[4] Laughl in, J. S., Genna, S., Calorimetry, Chapt. 16 in Radiation Dosimetry, Vol. 2, 2nd Ed., Attix, F. H., Roesch, W.C., eds., Academic Press, New York (1966)

[5] Radak, B.B., Marković, V.M., Calorimetry, Chapt. 3 in Manual on Radiation Dosimetry, Holm, N.W., Berry, R.J., eds., Marcel Dekker, New York (1970)

[6] Domen, S.R., Absorbed Dose Water Calorimeter, Med. Phys. 7, 157 (1980)

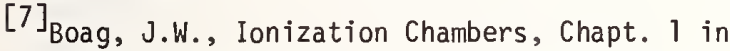
Radiation Dosimeter, Vol. 2, 2nd ed.,

Attix: F.H., Roesch, W.C., eds., Academic Press, New York (1966)

[8] Loevinger, R., Ionization chamber recombination loss in high intensity rodiation fields

"Selected Topics in Radiation Dosimetry", Proc. Int. Sympos., Vienna, 1960, International Atomic Energy Agency, Vienna 173 (1961)

${ }^{[9]}$ Chappel1, S.C., Humphreys, J.C., The dose rate response of a dye-polychlorostyrene film dosimeter, IEEE Trans. on Nucl. Sci. NS-19, 175 (1972)

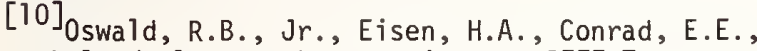
Pulsed electron beam dcisinietry, IEEE Trans. on Nuclear.Science., NS-13, 229 (1966)

[11] Miller, G.H., Lockwood, G.J., Halbleib, J.A., Improved Calorimeter method for energy deposition measurement, IEEE Trans. on Nicl. Sci., NS-21, 359 , (1974)

[12] Holm, N.W., Jarrett, R.D., An evaluation of dosimetry procedures for use in food irradiation, Nat. Acad. Sci., - Nat. Res. Council Pub1. 1273, NAS-NRC, Washington, D.C., (1965)

[13]

Radak, B.B., Kosanić, M.M., Šešić, M.B., McLaughlin, W.L., A calorimetric approach to the calibration of liquid dose meters in highintensity electron beams, Biomedical Dosimetry
Proc. Int. Sympos., Vienna, 1975, International Atomic Energy Agency, Vienna, 663 (1975)

$[14]_{\text {Rabin, H., Price, W.E., Mapping radiation }}$ fields with silver activated phosphate glass, Nucleonics 13 (3) 33 (1955)

[15] Petree, B., Lamperti, P., A comparison of abscirbed dose determinations in graphite by cavity ionization chamber and by calorimetry, NBS J. Res. 71C, 19 (1967)

[16] McLaughl in, W.L., A National Standardization programme for high-dose measurement, HighDose Measurements in Industrial Radiation Processing, IAEA Technical Reports Series, International Atomic Energy Agency (1980) (in press)

$[17]_{\text {Hubbel1, J.H., Photon mass attenuation and }}$ energy absorption coefficients for $1 \mathrm{keV}$ to $20 \mathrm{MeV}$, Trends in Radiation Dosimetry, McLaughlin, W.L., ed., Pergamon Press, 0xford, (1981) (in press)

[18] McLaughl in, W.L., Solid-phase chemical dosimeters, Sterilization by Ionizing Radiation, Gaughran, E.R.L., Goudie, A.J., eds., Multiscience, Montreal, 219 (1974)

${ }^{[19]}$ Chadwick, K.A., Ehlermann, D.A.E., McLaughl in, W.L., Manual on Food Irradiation Dosimetry, IAEA Technical Reports Series No. 178, International Atomic Energy Agency, Vienna (1977)

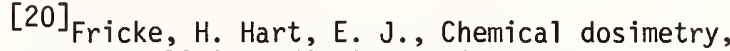
Chapt. 12 ir Radiation Dosimetry, Vol. 2, 2nd ed., Attix, F.H., Roesch, W.C., eds., Academic Press, New York (1966)

$[21]_{\text {Ehrlich, M. Soares, C.G., Measurement assur- }}$ ance studies of high-energy electron and photon dosimetry in radiation theraphy applications; Intercomparison Procedures in the Dosimetry of High-Energy Electrons and X-rays, IAEA Technical Reports Series, International Atomic Energy Agency, Vienna (1980) (in press)

[22] Sehested, K., The Fricke dosimeter, Manual on Radiation Dosimetry, Holm, N.W. , Berry, R.J., eds., Marcel Dekker, New York, 313 (1970)

[23] Bjergbakke, E., Sehested, K., Lang Rassmussen, 0 ., The reaction mechanism, and rate constants in the radiolysis of $\mathrm{Fe}^{2+}-\mathrm{Cu}^{2+}$ Solutions, Radiat. Res., 66, 433 (1976)

[24] Bjergbakke, E., Ceric-cerous sulfate dosimetry, Trends in Radiation Dosimetry, McLaugh1 in, W.L., ed., Pergamon Press, Oxford (1981) (in press) 
[25] McLaughlir, W.L., Dosimetry standards for industrial radiation frocessing, National and International Standardization of Radiation Dosimetry, Vol. 1, Prec. Int. Sympos., Atlanta, 1977, International At.omic Energy Agency, Vienna, 89 (1978)

$[26]$ Vas, K., Beck, E.R.A., McLaughl in, W.L., Ehlermann, Chadwick, K.H., Dose limits versus dose range, Acta Alimentaria 7 (2) 343 (1978)

[27] Humphreys, J.C., McLatigh] in, W.L., Dye film dosimetry for radiation processing, Application of Accelerators in Research and Industry, Proc. of 6th Conf., North Texas State University, 1980, U.S. Department of Energy (1981) (in press)

[28] McLaugh] in, W.L., Radiation measurement and quality control, Radiat. Phys. Chem. 9, 147 (1977)

$[29]_{\text {Barrett, J.H., Sharpe, P.H.G., Stuart, I.P., }}$ Dosimetry with dyed ard indyed acrylic plastic, Trends in Radiation Dosimetry, McLaughl in, W.L., ed., Pergamon Press, Ltd., Oxford (1981) (in press)

[30] Gehringer, P., Eschweiler, H., Proksch, E., Dose-rate and humidity effects upon the gammaradiation response of nylon-based radiochromic film dosimeters, Int. J. Appl. Radiat. Isotopes $31595(1980)$

[31] McLaughlin, W.L., Humphreys, J.C., Levine, H., Miller, A., Radak, B.B., Rativanich, N., The gamma-ray response of radiochromic dyes at different absorbed dose rates, Advances in Radiation Processing, Vol. 4, Silverman, J., ed., Pergamon Press, Ltd., 0xford; Radiat. Phys. Chem. (1981) (in press)

[32] McLaughl in, W.L., Humphreys, J.C., Radak, B.B., Miller, A., Oleinik, J.A., The response of plastic dosimeters to ganima rays and electrons at high absorbed dose rates, Advances in Radiation Dosimetry, Vol. 2, Silverman, J., ed., Pergamon Press Ltd., Oxford, Radiat. Phys. Chem. 14, 535 (1980)

$[33]_{\mathrm{M}}$ McLaughl in, W.L., Rosenstein, M., Levine, H., Bone-and muscle-equivalent sol id chenical dose meters for photon and eilectron doses above cne kilorad, Biomedical Dosimetry, Proc. Int. Sympos., Vienna, 1975, International Atomic Energy Agency, Vienna, 267 (1975)

$[34]_{1}$ Hansen, J., Ris $\varnothing$ National Laboratory, Roskilde, Denmark, private communication, (1980)

[35] Levine, H., McLaughlin, W.L., Miller, A., Temperature and humidity effects on the garma-ray resporise and stability of plastic and dyed plastic dosimeters, Advances in Radiation Processing, Vol. 2, Silverman, J., $\equiv$ ed., Pergamon Press, Ltd., Oxford; Radiat. Phys. Chem. 14, 551 (1980)

$\left[{ }^{[6]}\right]_{\text {Kantz, A.D., Humpherys, K.C., Qual ity }}$ assurance for radiation processing, Advances in Radiation Processing, Vol. 2, Silverman, J., ed., Pergamon Press, L.td., 0xford; Radiat. Phys. Chem. 14, 575 (1980) 


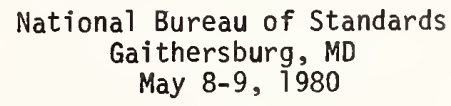

List of Attendees

John Arras

Armed Forces Radiobiology Research Institute Bethesda, MD 20014

Al len Brodsky

U.S. Nuclear Regulatory Commission

Office of Standards Development

Washington, DC 20555

Doris Brunner

Penn. Dept. of Environmental Resources

Bureau of Radiation Protection

P.0. Box 1467

Harrisburg, PA 17120

Lily Buja-Bijunas

National Research Council of Canada

B1dg $\mathrm{M}-35$

Montreal Road

Ottawa, Ont. K1A OR6 CANADA

George Campbel1

Lawrence Livermore National Laboratory

Hazards Control Department

Livermore, CA 94550

Arthur Carlson

Illinois Department of Public Health

Division of Radiation Protection

535 West Jefferson St.

springfield, IL 62761

Randall S. Caswell

National Bureau of Standards

Center for Radiation Research

Washington, DC 20234

Lucy Caval lo

National Bureau of Standards

Center for Radiation Research

Washington, DC 20234

Lawrence K. Cohen

U.S. Nuclear Regulatory Commission

Office of Inspection \& Enforcement

Washington, DC 20555

R. Collé

National Bupeau of Standards

Center for Radiation Research

Washington, DC 20234

Dave Dieter

Eastman Kodak Co.

Kodak Part B6 MC5

Rochester, NY 14650
Dave Dieterly

New England Nuclear

Medical Diagnostic Division

601 Treble Cove Rd

North Billerica, MA 01862

Margarete Ehrlich

National Bureau of Standards

Center for Radiation Research

Washington,

Elmer $H$. Eisenhower

National Bureau of Standards

Center for Radiation Research

Washington, DC 20234

Robert R. Eng

Armed Forces Radiobiology Research Institute

B1dg 42 NNMC

Bethesda, MD 20014

Roger W. Ferris

Amersham Corporation

2636 Clearbrook Dr.

Arlington Heights, IL 60005

Leo Fitzpatrick

Biomedics Corp. (Mail Stop TBC)

CIF Bldg Rm 398

Kennedy Space Center, FL 32899

D.M. Fleming

Battelle, Pacific Northwest Labs.

Battelle Blvd

Richland, WA 99352

Ralph D. Flint

Battelle Memorial Institute

505 King Ave.

Columbus, $\mathrm{OH} 43201$

Claude Florg

Armed Forces Radiobiology Research Institute

Bethesda, MD, 20014

Andreas George

U.S. Department of Energy

Environmental Measurement Laboratory

376 Hudson St.

New York, NY 10014

Thomas F. Gesel1

University of Texas School of Public Health

P.0. Box 20106

Houston, TX 77025

Robert Golden

Walter Reed Army Medical Center

Diagnostic Radiology Services

Department of Radiology

Washington, DC 20012 
Michael Grisson

Armed Forces Radiobiology Research Institute

Bldg 42, NNMC

Bethesda, MD 20014

Ken Groves

Navy Nuclear Power Unit

Code 40

Port Hueneme, CA 93043

James A. Grund 1

National Bureau of Standards

Center for Radiation Research

Washington, DC 20234

H.T. Heaton, II

National Bureau of Standards

Center for Radiation Research

Washington, DC 20234

Gene Hendrix

Naval Facilities Engineering Command

Attn: $111 \mathrm{~N}$

200 Stovall St.

Alexandria, VA 22332

Phil Hesse

Naval Surface Weapons Center

Silver Spring, MD 20910

J.M.R. Hutchinson

National Bureau of Standards

Center for Radiation Research

Washington, DC 20234

Jeffrey N. Iadisernia

Keithley Instruments

31300 Bainbridge Rd.

Solon, $\mathrm{OH} \quad 44129$

Kenneth Inn

National Bureau of Standards

Center for Radiation Research

Washington, DC 20234

Richard Jaquish

Battelle, Pacific Northwest Labs.

Box 999

Richland, WA 99352

Arthur N. Jarvis

U.S. Environmental Protection Agency

Office of Quality Assurance-Radiation National Environmental Research Center P.0. Box 15027

Las Vegas, NV 89114

W.A. Jennings

National Physical Laboratory

Division of Radiation Science and Acoustics

Teddington, Middlesex, TW 11 LLW

UK

M. Jimenez

Duke Power Co.

Steam Production Dept.

P.0. Box 33189

Charlotte, NC

Don Jordan

USAF

OE HL/RZE

Brooks Air Force Base, TX 78235
Ronald L. Kathren

Battelle, Pacific Northwest Labs.

Battelle Blvd

Richland, WA 99352

Bergene Kawin

Food and Drug Administration

5600 Fishers Lane, HFX-150

Rockville, MD 20857

Frank Kearly

Bureau of Radiological Health, HFX-70

5600 Fishers Lane

Rockville, MD 20857

Kirk J. King

Naval Research Labs, Code 6073

Washington, DC 20375

George Komada

Bureau of Radiological Health, HFX-260

5600 Fishers Lane

Rockville, MD 20857

Chris E. Kuyatt

National Bureau of Standards

Center for Radiation Research

Washington, DC 20234

George T. Lalos

Naval Surface Weapons Center

Silver Spring, MD 20910

John J. Lanza

Naval Surface Weapons Center

Silver Spring, MD 20910

Robert Loevinger

National Bureau of Standards

Center for Radiation Research

Washington, DC 20234

Ronald B. Luersen

Naval Research Labs, Code 6073

Washington, DC 20375

William McLaughlin

Nationa 1 Bureau of Standards

Center for Radiation Research

Washington, DC 20234

Robert Mills

Brookhaven National Laboratory

Bldg $535 \mathrm{~A}$

Upton, NY 11973

Robert Morton

Bureau of Radiological Health, HFX-70

5600 Fishers Lane

Rockville, MD 20857

Robert J. Murray

PA Power \& Light

2 North Ninth St

Allentown, PA 18101

Harold W. Nass

Union Carbide

Box 324

Tuxedo, NY 10987 
Richard E. Needham

Dept. Health and Human Services

Food and Drug Authority

Engineering \& Analytical Center

109 Holton St.

Winchester, MA 01890

Maury Neuweg

Illinois Dept. of Public Health

Division of Radiation Protection

535 West Jefferson St.

Springfield, IL 62761

Thomas R. Ohlhaber

Bureau of Radiological Health

5600 Fishers Lane

Rockville, MD 20857

Dale 01son

U.S. Dept. of Energy

550 2nd St.

Idaho Falls, ID 83401

Phillip Plato

Univ. of Michigan

School of Public Health

Ann Arbor, MI 48109

Adelbert Potter

New York State Dept. of Health

Bureau of Radiological Health

Rm 359 Tower B1dg

E.S.P.

Albany, NY 12237

Federick Prevo

Bureau of Radiological Health, HFX-260

5600 Fishers Lane

Rockville, MD 20857

Lawrence A. Proud

The Boeing Co.

P.0. Box $3707 \mathrm{M} / \mathrm{S} 2 \mathrm{~T}-04$

Seattle, WA 98124

Nongnooch Ratinavich

Office of Atomic Energy for Peace

Bancock, THAILAND

Dennis Riley

Dosimeter Corp. of America

P. 0. Box 42377

Cincinnati, $\mathrm{OH} 45242$

Genevieve Roessler

Univ. of Florida

237 Nuclear Science Center

Gainesville, FL 32611

Daniel Sam

Naval Surface Weapons Center

Silver Spring, MD 20910

Robert J. Shalek

M.D. Anderson Hospital

Physics Dept.

Houston, TX 77030

Donovan Smith

U.S. Nuclear Regulatory Commission

Washington, DC 20555
C. Soares

National Bureau of Standards

Center for Radiation Research

Washington, DC 20234

Paul B. Sundy

RADCAL Corp.

426 W. Duarte Rd.

Monrovia, CA 91016

Kathy Teasdale

Reynolds Electrical \& Engineering Co.

P.0. Box 14400

Las Vegas, NV 89114

Bruce Thomadsen

Univ. of Wisconsin

K4/B100 Clinical Science Center

600 Highland Avenue

Madison, WI 53792

Anthony Tse

U.S. Nuclear Regulatory Commission

Washington, DC 20555

Paul Tyree

New England Nuclear

NS Division

601 Treble Cove Rd

North Billercia, MA 01862

Ivan Vajcovec

Atomic Energy of Canada, Limited

Commercial Products

Box 6300, Station J

0ttawa K2A 3W3 CANADA

Lorraine Vekens

New England Nuclear Corp.

601 Treble Cove Rd.

North Billerica, MA 01862

Stephen S. Voris

Bel1 Laboratories

600 Mountain Ave.

Murray Hill, NJ 07974

Graham V. Walford

Technology for Energy Corp.

975 West Outer Drive

Oak Ridge, TN 37830

R.C. Yoder

Battele, Pacific Northwest Labs.

P.0. Box 999

Richland, WA 99352

Robert Zapp

Battelle Memorial Institute

505 King Ave.

Columbus, $\mathrm{OH} 43201$

Joseph Zelenski

E.R. Squibb and Sons, Inc.

Rt. 1, Box 89

Stockton, NJ 08559

Garry Zeman

National Naval Medical Center

Bethesda, MD 20014 


\begin{tabular}{|c|c|c|c|}
\hline $\begin{array}{l}\text { U.S. DEPT. OF COMM. } \\
\text { BIBLIOGRAPHIC DATA } \\
\text { SHEET (See in structions) }\end{array}$ & $\begin{array}{l}\text { 1. PUBLICATION OR } \\
\text { REPORT NO. } \\
\text { NBS SP } 609\end{array}$ & 2. Performing Organ. Report Nof & $\begin{array}{l}\text { 3. Publication Date } \\
\text { FEBRUARY } 1982\end{array}$ \\
\hline \multicolumn{4}{|l|}{ 4. TITLE AND SUBTITLE } \\
\hline \multicolumn{4}{|c|}{$\begin{array}{l}\text { Proceedings of a Meeting on Traceability for Ionizing Radiation Measurements } \\
\text { held at the National Sureau of Standards, Gaithersburg, MD, on May 8-9, } 1980 \text {. }\end{array}$} \\
\hline \multicolumn{4}{|c|}{$\begin{array}{l}\text { 5. EDITOR: } \\
\text { H. Thomoson Heaton, II }\end{array}$} \\
\hline \multicolumn{3}{|c|}{$\begin{array}{l}\text { 6. PERFORMING ORGANIZATION (If joint or other than NBS, see instructions) } \\
\text { NATIONAL BUREAU OF STANDARDS } \\
\text { DEPARTMENT OF COMHERCE } \\
\text { WASHINGTON, DC } 20234\end{array}$} & $\begin{array}{l}\text { 8. Type of Report \& Perlod Covered } \\
\text { Final }\end{array}$ \\
\hline
\end{tabular}

9. SPONSORING ORGANIZATION NAME AND COMPLETE ADDRESS (Street, City, $\overline{\text { Stote, }}$ ZIP)

Same as no. 6

10. SUPPLEMENTARY NOTES

Library of Congress Catalog Card Number: 81-600197

Document describes a computer program; SF-185, FIPS Software Summary, is attached.

11. ABSTRACT (A 200-word or less factual summary of most significant information. If document includes a significant bibliography or literature survey, mention it here)

These proceedings are the compilation of 21 papers presented at a seminar on Traceability for Ionizing Radiation Measurements held at the National Bureau of Standards, Gaithersburg, MD, on May 8-9, 1980. General concepts of traceability were presented from several perspectives. The national standards for radiation dosimetry, radioactivity measurements, and neutron measurements were described. Specific programs for achieving traceability to the national standards for radiation measurements in medical, occupational, and environmental applications were summarized.

12. KEY WORDS (Six to twelve entries; alphabetical order; capitolize only proper names; and seporate key words by semicolons) Calibrations, ionizing radiation, measurements, national standards, quality assurance, secondary standard Taboratory, traceability.

13. AVAILABILITY

[X] Unlimited

For Official Distribution. Do Not Release to NTIS

Order From Superintendent of Documents, U.S. Government Printing Office, Washington, D C 20402.

14. NO. OF PRINTED PAGES

175

Order From National Technical Information Service (NTIS), Springfield, VA

22161 


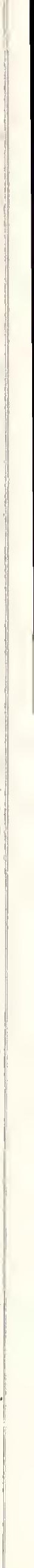




\section{NBS TECHNICAL PUBLICATIONS}

\section{PERIODICALS}

JOURNAL OF RESEARCH-The Journal of Research of the National Bureau of Standards reports NBS research and development in those disciplines of the physical and engineering sciences in which the Bureau is active. These include physics, chemistry, engineering, mathematics, and computer sciences. Papers cover a broad range of subjects, with major emphasis on measurement methodology and the basic technology underlying standardization. Also included from time to time are survey articles on topics closely related to the Bureau's technical and scientific programs. As a special service to subscribers each issue contains complete citations to all recent Bureau publications in both NBS and nonNBS media. Issued six times a year. Annual subscription; domestic \$18; foreign \$22.50. Single copy $\$ 4.25$ domestic; $\$ 5.35$ foreign.

NOTE: The Journal was formerly published in two sections: Section A "Physics and Chemistry" and Section B "Mathematical Sciences."

DIMENSIONS/NBS-This monthly magazine is published to inform scientists, engineers, business and industry leaders, teachers, students, and consumers of the latest advances in science and technology, with primary emphasis on work at NBS. The magazine highlights and reviews such issues as energy research, fire protection, building technology, metric conversion, pollution abatement, health and safety, and consumer product performance. In addition, it reports the results of Bureau programs in measurement standards and techniques, properties of matter and materials, engineering standards and services, instrumentation, and automatic data processing. Annual subscription: domestic \$11; foreign $\$ 13.75$.

\section{NONPERIODICALS}

Monographs-Major contributions to the technical literature on various subjects related to the Bureau's scientific and technical activities.

Handbooks-Recommended codes of engineering and industrial practice (including safety codes) developed in cooperation with interested industries, professional organizations, and regulatory bodies.

Special Publications-Include proceedings of conferences sponsored by NBS, NBS annual reports, and other special publications appropriate to this grouping such as wall charts, pocket cards, and bibliographies.

Applied Mathematics Series-Mathematical tables, manuals, and studies of special interest to physicists, engineers, chemists, biologists, mathematicians, computer programmers, and others engaged in scientific and technical work.

National Standard Reference Data Series-Provides quantitative data on the physical and chemical properties of materials, compiled from the world's literature and critically evaluated. Developed under a worldwide program coordinated by NBS under the authority of the National Standard Data Act (Public Law 90-396).
NOTE: The principal publication outlet for the foregoing data is the Journal of Physical and Chemical Reference Data (JPCRD) published quarterly for NBS by the American Chemical Society (ACS) and the American Institute of Physics (AIP). Subscriptions, reprints, and supplements available from ACS, 1155 Sixteenth St., NW, Washington, DC 20056.

Building Science Series-Disseminates technical information developed at the Bureau on building materials, components, systems, and whole structures. The series presents research results, test methods, and performance criteria related to the structural and environmental functions and the durability and safety characteristics of building elements and systems.

Technical Notes-Studies or reports which are complete in themselves but restrictive in their treatment of a subject. Analogous to monographs but not so comprehensive in scope or definitive in treatment of the subject area. Often serve as a vehicle for final reports of work performed at NBS under the sponsorship of other government agencies.

Voluntary Product Standards-Developed under procedures published by the Department of Commerce in Part 10, Title 15, of the Code of Federal Regulations. The standards establish nationally recognized requirements for products, and provide all concerned interests with a basis for common understanding of the characteristics of the products. NBS administers this program as a supplement to the activities of the private sector standardizing organizations.

Consumer Information Series-Practical information, based on NBS research and experience, covering areas of interest to the consumer. Easily understandable language and illustrations provide useful background knowledge for shopping in today's technological marketplace.

Order the above NBS publications from: Superintendent of Documents, Government Printing Office. Washington. DC 20402

Order the following NBS publications-FIPS and NBSIR's-from the National Technical Information Services, Springfield, VA 22161.

Federal Information Processing Standards Publications (FIPS PUB)-Publications in this series collectively constitute the Federal Information Processing Standards Register. The Register serves as the official source of information in the Federal Government regarding standards issued by NBS pursuant to the Federal Property and Administrative Services Act of 1949 as amended. Public Law 89-306 (79 Stat. 1127), and as implemented by Executive Order 11717 (38 FR 12315, dated May 11, 1973) and Part 6 of Title 15 CFR (Code of Federal Regulations).

NBS Interagency Reports (NBSIR) - A special series of interim or final reports on work performed by NBS for outside sponsors (both government and non-government). In general, initial distribution is handled by the sponsor: public distribution is by the National Technical Information Services, Springfield, VA 22161. in paper copy or microfiche form. 
U.S. DEPARTMENT OF COMMERCE

National Bureau of Standards

Washington, DC 20234

PDSTAGE AND FEES PAID

$U$ S. DEPARTMENT OF COMMERCE COM -215

OFFICIAL BUSINESS

Penalty for Private Use, $\$ 300$ 